\title{
EFFECTS OF CURING CYCLE AND LOADING RATES ON DOUBLE SHEAR COMPOSITE JOINTS
}

\author{
A Thesis \\ presented to \\ the Faculty of California Polytechnic State University, \\ San Luis Obispo
}

\author{
In Partial Fulfillment \\ of the Requirements for the Degree \\ Master of Science in Aerospace Engineering
}

by

Mateja Andrejic

April 2016 
(C) 2016

Mateja Andrejic

\section{ALL RIGHTS RESERVED}




\section{COMMITTEE MEMBERSHIP}

TITLE:

AUTHOR:

DATE SUBMITTED:

COMMITTEE CHAIR:

COMMITTEE MEMBER:

COMMITTEE MEMBER:

COMMITTEE MEMBER:
Effects of Curing Cycle and Loading Rates on Double Shear Composite Joints

Mateja Andrejic

April 2016

Faysal Kolkailah, Ph.D., PE

Professor of Aerospace Engineering

Eltahry Elghandour, Ph.D.

Lecturer of Aerospace Engineering

Eric Kasper, Ph.D.

Professor of Civil Engineering

Dianne J DeTurris, Ph.D.

Professor of Aerospace Engineering 


\author{
ABSTRACT \\ Effects of Curing Cycle and Loading Rates \\ on Double Shear Composite Joints \\ Mateja Andrejic
}

In the last few decades, there has been a shift to using more lightweight materials for the potential of fuel consumption reduction. In the Aerospace Industry, conventional metal structures are being replaced by advanced composite structures. The major advantage of an advanced composite structure is the huge reduction in the number of parts and joints required. Also composite materials provide better resistance to creep, corrosion, and fatigue. However, one cannot eliminate all the joints and attachments in an aircraft's structure. Eliminating structural joints is impractical in present-day aircraft because of the requirements for inspection, manufacturing breaks, assembly and equipment access, and replacement of damaged structures. Currently, composite joints are overdesigned which leads to weight penalties. Understanding how to optimize the ultimate bearing strength of a composite joint by altering the cure cycle might be beneficial to the composite joint design process.

This study investigates, through numerical and experimental analysis, the mechanical behavior of double shear joints. The first task is to test Aluminum double shear joint specimens inside the double shear joint fixture at a loading rate of $0.05 \mathrm{in} . / \mathrm{min}$. (quasi-static). The second task is to numerically model and validate the aluminum double shear joint specimen. The third task is to test the Unidirectional MTM 49 carbon fiber pre-preg double shear composite joint specimens with two different cure cycles and five different loading rates $(0.05 \mathrm{in} . / \mathrm{min} ., 0.1 \mathrm{in.} / \mathrm{min} ., 1 \mathrm{in.} / \mathrm{min} ., 2$ 
in./min. and 6 in./min.). The double shear composite joint specimens are made, using a heat press,

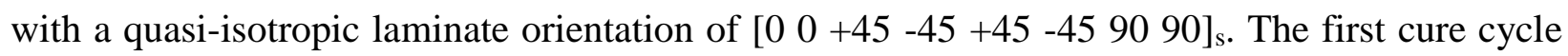
used is called the alternate cure cycle, which is Cytec's MTM 49 Unidirectional Carbon Fiber prepreg material cure cycle, and the second cure cycle used is called the datasheet cure cycle, which is Umeco's MTM 49 Unidirectional Carbon Fiber pre-preg material cure cycle. The datasheet cure cycle and an alternate cure cycle are both compared to see how they affect the mechanical characteristics of the matrix along with the bearing stress. The fourth task is to adjust the Aluminum double shear joint numerical model for the double shear composite joint specimen. The numerical results for both the Aluminum and the composite specimens are in agreement with the experimental results. The theoretical in-plane material properties of the quasi-isotropic laminate were in agreement with the experimental results. One can see that at $0.05 \mathrm{in} . / \mathrm{min}$. and $0.1 \mathrm{in} . / \mathrm{min}$. (for both cure cycles) the composite double shear specimens carried more load compared to the higher loading rates of $1 \mathrm{in.} / \mathrm{min} ., 2 \mathrm{in.} / \mathrm{min}$. and $6 \mathrm{in} . / \mathrm{min}$. The tensile modulus of elasticity of an Aluminum sample is measured using a crosshead displacement, a strain gage and an extensometer. The crosshead displacement yielded very inaccurate results when compared to the strain gage and the extensometer.

Keywords: Aerospace Engineering, Composite Materials, Composite Double Shear Joints, Mechanically Fastened Joints, Unidirectional Carbon Fiber Material, Quasi-isotropic laminate, Aluminum double shear joint 


\section{ACKNOWLEDGMENTS}

I would like to thank my thesis advisor, Dr. Faysal Kolkailah, and my co-advisor Dr. Eltahry Elghandour. They have been extremely helpful these last few years. Their availability to meet with me even though they were not scheduled to do so was very impressive. I would also like to thank Dr. Eric Kasper who served as one of my committee members and who helped me with my finite

element model. In particular, Dr. Kasper helped point me in the right direction when it came to modeling my 3D experimental assembly and with the surface-to-surface interaction in Abaqus. I cannot neglect to mention Dr. Tom George Mase who helped me refine my mesh for my finite element model and introduced me to meshing a solid externally without Abaqus. I would like to thank Dr. Dianne DeTurris for being a last minute addition to my committee and providing me with helpful feedback. Thank you Ken Gamble for all the composite material donations you have given us at our composites lab. Without you, none of this would have been possible. I also want to thank the SAMPE club for letting us use your material.

I want to thank all my professors I have had at Cal Poly. Without each of you, none of this would have been possible. I would like to thank everyone who worked alongside me at the composites lab. Thanks to the endless support, all of you have given me in these past two years. There is always something new to learn about composite materials. I want to thank all my friends I have met at Cal Poly.

I cannot forget to thank my family. You guys have put up with me through all these years. Your endless support cannot be taken for granted. My family has taught me so much and I will continue learning as I grow. I cannot wait to end my studies and transition into a new chapter in my life. Thanks again to everyone who has supported me through the past years. 


\section{TABLE OF CONTENTS}

Page

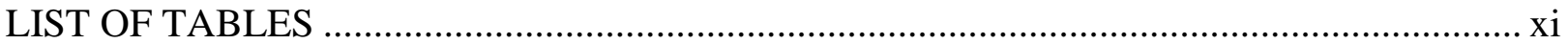

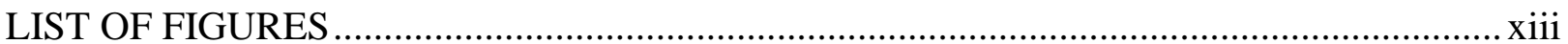

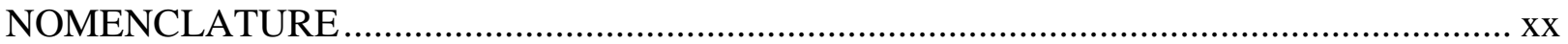

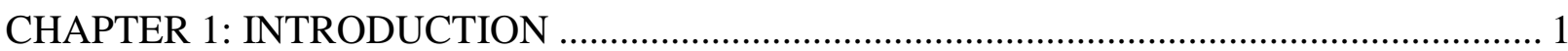

1.1 Introduction to Conventional \& Advanced Composite Structures .............................. 1

1.2 Introduction to Adhesively Bonded Joints \& Mechanically Fastened Joints ................. 2

1.3 Previous Literature on Mechanically Fastened Composite Joints .............................. 4

1.3.1 Previous Literature on Loading Rate Effects on Mechanically Fastened Composite Joints .................................................................................................... 6

1.3.2 Types of Failure in Mechanically Fastened Composite Joints........................... 7

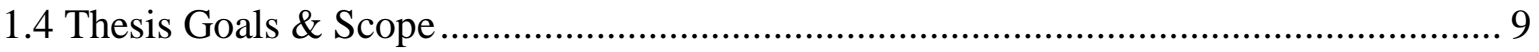

CHAPTER 2: MANUFACTURING \& PREPARING OF THE SPECIMENS ..................... 11

2.1 Tensile Specimen \& Double Shear Specimen Dimensions ................................... 11

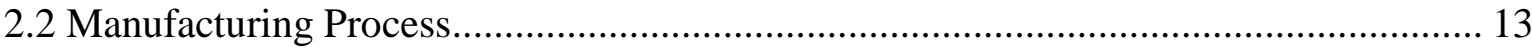

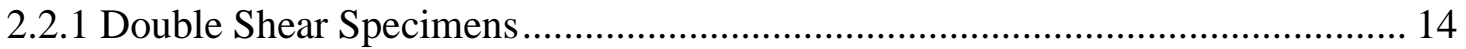

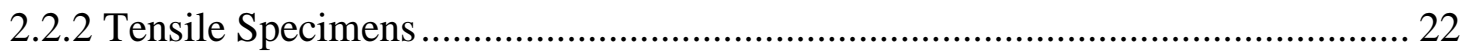

CHAPTER 3: TESTING PREPARATION \& PROCEDURE............................................... 24

3.1 Intro to Uniaxial Testing Using the Instron 8801 Servo-hydraulic Test Machine ........ 24

3.1.1 Instron Servo-hydraulic Test Machine Recommendations .............................. 26

3.1.2 Tutorial on Auto-Loop Tuning of the Load Cell for an 1 in. wide By 1/16 in. Thick Aluminum Specimen ..................................................................... 28

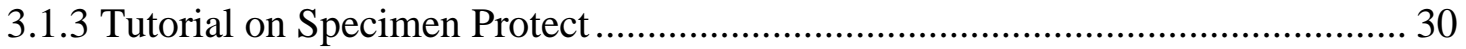




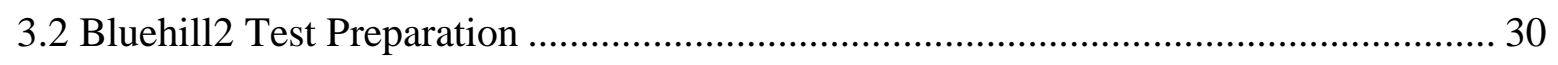

3.2.1 Bluehill2 Test Parameter Setup ......................................................................... 31

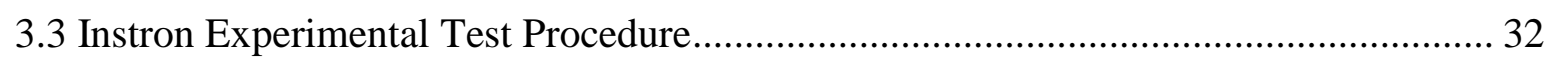

3.3.1 Tensile Testing Procedure ……………………............................................ 32

3.3.2 Double Shear Testing Procedure …………………......................................... 34

CHAPTER 4: THEORETICAL SOLUTION METHOD ........................................................ 37

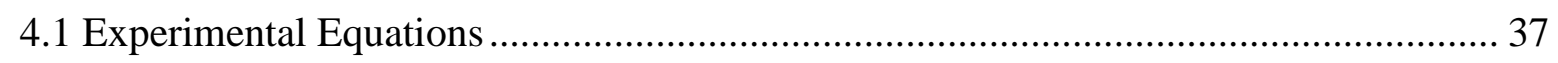

4.1.1 Equations Used for Unidirectional Carbon Fiber and Aluminum Double Shear

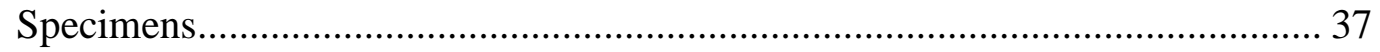

4.1.2 Equations Used for Tensile Testing of Unidirectional Carbon Fiber and Aluminum Specimens .................................................................................... 38

4.1.3 Equations Used with the Rosette Strain Gage ................................................... 40

4.1.4 Equations Used for In-Plane Shear Modulus Testing of Unidirectional Carbon

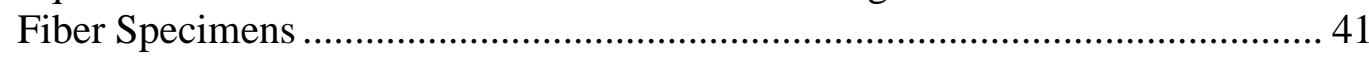

4.1.5 Equations Used for Volume Fraction Testing of Cured Reinforced Resins ....... 42

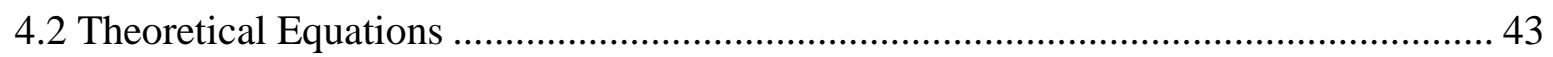

4.2.1 Equations Used to Find Laminate In-Plane Engineering Constants ................... 43

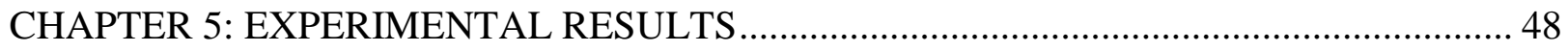

5.1 Experimental Measurement Device Validation ......................................................... 48

5.1.1 Extensometer vs. Axial Strain Gage vs. Crosshead Displacement ..................... 49

5.1.2 Poisson's Ratio Validation Using Axial and Transverse Strain Gages ............... 52

5.2 Summary of Carbon Fiber Material Properties.............................................................. 53

5.3 Unidirectional Carbon Fiber Material Property Testing ................................................ 55

5.3.1 Test for $0^{\circ}$ Unidirectional Carbon Fiber Composite Tensile Specimens ............ 55

5.3.2 Test for $90^{\circ}$ Unidirectional Carbon Fiber Composite Tensile Specimens .......... 60

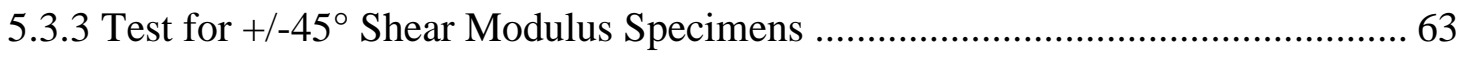




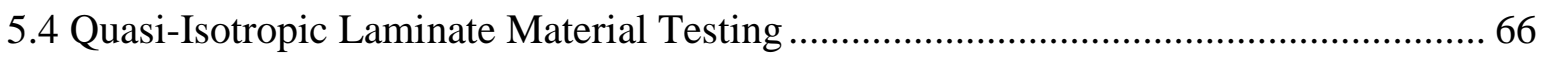

5.4.1 Test for Quasi-isotropic Tensile Specimens...................................................... 66

5.4.2 Quasi-Isotropic Tensile Specimen \#1 In-Plane Experimental Material Properties..................................................................................................... 72

5.4.3 Quasi-Isotropic Laminate In-Plane Theoretical Material Properties .................. 73

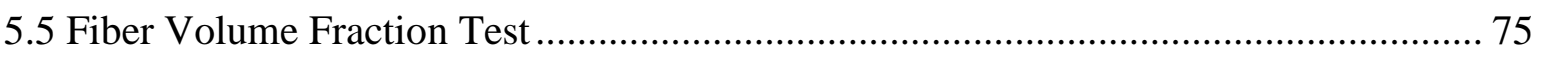

5.6 Aluminum 2024-T4 Double Shear Test................................................................. 78

5.7 Composite Double Shear Test ………………………....................................... 82

5.7.1 Curing Cycle 1 (Cytec's MTM 49 Unidirectional Carbon Fiber Cure Cycle) for Double Shear Test …………………………………………………...... 86

5.7.2 Curing Cycle 2 (Umeco's MTM 49 Unidirectional Carbon Fiber Cure Cycle) for Double Shear Test ...................................................................................... 91

5.7.3 Comparison between Cure $1 \&$ Cure 2 ………................................................ 94

5.7.4 Comparison Between The Aluminum Double Shear Specimens \& QuasiStatically Loaded (0.05 in./min.) Composite Double Shear Specimens .............. 95

CHAPTER 6: NUMERICAL ANALYSIS ................................................................................. 97

6.1 Finite Element Analysis Introduction ……………………………………………..... 97

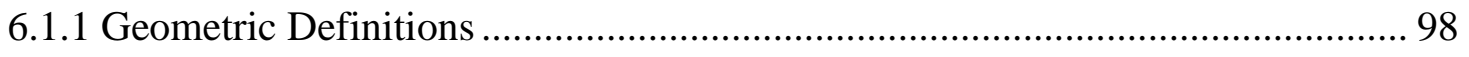

6.1.2 Material Creation, Section Assignments, \& Meshing ........................................ 98

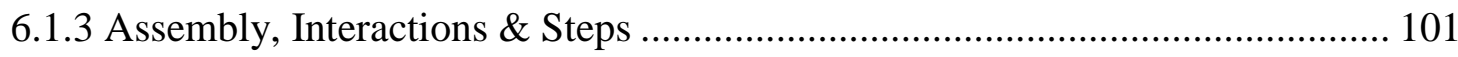

6.1.4 Boundary Conditions \& Loads .......................................................................... 101

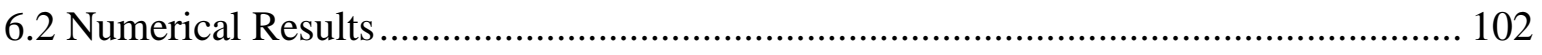

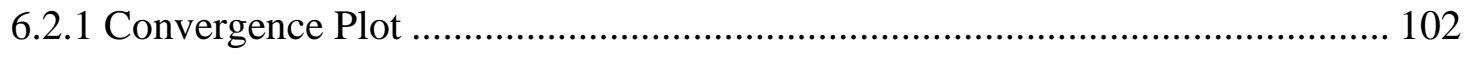

6.2.2 Factors That Influenced the Numerical Results ................................................ 103

CHAPTER 7: COMPARISON BETWEEN EXPERIMENTAL \& NUMERICAL DOUBLE

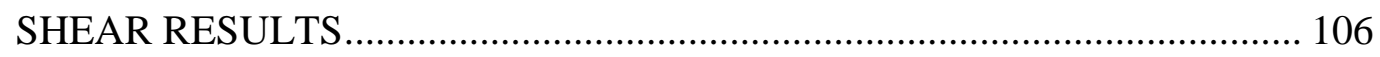


7.1 Numerical Aluminum Model Comparison to Experimental Results ........................ 106

7.2 Composite Numerical Model Comparison to Experimental Results ........................ 108

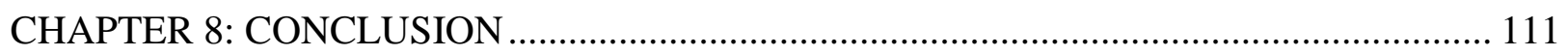

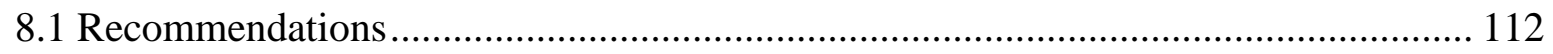

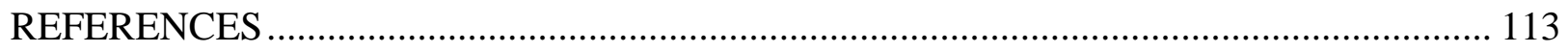

\section{APPENDICES}

A.1. Drawings for the Fixture Assembly ............................................................... 116

A.2. Tutorial on Bluehill2 Test File Setup................................................................ 118

A.3. Tutorial on Finding the Unknown Engineering Constants ................................. 127

A.4. Tutorial on Outputting Force vs. Pin Deflection from Abaqus............................... 130

A.5. Tutorial on Modeling the Double Shear Bearing Specimen Assembly ................... 135

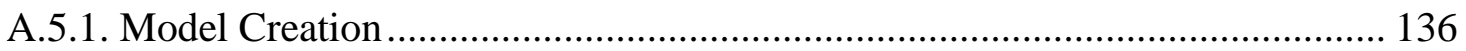

A.5.2. Part Creation ........................................................................................... 137

A.5.3. Partition Creation................................................................................. 144

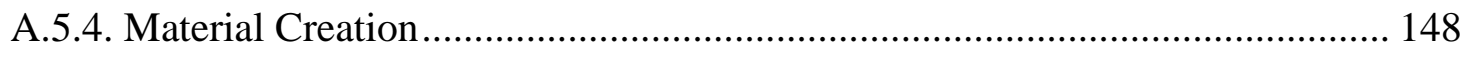

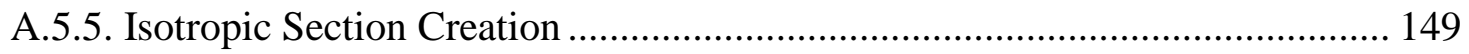

A.5.6. Composite Laminate Section Creation ..................................................... 151

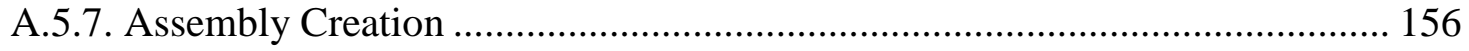

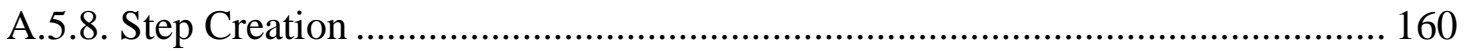

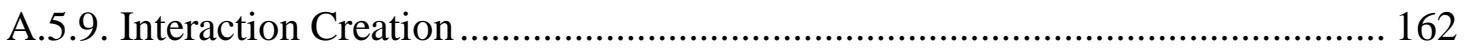

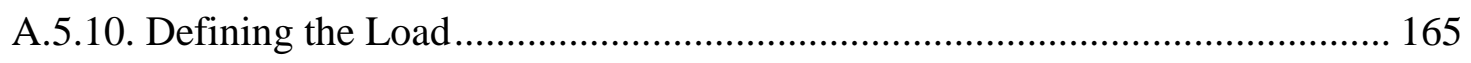

A.5.11. Defining the Boundary Conditions..................................................... 167

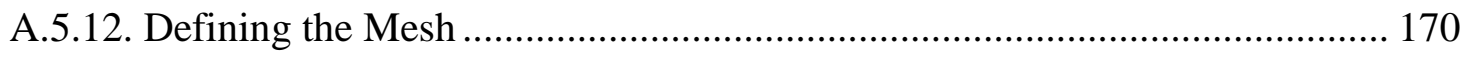

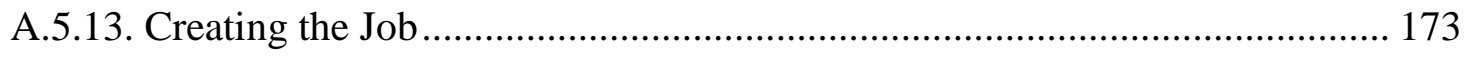




\section{LIST OF TABLES}

Table

Page

1. Comparison of extensometer, strain gage and crosshead on an aluminum specimen .......... 51

2. Umeco's mtm 49 unidirectional datasheet ${ }^{[21]}$ properties ............................................. 54

3. Umeco's mtm 49 unidirectional properties tested in cal poly's aerospace composites

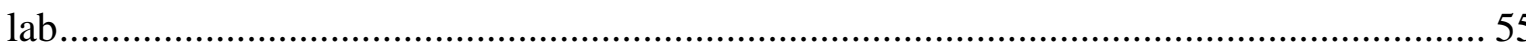

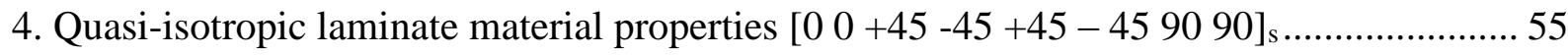

5. $0^{\circ}$ Unidirectional carbon fiber composite tensile specimen data ..................................... 59

6. $90^{\circ}$ Unidirectional carbon fiber composite tensile specimen data ................................... 62

7. $+/-45^{\circ}$ Unidirectional carbon fiber composite tensile specimen data................................ 65

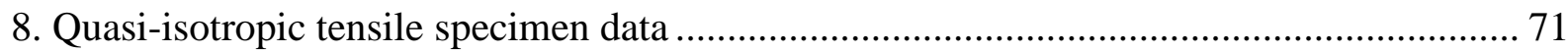

9. Datasheet material properties of one unidirectional carbon fiber ply which was inputted

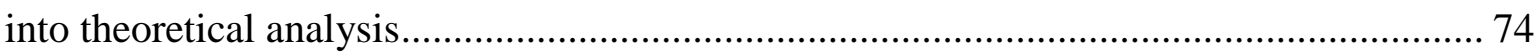

10. Comparison between experimental and theoretical quasi-isotropic tensile

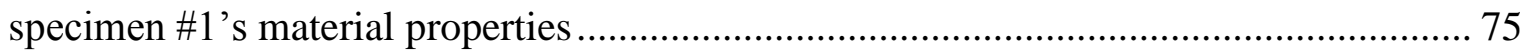

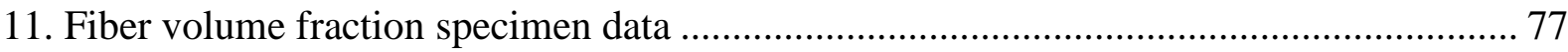

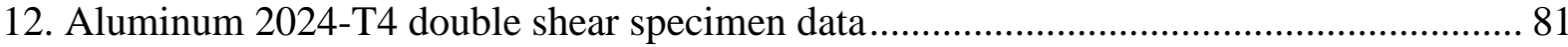

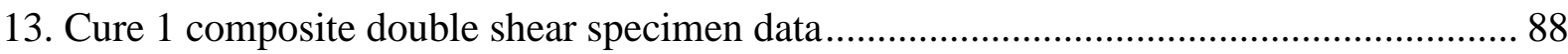

14. Cure 1 composite double shear specimen data continued ........................................... 89

15. Cure 2 composite double shear specimen data...................................................... 92

16. Cure 2 composite double shear specimen data continued ........................................... 93

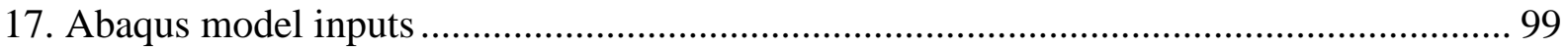


18. Engineering material constants from simulation composite analysis 2015 material manager

19. Comparison between experimental slope and numerical slope of the aluminum

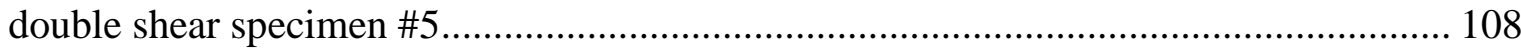

20. Comparison between experimental slopes and numerical slope of the composite

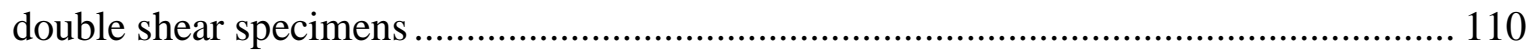

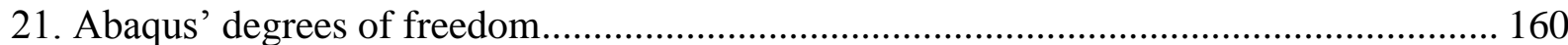




\section{LIST OF FIGURES}

Figure

1. Three basic joint configurations ${ }^{[2]}$ adhesively bonded single shear joint (top) mechanically fastened single shear joint (center) mechanically fastened double shear joint (bottom)

2. Three failure mechanisms for a mechanically fastened composite joint ${ }^{[4]}$...................... 8

3. ASTM D3039 ${ }^{[19]} 0^{\circ}, 90^{\circ}$, balanced \& symmetric tensile specimen dimensions ............... 12

4. $0^{\circ}$ Specimen $(\mathrm{left})+/-45^{\circ}$ specimen $\&$ quasi-isotropic laminate specimen (center)

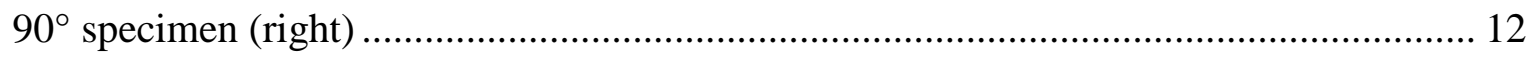

5. ASTM D5961 ${ }^{[18]}$ Composite Double Shear Specimen Dimensions ............................... 13

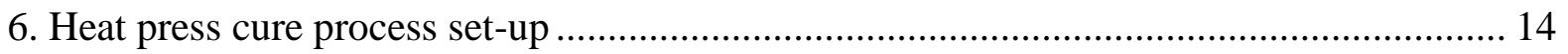

7. Laid up carbon fiber unidirectional pre-preg material ............................................. 15

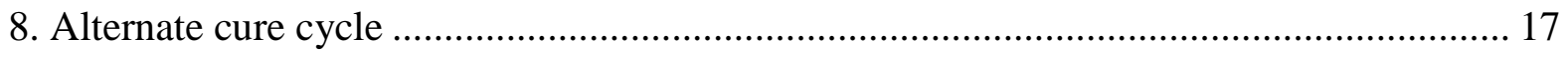

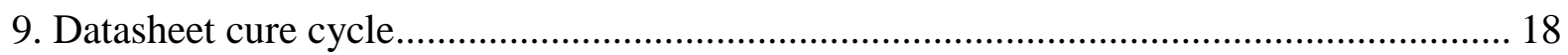

10. Tile saw with diamond coated blade used to cut the tensile and double shear

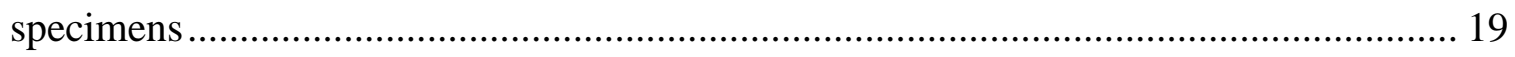

11. Drill fixture and aluminum template used to drill 5 holes at once.............................. 20

12. Side photo of the aluminum template \& composite double shear specimen (left) .......... 21

13. Specimen, blue painters tape \& emery cloth (left) .............................................. 22

14. $0^{\circ}$ Unidirectional carbon fiber composite tensile specimens with 2 in. aluminum tabs (left)

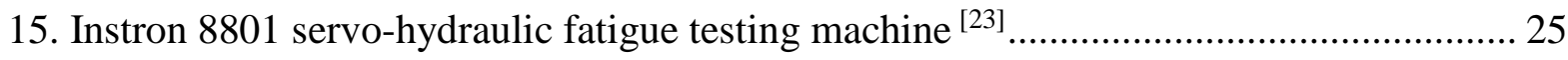


16. Instron 8801 crossheads clamping onto a thick steel tensile specimen ${ }^{[23]}$ 26

17. Dynamic extensometer 0.5 in. gage length with a range of $+/-0.1 \mathrm{in}$. 27

18. Composite tensile specimen between the clamps (left) composite tensile specimen with extensometer (right) 34

19. Double shear fixture between the clamps (left) composite double shear specimen inside double shear fixture (center) close-up of the composite double shear specimen assembly (right) 36

20. Bolt-collar assembly shown (left) fully assembled bolt-collar assembly (center) parts needed to fix the extensometer to the double shear fixture assembly (right) 36

21. Aluminum specimen between both clamps (left) aluminum specimen with a transverse strain gage, axial strain gage \& extensometer (center) tensile specimen showing the clamped sections and the 3 principle directions (right).....

22. Tensile stress vs. tensile strain response comparison between extensometer $\&$ strain gage of the aluminum 2024-T4 specimen. 52

23. Axial and transverse strain vs. axial load of the aluminum 2024-T4 specimen 53

24. $0^{\circ}$ Unidirectional carbon fiber composite tensile specimens with aluminum tabs (left) post-test $0^{\circ}$ unidirectional carbon fiber composite tensile specimen (right)

25. Tensile stress vs. tensile strain response of (7) $0^{\circ}$ unidirectional carbon fiber composite tensile specimens

26. Extensometer attached using two rubber bands on a $0^{\circ}$ unidirectional carbon fiber composite tensile specimen. 58

27. (8) $90^{\circ}$ Unidirectional carbon fiber composite tensile specimens with emery cloth tabs 61 
28. Tensile stress vs. tensile strain response of (8) $90^{\circ}$ unidirectional carbon fiber

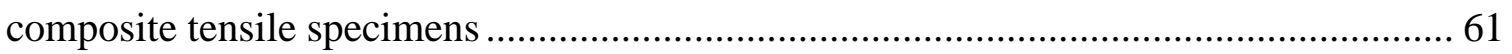

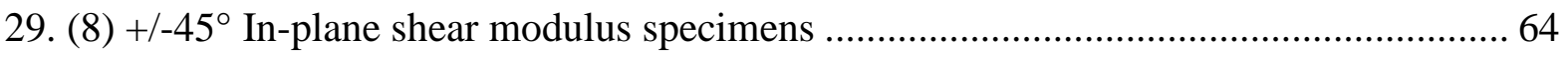

30. Shear stress vs. shear strain response of $(8)+/-\mathbf{4 5}^{\circ}$ shear modulus specimens ............... 64

31. Quasi-isotropic tensile specimens where specimen \#1 has a strain rosette (left) post-test quasi-isotropic tensile specimens (right) ....................................................... 67

32. Close-up of a quasi-isotropic tensile specimen failure ……............................................. 67

33. Quasi-isotropic tensile specimen with rectangular rosette strain gage attached ............... 69

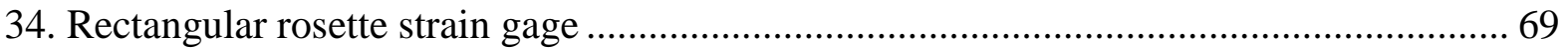

35. Tensile stress vs. tensile strain of the quasi-isotropic tensile specimens ........................... 70

36. Axial, $+45^{\circ} \&$ transverse strain vs. tensile stress of the quasi-isotropic tensile

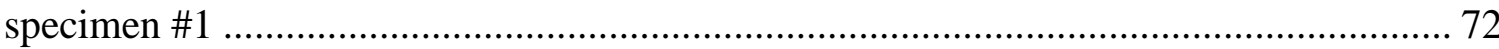

37. Resin-free fiber volume fraction specimen (left) furnace used to burn off resin (right) .. 77

38. Bearing stress vs. bearing strain response of (5) aluminum 2024-T4 double shear specimens

39. Bearing stress vs. bearing strain response of (5) aluminum 2024-T4 double shear specimens with strain correction region and non-linear region removed ......................... 80

40. Example of a bearing failure of an aluminum 2024-T4 double shear specimen .............. 82

41. Aluminum 2024-T4 double shear specimens before test (left) aluminum 2024-T4 double shear specimens after test (right) .................................................................. 82

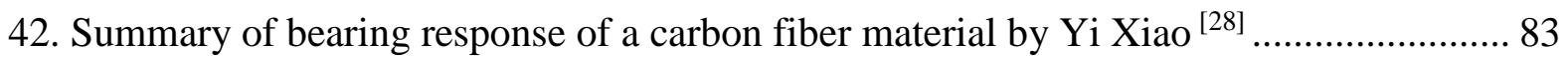

43. Example of bearing failure where the fibers end up crushing near the pin location ........ 84 
44. ASTM 5961- bearing test failure codes with illustrations of common modes 85

45. Carbon fiber double shear specimens before test (left) carbon fiber double shear specimens after test (right) 86

46. Cure 1 (alternate cure) bearing stress vs. bearing strain response five speed rates: $0.05 \mathrm{in.} / \mathrm{min} ., 0.1 \mathrm{in.} / \mathrm{min} ., 1 \mathrm{in} . / \mathrm{min} ., 2 \mathrm{in.} / \mathrm{min} . \& 6 \mathrm{in.} / \mathrm{min}$. 90

47. Cure 2 (datasheet cure) bearing stress vs. bearing strain response five speed rates: 0.05 in./min., 0.1 in./min., 1 in. $/ \mathrm{min} ., 2$ in. $/ \mathrm{min} . \& 6 \mathrm{in.} / \mathrm{min}$. 94

48. Ultimate bearing strength comparison between both cure cycles..... 95

49. Partitioned double shear specimen drawn carefully to preserve symmetry..... 104

50. A close-up of the partitioned region around the hole of the double shear specimen...... 104

51. Convergence plot of pin deflection vs. total nodes per element 105

52. Bearing stress vs. bearing strain response of aluminum 2024-T4 double shear specimen 107

53. Load (reaction force) vs. pin displacement comparing experimental to numerical of the double shear aluminum specimens 107

54. Load (reaction force) vs. pin displacement comparing numerical to experimental of the double shear composite specimens 109

55. Drawing of the two steel side plates 116

56. Drawing of the center plate of the fixture. 117

57. Drawing of the smaller top plate 118

58. Bluehill2 load rate adjustment screen 119

59. Bluehill2 end of test screen. 120

60. Bluehill2 sampling screen. 121 


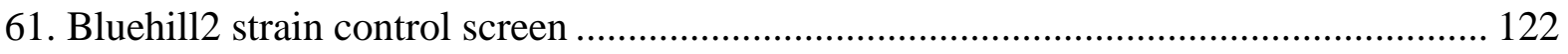

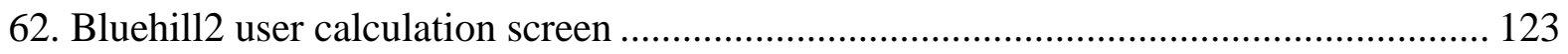

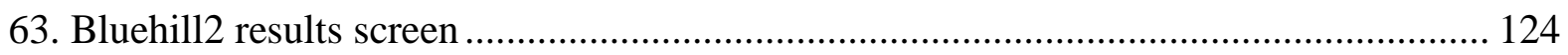

64. Bluehill2 graph screen ......................................................................................... 125

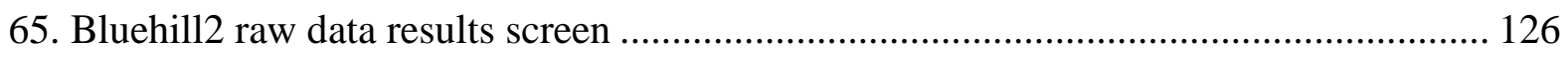

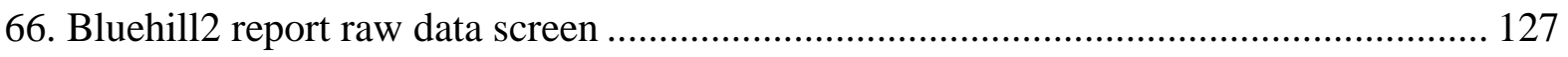

67. Autodesk simulation composite analysis 2015 material manager strength input

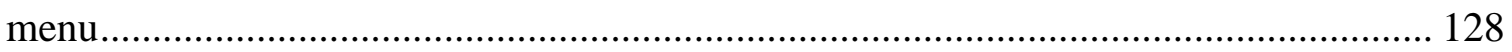

68. Autodesk simulation composite analysis 2015 material manager lamina engineering

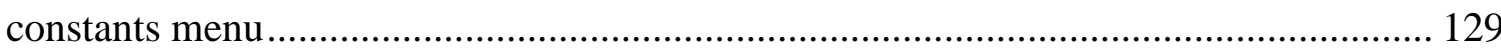

69. Simulation composite analysis 2015 material manager optimization and save menu.... 130

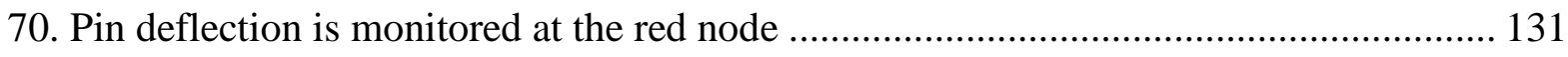

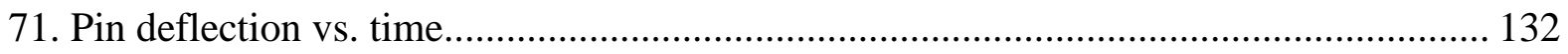

72. Fixed nodes selected in red (left) selected steps which are monitored in the analysis

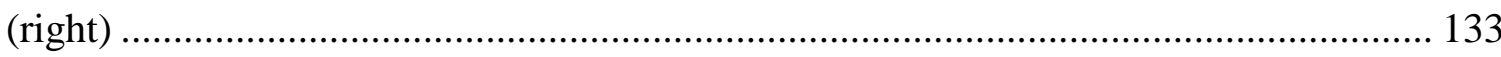

73. Force vs. time plot at the reaction nodes (left) summed up force vs. time plot (right)... 134

74. Once combined the force vs. pin deflection plot ……………….............................. 135

75. Finished parts for numerical model ....................................................................... 136

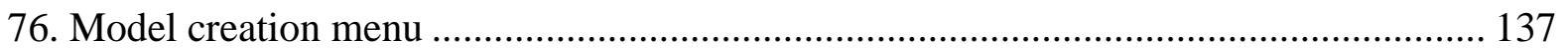

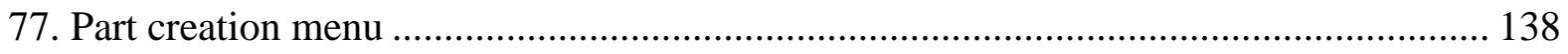

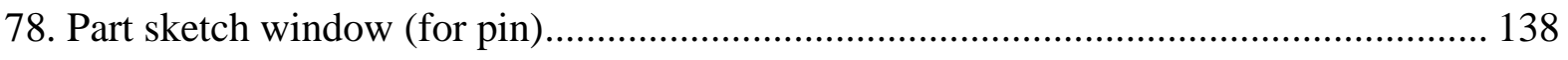

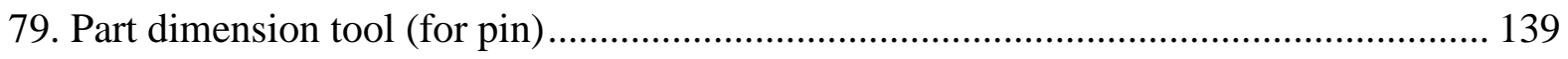

80. Base extrusion menu (for pin) ................................................................................ 140 


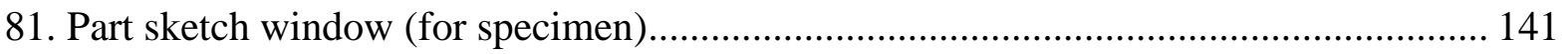

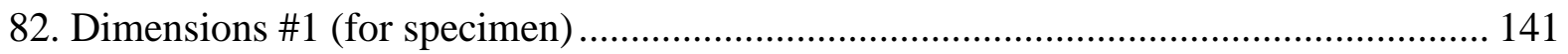

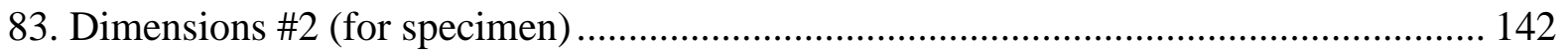

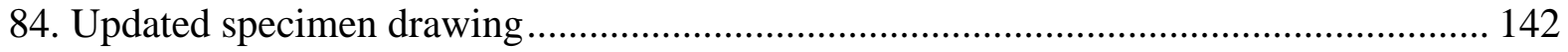

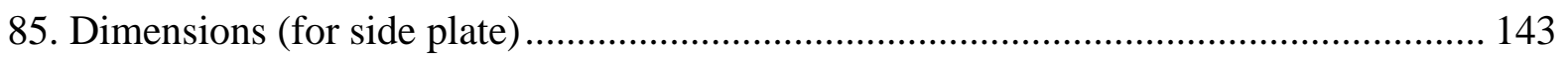

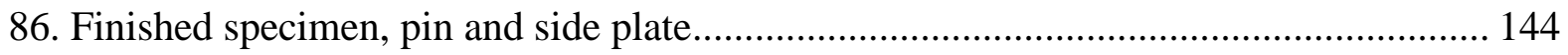

87. Partition creation screen (for side plate) …......................................................... 145

88. Final partition dimensions (for side plate) …....................................................... 146

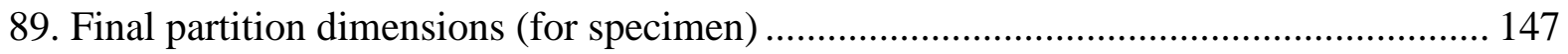

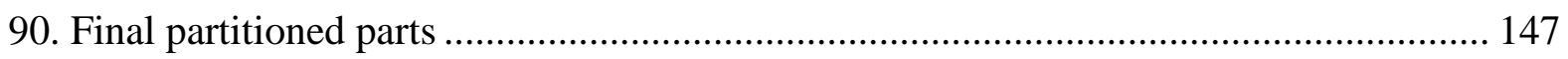

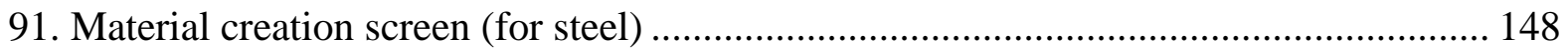

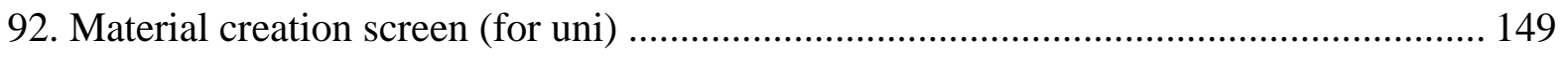

93. Section creation menu (for a solid/homogeneous material) ................................... 150

94. Section assignment screen (for sideplate \& sideplate2) ........................................ 151

95. Initial composite layup menu (for specimen) ................................................... 152

96. Composite layup menu (for specimen) …..................................................... 153

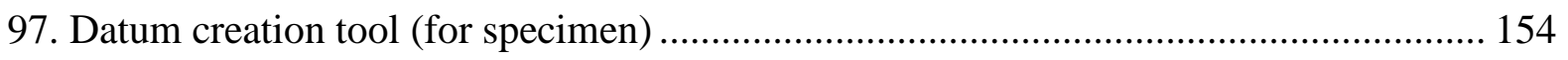

98. Datum point selection screen (for specimen).................................................... 155

99. Final composite layup screen (for specimen) ................................................. 156

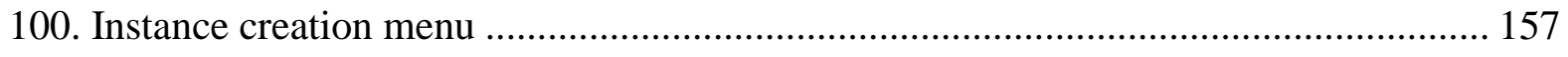

101. Three views of the assembly (top) close up of pin and side plate (bottom) ................ 158

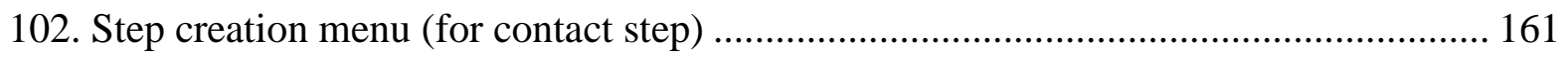

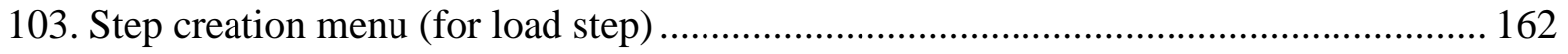


104. Surface-to-Surface contact menu \& master surface selection screen

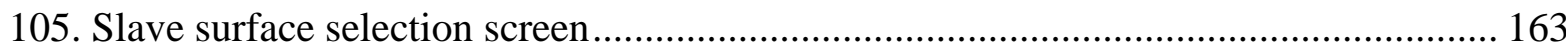

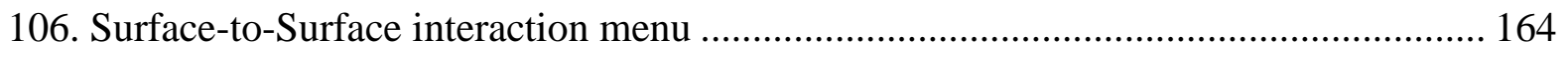

107. Tangential \& normal behavior contact property menus ........................................ 165

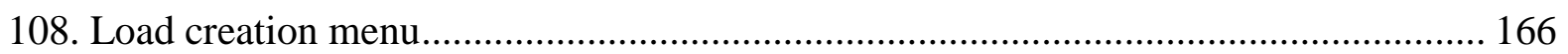

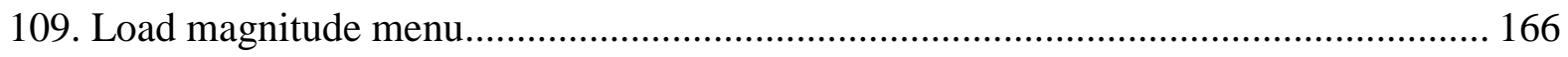

110. Fixed boundary condition (for top of specimen) …............................................ 168

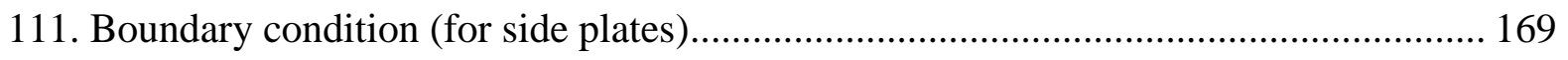

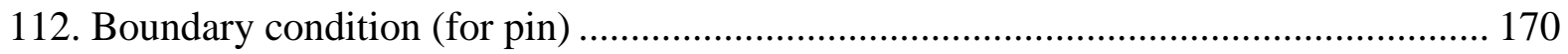

113. Modifying the boundary condition (for pin) …............................................. 170

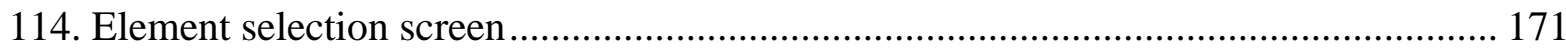

115. Mesh control menu ...................................................................................... 172

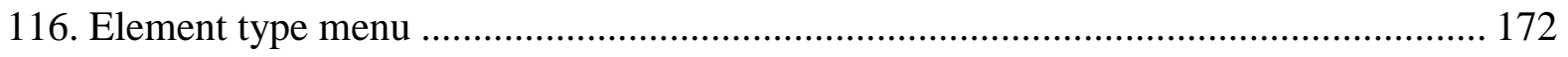




\section{NOMENCLATURE}

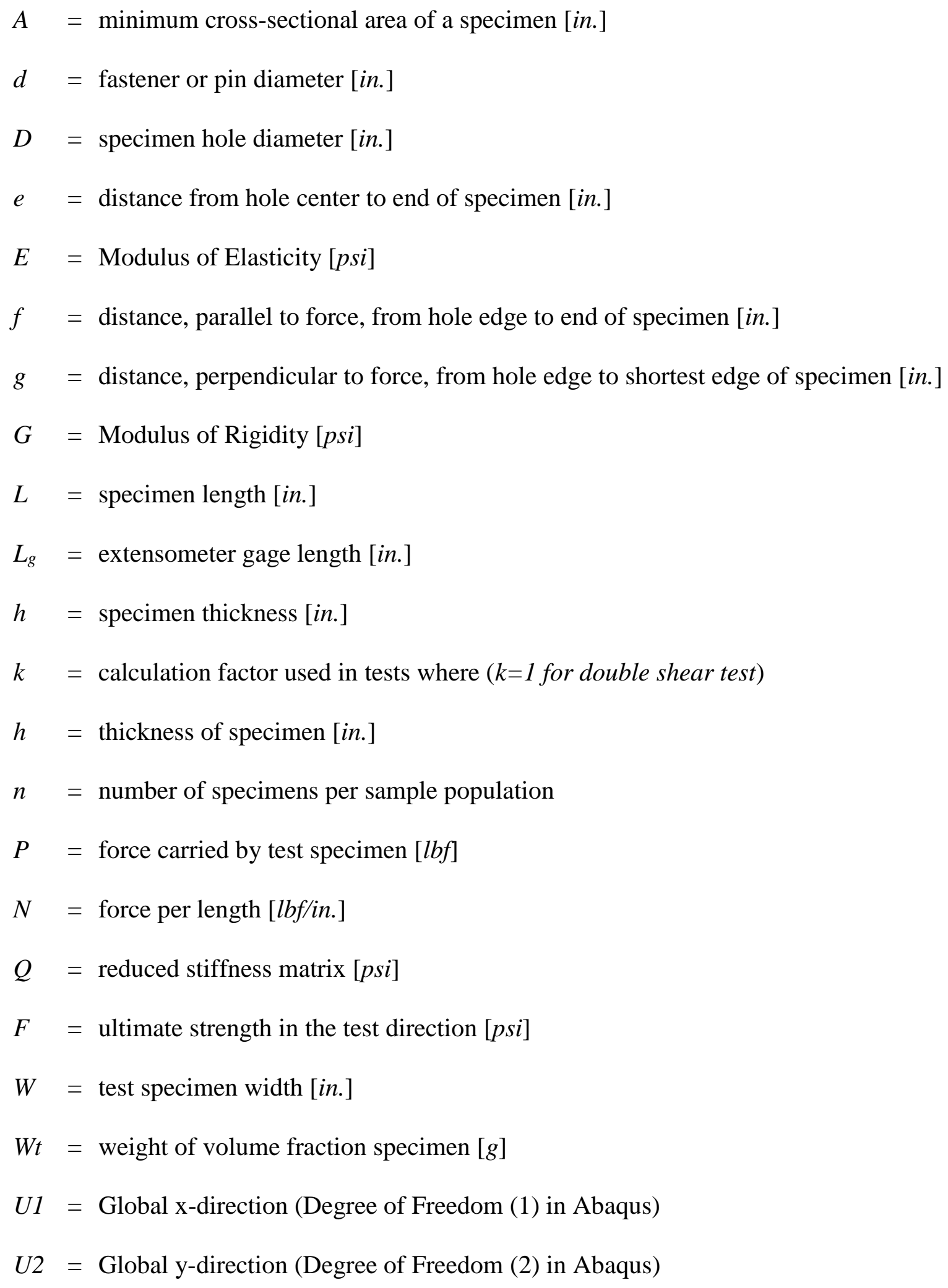




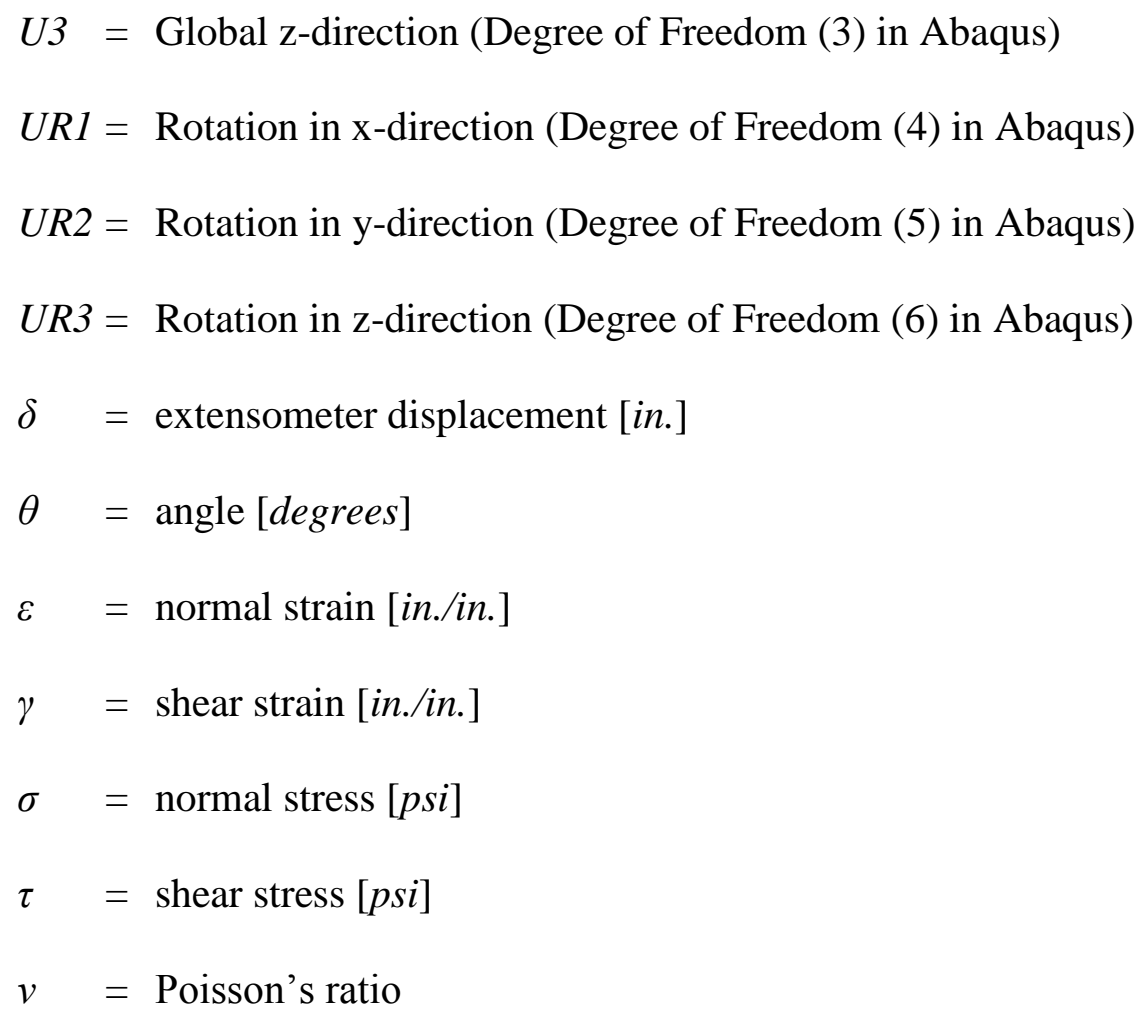




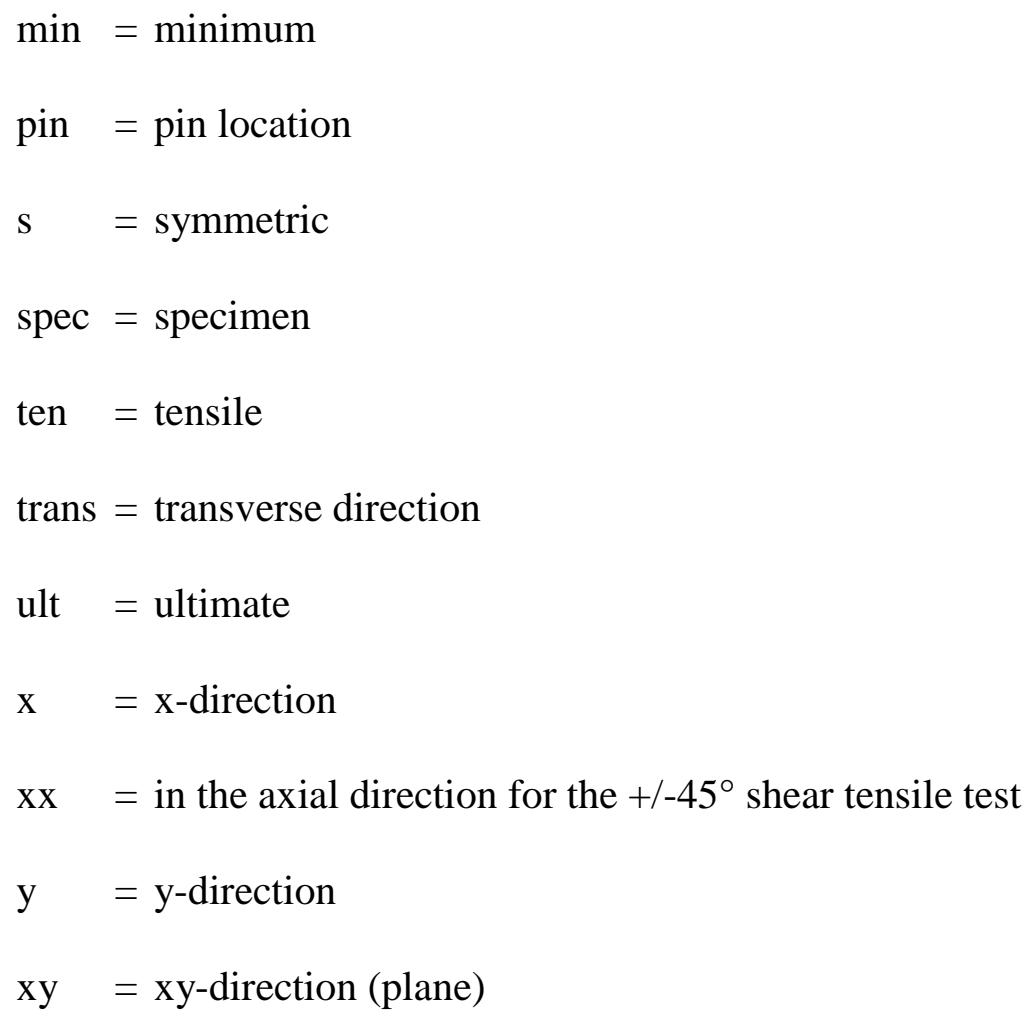




\section{CHAPTER 1: INTRODUCTION}

In this chapter, previous and current thesis work is introduced. Section 1.1 introduces the different two different types of aircraft structures. In Section 1.2, the differences between an adhesively bonded joint and a mechanically fastened joint are explained. In Section 1.3, previous work is mentioned, considerations are made in order to avoid testing parameters, which have already been tested, and the three different failure mechanisms are explained. Section 1.4 explains the thesis goal and the thesis scope.

\subsection{Introduction to Conventional \& Advanced Composite Structures}

When you think of an aircraft's wing, it is composed of multiple panels and not usually made as a single piece. The use of joints becomes essential in an aircraft's wing (since joints serve to attach multiple structural components together to form one part). Ideally, the designer wants to avoid using them, since they can contribute a significant amount of weight to the overall aircraft's structure. Current aircraft manufactures are transitioning from a conventional aircraft structure to an advanced composite structure since the advantage of switching to an advanced composite structure is the significant reduction in parts and joints. Composite materials have desirable characteristics such as being: very stiff, extremely strong, and extremely light. For example, the Airbus' A350 aircraft structure is made up of $53 \%$ composite materials ${ }^{[1]}$. Even though the total amount of joints can be significantly reduced, that does not mean they can be avoided altogether. 
As composites become more widely used in the Aerospace Industry, there still lies limited research in their ability to perform as joints. Their main flaw is their poor behavior in redistributing stress concentrations. Even though there has been a lot of research in composite joints, not enough advancement has been made compared to its metal counterpart. Metal joints (in particular, Aluminum joints) have been used for years in the Aerospace Industry. Currently, composite joints are overdesigned (made a lot thicker than they need to be) which leads to weight penalties. Design that is more detailed needs to done on composite joints in order to improve its ultimate bearing strength.

\subsection{Introduction to Adhesively Bonded Joints \& Mechanically Fastened Joints}

Two types of joints exist: one is the mechanically fastened joint, and the other is the adhesively bonded joint. In Figure 1, one can see an adhesively bonded single shear joint, a mechanically fastened single shear joint and a mechanically fastened double shear joint. The region between the two plates, in the adhesively bonded double shear joint, is the thin layer of structural adhesive used to bond both structural components together. Adhesively bonded joints are typically lighter but are often more difficult to design. No holes need to be made in an adhesively bonded joint. Reduction of holes reduces the amount of stress concentrations. Adhesively bonded joints can be problematic since the surface finish needs to be accounted for to achieve a strong bond between two surfaces. Another issue with adhesively bonded joints is that they cannot be removed as easily as a mechanical joint. 
Mechanically fastened joints are widely used in the Aerospace Industry since they are more practical in the sense that they can be easily removed if a part needs to be replaced, repaired, or checked. Two types of mechanically fastened joints exist: single shear and double shear. In addition, a mechanically fastened joint can contain many fasteners. Mechanically fastened joints require a hole through both structural components, which creates stress concentrations. Both of the structural assemblies are held together by a bolt, and nut.

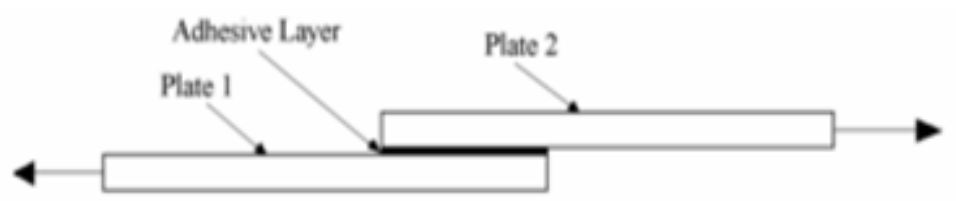

(a)
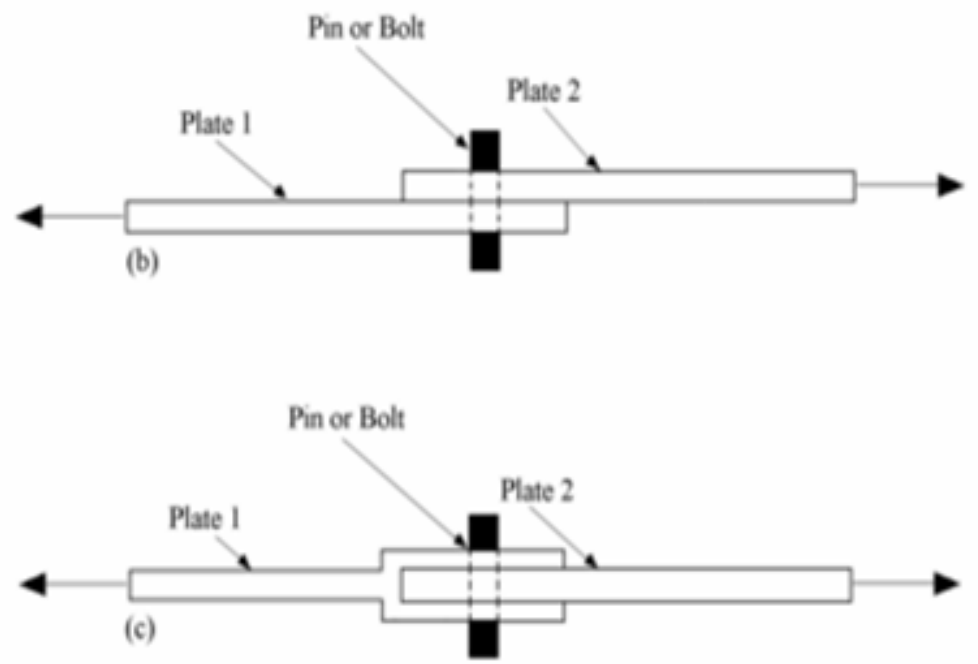

Figure 1 . Three basic joint configurations ${ }^{[2]}$ adhesively bonded single shear joint (top) mechanically fastened single shear joint (center) mechanically fastened double shear joint (bottom) 


\subsection{Previous Literature on Mechanically Fastened Composite Joints}

Numerous papers have been made on mechanically fastened composite joints, and in this

section, the most important finds will be mentioned. According to Alan Baker ${ }^{[3]}$, for a mechanically fastened double shear joint, load is transferred mainly through compression on the internal face of the fastener holes and as well as on a component of shear on the outer faces of the plate due to friction. Mechanically fastened composite joints can be made very durably but the designer needs to spend a longer time in the design process. According to Okutan ${ }^{[4]}$, problems arise when the designer wants to analyze them since they have an anisotropic and heterogeneous nature.

According to Chen ${ }^{[5]}$, the behavior of a composite joint could be influenced by four parameters. The first is the material parameter. The material parameter includes fiber types, form, resin type, fiber orientation, laminate stacking sequence, material cure cycle, etc. The second is the geometric parameter. This includes the specimen width $(W)$ and the hole edge distance $(e)$. These are usually reported as $W / D$ and $e / D$ ratios where $D$ is the diameter of the hole. A huge contributor to the strength of the specimen is the specimen thickness $(t)$. The pitch is the distance between two or more holes in a multiple hole composite joint. The third (also very important) is the fastener parameter. This includes fastener type, fastener size, washer size, hole size, and tolerance. The last is the design parameter. The design parameter includes loading type (tension, compression, fatigue), loading direction, loading speed, hydraulic clamping pressure, joint type (single lap, double lap), environment, etc. 
The lay-up sequence also played a significant role in the overall strength of the double shear joint, as well. Quinn \& Matthews ${ }^{[6]}$ studied in detail the effect of stacking sequences on the pin bearing strength in glass-reinforced plastics. They concluded that placing a $90^{\circ}$ layer ply on the outer surface of the laminate increased the overall bearing strength. Liu ${ }^{[7]}$ tested different laminate thicknesses by varying the bolt diameter. He concluded that thick laminates with smaller diameter holes and thin laminates with larger diameter holes were a lot weaker than laminates with similar hole and laminate thicknesses.

Stockdale \& Matthews ${ }^{[8]}$ studied the effects of bolt clamping pressure and found that boltclamping pressure played a huge role in the overall strength of the composite joint. Kim ${ }^{[9]}$ tested to see the effects of temperature and moisture on the strength of graphite-epoxy laminates. From this experiment, the actual stress distribution of the joint is very difficult to find since the region is so small. The use of strain gages is impractical because that region is under a very high stress so any kind of strain gage applied would crush because of the force. That is why numerous researchers have been working on methods of modeling composite joints with the help of various finite element programs. The load capacity of a laminate is severely degraded due to the effects of hole clearance and friction. Hyer \& Klang ${ }^{[10]}$ investigated this phenomenon with a pin-loaded orthotropic plate. Pierron ${ }^{[11]}$ used Abaqus to calculate the stress distribution around the hole of a woven composite joint. Most finite element modeling was done using 2D shell elements and recently there has been an increased amount of 3D modeling of composite joints.

Previous researchers mention that the joint strength depends mainly on the failure criterion. 
Only a small section of the bearing stress vs. bearing strain curve is linear, and then after, it becomes nonlinear. Stress concentrations cause crushing in a small section of the geometry, making it a very difficult nonlinear problem. Chang ${ }^{[12]}$ created a 2D finite element model and assumed a frictionless contact with a rigid pin and a cosine normal load distribution in the pin-hole boundary. Another difficulty in modeling the composite joint requires the user to combine the failure criteria with a property degradation model. As the composite takes more load, the actual material properties are degrading over time, which would mean the modulus is decreased after each new load is applied. Lessard ${ }^{[2]}$ used a 2D linear model along with a non-linear model to predict the strength of the composite joint. There are five different kinds of failure, which can occur in a laminate: matrix tensile, compressive failure, fiber/matrix shearing, fiber tensile, and fiber compressive failure. The Hashin failure criterion is an important criterion used to characterize failure within a laminate.

\subsubsection{Previous Literature on Loading Rate Effects on Mechanically Fastened Composite Joints}

In flight, the aircraft might experience various dynamic loading conditions, so not only do composites need to be tested in quasi-static loading case, but also in a dynamic load case. Metals are not as load rate dependent as composite materials.

Ger $^{[13]}$ tested a number of carbon and carbon fiber glass hybrid composites at dynamic loading rates of 6 to $7 \mathrm{~m} / \mathrm{s}$. The double shear joint configuration carried more load at high loading rates. It was also noted that for all joint configurations the stiffness of the joint increased significantly with 
loading rate. In addition, what was noted was that the total energy absorption of the joint decreased significantly in the dynamic tests. Contradictory to $\mathrm{Ger}^{[13]}, \mathrm{Li}^{[14]}$ tested different types of joint configurations subject to a bearing load and found that energy absorption increased. $\mathrm{Li}^{[14]}$ tested at higher rates of $4-8 \mathrm{~m} / \mathrm{s}$ and found this interesting trend. The dynamic behavior of composite joints is much more complicated than its behavior for the quasi-static condition due to the involvement of strain rate and inertial effects. $\mathrm{Li}^{[14]}$ concluded that crashworthiness design of tested composite joints could be based on their tensile strength design. Ger ${ }^{[13]}$ mentioned there must be a significant safety factor applied to take into account bearing strength variations with loading rate. The failure modes might also be affected due to an increased loading rate.

\subsubsection{Types of Failure in Mechanically Fastened Composite Joints}

According to Larry Lessard ${ }^{[2]}$, it has been observed experimentally that mechanically fastened composite joints fail under three basic mechanisms: net-tension, shear-out, and bearing (in addition, combinations of these mechanisms are often given separate names). Typical damage mechanism is shown below in Figure 2. Looking at previous work, a net-tension and a shear-out failure are more catastrophic than a bearing failure. The best way to see if a bearing failure has occurred is to look at the bearing stress vs. bearing strain plot. Once the stress gets to its peak value and suddenly drops off to zero, then one can conclude it was a shear-out or a net-tension failure. If after the ultimate bearing stress, the specimen continues to carry load but deforms as a result, this means that the joint was designed very safely. According to Okutan ${ }^{[4]}$, the optimum orientation for a bearing type of failure is a quasi-isotropic laminate orientation. A quasi-isotropic laminate 
orientation means the laminate has the isotropic properties in plane. According to USNA ${ }^{[15]}$, a quasi-isotropic part has either randomly oriented fiber in all directions, or has fibers oriented such that equal strength is developed all around the plane of the part.

The geometry of a mechanically fastened composite joint is quite complex since it can affect the failure mode of the double shear joint specimen. Kretsis ${ }^{[16]} \&$ Matthews ${ }^{[16]}$ tested fiber glass and carbon fiber reinforced plastics and found that the $\operatorname{width}(W)$, end distance $(e)$, diameter of hole $(D)$, and laminate thickness $(h)$ all contribute to the overall mechanically fastened double shear joint strength. The most interesting aspect is that as the width of the specimen decreases to a specific amount, the mode of failure changes from bearing to net-tension. The W/D (width to hole diameter ratio of the composite double shear joint specimen) must be at least 5 order to avoid the net tensile type failure. Another interesting thing to note is when the end distance of the hole is a certain distance from the edge of the plate, the failure turned from bearing to shear-out (where shear-out is considered a special case of bearing failure).

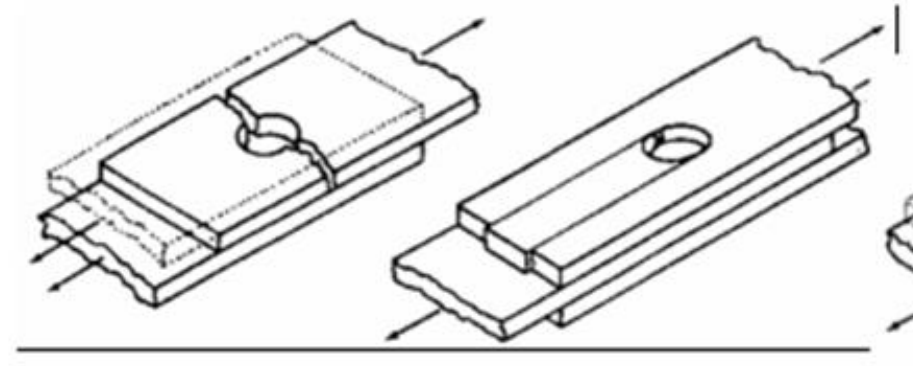

Tension failure
Shear-out failure

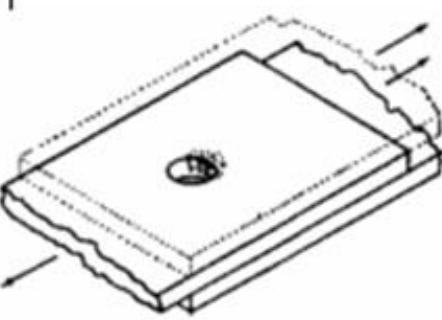

Bearing failure

Figure 2. Three failure mechanisms for a mechanically fastened composite joint ${ }^{[4]}$ 


\subsection{Thesis Goals \& Scope}

In the preceding sections of this thesis paper, the word double shear specimen will be used to represent one test specimen with a mechanically fastened double shear joint configuration. The goal of the thesis is to determine how the strength of a composite double shear joint is affected by two different cure cycles and five different loading rates. The composite joint will be tested in the double shear case and the laminate orientation was decided to be a quasi-isotropic laminate (based upon based on Yeole's double shear experimental results $\left.{ }^{[17]}\right)$. Yeole ${ }^{[17]}$ tested three different laminate orientations in his thesis, and concluded that a quasi-isotopic laminate took the highest stress. Yeole ${ }^{[17]}$ also mentioned that the testing of composite materials at fast loading rates could be an interesting topic to explore. ASTM 5961 ${ }^{[18]}$, which is the ASTM for bearing response of composite materials, required an extensometer to measure the relative pin displacement since using crosshead displacement is not an accurate method. A fixture was designed and manufactured in order to accommodate an extensometer. Finally, the numerical model was made to validate only the linear elastic portion of the experimental results.

There are seven chapters in this thesis. Chapter 1, the introduction, includes a brief introduction to: composite materials, the difference between adhesively bonded joints and mechanically fastened composite joints, and the loading rate effects on mechanically fastened composite double shear joint bearing strengths. It also includes a brief literature review, the statement of the problem and the objective and organization of thesis. Chapter 2 focuses on manufacturing of the double shear specimens and the tensile specimens. Chapter 3 focuses on the experimental material testing 
procedure conducted on the MTM49 Unidirectional Carbon Fiber pre-preg. It also explains the double shear fixture used for the testing. Chapter 4 focuses on the equations used in the experimental and theoretical calculations. Chapter 5 introduces the experimental result validation and then discusses the experimental results. Chapter 6 introduces: the numerical model, which was created using Abaqus 6.14 software, the convergence plot, and lastly, what, influences the numerical results. Chapter 7 is where the experimental results are compared to the numerical finite element results. Lastly, Chapter 8 is where the conclusions are drawn and different recommendations are made for the future work. In the reference section, one can find most of the related topics in the form of theses, books, reports and even papers published in numerous journals. In the appendix section, one find: drawings of the fixture, a tutorial on setting up the Bluehill2 double shear test method, a tutorial on finding the unknown engineering constants with the Autodesk software, a tutorial on outputting the force vs. hole deformation in Abaqus, and a tutorial on the composite double shear specimen Abaqus model. 


\section{CHAPTER 2: MANUFACTURING \& PREPARING \\ OF THE SPECIMENS}

This chapter will introduce the type of specimens that were manufactured and tested in the Instron machine along with their dimensions. All the dimensions were based on published ASTM test standards. ASTM is an international standards organization, which develops and publishes voluntary consensus technical standards for a wide range of materials, products, systems and services.

\subsection{Tensile Specimen \& Double Shear Specimen Dimensions}

The dimensions for the $0^{\circ}$ tensile specimens and the $90^{\circ}$ tensile specimens were found in ASTM D3039 ${ }^{[19]}$ Standard test method for tensile properties of fiber-resin composites. The dimensions used for the shear modulus $+/-45^{\circ}$ were found in ASTM D3518 ${ }^{[20]}$. Below in Figure 3 , one can see all of the tensile specimen dimensions for each specific fiber orientation angle. Figure 4 shows a drawing of all four different fiber orientation tensile specimens. The $+/-45^{\circ}$ shear specimens and the quasi-isotropic laminate specimens had the same dimensions. Figure 5 shows

the dimensions, based on ASTM D5961 ${ }^{[18]}$, of the composite double shear specimens. The quasiisotropic tensile specimens were tested to see how the theoretical material properties matched. 
TABLE 2 Tensile Specimen Geometry Recommendations ${ }^{A}$

\begin{tabular}{|c|c|c|c|c|c|c|}
\hline $\begin{array}{c}\text { Fiber } \\
\text { Orientation }\end{array}$ & $\begin{array}{l}\text { Width, } \\
\text { mm [in.] }\end{array}$ & $\begin{array}{c}\text { Overall Length, } \\
\text { mm [in.] }\end{array}$ & $\begin{array}{c}\text { Thickness, } \\
\text { mm [in.] }\end{array}$ & $\begin{array}{l}\text { Tab Length, } \\
\text { mm [in.] }\end{array}$ & $\begin{array}{c}\text { Tab Thickness, } \\
\text { mm [in.] }\end{array}$ & $\begin{array}{c}\text { Tab Bevel } \\
\text { Angle, }^{\circ}\end{array}$ \\
\hline $0^{\circ}$ unidirectional & $15[0.5]$ & $250[10.0]$ & $1.0[0.040]$ & $56[2.25]$ & $1.5[0.062]$ & 7 or 90 \\
\hline $90^{\circ}$ unidirectional & $25[1.0]$ & $175[7.0]$ & $2.0[0.080]$ & $25[1.0]$ & $1.5[0.062]$ & 90 \\
\hline balanced and symmetric & $25[1.0]$ & $250[10.0]$ & $2.5[0.100]$ & emery cloth & - & - \\
\hline random-discontinuous & $25[1.0]$ & $250[10.0]$ & $2.5[0.100]$ & emery cloth & - & - \\
\hline
\end{tabular}

${ }^{A}$ Dimensions in this table and the tolerances of Fig. 2 or Fig. 3 are recommendations only and may be varied so long as the requirements of Table 1 are met.

Figure 3. ASTM D3039 ${ }^{[19]} 0^{\circ}, 90^{\circ}$, balanced \& symmetric tensile specimen dimensions
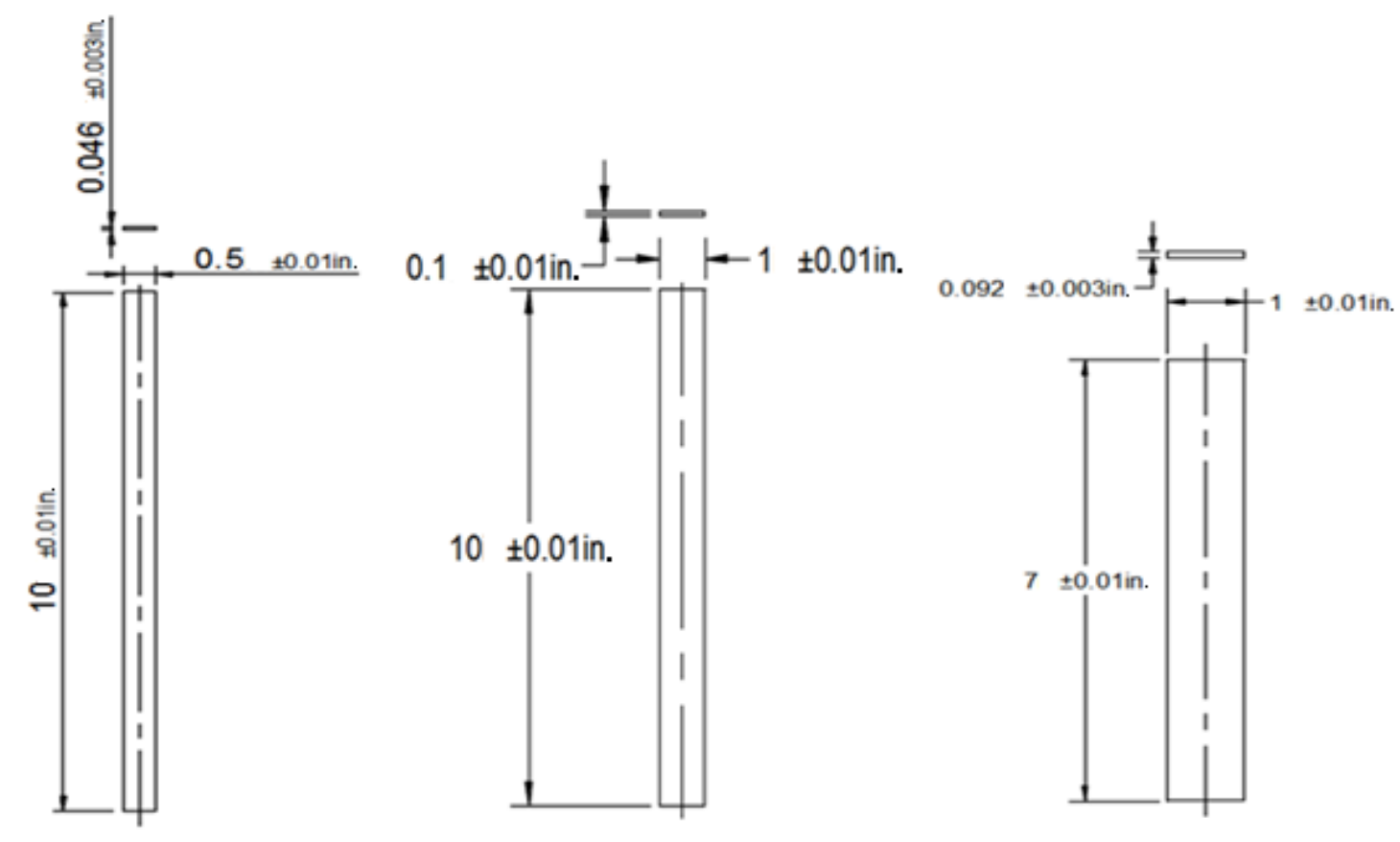

Figure 4. $0^{\circ}$ Specimen (left) $+/-45^{\circ}$ specimen \& quasi-isotropic laminate specimen (center) $90^{\circ}$ specimen (right) 

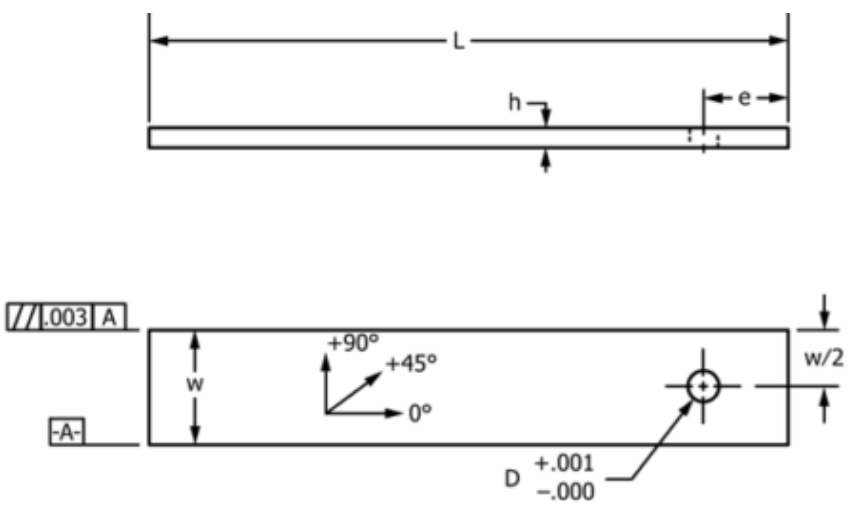

\begin{tabular}{lc}
\hline \multicolumn{1}{c}{ Parameter } & Standard Dimension, in. \\
\hline fastener or pin diameter, d & $0.250+0.000 /-0.001$ \\
hole diameter, D & $0.250+0.001 /-0.000$ \\
thickness range, h & $0.125-0.208$ \\
length, L & 5.5 \\
width, w & $1.5 \pm 0.03$ \\
edge distance, e & $0.75 \pm 0.03$ \\
countersink & none \\
\hline
\end{tabular}

Figure 5. ASTM D5961 ${ }^{[18]}$ Composite Double Shear Specimen Dimensions

\subsection{Manufacturing Process}

In the Cal Poly's Aerospace Engineering Composites Lab, there are two ways to manufacture a composite. One can use pre-preg material or apply a wet layup process. Pre-preg material is a lot easier to use since it already has the resin infused inside the material. In order to preserve the resin in the pre-preg material, it needed to be stored in a freezer at low temperatures. Once the pre-preg material is thawed, then the user is able to apply it to a mold or create a plate out of it.

The second way, the wet-layup process, consisted of having the fibers in their pure form, which usually come in a roll, and having a two-part epoxy. Once the fibers were cut out from the roll, the two-part epoxy is mixed with the correct ratio and then applied to the dry fibers. The part is then sealed, with a vacuum bag (where all the air is removed from the part). Then the cure cycle of the 
resin is applied to the vacuum-bagged part.

All of the tensile and double shear specimens were made on the heat press. When making a composite plate in the heat press, the user needed to sandwich the laminate between two nonporous sheets and two 0.25 in. thick Steel plates. Figure 6 shows how the heat press cure process was set-up. The non-porous sheets served to prevent the resin from sticking to the steel plates. The composite plate, the steel plates and the non-porous sheets were placed inside the heat press and then the cure cycle was programmed. Once cured, the composite plate was cut into various size specimens.

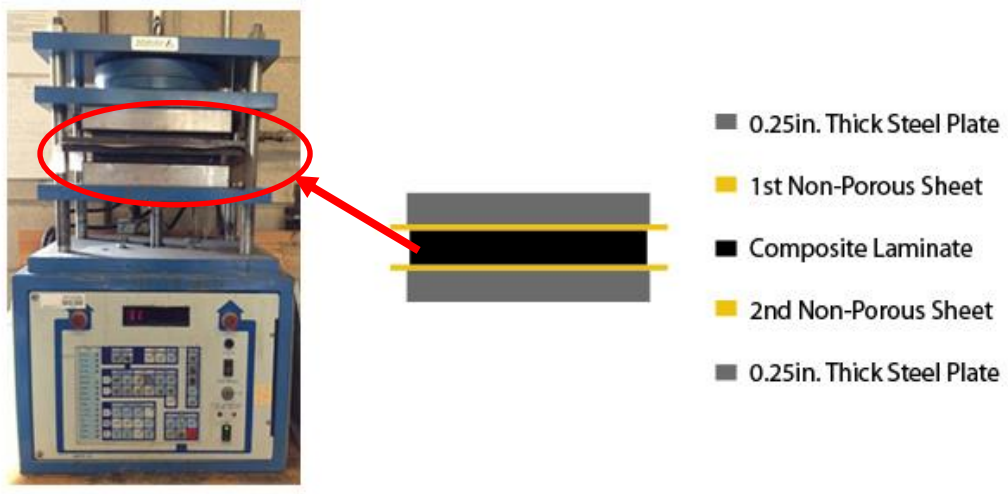

Figure 6. Heat press cure process set-up

\subsubsection{Double Shear Specimens}

All the composite double shear specimens were made with the quasi-isotropic laminate

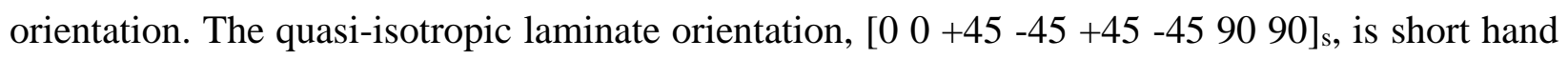
for $[00+45-45+45-459090 / / 9090-45+45-45+4500]$. The subscript $s$ means that the laminate 
is symmetrical about the last ply (which in this case is a $90^{\circ}$ ply). The alternate cure cycle was the Cytec's MTM 49 cure cycle and the datasheet cure cycle was the Umeco's MTM 49 cure cycle..

The material was first thawed since according to the Umeco's ${ }^{[22]}$ MTM 49 datasheet, if the roll is open to the environment, condensation will occur on the pre-preg material, which will degrade the quality and the aesthetic look of the material. Sixteen $12 \mathrm{in.} \mathrm{by} 12 \mathrm{in.}$. plies were cut out and orientated in the quasi-isotropic laminate orientation of $[00+45-45+45-459090]_{s}$ s. All the respective angles within each ply of the laminate were carefully kept within $\pm 1^{\circ}$. Shown in Figure 7 , a protractor was used to make sure each ply in the laminate was within $\pm 1^{\circ}$. Once all the plies were stacked very carefully (in order to prevent air pockets from occurring within the laminate), the cure cycle was programmed into the heat press. Air pockets create areas where delamination can occur, which leads to the formation of cracks. Cracks can severely weaken composite structures.

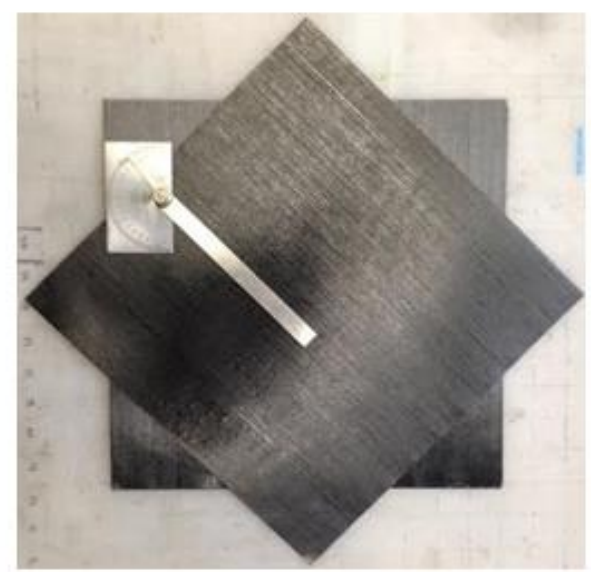

Figure 7. Laid up carbon fiber unidirectional pre-preg material

The second step consisted of programming the cure cycle into the heat press. Shown in Figure 15 
8, is Cytec's MTM 49 Unidirectional Carbon Fiber pre-preg cure cycle ${ }^{[2]}$. Two different cure cycles were tested to see its effects on the material's double shear bearing stress. Increasing the dwell temperature from $248^{\circ} \mathrm{F}$ to $275^{\circ} \mathrm{F}$ and increasing the dwell time from 60 minutes to 90 minutes both affect the mechanical characteristics of the resin. The dwell temperature is the temperature which is held constant in the cure process (for this material, it occurs after the temperature ramp up stage). The dwell time is the duration of the dwell temperature stage. Each different carbon fiber matrix system will have its own recommended cure cycle printed in its specific datasheet. In the experimental section, one can see the difference in mechanical properties of the material based on the two different cure cycles.

The first cure cycle was Cytec's MTM 49 Unidirectional Carbon Fiber pre-preg cure cycle ${ }^{[22]}$ (also known as the alternate cure cycle). The heat press was adjusted to the specific cure cycle. First, the cure cycle temperature ramped up from room temperature of $77^{\circ} \mathrm{F}$ to $275^{\circ} \mathrm{F}$, at a rate of $5^{\circ} \mathrm{F} / \mathrm{min}$. The second cooking step dwelled (kept temperature constant) the $275^{\circ} \mathrm{F}$ for 90 minutes. After the 90 minutes, the material cooled down to $120^{\circ} \mathrm{F}$ at a rate of $5^{\circ} \mathrm{F} / \mathrm{min}$. for 15 minutes. A uniform pressure of 2 psi was applied on top and bottom of the plate. 


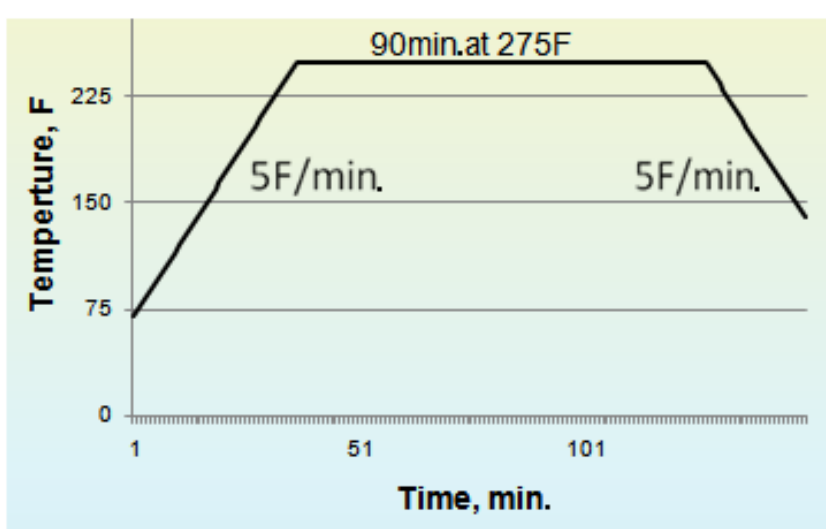

Figure 8. Alternate cure cycle cytec's mtm 49 unidirectional carbon fiber pre-preg cure cycle ${ }^{[22]}$

The second cure cycle was Umeco’s MTM 49 Unidirectional Carbon Fiber pre-preg cure cycle ${ }^{[21]}$, shown in Figure 9 (also known as the datasheet cure cycle). The heat press was adjusted to the specific cure cycle. First, the press ramped the temperature up from the room temperature to $248^{\circ} \mathrm{F}$, at a rate of $5^{\circ} \mathrm{F} / \mathrm{min}$. The second cooking step dwelled (kept temperature constant) the $248^{\circ} \mathrm{F}$ for 60 minutes. After the 60 minutes, the material cooled down to $120^{\circ} \mathrm{F}$ at a rate of $5^{\circ} \mathrm{F} / \mathrm{min}$. for 15 minutes. The pressure was held constant between both cure cycles. 


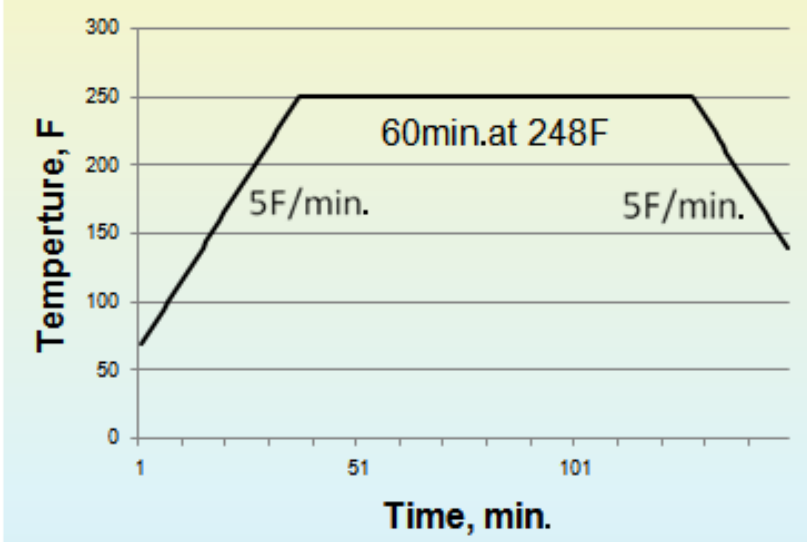

Figure 9. Datasheet cure cycle umeco's mtm 49 unidirectional carbon fiber pre-preg cure cycle ${ }^{[21]}$

The third step consisted of preparation of the test specimens. Once the composite laminate finished curing, the material was removed from the press and was cut with a tile saw, which had a diamond-coated blade. The tile saw had an adjustable clamp that helped keep the cuts within 0.1 of an inch. Figure 10 shows the tile saw used to cut the specimens. A straight cut was made on the composite laminate, in order to clean up the edge of the plate. Next, the top side of the plate was aligned to the straight section of the small tile saw. The cuts were made carefully in order to keep a $90^{\circ}$ angle on the side of the cured laminate.

Once all the cuts were made, and the zero direction of the laminate was located accordingly, specimens were cut to the correct width. Based on ASTM D5961 ${ }^{[18]}$, a W/D (specimen width to hole diameter ratio of the composite double shear joint specimen) of 6 and $e / D$ (hole edge distance to diameter of hole ratio) of 3 were used. These geometric conditions guaranteed the double shear composite specimens failed in bearing and not in net-tension or shear-out. Based on these geometric conditions, the specimens needed to be $1.5 \mathrm{in}$. wide by $5.5 \mathrm{in}$. in length. The tile saw 
was used to trim the long $1.5 \mathrm{in}$. wide specimens to their final length of $5.5 \mathrm{in}$. A small aluminum block was clamped to the tile saw, which helped minimize variations in the length of all the specimens and allowed multiple specimens to be cut at the same time.

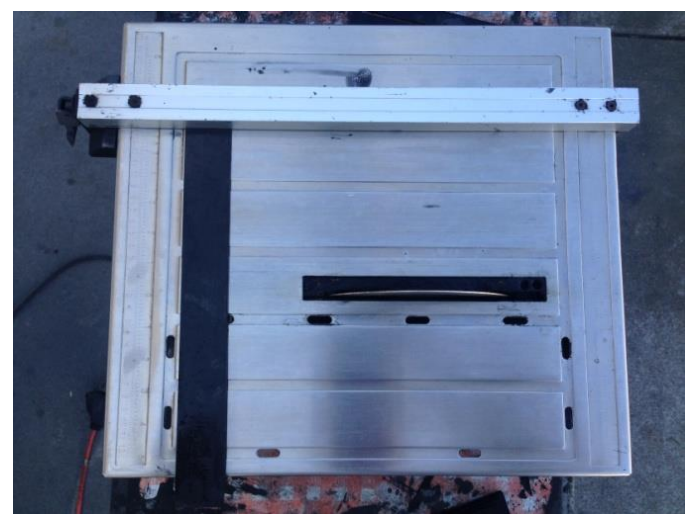

Figure 10. Tile saw with diamond coated blade used to cut the tensile and double shear specimens

After the specimens were cut to their specified length and width, they were grouped into sets of five. A mini microfiber-board fixture was created in order for five holes to be drilled at the same time. The fixture was clamped into the drill press. Five composite double shear specimens were stacked onto the drill fixture and the top left corner of each composite double shear specimen was aligned to the top left corner of the fixture. An Aluminum template was placed on top of the composite double shear specimens and was used to align the 0.25 in. diamond coated end mill bit. Once the composite double shear specimens were aligned accordingly, a small c-clamp was used to constrain the specimens along with the Aluminum template from moving/rotating during the drilling process. In Figure 11, one can see the fixture, the Aluminum template and the end mill bit used for the hole drilling process. 


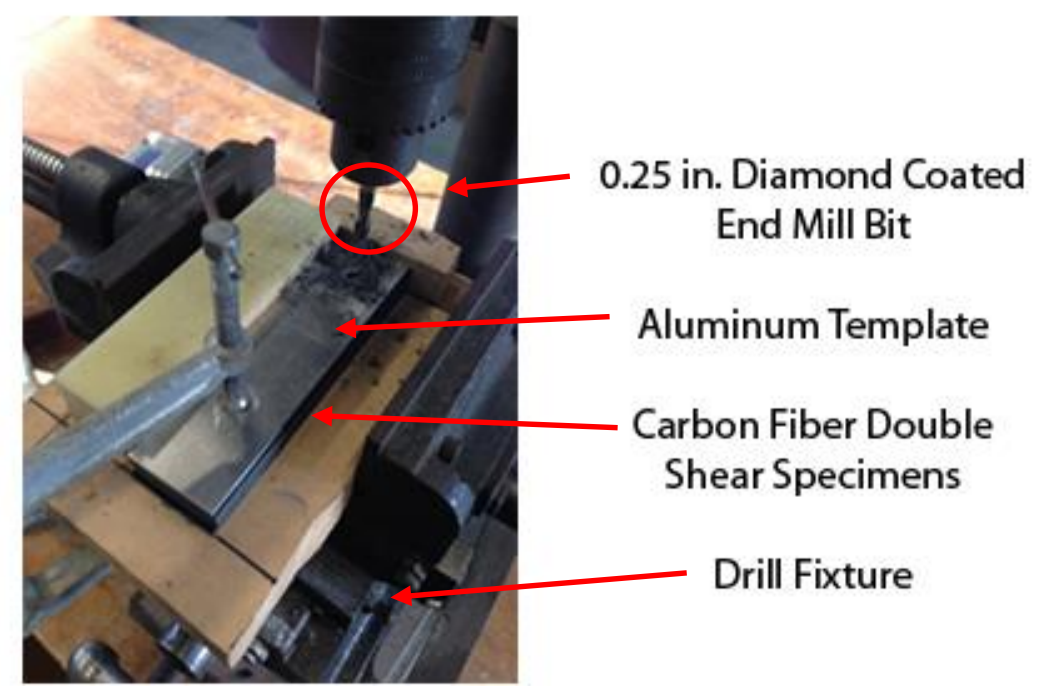

Figure 11. Drill fixture and aluminum template used to drill 5 holes at once in the composite double shear specimens

Once the holes were created for all the composite double shear specimens, there needed to be a 0.5 in. wide horizontal slit on each face of the composite double shear specimens. A thin Aluminum template was created to assist in locating a specific distance from the hole. This slit needed to be placed accurately within a tolerance of $0.01 \mathrm{in}$. The template is shown below in Figure 12, and the flat edge of the Aluminum template was used to locate the slit location. The slit needed to be as horizontal as possible and deep enough to catch the moveable knife-edge of the extensometer. 

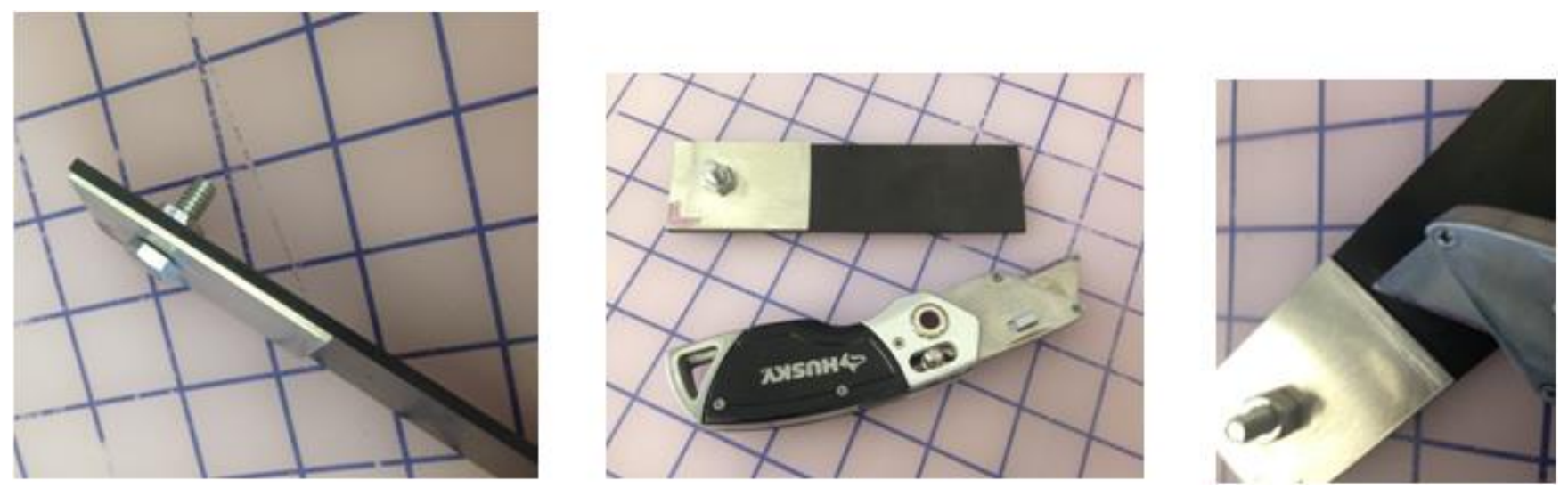

Figure 12. Side photo of the aluminum template $\&$ composite double shear specimen (left) composite double shear specimen with an aluminum template attached \& scalpel (center) shows how the slit was created on the surface (right)

Emery cloth helped distribute the high clamping pressure (which is applied by the hydraulic clamps) which occurred at the bottom of the double shear specimen and the emery cloth prevented the composite double shear specimen from slipping during the test. Aluminum tabs were not needed for the double shear test because the specimens failed before reaching 7,000 lbs. The emery cloth works up to a maximum load of 7,000 lbs. The emery cloth was $1.5 \mathrm{in}$. wide and had a grit level of 120, which is shown in Figure 13. Each specimen only needed emery cloth on one end. Only a 3 in. long piece was needed to cover all of the specimen's width. A small portion of painters tape served to hold the emery cloth in position. The emery cloth was also reusable; so one piece of emery cloth could be used on two or more specimens. In Figure 13, on the right, shows the ready-to-test composite double shear specimen. 

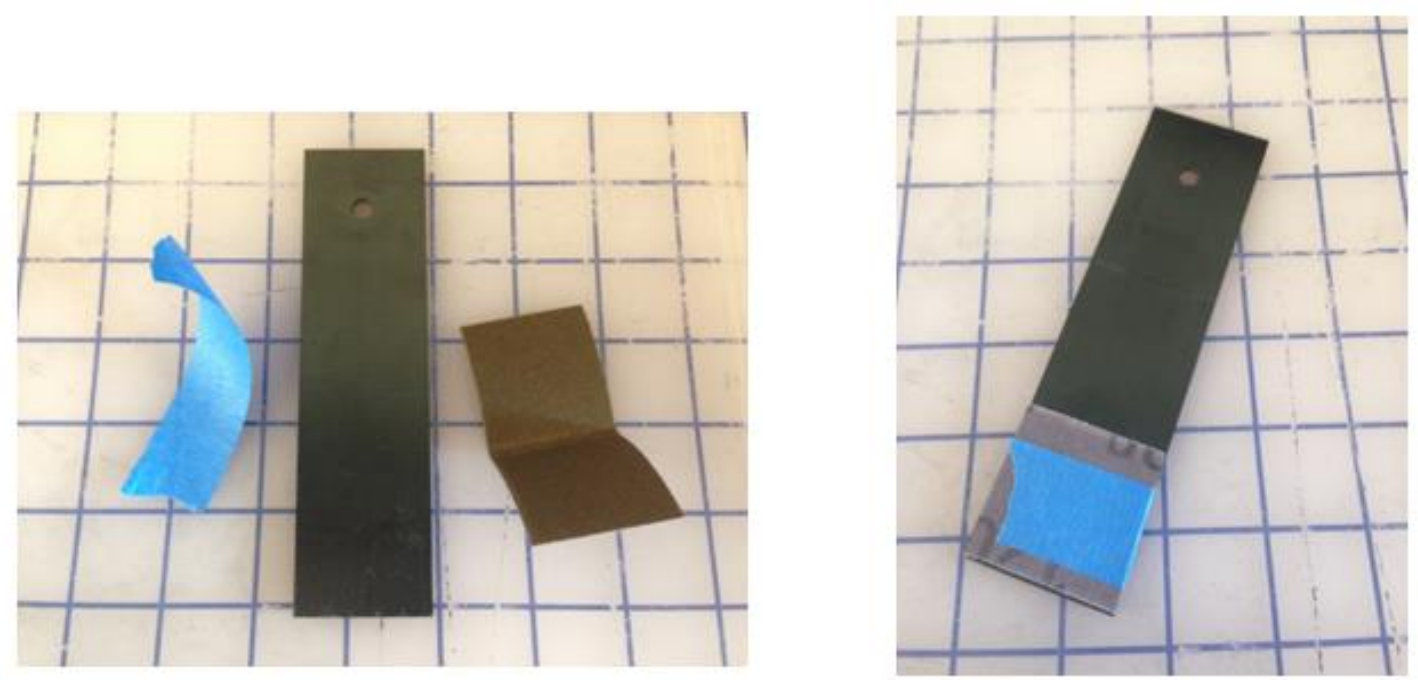

Figure 13. Specimen, blue painters tape \& emery cloth (left) specimen ready for testing (right)

\subsubsection{Tensile Specimens}

The same method was applied for the composite tensile specimens, except that these specimens did not have a hole. Stacking the layers needed to be done in a very careful manner in order to prevent misalignment. Once the composite shear modulus specimens and the $90^{\circ}$ composite tensile specimens were cut to $10 \mathrm{in.}$ by $1 \mathrm{in}$., then all that was needed was to apply the emery cloth to the ends. Painters tape was used to secure the emery cloth in position. Then, the composite shear modulus specimens and the $90^{\circ}$ specimens were ready for testing.

The $0^{\circ}$ unidirectional carbon fiber composite tensile specimens required 2 in. long aluminum tabs (as specified by ASTM $3039^{[19]}$ ). Sandpaper was used on the surface, near the ends of the $0^{\circ}$ unidirectional carbon fiber composite tensile specimens. A small section of the surface was 
abraded, and then, acetone was used to clean the surface. Structural adhesive was used to bond the Aluminum tabs to the $0^{\circ}$ unidirectional carbon fiber composite tensile specimens. After a full day of curing, the $0^{\circ}$ unidirectional carbon fiber composite tensile specimens were ready to be tested in the Instron 8801 machine. In Figure 14, one can see the ready-to-test $0^{\circ}$ unidirectional carbon fiber composite tensile specimens and the $+/-45^{\circ}$ composite shear modulus specimens.
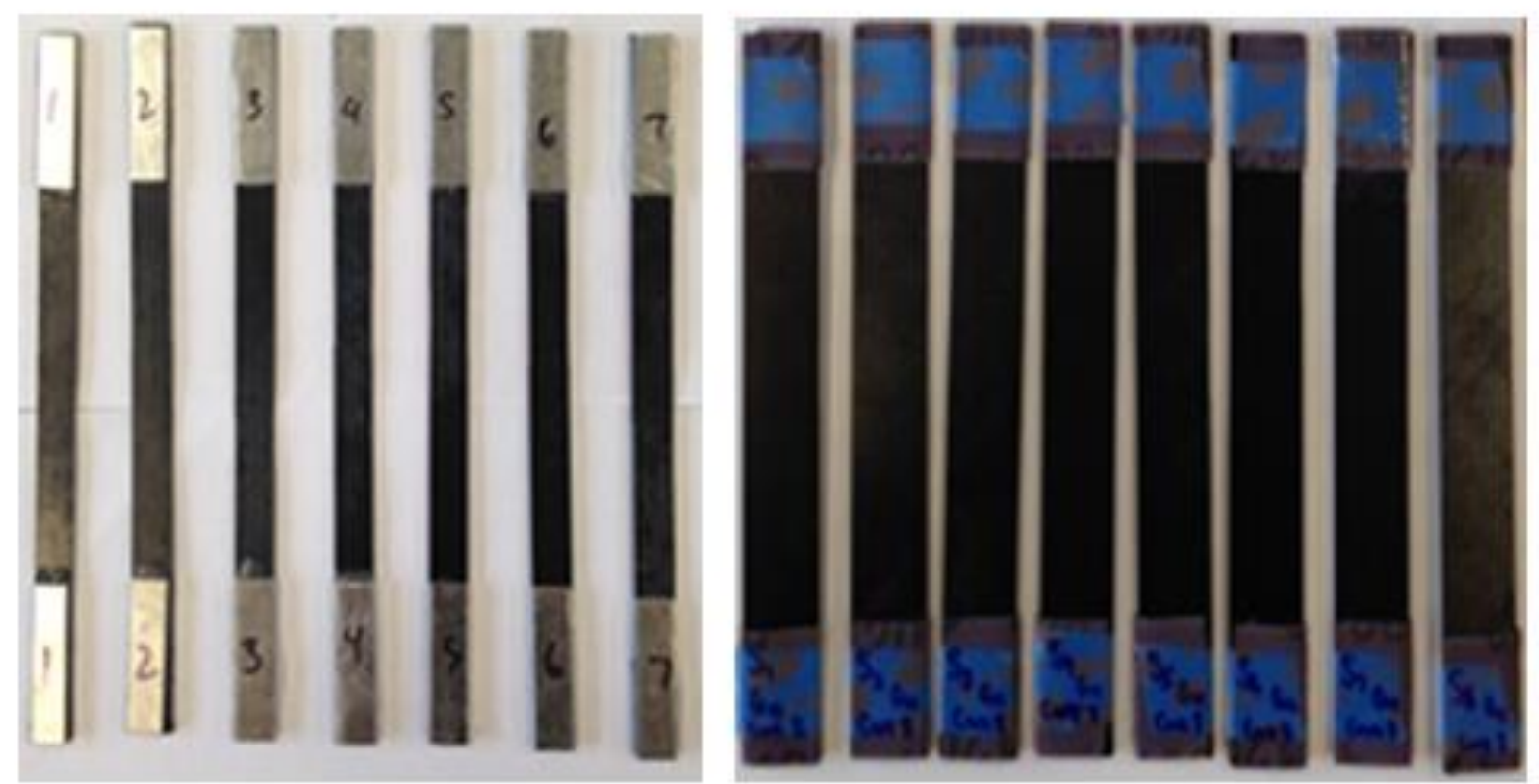

Figure $14.0^{\circ}$ Unidirectional carbon fiber composite tensile specimens with 2 in. aluminum tabs (left) $+/-45^{\circ}$ composite shear modulus specimens with emery cloth (right) 


\section{CHAPTER 3: TESTING PREPARATION \& PROCEDURE}

In this chapter, the test preparation and procedure are explained thoroughly. Section 3.1 introduces the type of testing machine used for the experiment. Various test recommendations are made and included inside the preceding subsection. The Auto-Loop tuning feature is explained in detail and an example is made to assist the user in using this feature. The Specimen Protect feature in Bluehill2 is explained with full detail, which helped produce very consistent experimental results. Finally, in Section 3.3, the tensile double shear test and tensile test procedures are explained. The design and set-up of the double shear fixture is shown in detail as well. In the Appendix, the Bluehill2 test method creation was explained for a double shear tensile test.

\subsection{Intro to Uniaxial Testing Using the Instron 8801 Servo-hydraulic Test Machine}

All the material tests were conducted on an Instron 8801. This machine is a dual column servohydraulic testing system. It meets the challenging demands of various dynamic and static testing requirements. The machine allows the user to hook up external force or strain transducers. A dynamic knife-edge extensometer was used for both, the tensile and double shear tests. The machine works in conjunction with a controller, which can be used to control the machine without the use of a computer. A servo-hydraulic system is composed of an actuator, which can apply a tremendous amount of load onto a test specimen. The load cell has a $+/-100 \mathrm{kN}$ limit which means it can measure accurately up to $+/-22,000 \mathrm{lbs}$. axial force (in compression/tension). For the tensile double shear test, the maximum load that was seen during the test was around 1,700 lbs. and for 
the tensile test, a maximum load of 7,000 lbs. was seen. The thicker the laminate, the higher the load the specimen could take before failure. Shown in Figure 15, one can see the Instron 8801 testing setup.

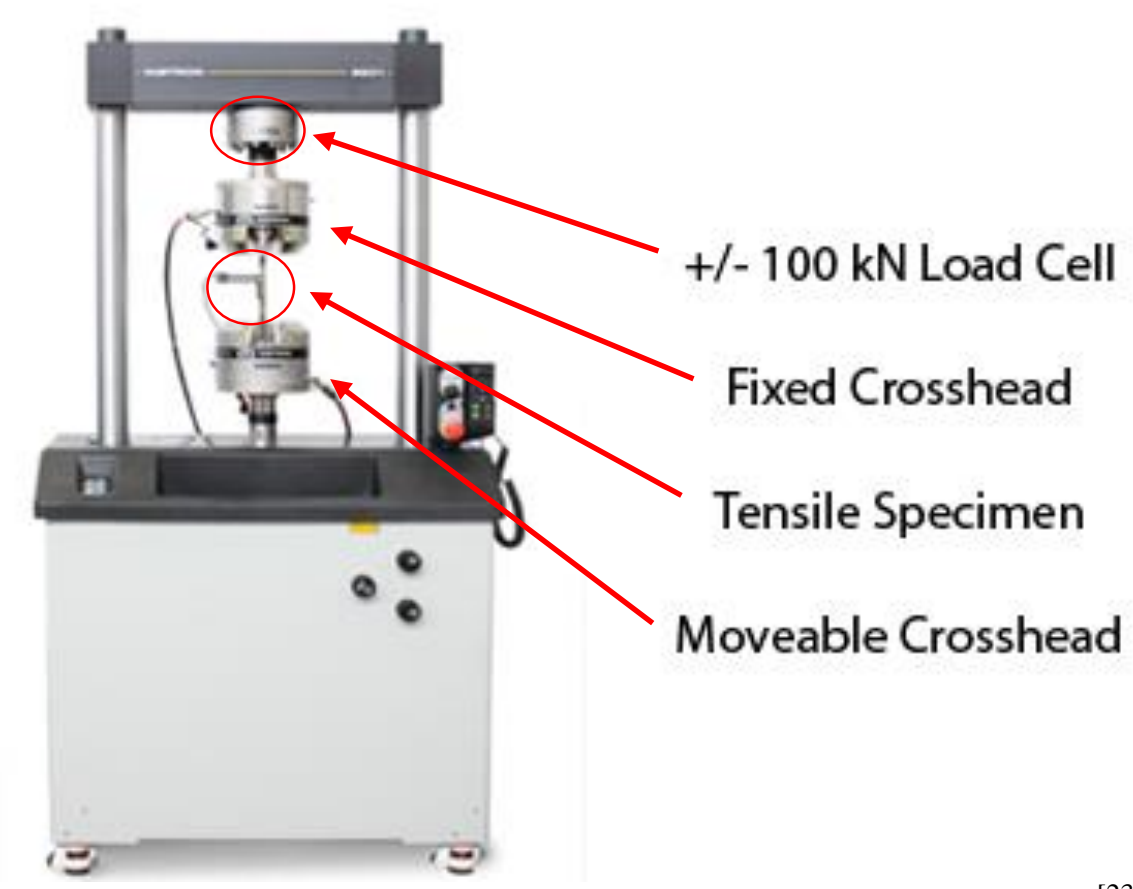

Figure 15. Instron 8801 servo-hydraulic fatigue testing machine ${ }^{[23]}$

The machine's crossheads contain metal jaws, which (powered by a hydraulic system) are able to clamp the specimen. The hydraulic clamping pressure is adjustable so for standard tensile testing, the pressure is set to 160 bar and for testing fragile composite resins, one would want to drop the pressure to 80 bar. Lowing the hydraulic pressure helped reduce premature specimen cracking. The crosshead mechanism loaded with a specimen is shown below in Figure 16. The specimen is placed carefully between two the hydraulically powered metal clamps which secure 
the specimen in place.

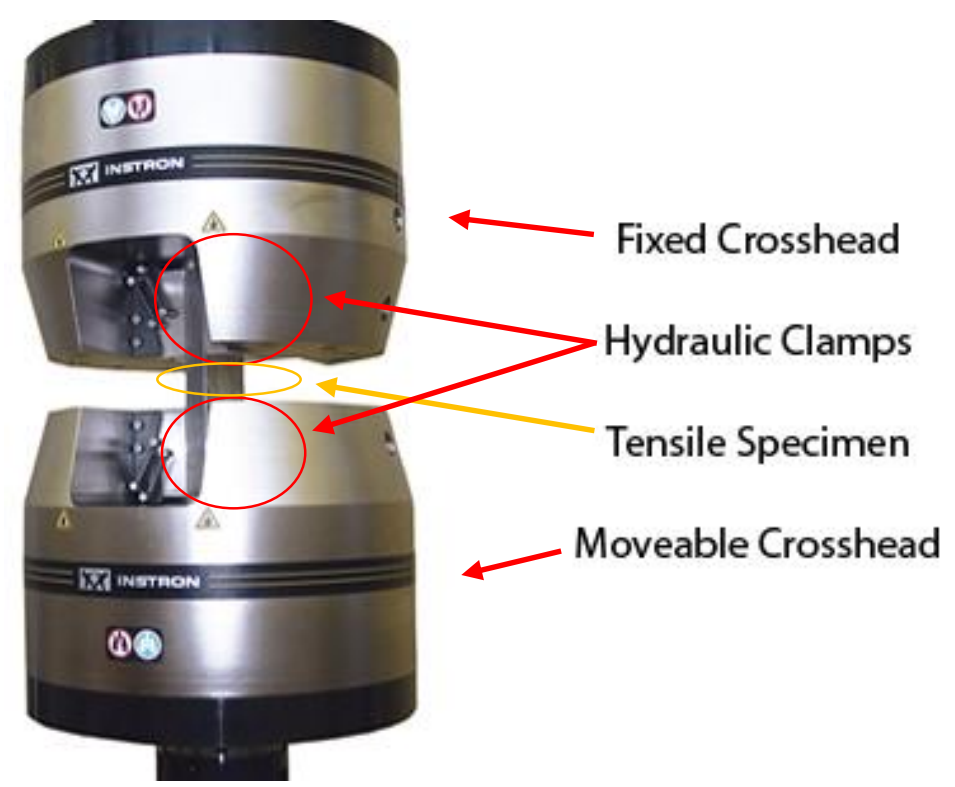

Figure 16. Instron 8801 crossheads clamping onto a thick steel tensile specimen ${ }^{[23]}$

\subsubsection{Instron Servo-hydraulic Test Machine Recommendations}

For determining the modulus of elasticity along with the modulus of rigidity, the most accurate measuring tools were the extensometer and the strain gage. The crosshead displacement was not very accurate since the system displaces due to the compliance in the grips, and the actuator assembly. This displacement of the crosshead can cause unreliable results in the modulus of elasticity where accuracy is very important. The Instron crosshead and the extensometer both yielded slightly different stress/strain curves. This difference in stress/strain curves is due to the Instron crossheads displacing a little more than the extensometer. The extensometer measured only the deflection of the specimen relative to both of the extensometer knife-edges. The extensometer 
had a gage length of $0.5 \mathrm{in}$. and a knife-edge width of $0.5 \mathrm{in}$. The dynamic extensometer, catalog no. 2620-826, can be seen in Figure 17. The top knife-edge is fixed and the bottom knife-edge records precise deflections. The extensometer was attached using two rubber bands. The rubber bands were wrapped multiple times around the specimen to prevent the knife-edges from slipping. Whenever the extensometer was handled, the safety pin was in place at all times.

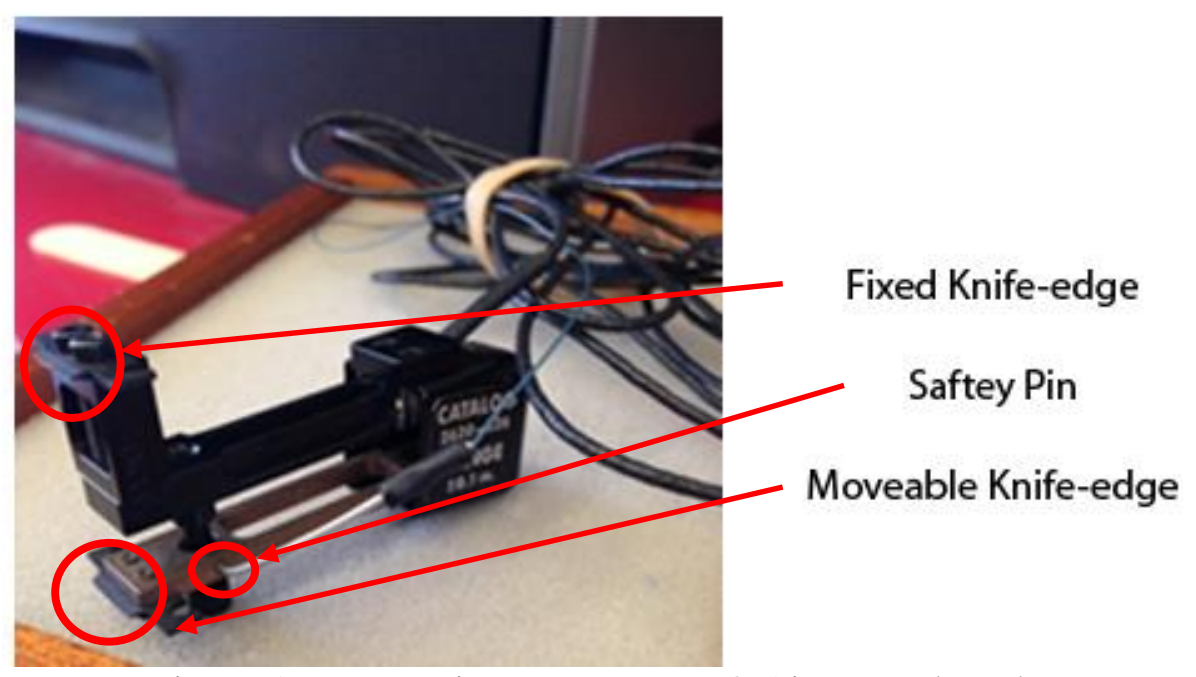

Figure 17. Dynamic extensometer 0.5 in. gage length with a range of $+/-0.1 \mathrm{in}$.

If the user wants to run a three-point or 4-point bend test, the crosshead displacement is accurate enough to capture the vertical displacement accurately. If the user wants even more accuracy, they are able to hook up an extensometer to the three-point bend fixture and record vertical displacement with that device rather than the crosshead displacement.

The Instron 8801 machine has a few features, which need to be utilized in order to minimize testing errors. The load and position calibration should never be changed or conducted. Before any 
test is conducted, the user should Auto-loop tune the load cell only once. Each time a new material is being tested; for example, carbon fiber compared to Aluminum, the load cell should be Autoloop tuned. A list of load cell control gains should be recorded in a separate table for each material, to avoid having inexperienced individuals auto-loop tune the machine. Some precautions in the auto-loop tuning process include to never auto-loop tune a material that will fails under $120 \mathrm{lbs}$. and to never set the force amplitude above $500 \mathrm{lbs}$. This may cause the machine to cycle through very rapidly.

3.1.2 Tutorial on Auto-Loop Tuning of the Load Cell for an 1 in. wide By 1/16 in. Thick Aluminum Specimen

Each time a new type of material is tested in the machine the load cell needs to be auto-loop tuned whether it be Aluminum, Steel, carbon fiber, hemp composite, fiberglass or any other composite material. Auto-loop tuning the force insured that the load cell is set up to perform accurately for each specific material. The auto-loop tuning tool adjusted various gains on the load cell controller. This was done through the Bluehill2 console (under the load cell menu).

Measure the cross-sectional area of the tensile specimen and note its yield stress (if a metal) or ultimate stress (if a brittle material). For example, for Aluminum, the yield stress is around $35 \mathrm{ksi}$ and the tensile specimen had a cross-sectional area of 0.062 in. ${ }^{2}$. Make sure to apply a force which keeps the material well under its yield or ultimate stress (so $25 \mathrm{ksi}$ was applied to the Aluminum specimen). 
Insert the Aluminum tensile specimen into the hydraulic clamps and load the specimen to 1,500 lbs. Also, set the amplitude force to $500 \mathrm{lbs}$. In the auto-loop tuning wizard, the Proportional gain $(P)$ needs to be set to one before any auto-loop tuning is conducted. The specimen will be exposed to a cyclic load of 1,500 lbs. $\pm 500 \mathrm{lbs}$. After the auto-loop tuning completes, it will say Auto-loop tuning completed successfully and then, in the next window record the $P, I, D$ and $L$ values. The $P$ value should be 12.564 , the $I$ value should be 0.56 , the $D$ value should be 0.49 and the $L$ value should be 0.8 . These gain values are essential to the auto-loop tuning process.

Each time a new material is tested, it is advised to specify the correct $P, I, D$ and $L$ values in the console and only if those values are unknown then the material needs to be auto-loop tuned. After running the auto-loop tuning tool on the MTM 49 unidirectional carbon fiber material, the $P$ (proportional gain) equaled 13.481 and I (integral gain) equaled 0.578. Both $D$ and $L$ equaled zero. Typically, the material needs to be auto-loop tuned in a load range where accuracy is needed. This range is typically, where the modulus of elasticity is measured in between $25 \%$ to $50 \%$ of ultimate stress as stated by ASTM D3039 Tensile Properties of Polymer Matrix Composite Materials ${ }^{[19]}$. If the material fails during the auto-loop tuning process, the actuator will shake violently and will not stop itself. Hit the red emergency stop button on the control panel or hit the red button on the Instron servo-hydraulic machine to power off the actuator. Start back up the machine and run the auto-loop tuning tool again at a lower force. 


\subsubsection{Tutorial on Specimen Protect}

The specimen is prone to premature failure due to high clamping forces exerted by the hydraulic clamps. Instron's Specimen Protect feature protects a specimen against this phenomenon. This feature is found inside the console, it is labeled Specimen Protect, and the symbol looks like small shield. Before using the Specimen Protect feature, go into the console, enter the Specimen Protect option menu and make sure the load threshold is set to $44 \mathrm{lbs}$. Clamp the bottom of the test specimen. Once the bottom of the specimen is clamped, move the actuator up until the top of the specimen sits in between the top crosshead's clamps. Turn on the Specimen Protect feature in the console and this will automatically move the bottom crosshead slightly up or down in order to prevent the specimen from experiencing more than $44 \mathrm{lbs}$. After both the top and bottom of the specimen are clamped, turn off the Specimen Protect feature and continue with the test. Every time a new specimen is inserted into the hydraulic clamps, this feature needs to be utilized in order to prevent premature failure.

\subsection{Bluehill2 Test Preparation}

The machine was connected to a Windows desktop and from there Bluehill2 and the console were used to monitor machine inputs and outputs. According to Instron, the console software provides full system control from a PC: including waveform generation, calibration limit set up, and status monitoring. In real-time, Bluehill2 outputted various experimental results: strain values, load values, displacement values, and exc. All the raw data was outputted into an Excel file, which 
could be used for post-processing calculations.

\subsubsection{Bluehill2 Test Parameter Setup}

The main software of interest was the Bluehill2 software. In Bluehill2, the user has options of changing various testing parameters. Each test can be created and saved to a separate testing file, which can later be accessed when the user needs to conduct that type of test. Three different tests were created in the Bluehill2 software. The tensile test and tensile double shear test were created with the Bluehill2 software.

Before a test file is created, it is required of the user to know what values are of interest for a specific structural test. The ASTM should exactly specify which the testing parameters should be used for the specific test. ASTM D5961 ${ }^{[18]}$ suggested to test at a load rate of $0.05 \mathrm{in} . / \mathrm{min}$. , to sample at a rate of at least 2 samples per second, and to output the extensometer displacement instead of the crosshead displacement. It also specified to run the test until a maximum force is reached and until the maximum force decreased by $30 \%$. If the force didn't drop to $30 \%$ of the maximum; run the test until the pin displacement is equal to half of the hole diameter. For the pin displacement, the test ended once the extensometer read a displacement of $0.1 \mathrm{in}$. since that was the maximum range of the extensometer. The test specimen slipped in the grips when the force in the force vs. time plot flattens out, with respect to time, the specimen was slipping. The hydraulic pressure was manually set to 160 bar on the side of the machine. The fastener, which secured the Steel collars to the sides of the specimen, was hand tightened. Five different loading rates were 
applied and adjusted accordingly inside the Bluehill2 software.

\subsection{Instron Experimental Test Procedure}

The Instron start-up checklist was followed in the lab in order to start the machine safely. The first step of the checklist was to turn on the main power switch in the back of the lab. After turning on the main power switch, the next step was to turn on the Instron controller by pressing the power switch in the back of the Instron controller. Once the controller warmed up fully, a small blinking light appeared on the load calibration section of the controller. The calibrate button was pressed on the load menu of the controller. Next, the Cal button was pressed. Once the Restore button was pressed, the machine was fully calibrated even though it read "Calibration not restorable." The desktop was turned on, and once the system booted up, the Bluehill2 software was started. As the software started up, it automatically started the console. The console is how the computer communicates with the Instron machine. The extensometer was plugged into the back of the Instron machine and it showed up under Strain 1 (in the Bluehill2 software). Once the extensometer was plugged in, it flashed in the console screen reminding the user that it needed to be calibrated. The extensometer's calibration was restored to a previous calibration. From this point on, the tensile test, or the double shear bearing test could be started.

\subsubsection{Tensile Testing Procedure}

Before starting any ordinary tensile test, the user needed to have at least six tensile specimens 
prepared for the test. For each tensile specimen, the thickness, width and gage length (distance between the tabs) were recorded. The Specimen Protect feature was also used when initially clamping the specimens. The first composite tensile specimen was tested to failure (without the extensometer), in order to find its ultimate failure load. A limit load was created for the extensometer and was decided based on the ASTM D3039 ${ }^{[19]}$. As stated in ASTM D3039 ${ }^{[19]}$, the material's modulus of elasticity can be measured anywhere between $25 \%$ and $50 \%$ of its ultimate load or yield load (if it is a metal). The limit load was calculated by multiplying the $1^{\text {st }}$ specimen's ultimate load by 0.25 and this value was specified in Bluehill2's end of test criteria. In Bluehill2 software, there is an option of recording the strain using an extensometer and once the limit load is reached, the test will pause allowing the user to remove the extensometer. Next, the remaining five composite tensile specimens were tested. The next composite tensile specimens were loaded in the machine and the extensometer was attached for each specimen. Figure 18 shows a composite tensile specimen (with an extensometer mounted on its surface). Once at the limit load, the extensometer was removed, and the test continued up to the ultimate load. Note that the initial modulus recorded by the extensometer was very accurate, and after removal of the extensometer, the crosshead took over and the accuracy declined. 

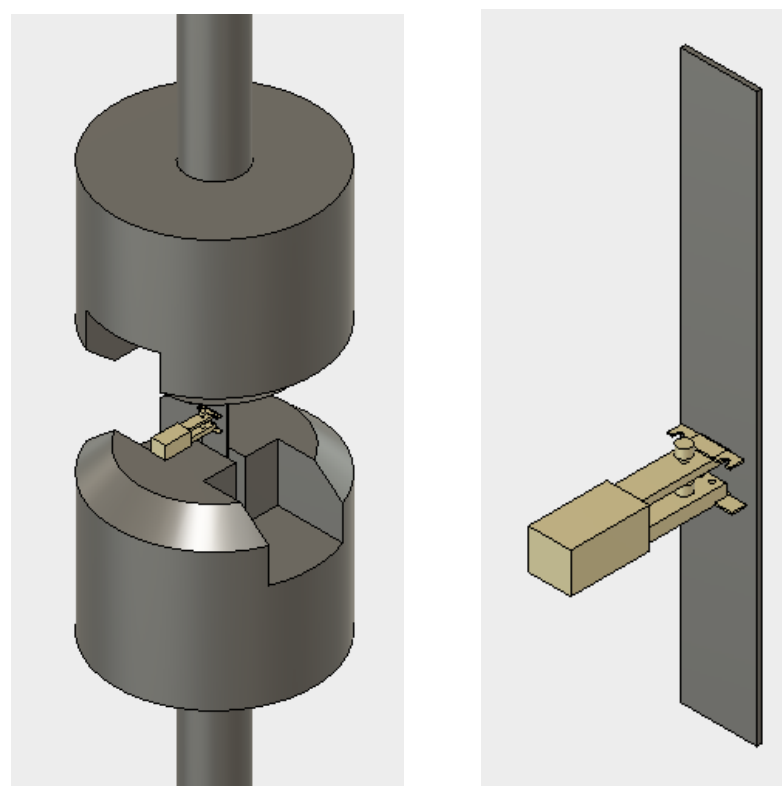

Figure 18. Composite tensile specimen between the clamps (left) composite tensile specimen with extensometer (right)

\subsubsection{Double Shear Testing Procedure}

Once the standard Instron startup procedure was completed, the tensile double shear Bluehill2 test method was started. In the Appendix, one can find a detailed tutorial on the tensile double shear Bluehill2 test method. Procedure A double shear tension, in ASTM $5961^{[18]}$, was followed closely. The user needed to make sure that all the dimensions were recorded such as specimen width, specimen length, and specimen thickness and distance between the edge of the specimen to the hole edge. The fixture used for the double shear test consisted of an assembly made up of three cold drawn Steel plates with two bolts and nuts connecting all three plates. The double shear fixture is shown in between the clamps on the left in Figure 19. The double shear fixture is shown, in the center, in Figure 19. The close-up of the collar-specimen assembly is shown, on the right side, in 
Figure 19 as well. Each double shear joint specimen was sandwiched between two Steel plates, two Steel collars, four washers and a nut, which can be seen on the left and the center in Figure 20. The extensometer, as required by the ASTM $5961^{[18]}$, is fixed on the fixture with a small steel plate and two bolts, shown on the right in Figure 20. The extensometer's knife edge was carefully placed inside the slit of the specimen and secured with a rubber band. The nut which held the screw assembly together with the specimen was only hand tightened.

In the Bluehill2 software, as stated earlier, the end of test occured if the maximum force droped by $30 \%$ or if the maximum extensometer displacement was $0.1 \mathrm{in}$. This end of test criteria worked perfectly for the $0.05 \mathrm{in} . / \mathrm{min} ., 0.1 \mathrm{in} . / \mathrm{min}$. and $1 \mathrm{in} . / \mathrm{min}$. loading rates. But for the $2 \mathrm{in} . / \mathrm{min}$. and 6in./min. loading rates, the maximum extensometer displacement was lowered to 0.05 in. At faster loading rates (above $2 \mathrm{in.} / \mathrm{min}$.), the actuator had problems stopping immediately at very small deflections $(0.1$ in.) so applying this adujstment prevented the extensometer from accidently breaking due to over-deflection of the crossheads. 

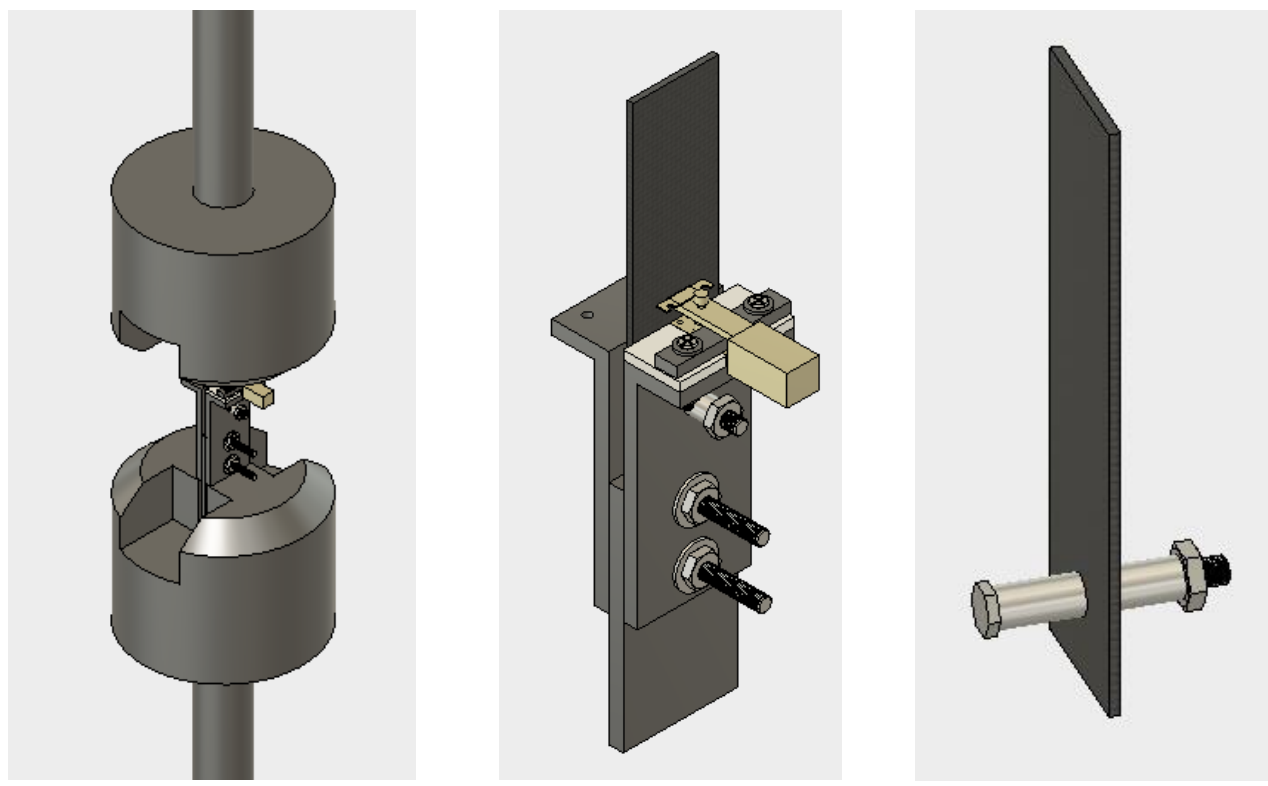

Figure 19. Double shear fixture between the clamps (left) composite double shear specimen inside double shear fixture (center) close-up of the composite double shear specimen assembly (right)
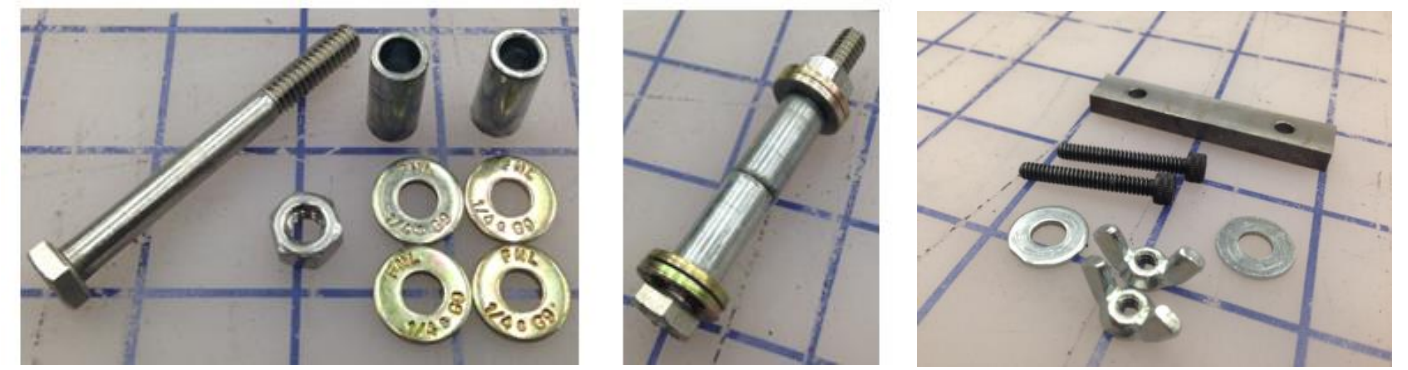

Figure 20. Bolt-collar assembly shown (left) fully assembled bolt-collar assembly (center) parts needed to fix the extensometer to the double shear fixture assembly (right) 


\section{CHAPTER 4: THEORETICAL SOLUTION METHOD}

In this chapter, information is given on the equations that were used to find all of the mechanical properties of the material used. The theoretical equations used to come up with the macromechanical behavior of a lamina and laminate are included as well.

\subsection{Experimental Equations}

\subsubsection{Equations Used for Unidirectional Carbon Fiber and Aluminum Double Shear Specimens}

The width to diameter ratio of the specimens needed to be measured and recorded. Below, $W$, is the specimen width, and $D$ is the diameter of the hole.

$$
\frac{W}{D} \text { ratio }=W / D
$$

The edge to diameter ratio of the specimens needed to be measured and recorded.

$$
\frac{E}{D} \text { ratio }=(g+D / 2) / D
$$

The diameter to thickness ratio of the specimens was measured and recorded. Below $h$ is specified as the thickness of the specimen.

$$
\frac{D}{h} \text { ratio }=D / h
$$

The bearing stress was calculated by dividing the force, $P$, by the force per hole factor, $k$ (equal 
to 1 for double shear test), with the diameter of the whole, $D$ and by the thickness of the specimen, $h$.

$$
\sigma_{i}^{b r}=P_{i} /(k * D * h)
$$

The bearing strength was calculated by dividing the maximum force, $P_{\max }$, by the force per hole factor, $k$, with the diameter of the hole, $D$ and by the thickness of the specimen, $h$.

$$
F^{b r}=P^{\max } /(k * D * h)
$$

The bearing strain was determined from the extensometer displacement, $\delta_{i}$ divided by the $k$, force per hole factor, and the diameter of the hole, $D$.

$$
\epsilon_{i}^{b r}=\delta_{i} /(k * D)
$$

The bearing chord stiffness was only reported if there existed an offset bearing strength. The linear portion, where the bearing stress ranges from $25-40 \mathrm{ksi}$, is the bearing chord stiffness region.

$$
E^{b r}=\Delta \sigma^{b r} / \Delta \epsilon^{b r}
$$

4.1.2 Equations Used for Tensile Testing of Unidirectional Carbon Fiber and Aluminum Specimens

The maximum tensile strength $F$, was calculated by dividing the maximum force by the cross- 
sectional area A.

$$
F=P_{\max } / A
$$

The tensile stress, $\sigma$, was calculated by dividing the force by the cross-sectional area, $A$.

$$
\sigma_{i}=P_{i} / A
$$

The chord modulus of elasticity, $E$, was calculated by the difference two tensile stress points and their equivalent tensile strain points.

$$
E=\Delta \sigma / \Delta \varepsilon
$$

The extensometer strain, $\epsilon_{\text {extes }, i}$, was calculated by dividing the extensometer displacement, $\delta_{i}$, by the extensometer's gage length, $L_{g}$. The gage length of the extensometer was always $0.5 \mathrm{in}$.

$$
\epsilon_{\text {extes }, i}=\delta_{i} / L_{g}
$$

The axial and transverse strains were plotted with respect to axial force. The slope of the transverse strain vs. axial load, $\frac{-d \epsilon_{t}}{d P}$, was divided by the slope of the axial strain vs. axial load, $\frac{d \epsilon_{l}}{d P}$ , and this equaled the Poisson's ratio of the material.

$$
v=\frac{-d \epsilon_{t}}{d P} / \frac{d \epsilon_{l}}{d P}
$$




\subsubsection{Equations Used with the Rosette Strain Gage}

Using the Equations (13) - (15), one can find the principle strains in the x-direction, $\epsilon_{x}, \mathrm{y}-$ direction, $\epsilon_{y}$ and finally the shear strain in the xy-direction, $\gamma_{x y}$. The three different theta values, $\theta_{1}, \theta_{2}, \theta_{3}$ were all angles relative to the axial strain gage. The strain rosette was placed on the composite quasi-isotropic specimen's surface so that each strain gage was in $0^{\circ},+45^{\circ}$ and $90^{\circ}$. So $\theta_{1}$ equaled $0^{\circ}, \theta_{2}$ equaled $+45^{\circ}$, and lastly $\theta_{3}$ equaled $90^{\circ}$.

$$
\begin{aligned}
& \varepsilon_{\theta 1}=\varepsilon_{x} \cos ^{2} \theta_{1}+\varepsilon_{y} \sin ^{2} \theta_{1}+\gamma_{x y} \cos \theta_{1} \sin \theta_{1} \\
& \varepsilon_{\theta 2}=\varepsilon_{x} \cos ^{2} \theta_{2}+\varepsilon_{y} \sin ^{2} \theta_{2}+\gamma_{x y} \cos \theta_{2} \sin \theta_{2} \\
& \varepsilon_{\theta 3}=\varepsilon_{x} \cos ^{2} \theta_{3}+\varepsilon_{y} \sin ^{2} \theta_{3}+\gamma_{x y} \cos \theta_{3} \sin \theta_{3}
\end{aligned}
$$

The principle plane stresses were also transformed with a transformation matrix to the desired angle, $\theta$. In the transformation matrix $c=\cos \theta$ and $s=\sin \theta$. Where $\mathbf{A}$ is considered the transformation matrix below. The transformed plane stresses, $\sigma^{\prime}$, equaled the transformation matrix, $\mathbf{A}$ times the plane stresses, $\sigma$.

$$
\begin{gathered}
\boldsymbol{\sigma}^{\prime}=\mathbf{A} \boldsymbol{\sigma} \\
\left\{\begin{array}{c}
\sigma_{1} \\
\sigma_{2} \\
\tau_{12}
\end{array}\right\}=\left[\begin{array}{ccc}
c^{2} & s^{2} & 2 s c \\
s^{2} & c^{2} & -2 s c \\
-s c & s c & c^{2}-s^{2}
\end{array}\right]\left\{\begin{array}{c}
\sigma_{x} \\
\sigma_{y} \\
\tau_{x y}
\end{array}\right\}
\end{gathered}
$$


Once the three principle strains were calculated then a transformation matrix was used to transform each of the three strains to the desired angle, $\theta$. The transformed plane strains, $\epsilon^{\prime}$, equals Reuter's Matrix, R, times the transformation matrix, A, by the inverse of the R matrix, and lastly times the plane strains.

$$
\begin{aligned}
{[\mathbf{R}] } & =\left[\begin{array}{lll}
1 & 0 & 0 \\
0 & 1 & 0 \\
0 & 0 & 2
\end{array}\right] \\
{[\mathbf{R}]^{-1} } & =\left[\begin{array}{lll}
1 & 0 & 0 \\
0 & 1 & 0 \\
0 & 0 & \frac{1}{2}
\end{array}\right] \\
\boldsymbol{\epsilon}^{\prime} & =\mathbf{R A R}^{-1} \boldsymbol{\epsilon}
\end{aligned}
$$

The modulus of rigidity, G, was found by dividing the modulus of elasticity, $E$, by 2 times Poisson's ratio, $v$, plus 1 .

$$
G=\frac{E}{2(1+v)}
$$

4.1.4 Equations Used for In-Plane Shear Modulus Testing of Unidirectional Carbon Fiber Specimens

The maximum shear stress, $\tau_{12, \max }$, is calculated by dividing the maximum force, $P^{\max }$ 41 
divided by the cross-sectional area times two.

$$
\tau_{12, \max }=\frac{P^{\max }}{2 A}
$$

The shear stress, $\tau_{12}$, is calculated by dividing the maximum force, $P^{\max }$ divided by the crosssectional area times two.

$$
\tau_{12, i}=\frac{P_{i}}{2 A}
$$

The modulus of elasticity in the $+/-45^{\circ}$ shear modulus test, $E_{x x}$, was calculated by the difference two stress points and their equivalent strain points.

$$
E_{x x}=\frac{-\Delta \sigma}{\Delta \varepsilon}
$$

The shear chord modulus of elasticity, $G_{12}$, was calculated by the Equation (25).

$$
G_{12}=1 /\left(4 / E_{x x}-1 / E_{1}-1 / E_{2}+2 v_{12} / E_{1}\right)
$$

Converting normal strain to shear strain is done by dividing the shear strain by 2 .

$$
\epsilon=1 / 2 * \gamma
$$

\subsubsection{Equations Used for Volume Fraction Testing of Cured Reinforced Resins}

The ignition loss of the specimen in weight percent is calculated by subtracting the weight of the specimen, $W_{1}$, and the weight of the residue, $W_{2}$. 


$$
\text { Ignition lost, weight } \%=\left[\left(W_{1}-W_{2}\right) / W_{1}\right] * 100
$$

\subsection{Theoretical Equations}

\subsubsection{Equations Used to Find Laminate In-Plane Engineering Constants}

The NASA Composite Laminate Report ${ }^{[24]}$ was used to find all the laminate in-plane engineering constants (or also known as in-plane laminate material properties). Before finding the laminate in-plane engineering constants, the assumptions must be stated. The quasi-isotropic laminate, with a layup sequence of $\left[\begin{array}{lll}0 & 0+45-45+45-4590 & 90\end{array}\right]_{\mathrm{s}}$, meant that it's symmetrical and balanced. A symmetrical laminate simplifies the calculations since all that is needed to determine the in-plane engineering constants is the $\boldsymbol{A}$ matrix since the $\boldsymbol{B}$ matrix is composed of all zeros. But for asymmetrical laminates, one would need $\boldsymbol{A}, \boldsymbol{B}$, and $\boldsymbol{D}$ matrices. The subscripted numbers after the matrix, for example, the 1 and 2 in $A_{12}$, which is in the number in the first row and second column of the matrix.

The theoretical method of finding the laminate in-plane engineering constants required knowledge of Umeco's MTM 49 Unidirectional Carbon Fiber pre-preg material properties ${ }^{[21]}$. The experimental datasheet material properties were used inside the theoretical method.

In Equation (28), to find the modulus in the $\mathrm{x}$-direction, the stress in the $\mathrm{x}$-direction is divided by the strain in the x-direction. Which can be also written as force per length in the x-direction, $N_{x}$ , divided by the laminate thickness, $h$ all over the strain. 


$$
E_{x}=\frac{\sigma_{x}}{\varepsilon_{x}}=\frac{N_{x} / h}{\varepsilon_{x}}
$$

The $\boldsymbol{A}$ matrix simplifies to the one below since the $\boldsymbol{B}_{i j}$ matrix is all zeros. For each layer in the laminate one needs to solve for a unique $\boldsymbol{Q}$ matrix. If a laminate has 16 different layers then there will be $16 \boldsymbol{Q}$ matrices and after they are all solved they need to be summed together to form the $\boldsymbol{A}$ matrix. Equations (29) - (40) will be needed in order to solve for each value in the $\mathbf{Q}$ matrix.

$$
\begin{gathered}
Q_{11}=\frac{E_{1}}{1-v_{12} v_{21}} \\
Q_{22}=\frac{E_{2}}{1-v_{12} v_{21}} \\
Q_{12}=\frac{v_{12} E_{2}}{1-v_{12} v_{21}}=\frac{v_{21} E_{1}}{1-v_{12} v_{21}} \\
Q_{66}=G_{12}
\end{gathered}
$$

For any angled ply, one uses Equations (33) - (40).

$$
\begin{aligned}
& m=\cos \theta \\
& n=\sin \theta
\end{aligned}
$$




$$
\begin{gathered}
\bar{Q}_{11}=Q_{11} m^{4}+2\left(Q_{12}+2 Q_{66}\right) m^{2} n^{2}+Q_{22} n^{4} \\
\bar{Q}_{12}=\left(Q_{11}+Q_{22}-4 Q_{66}\right) m^{2} n^{2}+Q_{12}\left(m^{4}+n^{4}\right) \\
\bar{Q}_{22}=Q_{11^{n}}{ }^{4}+2\left(Q_{12}+2 Q_{66}\right) m^{2} n^{2}+Q_{22} m^{4} \\
\bar{Q}_{16}=\left(Q_{11}-Q_{12}-2 Q_{66}\right) m^{3} n+\left(Q_{12}-Q_{22}+2 Q_{66}\right) m n^{3} \\
\bar{Q}_{26}=\left(Q_{11}-Q_{12}-2 Q_{66}\right) n^{3} m+\left(Q_{12}-Q_{22}+2 Q_{66}\right) n m^{3} \\
\bar{Q}_{66}=\left(\begin{array}{l}
\left.Q_{11}+Q_{22}-2 Q_{12}-2 Q_{66}\right) m^{2} n^{2}+Q_{66}\left(m^{4}+n^{4}\right) \\
N_{x y}
\end{array}\right]=\left[\begin{array}{l}
N_{x} \\
A_{12} A_{22} A_{26} \\
A_{16} A_{26} A_{66}
\end{array}\right]\left[\begin{array}{l}
A_{12} A_{16} \\
\varepsilon_{y}^{0} \\
\gamma_{x y}^{0}
\end{array}\right]
\end{gathered}
$$

There is no force (or stress in the other two directions) so those are set to zero. This further simplifies the equations. 


$$
\begin{aligned}
& N_{x}=A_{11} \varepsilon_{x}^{0}+A_{12} \varepsilon_{y}^{0}+A_{16} \gamma_{x y}^{0} \\
& 0=A_{12} \varepsilon_{x}^{0}+A_{22} \varepsilon_{y}^{0}+A_{26} \gamma_{x y}^{0} \\
& 0=A_{16} \varepsilon_{x}^{0}+A_{26} \varepsilon_{y}^{0}+A_{66} \gamma_{x y}^{0}
\end{aligned}
$$

After further simplification of the Equations (42) - (44), Equation (46) was equal to our modulus in the x-direction, $E_{x}$, only after this number was divided by the laminate thickness, $h$.

$$
\begin{gathered}
\frac{N_{x}}{\varepsilon_{x}^{0}}=A_{11}+A_{12}\left(\frac{A_{26} A_{16}-A_{12} A_{66}}{A_{22} A_{66}-A_{26}{ }^{2}}\right)+A_{16}\left(\frac{-A_{16}}{A_{66}}+\frac{A_{26} A_{12} A_{66}-A_{26}{ }^{2} A_{16}}{A_{22} A_{66}{ }^{2}-A_{26}{ }^{2} A_{66}}\right) \\
E_{x}=N_{x} /\left(\epsilon_{x}^{0}\right) * 1 / h
\end{gathered}
$$

Next, the same exact method is applied to the y-direction. The modulus in the y-direction, $E_{y}$ equaled Equation (48).

$$
\begin{gathered}
\frac{N_{y}}{\varepsilon_{y}^{0}}=A_{12}\left(\frac{A_{16} A_{26}-A_{12} A_{66}}{A_{11} A_{66}-A_{16}{ }^{2}}\right)+A_{22}+A_{26}\left(\frac{-A_{26}}{A_{66}}+\frac{A_{16} A_{12} A_{66}-A_{16}{ }^{2} A_{26}}{A_{11} A_{66}{ }^{2}-A_{16}{ }^{2} A_{66}}\right) \\
E_{y}=N_{y} /\left(\epsilon_{y}^{0}\right) * 1 / h
\end{gathered}
$$

Next, the same exact method is applied to the xy-direction. The shear modulus in the xydirection was found, in Equation (50), $G_{x y}$, only after divided by the laminate thickness, $h$. 


$$
\begin{gathered}
\frac{N_{x y}^{\prime}}{\gamma_{x y}^{0}}=A_{66}-\frac{A_{26}{ }^{2}}{A_{22}}+\frac{2 A_{12} A_{16} A_{26} A_{22}-A_{12}{ }^{2} A_{26}{ }^{2}-A_{16}{ }^{2} A_{22}{ }^{2}}{A_{11} A_{22}{ }^{2}-A_{12}{ }^{2} A_{22}} \\
G_{x y}=N_{x y} /\left(\gamma_{x y}^{0}\right) * 1 / h
\end{gathered}
$$

Poisson's ratio, $v_{x y}$, of the laminate was calculated using Equation (51).

$$
v_{x y}=\frac{-\varepsilon_{y}^{0}}{\varepsilon_{x}^{0}}=\frac{\left(A_{12}-\frac{A_{16} A_{26}}{A_{66}}\right)}{\left(A_{22}-\frac{A_{26}^{2}}{A_{66}}\right)}
$$

Poisson's ratio, $v_{\mathrm{yx}}$, of the laminate can was calculated using Equation (52).

$$
v_{y x}=\frac{-\varepsilon_{x}^{0}}{\varepsilon_{y}^{0}}=\frac{\left(\frac{A_{16} A_{26}}{A_{66}}-A_{12}\right)}{\left(\frac{A_{16}{ }^{2}}{A_{66}}-A_{11}\right)}
$$




\section{CHAPTER 5: EXPERIMENTAL RESULTS}

In this chapter, the experimental results are explained in detail. Section 5.1 explained the validation process, which was conducted, on all the strain measurement devices. The axial modulus of elasticity and Poisson's ratio of Aluminum were validated. Section 5.2 summarized the material testing which was conducted on the unidirectional carbon fiber material. Section 5.3 explained the unidirectional carbon fiber material property testing. Section 5.4 explained the quasiisotropic carbon fiber laminate material property testing. Section 5.5 explained the experimental results found for the Aluminum double shear specimens. Section 5.6 explained the quasi-isotropic carbon fiber double shear specimens' experimental results.

\subsection{Experimental Measurement Device Validation}

Before any strain measurement device was used on a composite material, its accuracy needed to be validated with commonly known material. In this case, an Aluminum specimen was tensile tested with a strain gage orientated in the axial direction, and another strain gage orientated in the transverse direction. Since the axial strain gage, the extensometer and the crosshead were measuring axial strain, their readings were compared. In the past theses, students were using the crosshead displacement to measure the modulus of elasticity. Using the crosshead displacement was very unreliable and it is explained in more detail in the next sub section. 


\subsubsection{Extensometer vs. Axial Strain Gage vs. Crosshead Displacement}

The test set-up of the Aluminum specimen is shown in Figure 21. The three principle directions and the clamped sections of a standard uniaxial tensile specimen are shown in Figure 21. Below in Table 1, an Aluminum sample was loaded and unloaded three times up to a tensile stress of 25 ksi. The tensile stress was calculated using Equation (9). A tensile stress of $25 \mathrm{ksi}$ lies in the material's linear elastic region and it is far away from materials yield stress of 35 ksi. Table 1 shows the comparison of experimental results between the extensometer, strain gage and crosshead. Table 1 also shows the dimensions of the Aluminum specimen. The strain gage and extensometer experimental results were validated with the Aluminum 2024-T4 datasheet mechanical properties ${ }^{[25]}$. The moduli of elasticity, in Table 1 , are in $\mathrm{msi}\left(10 \mathrm{E}^{6} \mathrm{lbs} . / \mathrm{in} .{ }^{2}\right)$ and were calculated using Equation (10). There was less than $1 \%$ error between the extensometer and the strain gage when compared to the Aluminum 2024's modulus of elasticity. When comparing to the crosshead, there was an error of $64 \%$. The crosshead displacement is not as accurate as an extensometer or a strain gage, because the crossheads have compliance (inside the actuator assembly) which elongates as load is applied. The actuator assembly starts to elongate, which significantly affects the experimental strain results. The small standard deviation showed how consistent the results were when using the three different measurement tools and the testing machine. 

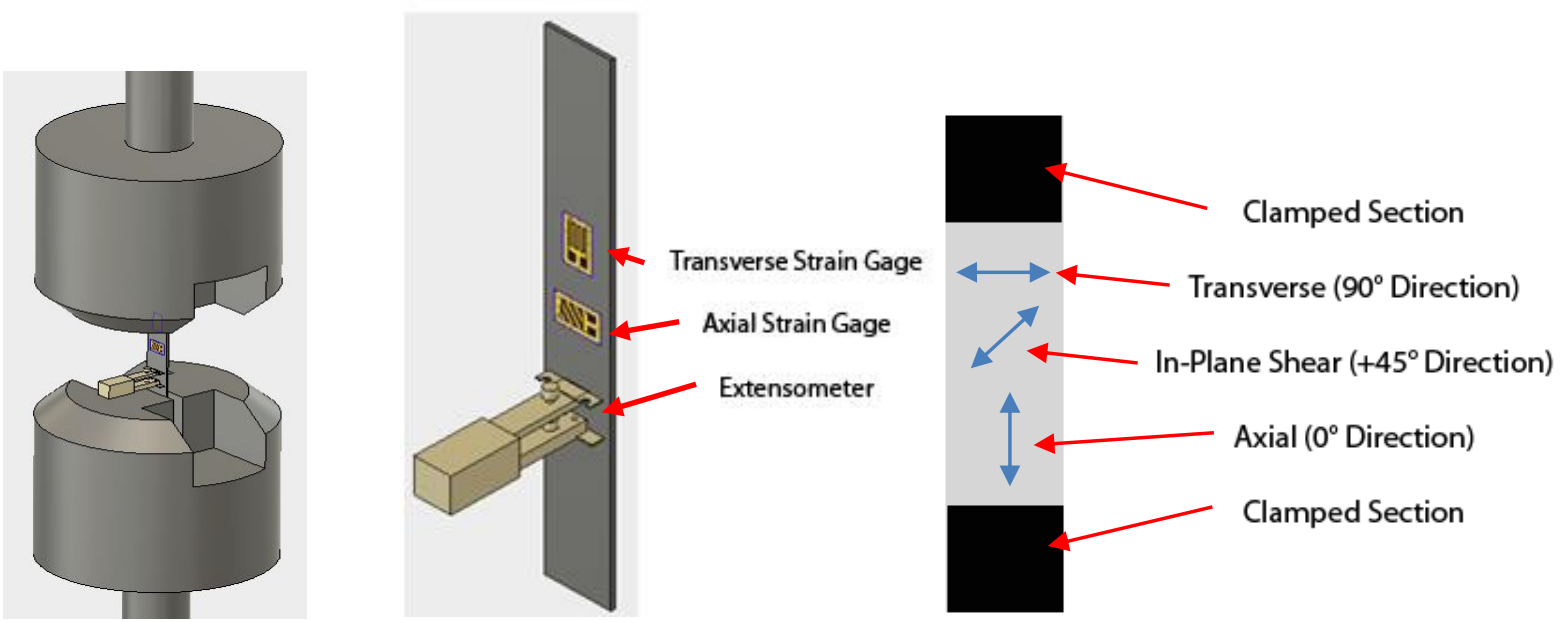

Figure 21. Aluminum specimen between both clamps (left) aluminum specimen with a transverse strain gage, axial strain gage \& extensometer (center) tensile specimen showing the clamped sections and the 3 principle directions (right) 
Table 1. Comparison of extensometer, strain gage and crosshead on an aluminum specimen

\begin{tabular}{|c|c|c|c|}
\hline $\begin{array}{c}\text { Aluminum } \\
\text { 2024-T4 }\end{array}$ & $\begin{array}{c}\text { Extensometer } \\
\text { Modulus of } \\
\text { Elasticity, } \\
\text { msi }\end{array}$ & $\begin{array}{c}\text { Strain Gage } \\
\text { Modulus of } \\
\text { Elasticity, } \\
\text { msi }\end{array}$ & $\begin{array}{c}\text { Crosshead } \\
\text { Modulus of } \\
\text { Elasticity, } \\
\text { msi }\end{array}$ \\
\hline Run 1 & 10.46 & 10.50 & 3.84 \\
\hline Run 2 & 10.57 & 10.62 & 3.83 \\
\hline Run 3 & 10.43 & 10.50 & 3.83 \\
\hline Average & 10.48 & 10.54 & 3.83 \\
\hline Std. Dev. & 0.074 & 0.069 & 0.005 \\
\hline $\begin{array}{l}\text { Coeff. of } \\
\text { Variance }\end{array}$ & 0.007 & 0.007 & 0.002 \\
\hline Datasheet ${ }^{[25]}$ & \multicolumn{3}{|c|}{10.5} \\
\hline$\%$ Difference & $0.1 \%$ & $0.4 \%$ & $63.4 \%$ \\
\hline \multicolumn{4}{|c|}{$\begin{array}{c}\text { Length }=7.50 \text { in. } \\
\text { Width }=1.002 \text { in. } \\
\text { Thickness }=0.062 \text { in. } \\
\text { Grip Pressure }=160 \text { bar } \\
\text { d Rate }=0.05 \text { in. } / \text { min. (Quasi-Static) }\end{array}$} \\
\hline
\end{tabular}

Below in Figure 22, one can see the three runs that were done using the extensometer and the axial strain gage. The crosshead displacement was excluded from Figure 22, since the experimental strain varied so drastically from the extensometer and the axial strain gage. The strain gage and the extensometer read very similar moduli of elasticity. The extensometer and strain gage proved to be reliable, so both measurement tools were used on the composite specimens. 


\section{Comparison Between Extensometer \& Strain Gage}

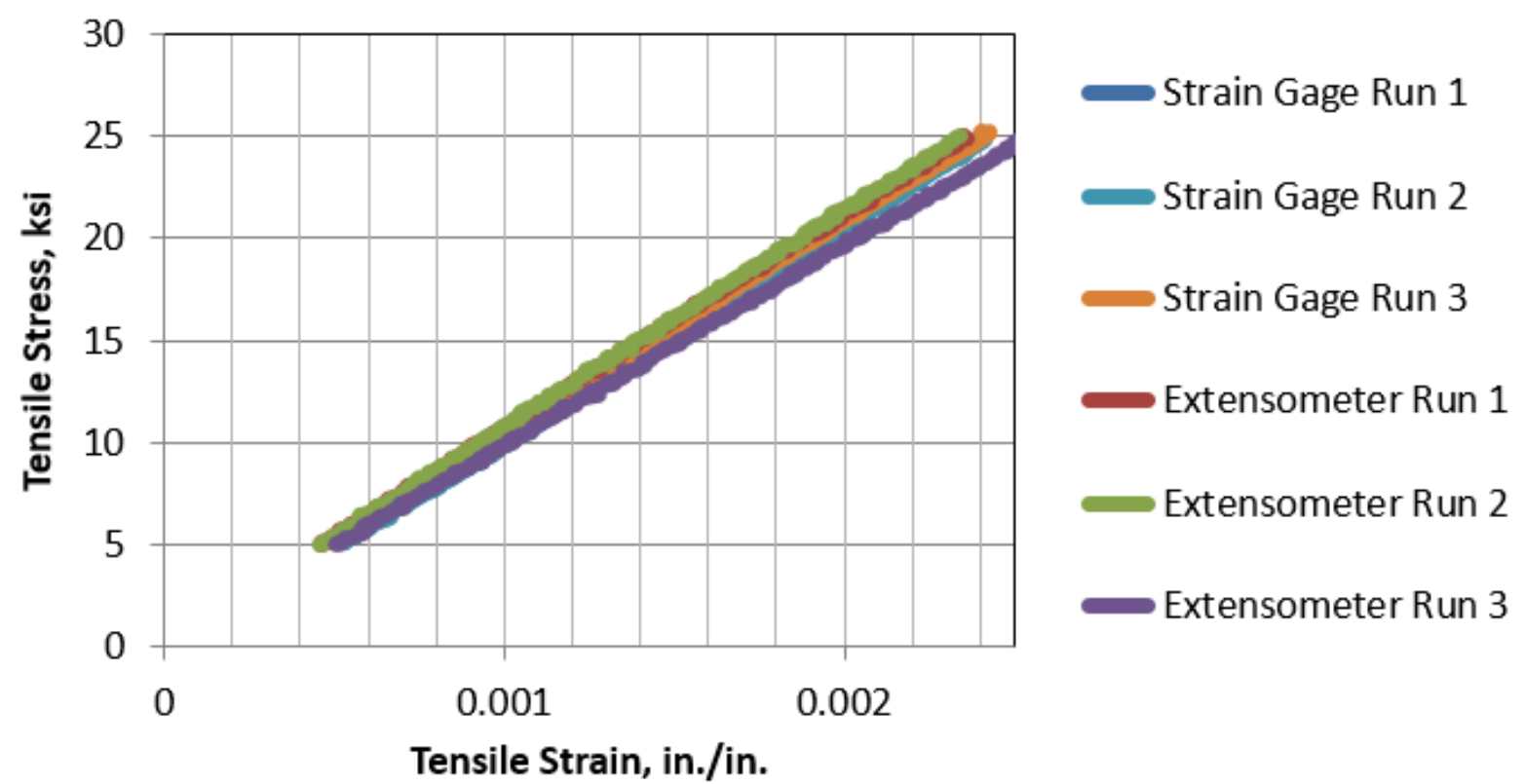

Figure 22. Tensile stress vs. tensile strain response comparison between extensometer \& strain gage of the aluminum 2024-T4 specimen

\subsubsection{Poisson's Ratio Validation Using Axial and Transverse Strain Gages}

The Poisson's ratio of the Aluminum 2024-T4 needed to be validated. In Figure 23, one can see the axial and transverse strains plotted with respect to the axial force. The axial strain gage output is shown in blue and the transverse strain gage is shown in red. A linear curve fit was applied to both sets of strain gage data and their respective linear equations are shown, as well. Poisson's Ratio equaled to a value of 0.26, for the Aluminum specimen, using Equation (13). 


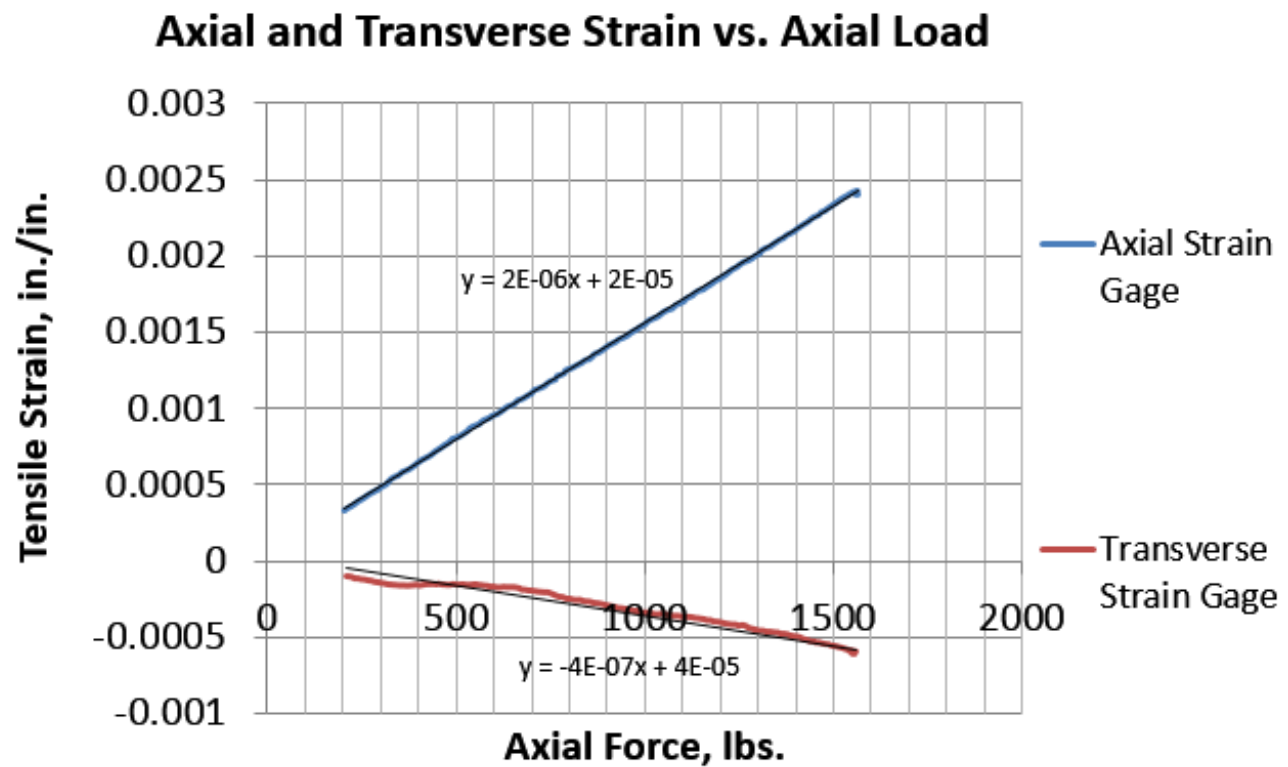

Figure 23. Axial and transverse strain vs. axial load of the aluminum 2024-T4 specimen

\subsection{Summary of Carbon Fiber Material Properties}

Below in Table 2, the results accumulated from Umeco's MTM 49 Unidirectional Carbon Fiber pre-preg material datasheet ${ }^{[21]}$ are summarized. The values which have a (-) dash meant that they were not given in the material's datasheet. The strengths were specified in ksi, which is $10 \mathrm{E}^{\wedge} 3$ lbs./in. Table 3 shows the experimental material properties of the Umeco's MTM 49 Unidirectional Carbon Fiber pre-preg material, which were experimentally tested in the Cal Poly's Aerospace Composites Lab. Table 4 shows the experimentally tested and calculated quasi-isotropic laminate properties. Poisson's ratio, for Umeco's MTM49 Unidirectional pre-preg material was used from a previous report's value ${ }^{[26]}$ of 0.25 . All these material properties are further explained in the next few sections. 
Looking at Table 2 and Table 3, the $0^{\circ}$ compressive modulus is $22.3 \mathrm{msi}$ and the $0^{\circ}$ tensile modulus is $26.6 \mathrm{msi}$. All of the tensile axial moduli of elasticity were similar but they were slightly higher than the compressive modulus specified in the datasheet. The tensile and compressive modulus should be very similar since the fibers are assumed to behave like an isotropic material. This material was not tested in compression since compression specimens need to be a lot shorter, in length (ideally have less than $0.5 \mathrm{in}$. in gage length). An extensometer could not be mounted on the surface of the compression specimen since there is not enough room between the grips. The best way to measure, the compressive modulus of elasticity would be to use an optical high-speed camera, which records the relative motion through optics.

Table 2. Umeco's mtm 49 unidirectional datasheet ${ }^{[21]}$ properties

\begin{tabular}{|c|c|c|}
\hline $\begin{array}{c}\text { Fiber Volume } \\
\text { Fraction, } \\
\mathrm{V}_{\mathrm{f}}=0.6\end{array}$ & $\begin{array}{c}\text { Modulus, } \\
\text { msi }\end{array}$ & $\begin{array}{c}\text { Strength, } \\
\mathbf{k s i}\end{array}$ \\
\hline $0^{\circ}$ Tensile & - & 286.2 \\
\hline $0^{\circ}$ Compressive & 22.3 & 197.0 \\
\hline $90^{\circ}$ Tensile & - & - \\
\hline $90^{\circ}$ Compressive & - & - \\
\hline$+/-45$ Shear & 0.46 & 16.0 \\
\hline
\end{tabular}


Table 3. Umeco's mtm 49 unidirectional properties tested in cal poly's aerospace composites lab

\begin{tabular}{|c|c|c|}
\hline $\begin{array}{c}\text { Fiber } \\
\text { Volume } \\
\text { Fraction, } \\
\mathrm{V}_{\mathrm{f}}=0.55\end{array}$ & $\begin{array}{c}\text { Modulus, } \\
\mathbf{m s i}\end{array}$ & $\begin{array}{c}\text { Strength, } \\
\mathbf{k s i}\end{array}$ \\
\hline $0^{\circ}$ Tensile & $26.6 \pm 1.90$ & $235.4 \pm 16.4$ \\
\hline $90^{\circ}$ Tensile & $0.99 \pm 0.191$ & $4.24 \pm 1.44$ \\
\hline +/- 45 Shear & $0.30 \pm 0.009$ & $9.14 \pm 0.45$ \\
\hline
\end{tabular}

Table 4. Quasi-isotropic laminate material properties [0 $0+45-45+45-459090]_{\mathrm{s}}$

\begin{tabular}{|c|c|c|}
\hline $\begin{array}{c}\text { Poisson's } \\
\text { Ratio, } \\
\text { v12 }=0.291\end{array}$ & $\begin{array}{c}\text { Modulus, } \\
\text { msi }\end{array}$ & $\begin{array}{c}\text { Strength, } \\
\text { ksi }\end{array}$ \\
\hline $\mathrm{E}_{1}=\mathrm{E}_{2}$ & $12.08 \pm 0.12$ & $58.9 \pm 3.87$ \\
\hline $\mathrm{G}_{12}$ & $4.68 \pm 0.018$ & - \\
\hline
\end{tabular}

5.3 Unidirectional Carbon Fiber Material Property Testing

\subsubsection{Test for $0^{\circ}$ Unidirectional Carbon Fiber Composite Tensile Specimens}

A laminate of 8 plies, $[0]_{8 \mathrm{~T}}$, was laid up and tested along the fiber direction. The $0^{\circ}$ direction is always the direction of the applied load in a uni-axial test. The ASTM $3039{ }^{[19]}$ required a minimum of five specimens per test, and having more than five specimens helped improve the 
consistency of the results. Each specimen was $10 \mathrm{in}$. long by $0.5 \mathrm{in}$. wide and with a thickness of 0.046 in. The ASTM $3039^{[19]}$ required curing 2 in. long by 0.5 in. wide Aluminum tabs on the specimens to prevent premature failures from occurring. The grip pressure was set to $160 \mathrm{bar}$.

The tensile test began with testing one $0^{\circ}$ unidirectional carbon fiber composite tensile specimen (without an extensometer) to failure, to find its ultimate load. The limit load of 2,000 lbs. was chosen since the ultimate load was 4,600 lbs. The last six $0^{\circ}$ unidirectional carbon fiber composite tensile specimens were loaded to 2,000 lbs., and at 2,000 lbs., the test was paused so that the extensometer could be removed safely. Once the extensometer was removed, the Instron machine's crossheads took over in measuring the tensile strain. The load cell accurately measured the ultimate load up to an accuracy of $+/-45 \mathrm{lbs}$. In Figure 24, the $0^{\circ}$ unidirectional carbon fiber composite tensile specimens are shown to the left and one of the clamped post-test $0^{\circ}$ unidirectional carbon fiber composite tensile specimen is shown on the right. Figure 25 shows all seven of the tested $0^{\circ}$ unidirectional carbon fiber composite tensile specimens (each color represents a different specimen). Figure 26 shows the extensometer mounted on the $0^{\circ}$ unidirectional carbon fiber composite tensile specimen with two rubber bands. The compressive modulus was specified in the datasheet and the tensile modulus was not specified in the datasheet. The experimental tensile modulus was compared to the compressive modulus and the difference between the two values was 19\%. A 17\% difference between the tensile strength when compared to the datasheet values. 

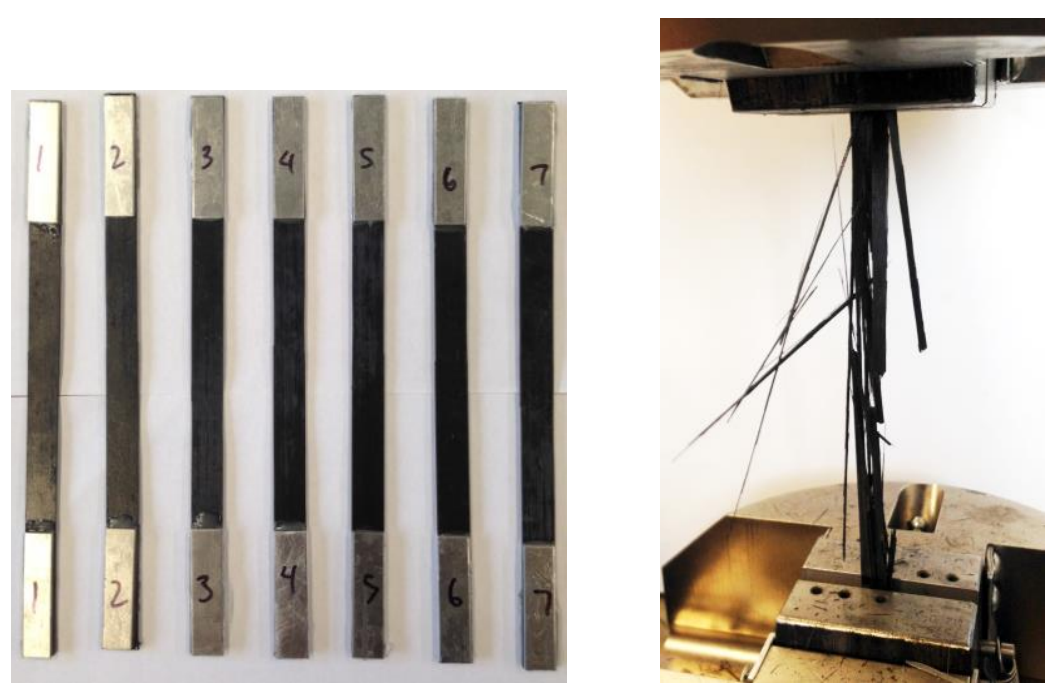

Figure $24.0^{\circ}$ Unidirectional carbon fiber composite tensile specimens with aluminum tabs (left) post-test $0^{\circ}$ unidirectional carbon fiber composite tensile specimen (right)

Tensile Stress vs Tensile Strain

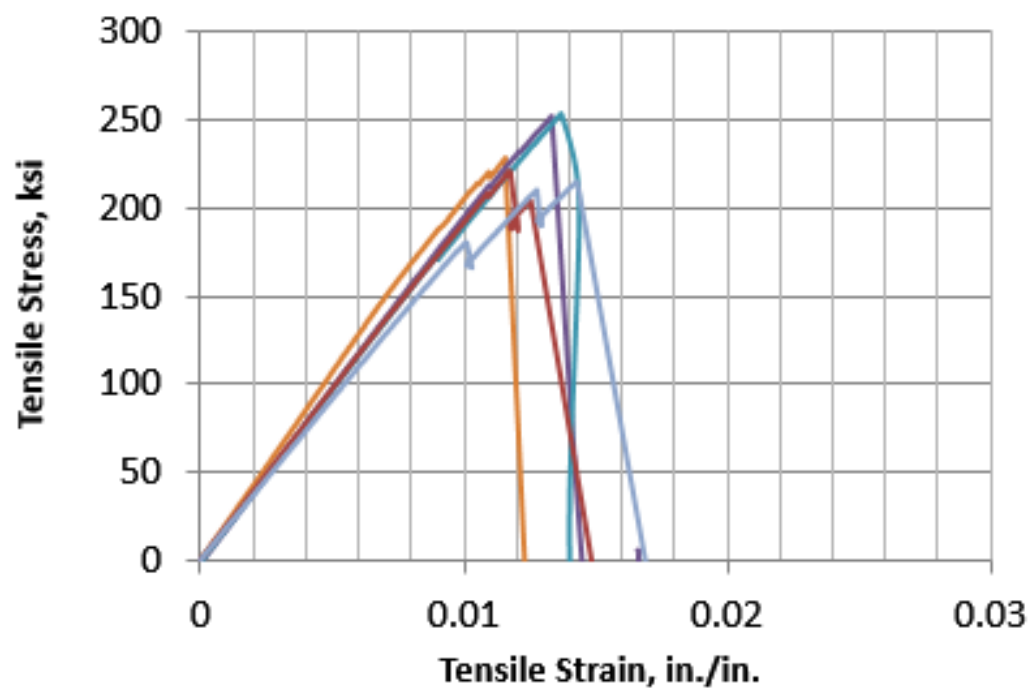

Figure 25. Tensile stress vs. tensile strain response of (7) $0^{\circ}$ unidirectional carbon fiber composite tensile specimens 


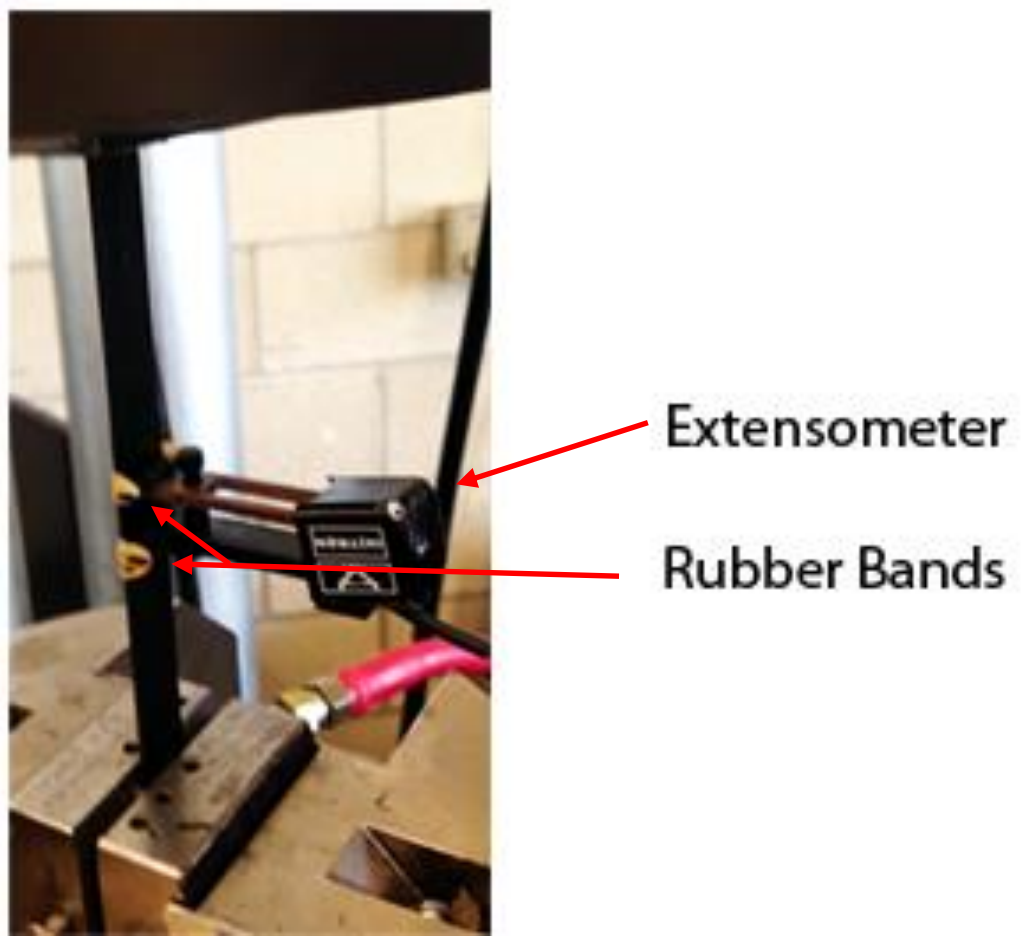

Figure 26. Extensometer attached using two rubber bands on a $0^{\circ}$ unidirectional carbon fiber composite tensile specimen 
Table 5. $0^{\circ}$ Unidirectional carbon fiber composite tensile specimen data

\begin{tabular}{|c|c|c|}
\hline$[0]_{8 \mathrm{~T}}$ & $\begin{array}{l}\text { Modulus } \\
\text { of } \\
\text { Elasticity, } \\
\text { msi }\end{array}$ & $\begin{array}{c}\text { Ultimate } \\
\text { Tensile } \\
\text { Strength, ksi }\end{array}$ \\
\hline S1 & - & 235.3 \\
\hline $\mathbf{S 2}$ & 26.7 & 228.1 \\
\hline S3 & 29.3 & 251.7 \\
\hline S4 & 26.5 & 242.0 \\
\hline S5 & 27.3 & 254.4 \\
\hline S6 & 26.9 & 221.3 \\
\hline S7 & 23.4 & 214.8 \\
\hline Average & 26.6 & 235.4 \\
\hline Std. Dev. & 1.90 & 16.4 \\
\hline Coeff. of Variance & 0.072 & 0.069 \\
\hline Datasheet $^{[21]}$ & 22.3 & 286.2 \\
\hline$\%$ Difference & $19 \%$ & $17 \%$ \\
\hline \multicolumn{3}{|c|}{$\begin{array}{l}\text { Modulus of Elasticity was measured up until } 2000 \\
\text { lbs. with an extensometer. }\end{array}$} \\
\hline $\begin{array}{r}\text { Leng } \\
\text { Width } \\
\text { Thicknes } \\
2 \text { in. Aluminum tabs }\end{array}$ & $\begin{array}{r}=10 \pm 0.01 \\
0.500 \pm 0.01 \\
=0.046 \pm 0.0 \\
\text { sed \& } 160 \mathrm{~b}\end{array}$ & in. \\
\hline
\end{tabular}




\subsubsection{Test for $90^{\circ}$ Unidirectional Carbon Fiber Composite Tensile Specimens}

Next, a laminate of 14 plies, [90 $]_{14 T}$, was laid up and tested along the matrix direction. A couple extra test specimens were tested to find the optimum hydraulic clamping pressure. The clamping pressure was initially set to 160 bar and once the specimen was clamped, it cracked. The hydraulic clamp pressure was reduced to $60 \mathrm{bar}$ in order to prevent this premature failure from occurring. Eight specimens were tested since the material is very brittle and unpredictable. When examining the stress-strain plot of the $90^{\circ}$ unidirectional carbon fiber composite tensile specimens, the ultimate tensile stress determined the location of where the specimen would fail. As one can see in Figure 27, the four $90^{\circ}$ unidirectional carbon fiber composite specimens, which failed at an ultimate tensile stress of around $5 \mathrm{ksi}$, ended up breaking in the center. Whereas, the specimens which failed at a lower ultimate tensile stress failed near the emery cloth. The experimental results (between all the specimens) showed a very consistent modulus of elasticity. The ultimate tensile strength of the material varied, due to the matrix is very brittle. The failure of a brittle material is very unpredictable which one can see in the Figure 28 . There was $17 \%$ difference between the datasheet $90^{\circ}$ modulus of elasticity and a $29 \%$ difference between the $90^{\circ}$ tensile strength when compared to the datasheet values. The ultimate tensile strength variations might have been due to the low accuracy of the load cell, which typically occurs at low loads (around $100 \mathrm{lbs}$.) since the accuracy of the load cell is $+/-45$ lbs. Table 6 shows the experimental results of all the $90^{\circ}$ unidirectional carbon fiber composite tensile specimens. 


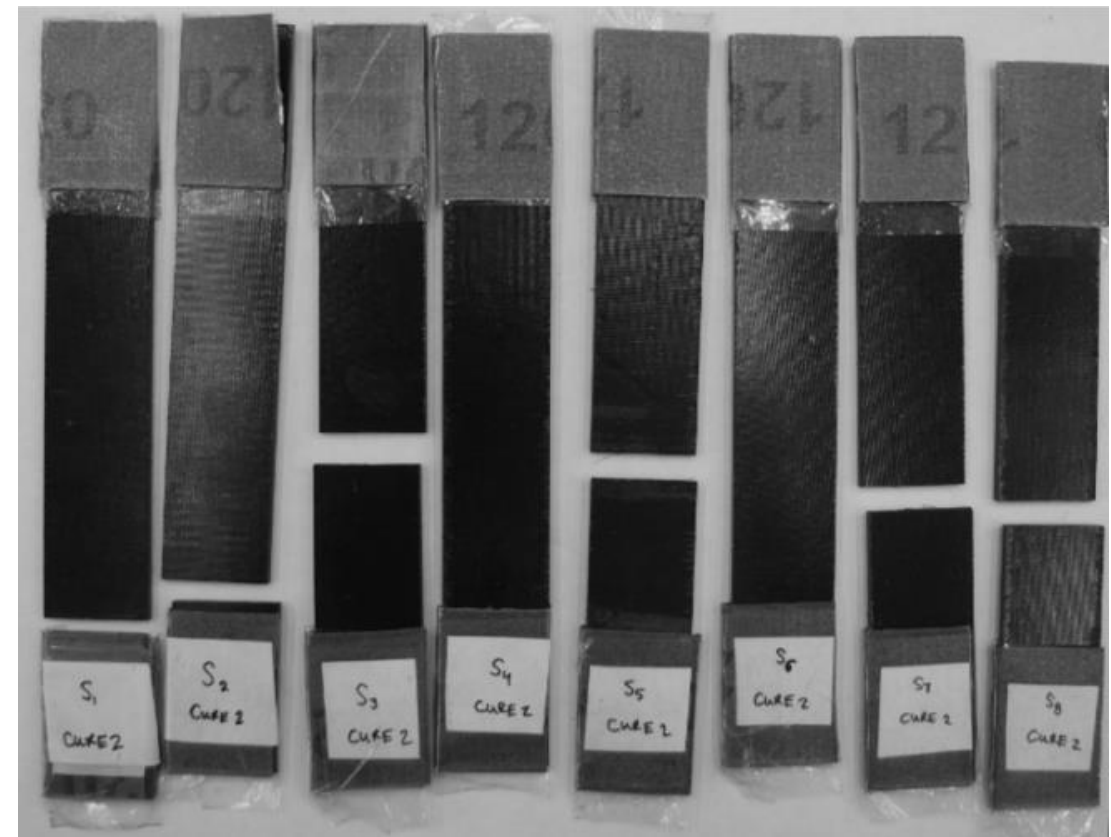

Figure 27. (8) $90^{\circ}$ Unidirectional carbon fiber composite tensile specimens with emery cloth tabs

\section{Tensile Stress vs Tensile Strain}

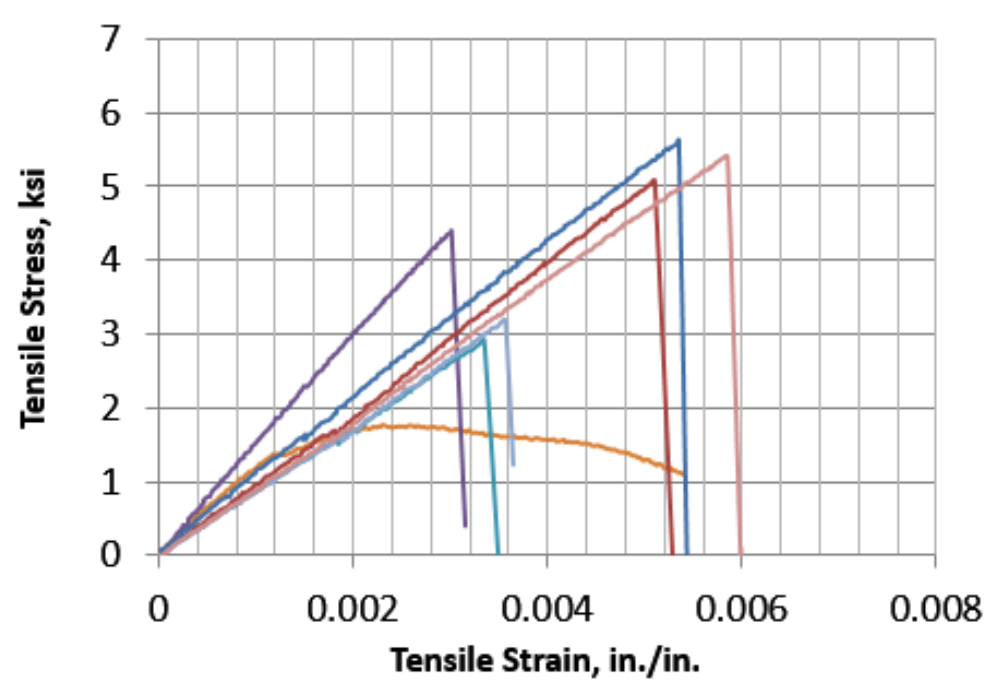

Figure 28. Tensile stress vs. tensile strain response of (8) $90^{\circ}$ unidirectional carbon fiber composite tensile specimens 
Table $6.90^{\circ}$ Unidirectional carbon fiber composite tensile specimen data

\begin{tabular}{|c|c|c|}
\hline$[90]_{14 \mathrm{~T}}$ & $\begin{array}{l}\text { Modulus } \\
\text { of } \\
\text { Elasticity, } \\
\text { msi }\end{array}$ & $\begin{array}{c}\text { Ultimate } \\
\text { Tensile } \\
\text { Strength, } \\
\text { ksi }\end{array}$ \\
\hline S1 & 0.94 & 1.78 \\
\hline $\mathbf{S 2}$ & 1.43 & 4.41 \\
\hline S3 & 0.99 & 5.51 \\
\hline S4 & 0.84 & 2.91 \\
\hline S5 & 0.92 & 5.09 \\
\hline S6 & 0.85 & 3.19 \\
\hline S7 & 1.04 & 5.62 \\
\hline S8 & 0.89 & 5.40 \\
\hline Average & 0.99 & 4.24 \\
\hline Std. Dev. & 0.191 & 1.44 \\
\hline $\begin{array}{c}\text { Coeff. of } \\
\text { Variance }\end{array}$ & 0.193 & 0.34 \\
\hline Datasheet $^{[21]}$ & 1.20 & 6.0 \\
\hline$\%$ Difference & $17 \%$ & $29 \%$ \\
\hline \multicolumn{3}{|c|}{ Modulus of Elasticity to $125 \mathrm{lbs}$. } \\
\hline \multicolumn{3}{|c|}{$\begin{array}{c}\text { Length }=7.0 \pm 0.02 \text { in. } \\
\text { Width }=1.03 \pm 0.01 \text { in. } \\
\text { Thickness }=0.092 \pm 0.004 \text { in. } \\
120 \text { grit emery cloth used } \\
\text { Grip Pressure }=80 \text { bar }\end{array}$} \\
\hline
\end{tabular}




\subsubsection{Test for $+/-45^{\circ}$ Shear Modulus Specimens}

After following ASTM D3518 ${ }^{[20]}$, a laminate was created with an orientation of [+/- 45] $]_{4}$ which is a symmetric laminate with alternating positive and negative $45^{\circ}$ plies. Another way to write this is $[+45-45+45-45+45-45+45-45]_{\text {s. }}$ The extensometer was placed at $0^{\circ}$ relative to the specimen. The axial modulus of elasticity, $\mathrm{E}_{\mathrm{xx}}$, was recorded and Equation (25) was used to find $\mathrm{G}_{12}$. Equation (25) requires knowledge of $\mathrm{E}_{1}, \mathrm{E}_{2}$, and $v_{12}$. Eight shear modulus specimens, for consistency, were tested since ASTM D3518 ${ }^{[20]}$ required a minimum of five shear modulus specimens. The shear modulus specimens are shown in Figure 29. The post-tested shear modulus specimens looked the same as the pre-tested shear modulus specimens (since the failure occurred in the matrix and not in the fiber). Figure 30 shows the highly consistent shear specimen results. Table 7 showed the detailed experimental results.

There was 35\% difference between the in-plane shear modulus and a $43 \%$ difference between the in-plane shear strength when compared to the datasheet values. Testing for the shear strength is not an easy task since the shear modulus specimen has to be in full shear state at failure. The tabs on the ends of the specimen create stress concentrations on the ends, which cause the specimen to fail prematurely. 


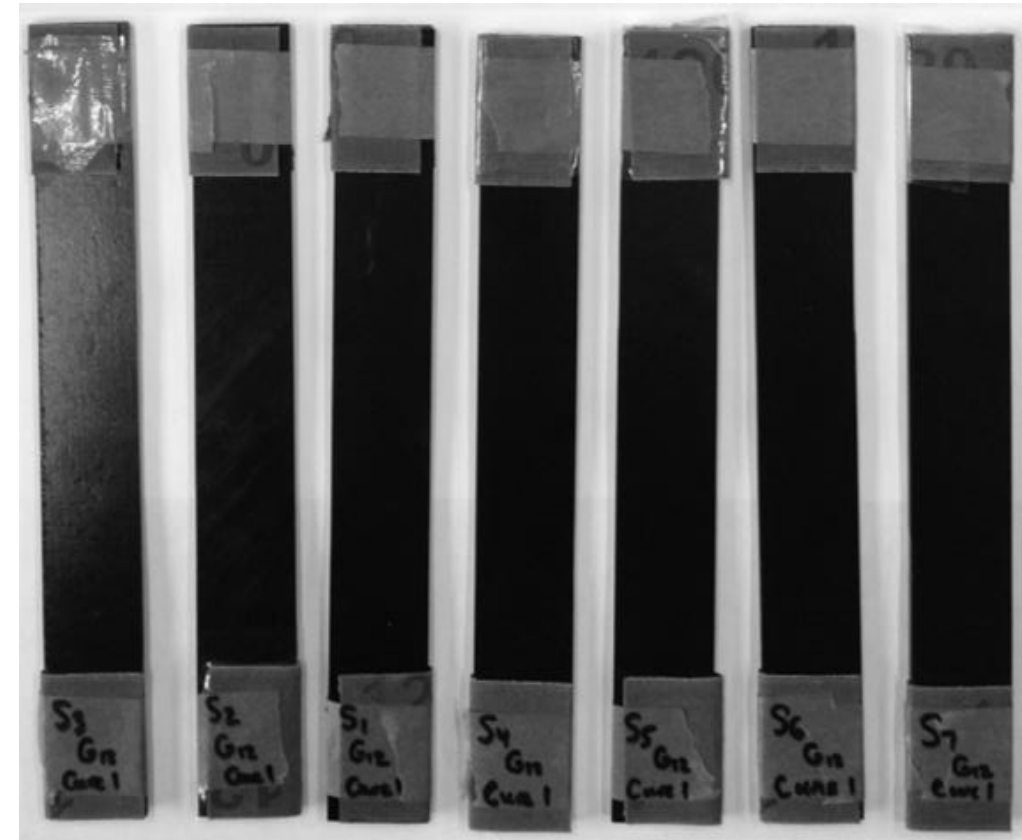

Figure 29. (8) $+/-45^{\circ}$ In-plane shear modulus specimens

Shear Stress vs Shear Strain

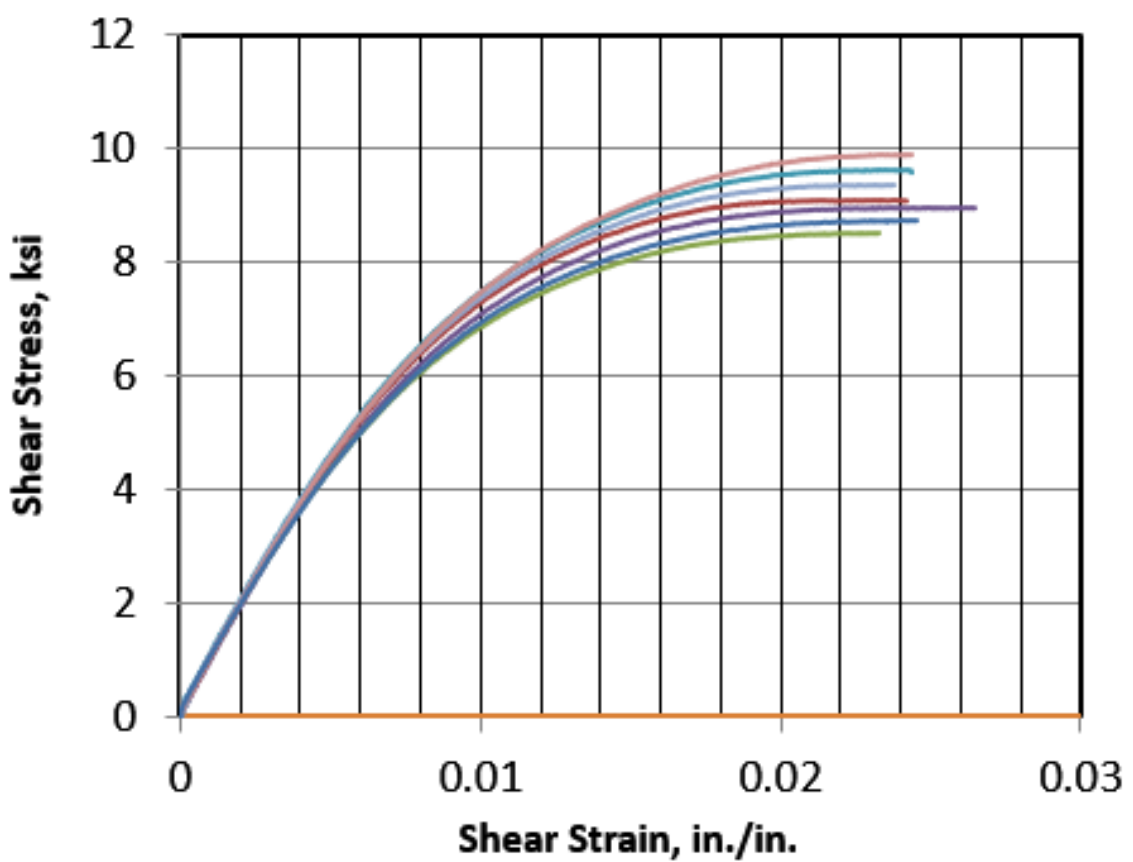

Figure 30. Shear stress vs. shear strain response of $(8)+/-45^{\circ}$ shear modulus specimens 64 
Table $7 .+/-45^{\circ}$ Unidirectional carbon fiber composite tensile specimen data

\begin{tabular}{|c|c|c|}
\hline$[+/-45] 4 s$ & $\begin{array}{l}\text { Modulus } \\
\text { of } \\
\text { Rigidity, } \\
\text { msi }\end{array}$ & $\begin{array}{c}\text { Ultimate } \\
\text { Shear } \\
\text { Strength, } \\
\text { ksi }\end{array}$ \\
\hline S1 & 0.31 & 8.96 \\
\hline S2 & 0.29 & 8.96 \\
\hline S3 & 0.29 & 8.54 \\
\hline S4 & 0.31 & 9.61 \\
\hline S5 & 0.31 & 9.08 \\
\hline S6 & 0.31 & 9.34 \\
\hline S7 & 0.31 & 9.91 \\
\hline S8 & 0.29 & 8.76 \\
\hline Average & 0.30 & 9.14 \\
\hline Std. Dev. & 0.009 & 0.45 \\
\hline $\begin{array}{l}\text { Coeff. of } \\
\text { Variance }\end{array}$ & 0.032 & 0.049 \\
\hline $\begin{array}{c}\text { Datasheet } \\
{[21]}\end{array}$ & 0.46 & 16.0 \\
\hline $\begin{array}{c}\% \\
\text { Difference }\end{array}$ & $35 \%$ & $43 \%$ \\
\hline \multicolumn{3}{|c|}{$\begin{array}{l}\text { Length }=10.0 \pm 0.02 \mathrm{in} . \\
\text { Width }=1.002 \pm 0.005 \mathrm{in} . \\
\text { Thickness }=0.101 \pm 0.002 \mathrm{in} . \\
120 \text { grit emery cloth used } \\
\text { Grip Pressure = } 160 \mathrm{bar}\end{array}$} \\
\hline
\end{tabular}




\subsection{Quasi-Isotropic Laminate Material Testing}

\subsubsection{Test for Quasi-isotropic Tensile Specimens}

The same test method used for the $0^{\circ}$ and $90^{\circ}$ specimens was used to test the carbon fiber quasi-isotropic tensile specimens. Once one quasi-isotropic tensile specimen was tested to failure, the ultimate load was recorded to be 6,500 lbs. The next six quasi-isotropic tensile specimens were tested with the extensometer up to a force of $2,000 \mathrm{lbs}$. The test paused once the force reached 2,000 lbs. and then the extensometer was removed. Figure 31 shows the quasi-isotropic tensile specimens before (on left) and after (on right) they were tested. The region circled in red showed the area where there was a fiber failure. Figure 32 showed a close-up of the tensile failure. In Figure 32 , looking at the picture on the right, one can see the $0^{\circ}$ fibers on the outer layer held together, while in the center of the laminate, a crack began to form. The crack, in Figure 32, is circled in red. 

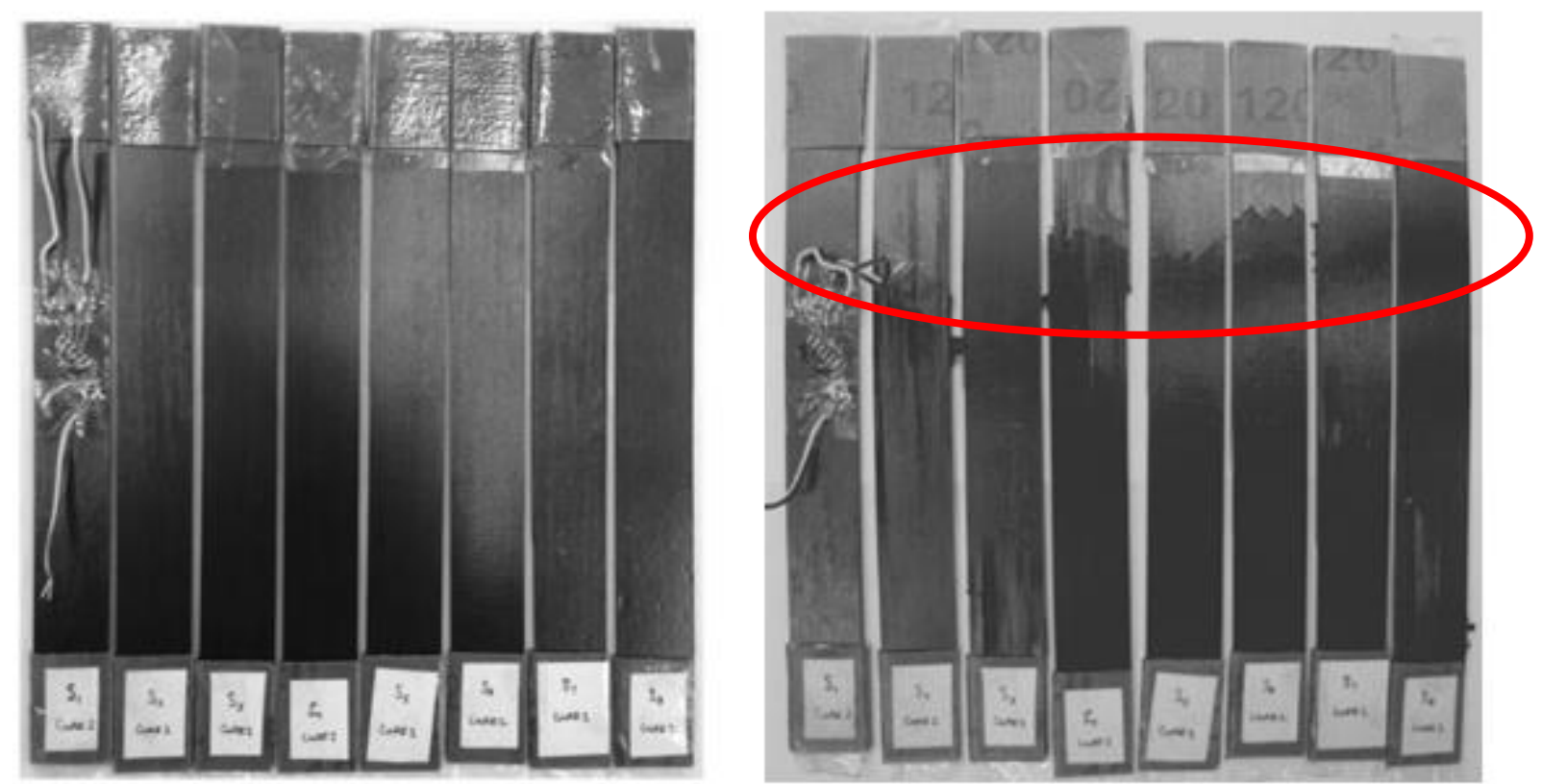

Figure 31. Quasi-isotropic tensile specimens where specimen \#1 has a strain rosette (left) post-test quasi-isotropic tensile specimens (right)
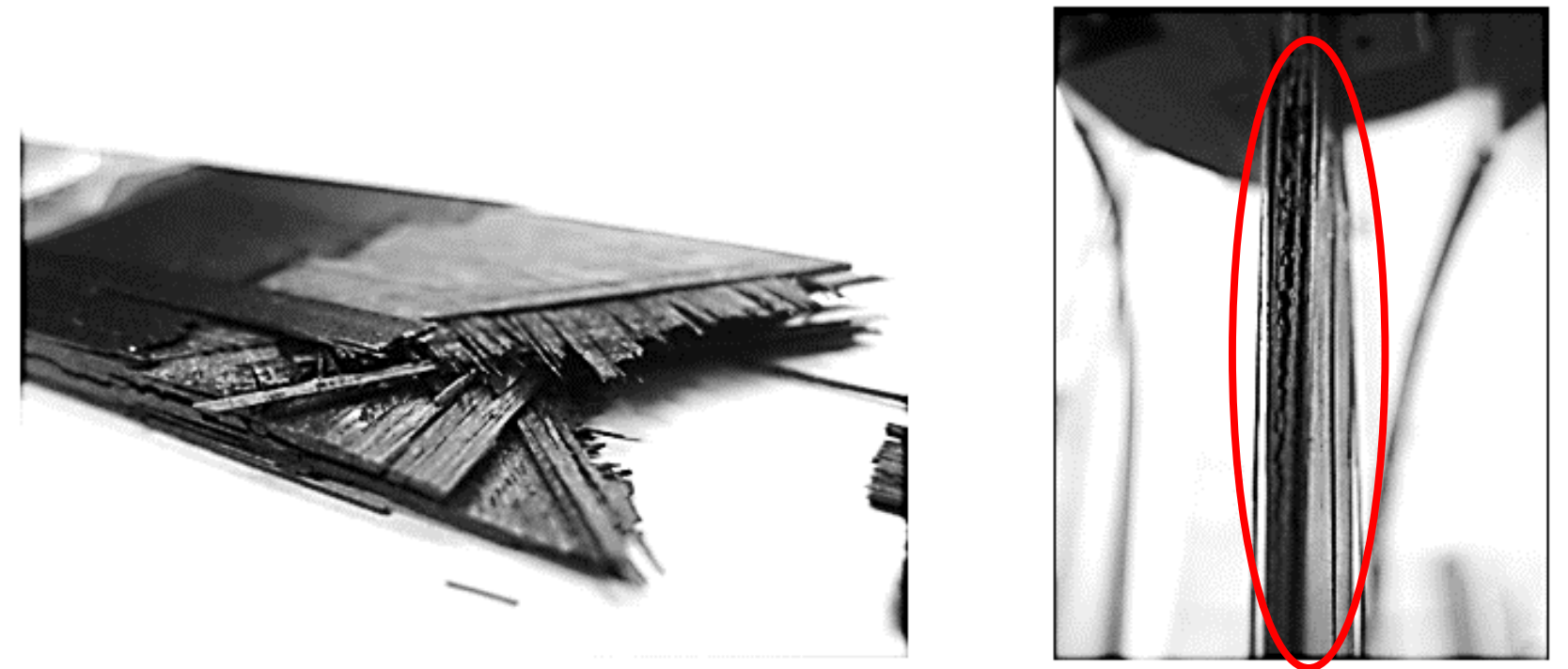

Figure 32. Close-up of a quasi-isotropic tensile specimen failure 
From Figure 33, one can see a close-up of the strain rosette, which was on Specimen \#1. Shown in Figure 34, a rectangular strain rosette (CEA- 06-120CZ-120 made by VishayPG) produced very accurate results. The rosette was placed on the quasi-isotropic tensile specimen at a $0^{\circ}-45^{\circ}-90^{\circ}$ orientation and the wires were soldered very accurately. Each strain gage resistance was checked (with a voltmeter) and read 120 Ohms. The strain gage worked correctly if the resistance across the strain gage read the correct resistance specified in the user manual. The quasi-isotropic tensile specimen \#1 was tested one time by recording the strains in the $0^{\circ}$ direction, $45^{\circ}$ direction and $90^{\circ}$ direction. In addition, when the strain gage was being applied to the surface, an 80-grit sandpaper was applied to the surface of the quasi-isotropic tensile specimen. The sanding of the outer $0^{\circ}$ layer might have affected the material's mechanical properties. Table 8 shows this $8 \%$ difference in modulus of elasticity between the extensometer and the strain gage. From Figure 35, one can see the slight drop in stress (at $20 \mathrm{ksi}$ ) due to the pause in the test. The different line colors show the seven different quasi-isotropic tensile specimens that were tested. The main thing to note is the percentage difference between the modulus of elasticity found with the strain rosette and the extensometer. The ultimate tensile strengths were very consistent which showed from a very low standard deviation of $3.87 \mathrm{ksi}$. 


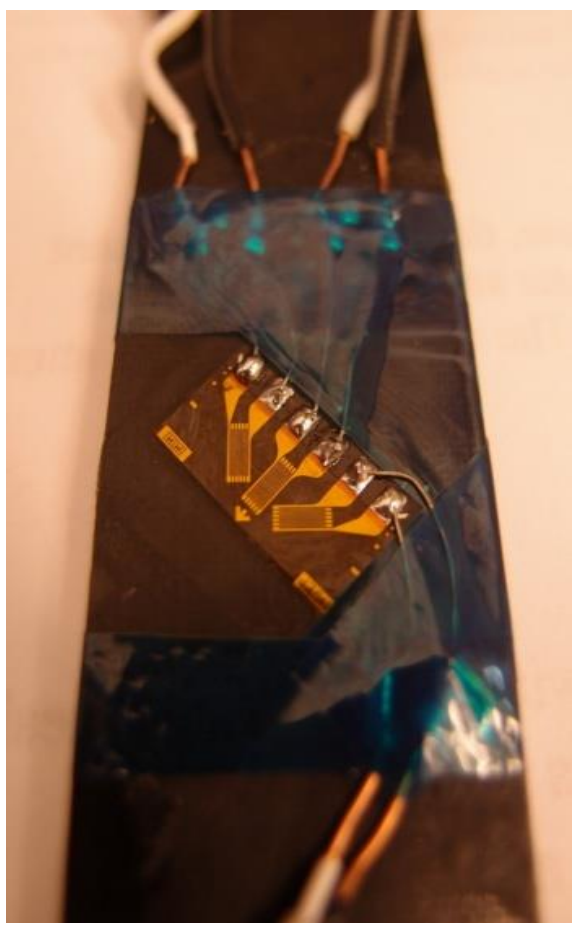

Figure 33. Quasi-isotropic tensile specimen with rectangular rosette strain gage attached

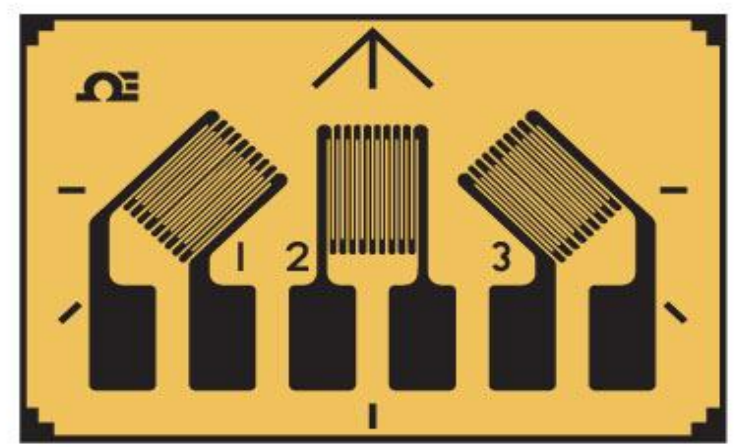

Figure 34. Rectangular rosette strain gage 


\section{Tensile Stress vs Tensile Strain}

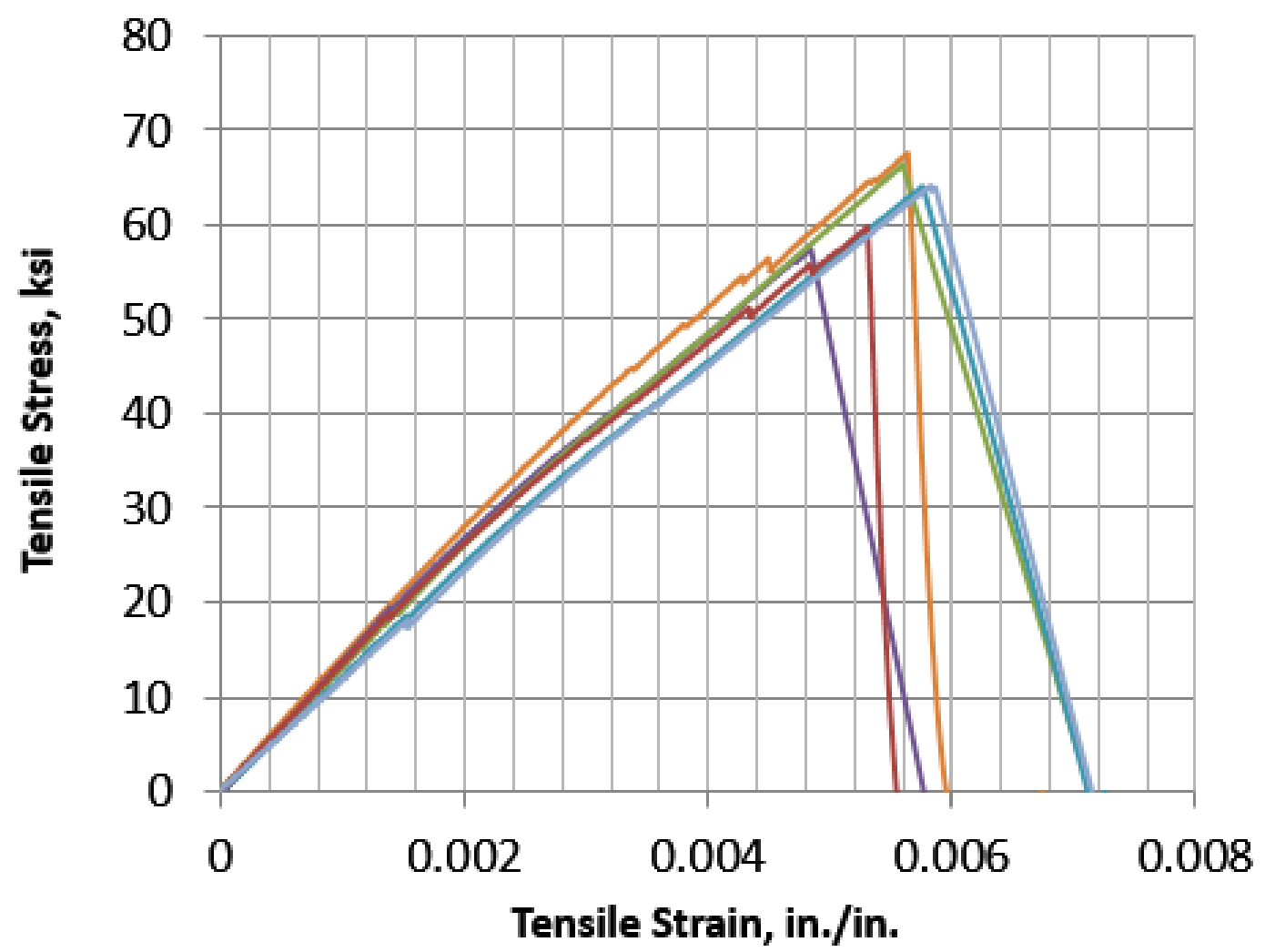

Figure 35. Tensile stress vs. tensile strain of the quasi-isotropic tensile specimens 
Table 8. Quasi-isotropic tensile specimen data

\begin{tabular}{|c|c|c|}
\hline $\begin{array}{c}{[00+45-} \\
45+45-4590 \\
90] s\end{array}$ & $\begin{array}{c}\text { Modulus of } \\
\text { Elasticity } \\
\text { (Extensometer), } \\
\text { msi }\end{array}$ & $\begin{array}{l}\text { Ultimate } \\
\text { Tensile } \\
\text { Strength, } \\
\quad \text { ksi }\end{array}$ \\
\hline S1 & 13.00 & - \\
\hline S2 & 13.00 & 67.5 \\
\hline S3 & 14.20 & 57.5 \\
\hline S4 & 13.47 & 66.4 \\
\hline S5 & 12.09 & 64.1 \\
\hline S6 & 13.41 & 59.7 \\
\hline S7 & 12.02 & 64.0 \\
\hline Average & 13.03 & 58.9 \\
\hline Std. Dev. & 0.85 & 3.87 \\
\hline $\begin{array}{l}\text { Coeff. of } \\
\text { Variance }\end{array}$ & 0.07 & 0.07 \\
\hline $\begin{array}{l}\text { Compared to } \\
\text { Strain Rosette }\end{array}$ & 12.08 & - \\
\hline \% Difference & $8.0 \%$ & - \\
\hline \multicolumn{3}{|c|}{ Extensometer was used up to $2000 \mathrm{lbs}$. } \\
\hline \multicolumn{3}{|c|}{$\begin{array}{c}\text { Length }=10.0 \pm 0.02 \mathrm{in} . \\
\text { Width }=1.03 \pm 0.01 \mathrm{in} . \\
\text { Thickness }=0.1 \pm 0.002 \mathrm{in} . \\
120 \text { grit emery cloth used } \\
\text { Grip Pressure }=160 \mathrm{bar}\end{array}$} \\
\hline
\end{tabular}


5.4.2 Quasi-Isotropic Tensile Specimen \#1 In-Plane Experimental Material Properties

Figure 36 shows experimental strain values of the extensometer, the axial strain gage, the $+45^{\circ}$ strain gage and the transverse strain gage. A slight variation exists between the axial strain gage and the extensometer because the extensometer was not placed in the same location as the strain gage. The sanding error, like stated in the previous section, might have also contributed to the error of $8 \%$. The test was stopped at a force of 2,000 lbs. A linear curve fit was applied to all of the three separate strain gage readings and are shown in Figure 36. Next, the Poisson's ratio of the quasiisotropic tensile specimen was found using Equation (12) and in-plane shear modulus of the quasiisotropic laminate was found using Equation (23). The axial modulus of elasticity was found using Equation (10).

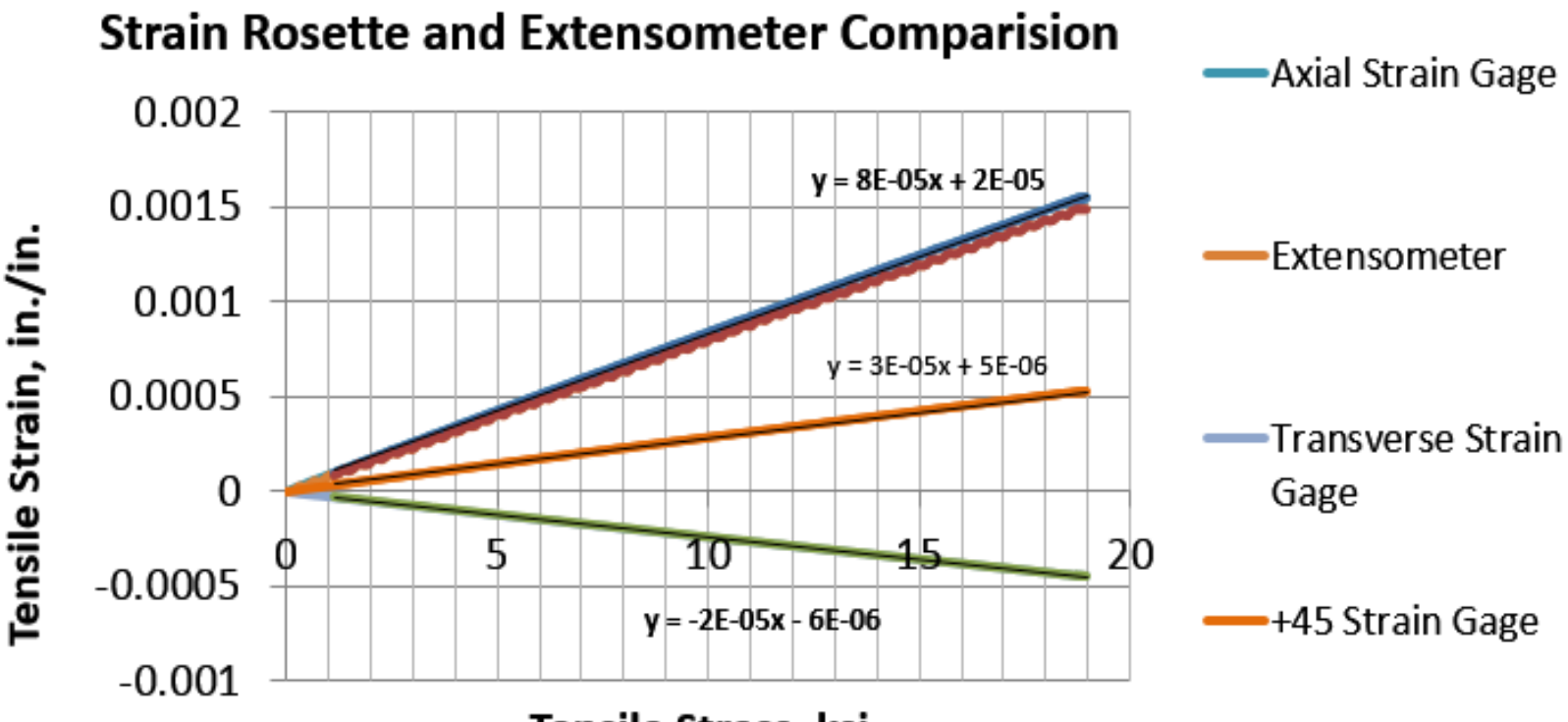

Tensile Stress, ksi

Figure 36. Axial, $+45^{\circ} \&$ transverse strain vs. tensile stress of the quasi-isotropic tensile specimen \#1 


\subsubsection{Quasi-Isotropic Laminate In-Plane Theoretical Material Properties}

The theoretical material properties were found using the NASA report on Basic Mechanics of Laminated Composite Plates ${ }^{[24]}$. In Section 4.2.1, one can find the equations used to calculate the theoretical material properties. Before these equations could be used, a few assumptions were made:

(1) The material to be examined is made of up of one or more plies (layers), each ply consisting of fibers that are all uniformly parallel and continuous across the material. The plies do not have to be of the same thickness or the same material. ${ }^{[23]}$

(2) The material to be examined is in a state of plane stress, i.e., the stresses and strains in the through-the-thickness direction are ignored. ${ }^{[23]}$

(3) The thickness dimension is much smaller than the length and width dimensions. ${ }^{\text {[23] }}$

The values in Table 9 were needed in order to come up with the theoretical material properties. Table 9 shows the values that were applied into the laminate theory since the laminate theory required knowledge of the material properties of one layer of the unidirectional carbon fiber material. With the help of a strain rosette and the use of Equations (13) - (15), all the in-plane principle strains could be found. 
Table 9. Datasheet material properties of one unidirectional carbon fiber ply which was inputted into theoretical analysis

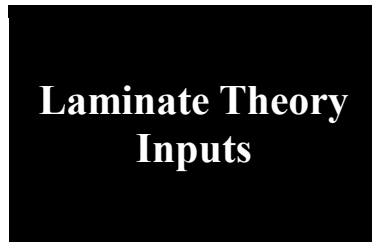

Umeco's MTM 49 Unidirectional ${ }^{[21]}$

$\mathbf{E}$
1
Axial
Modulus,
msi

30.0

$\mathbf{E}_{2}$
Transverse
$\begin{gathered}\text { Modulus, } \\ \text { msi }\end{gathered}$

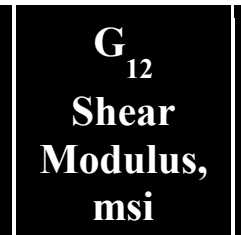

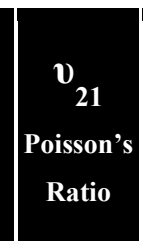

0.9

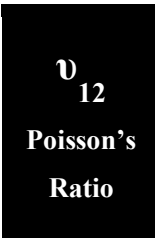

$0.25 \quad 0.0086$

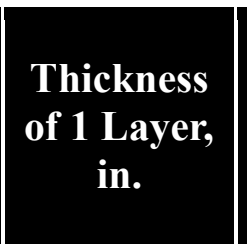

Thickness of

Laminate,

in.

0.006

Below in Table 10, one can see the calculated experimental material properties using the strain gage rosette. Three different in-plane laminate material properties were calculated based on three different force values (1500 lbs., $1750 \mathrm{lbs}$. and $1900 \mathrm{lbs}$.). The theoretical material properties were in agreement with the experimental material properties since the error between the modulus of elasticity was only around $10 \%$ and only $2 \%$ for the Poisson's ratio. The low standard deviation showed the reliability of the testing equipment and the strain measurement devices. 
Table 10. Comparison between experimental and theoretical quasi-isotropic tensile specimen \#1's material properties

\begin{tabular}{|c|c|c|c|}
\hline $\begin{array}{c}\text { Load Used } \\
\text { for Comparison, } \\
\text { lbs. }\end{array}$ & $\begin{array}{c}\mathbf{E}_{\mathbf{1}}=\mathbf{E} \\
\text { Axial \& Tran. } \\
\text { Modulus, } \\
\text { msi }\end{array}$ & $\begin{array}{c}\mathbf{G}_{\mathbf{1 2}} \\
\text { Shear } \\
\text { Modulus, } \\
\text { msi }\end{array}$ & $\begin{array}{c}\mathbf{v}_{\mathbf{1 2}} \\
\text { Poisson' } \\
\mathbf{s} \\
\text { Ratio }\end{array}$ \\
\hline 1500 & 12.03 & 4.663 & 0.291 \\
\hline 1750 & 12.09 & 4.685 & 0.291 \\
\hline 1900 & 12.13 & 4.698 & 0.291 \\
\hline Average & 12.08 & 4.682 & 0.291 \\
\hline Std. Dev. & 0.05 & 0.018 & 0 \\
\hline Theoretical & 11.08 & 4.27 & 0.3 \\
\hline \% Difference & $9.0 \%$ & $9.6 \%$ & $2.3 \%$ \\
\hline
\end{tabular}

5.5 Fiber Volume Fraction Test

ASTM D2584 [27], Standard Test Method for Ignition Loss of Cured Reinforced Resins, was followed closely. Three volume fraction specimens were tested inside the furnace shown on the right in Figure 37. On the left of Figure 37, one can see a fiber volume fraction test specimen. The fiber volume fraction specimen was placed on top of an Aluminum plate. While the furnace was preheated to a temperature of $1000^{\circ} \mathrm{F}$, the Aluminum plate was weighed and each fiber volume fraction specimen was weighed in grams and then converted to lbs. in order to keep the units consistent. The measuring scale had a least scale reading of $0.1 \mathrm{~g}$. The dimensions of each fiber 
volume fraction specimens were carefully measured and recorded. Each specimen was placed on the Aluminum plate and left inside the furnace for one hour. Once all the epoxy burned off, the fiber volume fraction specimen was weighed and this was weight of the fibers. The initial weight of the fiber volume fraction specimen minus the final weight of the fiber volume fraction specimen was the weight of the resin (matrix). After doing some simple calculations, along with using the cured resin matrix density of $1.24 \mathrm{~g} / \mathrm{cm}^{3}$ (from the material's datasheet); the fiber weight fraction along with the fiber volume fraction was calculated and compared to the datasheet.

In Table 11, one can see the three different fiber volume fractions along with the fiber weight fractions. The fiber volume fraction specimen dimensions are crucial to the determination of the fiber volume fraction. The measured thickness of the fiber volume fraction specimen varied from 0.1 in. to 0.103 in., which meant that the heat press cooked unevenly. The slight variation of the specimen's thickness affected the volume fraction by $4 \%$. The $8.3 \%$ difference between the experimental fiber volume fraction and the datasheet fiber volume fraction varied because not enough pressure was applied to the laminate during the curing process. The lower fiber volume fraction of 0.55 compared to 0.6 meant that there was more resin in the laminate. Not enough resin was squeezed out in the cure process. The pressure applied by the heat press was limited, so achieving the optimum fiber volume fraction (of 0.6) was difficult. The fiber volume fraction significantly affected all of the material property testing which was conducted on the Umeco MTM 49 unidirectional material. A low standard deviation showed that the data was very consistent. 

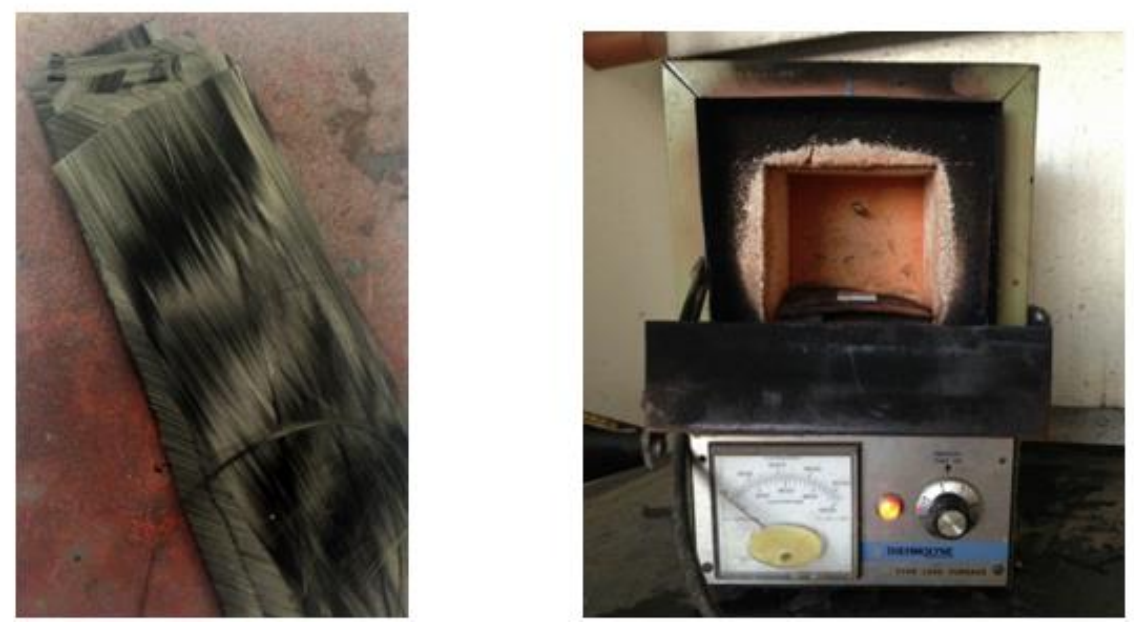

Figure 37. Resin-free fiber volume fraction specimen (left) furnace used to burn off resin (right)

Table 11. Fiber volume fraction specimen data

\begin{tabular}{|c|c|c|c|c|c|c|c|c|}
\hline & $\begin{array}{l}\text { Length, } \\
\text { in. }\end{array}$ & $\begin{array}{l}\text { Width, } \\
\text { in. }\end{array}$ & $\begin{array}{c}\text { Thickness, } \\
\text { in. }\end{array}$ & $\begin{array}{c}\text { Initial } \\
\text { Specimen } \\
\text { Volume, } \\
\text { in }^{3}\end{array}$ & $\begin{array}{c}\text { Initial } \\
\text { Weight, } \\
\text { lbs. }\end{array}$ & $\begin{array}{c}\text { Final } \\
\text { Weight, } \\
\text { lbs. }\end{array}$ & $\begin{array}{c}\text { Fiber } \\
\text { Volume } \\
\text { Fraction }\end{array}$ & $\begin{array}{c}\text { Fiber } \\
\text { Weight } \\
\text { Fraction }\end{array}$ \\
\hline S1 & 4.665 & 1.049 & 0.103 & 0.504 & 0.0272 & 0.0172 & 0.551 & 0.629 \\
\hline $\mathbf{S 2}$ & 4.662 & 1.004 & 0.103 & 0.482 & 0.0268 & 0.0172 & 0.551 & 0.639 \\
\hline S3 & 4.671 & 1.047 & 0.102 & 0.499 & 0.0268 & 0.0167 & 0.547 & 0.622 \\
\hline Average & & & & & & & 0.550 & 0.630 \\
\hline Std. Dev. & & & & & & & 0.002 & 0.009 \\
\hline $\begin{array}{c}\text { Datasheet } \\
{[21]}\end{array}$ & & & & & & & 0.60 & \\
\hline$\%$ Difference & & & & & & & $8.3 \%$ & \\
\hline
\end{tabular}


Section 5.6 was conducted in order to validate the numerical model with the experimental data. Modeling a metal before modeling a composite is very important because metals behave in a more predictable fashion. Metals are a lot simpler to model since they exhibit isotropic behavior whereas composites exhibit orthotropic behavior. The material property inputs for an isotropic material are much less than for a composite material. For a composite, the user has to input three different moduli of elasticity, three moduli of rigidity, and three Poisson's ratios. For metals, the user only inputs the modulus of elasticity and the Poisson's ratio. In this validation, Aluminum 2024-T4 was used as the material of choice. Once the linear elastic model was validated with a metal, then any other material should be validated as well, but only for the linear elastic region of the material. This also validates the boundary conditions and any interactions, which were used in the numerical model.

\subsection{Aluminum 2024-T4 Double Shear Test}

The Aluminum 2024-T4 double shear specimens were tested on the same double shear fixture as the composite double shear specimens. From Figure 38, one can see the bearing stress vs. bearing strain response of the five tested Aluminum double shear specimens. The first section of the bearing stress vs. bearing strain plot (the flat initial region) is the strain correction region. Compliance between the Instron parts, along with the clamps, occurred upon initial loading of the specimen. The deformation of all the internal parts of the Instron machine in the strain correction region. The linear elastic region, (shown inside the red square in Figure 38) for the Aluminum, was between $5 \mathrm{ksi}$ and $40 \mathrm{ksi}$ and after this region; the material experienced a non-linear behavior 
up to its ultimate bearing strength. The strain correction region and the non-linear region were removed, which can be seen in Figure 39. The non-linear region and the strain correction region were not part of the numerical model.

Figure 38 showed that specimen \#5 failed at an ultimate bearing stress of $130 \mathrm{ksi}$ and the other four specimens failed around $114 \mathrm{ksi}$. The extensometer's knife-edge slipped on the face of specimen \#1 through \#4, but for specimen \#5, the extensometer did not slip. The linear elastic region can be seen in Figure 39. The specimen alignment might have caused the variations in the linear elastic strain values. The ultimate bearing strength matched up the Aluminum 2024-T4 material's datasheet ${ }^{[25]}$. Table 12 shows the experimental results of the Aluminum double shear specimens. Both the yield and ultimate strengths were calculated in the Table 12. Figure 40 shows a bearing type of failure, which occurred in all the Aluminum double shear specimens. Figure 41 shows the Aluminum double shear specimens before and after they were tested. The region circled in red shows the area where the failure occurred. Each specimens' hole diameter increased in size and also each specimens' hole diameter did not go back to its original shape once the load was removed, which showed that the material reached a plastic deformation. 


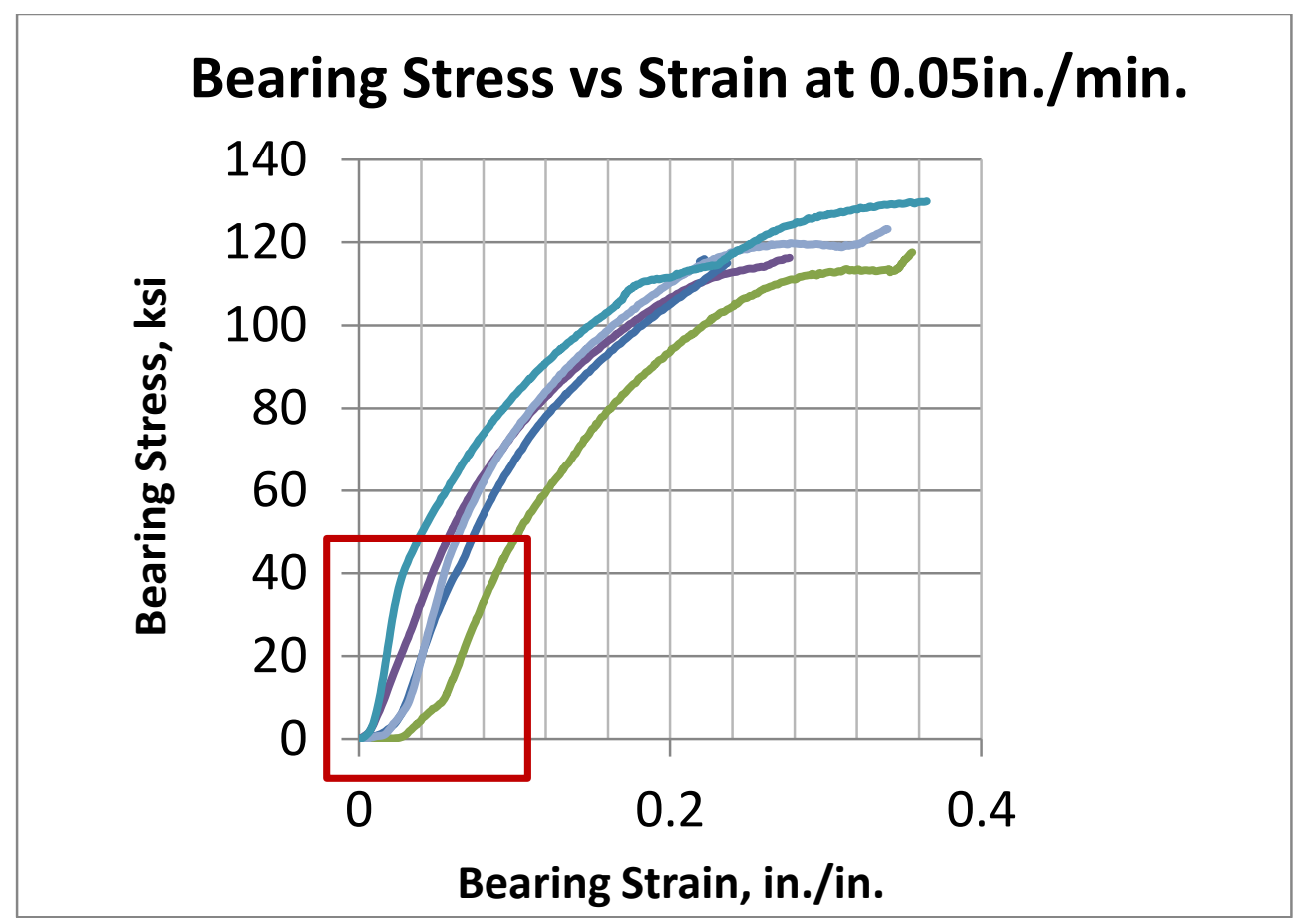

Figure 38. Bearing stress vs. bearing strain response of (5) aluminum 2024-T4 double shear specimens

\section{Linear Bearing Stress Region vs Strain}

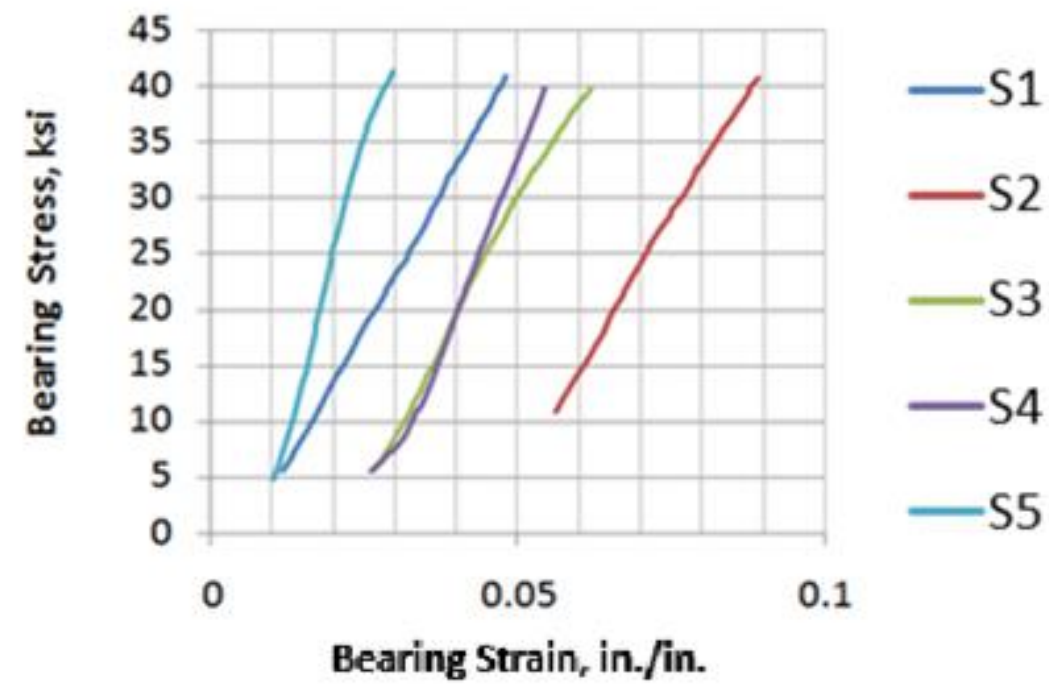

Figure 39. Bearing stress vs. bearing strain response of (5) aluminum 2024-T4 double shear specimens with strain correction region and non-linear region removed 
Table 12. Aluminum 2024-T4 double shear specimen data

\begin{tabular}{|c|c|c|}
\hline $\begin{array}{c}\text { Aluminum } \\
\text { 2024-T4 }\end{array}$ & $\begin{array}{l}\text { Bearing } \\
\text { Yield } \\
\text { Strength, } \\
\quad \text { ksi }\end{array}$ & $\begin{array}{l}\text { Ult. } \\
\text { Bearing } \\
\text { Strength, } \\
\text { ksi }\end{array}$ \\
\hline S1 & 40.1 & 114.0 \\
\hline S2 & 40.2 & 113.1 \\
\hline S3 & 38.2 & 113.4 \\
\hline S4 & 40.6 & 119.4 \\
\hline S5 & 37.5 & 130.3 \\
\hline Average & 39.32 & 118.0 \\
\hline Std. Dev. & 1.38 & 7.32 \\
\hline $\begin{array}{l}\text { Coeff. of } \\
\text { Variance }\end{array}$ & 0.035 & 0.062 \\
\hline \multicolumn{3}{|c|}{$\begin{array}{c}W / D=6.00 \pm 0.02 E / D=3.00 \pm 0.01 \\
D / h=4.03 \pm 0.01 \\
\text { Grip Pressure }=160 \mathrm{bar}\end{array}$} \\
\hline
\end{tabular}




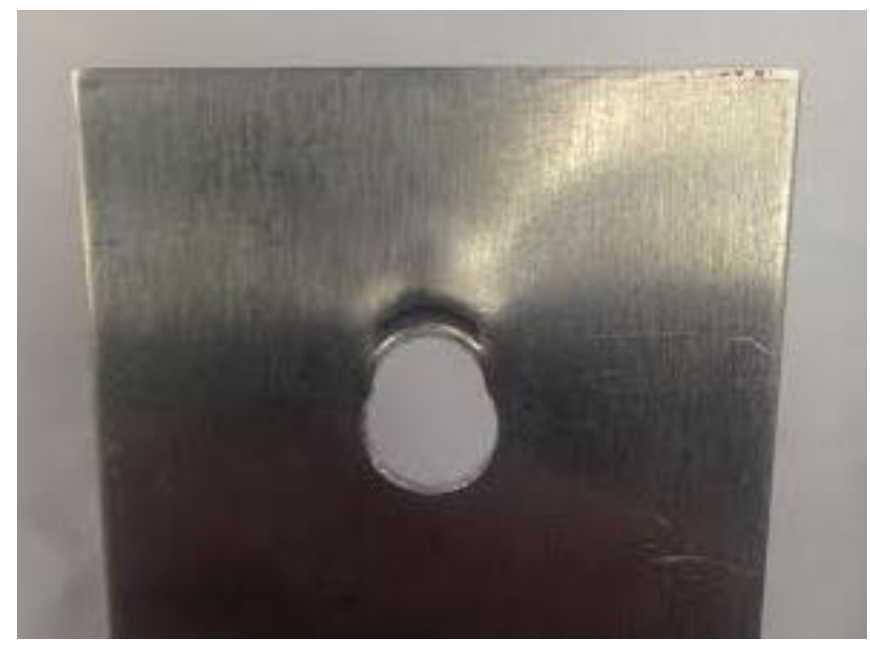

Figure 40. Example of a bearing failure of an aluminum 2024-T4 double shear specimen
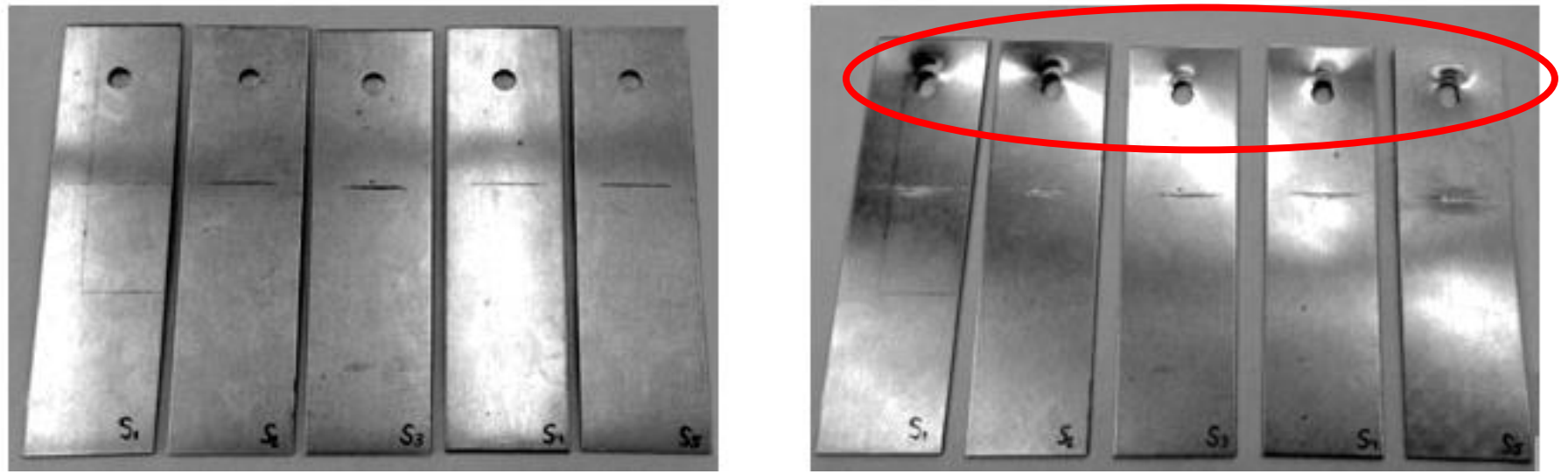

Figure 41. Aluminum 2024-T4 double shear specimens before test (left) aluminum 2024-T4 double shear specimens after test (right)

\subsection{Composite Double Shear Test}

As one can see in Figure 42 (from a paper by Yi Xiao ${ }^{[28]}$ ), the composite double shear specimens behaved differently than Aluminum double shear specimens. Recall, all the composite double shear specimens were manufactured with a quasi-isotropic laminate orientation of $[00+45$ 
$-45+45-459090]_{s}$. The $4 \% \mathrm{D}$ is considered the bearing strength of the material. The composite double shear specimens held load (without failing) up to the knee point. At the knee point, the first ply failed (after this point, the material properties started to degrade) and the slope of the curve was reduced. The load increased up to the final point, also known as the ultimate bearing strength of the material, where it maxed out. One positive thing about designing a structure to fail in bearing, as opposed to net-tension or shear-out, is that the force dropped $30 \%$ of the maximum load. Whereas, in net-tension or shear-out failure, the load dropped down to zero.

\section{Summary of the Idealized Bearing Response of Unidirectional CF}

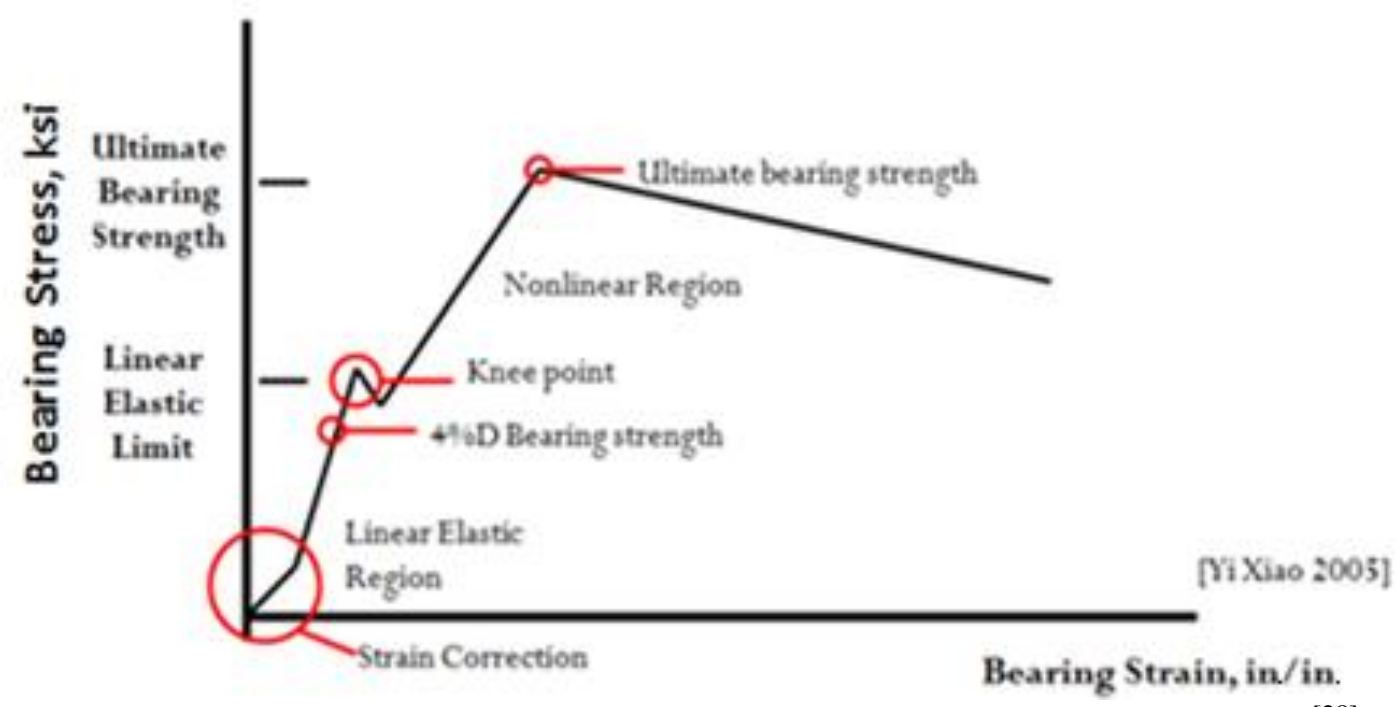

Figure 42. Summary of bearing response of a carbon fiber material by Yi Xiao ${ }^{[28]}$

Figure 43 shows a close-up of the bearing failure, which occurred on the composite double 
shear specimens. As one can see, there is an excessive amount of damage near the pin location. All of the specimens exhibited a similar type of failure, so there was no need to take a picture of each of the failed specimens. Figure 44 shows ASTM 5961's ${ }^{[18]}$ failure codes used to characterize any of the failure modes seen in a composite double shear test. The failure code, B1I, is used throughout the rest of the experimental section, which signifies a bearing type of failure.

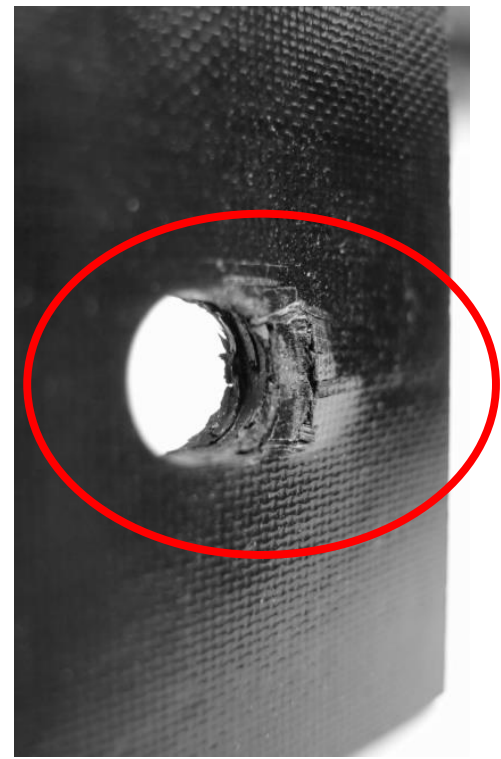

Figure 43. Example of bearing failure where the fibers end up crushing near the pin location 


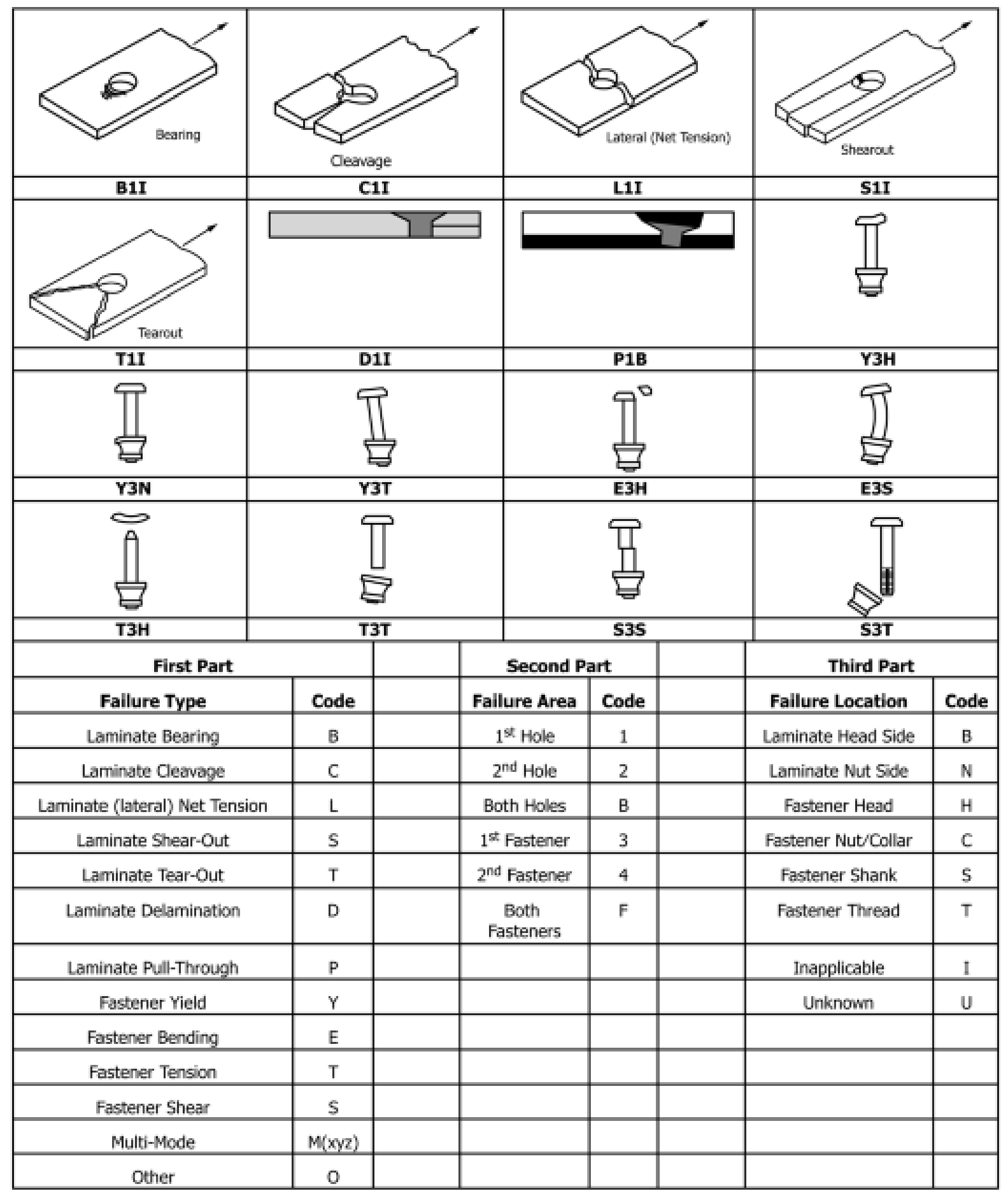

Figure 44. ASTM 5961- bearing test failure codes with illustrations of common modes 
5.7.1 Curing Cycle 1 (Cytec's MTM 49 Unidirectional Carbon Fiber Cure Cycle) for Double Shear Test

Figure 45 shows the composite double shear specimens before and after the double shear test. In Figure 45, on the right, highlights the crushing regions, in red. All the failures are consistent. Eight specimens were tested for each of the five loading rates. For load rate $0.1 \mathrm{in} . / \mathrm{min}$, the extensometer significantly slipped on specimen \#8, which is why the data was removed.
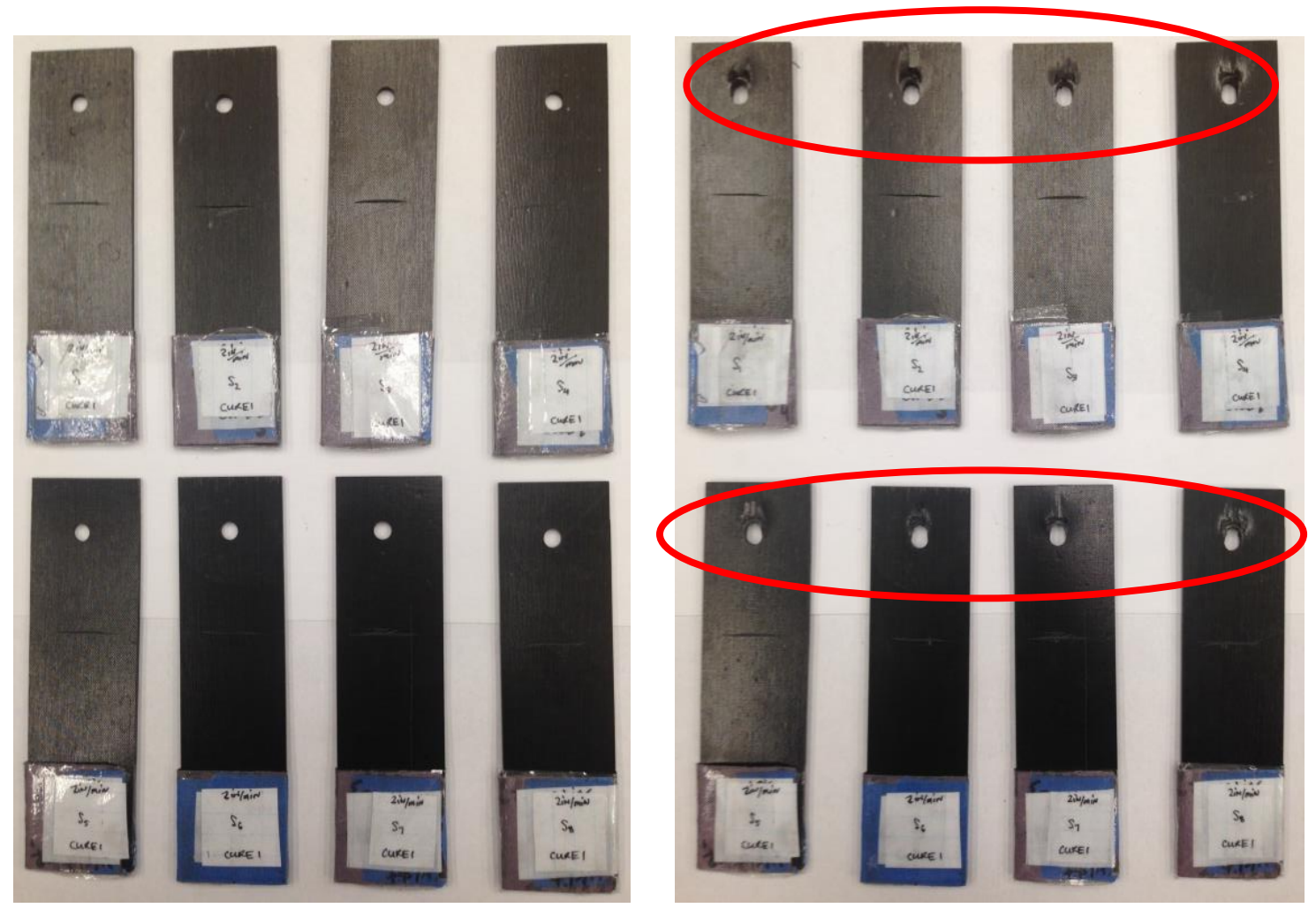

Figure 45. Carbon fiber double shear specimens before test (left) carbon fiber double shear specimens after test (right)

When looking at the alternate cure cycle experimental data, in Tables $13 \& 14$, an interesting 
trend appeared. At slower loading rates, the composite double shear specimens performed slightly better than at higher loading rates. At $0.05 \mathrm{in} . / \mathrm{min}$. and $0.1 \mathrm{in} . / \mathrm{min}$. the composite double shear specimens failed at an average stress of $64.4 \mathrm{ksi}$ and $63.5 \mathrm{ksi}$ whereas at $1 \mathrm{in} . / \mathrm{min} ., 2 \mathrm{in} . / \mathrm{min}$. and $6 \mathrm{in} . / \mathrm{min}$. the composite double shear specimens failed around $52.3 \mathrm{ksi}$. Looking at all the different loading rates, it seemed as if all the composite double shear specimens had a similar knee point. 2 in./min. and 6in./min. showed a greater drop in load after the composite double shear specimens reached their ultimate load. Loading rates $0.05 \mathrm{in} . / \mathrm{min}$. and $0.1 \mathrm{in} . / \mathrm{min}$. did not show a huge drop in load after the specimens reached the ultimate load. 
Table 13. Cure 1 composite double shear specimen data

\begin{tabular}{|c|c|c|c|}
\hline Cure 1 & $0.05 \mathrm{in} . / \mathrm{min}$. & $0.1 \mathrm{in} . / \mathrm{min}$. & $1.0 \mathrm{in} . / \mathrm{min}$. \\
\hline $\begin{array}{c}\text { Alternate } \\
\text { Cure [22] }\end{array}$ & $\begin{array}{c}\text { Ultimate } \\
\text { Bearing } \\
\text { Strength, } \\
\text { ksi }\end{array}$ & $\begin{array}{c}\text { Ultimate } \\
\text { Bearing } \\
\text { Strength, } \\
\text { ksi }\end{array}$ & $\begin{array}{c}\text { Ultimate } \\
\text { Bearing } \\
\text { Strength, } \\
\text { ksi }\end{array}$ \\
\hline S1 & 67.8 & 63.9 & 52.8 \\
\hline S2 & 70.5 & 62.1 & 48.0 \\
\hline S3 & 64.8 & 67.7 & 48.8 \\
\hline S4 & 66.8 & 60.8 & 53.4 \\
\hline S5 & 66.2 & 66.1 & 52.9 \\
\hline S6 & 61.7 & 62.8 & 54.3 \\
\hline S7 & 63.2 & 61.1 & 56.5 \\
\hline S8 & 54.1 & $*$ & 0.091 \\
\hline Average & 64.4 & 63.5 & 52.3 \\
\hline Std. Dev. & 4.97 & 2.58 & 2.80 \\
\hline Coeff. of Variance & 0.008 & 0.004 & 0.050 \\
\hline \multicolumn{4}{|c|}{$W / D=6.00 \pm 0.02 E / D=3.00 \pm 0.01 D / h=4.03 \pm 0.01$} \\
\hline \multicolumn{4}{|c|}{$\begin{array}{l}\text { Grip Pressure }=160 \text { bar } \\
*^{*} \text { Excluded due to excessive extensometer slippage. }\end{array}$} \\
\hline
\end{tabular}


Table 14. Cure 1 composite double shear specimen data continued

\begin{tabular}{|c|c|c|}
\hline Cure 1 & $\mathbf{2 . 0}$ in./min. & $\mathbf{6 . 0}$ in./min. \\
\hline $\begin{array}{c}\text { Alternate } \\
\text { Cure }{ }^{\text {22] }}\end{array}$ & $\begin{array}{c}\text { Ultimate } \\
\text { Bearing } \\
\text { Strength, } \\
\text { ksi }\end{array}$ & $\begin{array}{c}\text { Ultimate } \\
\text { Bearing } \\
\text { Strength, } \\
\text { ksi }\end{array}$ \\
\hline S1 & 51.7 & 49.4 \\
\hline S2 & 51.7 & 50.2 \\
\hline S3 & 53.9 & 51.4 \\
\hline S4 & 51.8 & 49.3 \\
\hline S5 & 54.0 & 50.9 \\
\hline S6 & 51.7 & 47.8 \\
\hline S7 & 54.1 & 52.0 \\
\hline S8 & 50.8 & 48.9 \\
\hline Average & $\mathbf{5 2 . 5}$ & $\mathbf{4 9 . 9}$ \\
\hline Std. Dev. & 1.3 & 1.4 \\
\hline Coeff. of Variance & 0.030 & 0.028 \\
\hline
\end{tabular}

The maximum values of all the plots, in Figure 46, were the ultimate bearing strengths. When looking at Figure 46, one can see that as the loading rate increased the non-linear region decreased in size. The red-circled sections, in Figure 46, show how the non-linear region decreased in size. The linear region does not change as drastically as the non-linear region. As the load rate increased, the rate of damage also increased which explained the reduction, in size, of the non-linear region. 
Looking at all of the load rates, the moduli in the non-linear regions are lower than the linear elastic regions. There was no standard equation or method of finding the actual knee point of the material, so only the ultimate bearing strength was analyzed.
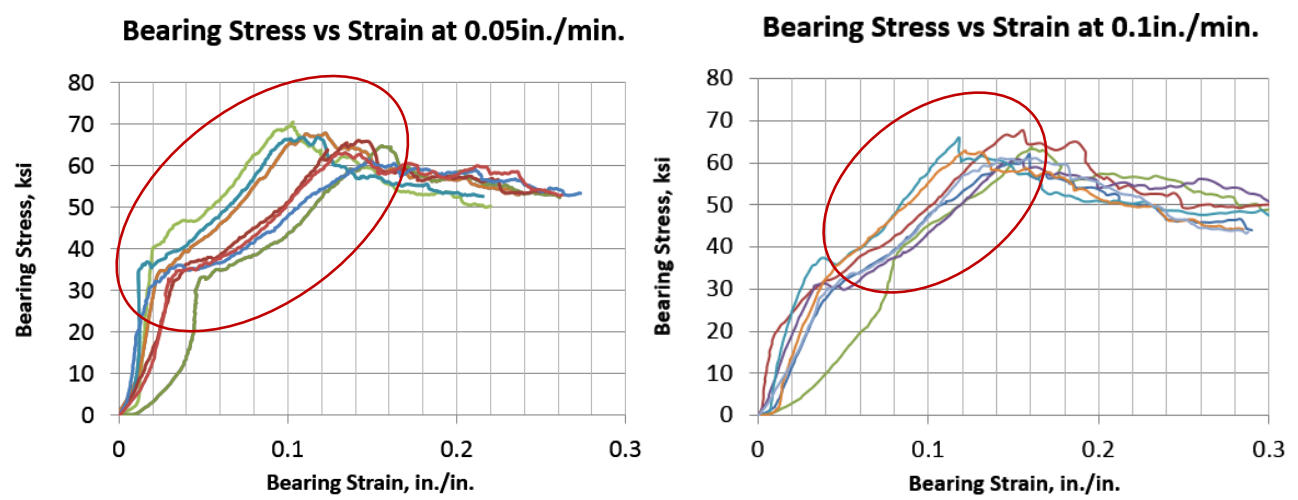

Bearing Stress vs Strain at 1in./min.

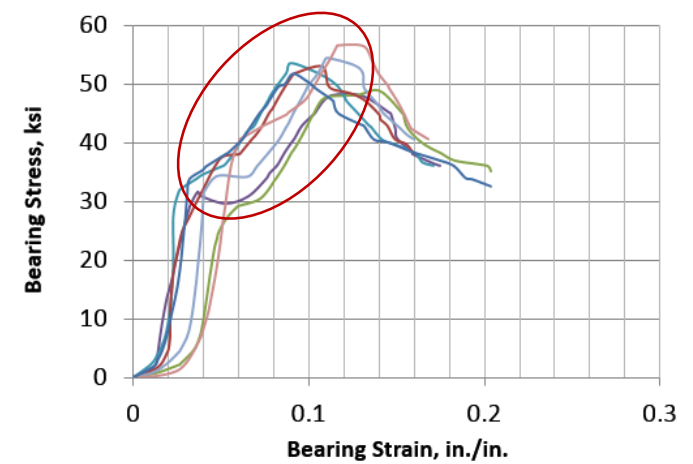

Bearing Stress vs Strain at 2in./min.

Bearing Stress vs Strain at 6in./min.
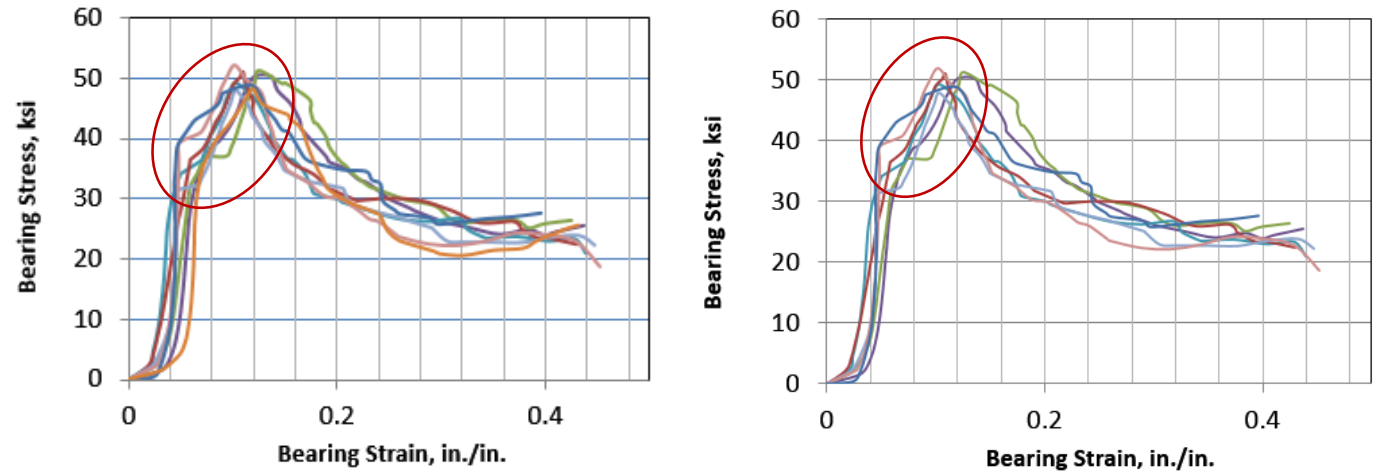

Figure 46. Cure 1 (alternate cure) bearing stress vs. bearing strain response five speed rates: $0.05 \mathrm{in.} / \mathrm{min} ., 0.1 \mathrm{in.} / \mathrm{min} ., 1 \mathrm{in} . / \mathrm{min} ., 2 \mathrm{in.} / \mathrm{min} . \& 6 \mathrm{in.} / \mathrm{min}$. 
5.7.2 Curing Cycle 2 (Umeco's MTM 49 Unidirectional Carbon Fiber Cure Cycle) for Double Shear Test

When looking at the datasheet cure cycle experimental data, in Tables $15 \& 16$, a similar trend appeared. At slower loading rates, the double shear specimens performed slightly better than at higher loading rates. At $0.05 \mathrm{in} . / \mathrm{min}$. and $0.1 \mathrm{in} . / \mathrm{min}$., the specimens failed at an average stress of $62.7 \mathrm{ksi}$ and $67.7 \mathrm{ksi}$, whereas at $1.0 \mathrm{in} . / \mathrm{min} ., 2 \mathrm{in} . / \mathrm{min}$. and $6 \mathrm{in} . / \mathrm{min}$., the specimens failed around or under $52.0 \mathrm{ksi}$. It also looks like at $2 \mathrm{in} . / \mathrm{min}$. and $6 \mathrm{in} / \mathrm{min}$. show a greater drop in bearing strength after the specimen reaches its ultimate load. Loading rates $0.05 \mathrm{in} . / \mathrm{min}$. and $0.1 \mathrm{in} . / \mathrm{min}$. do not show a huge drop in strength after the specimens reach the ultimate load. In general, fast loading causes more damage to the specimen which overall reduces the specimen's ability to carry load. There was no standard equation or method of finding the actual knee point of the material, so only the ultimate bearing strength was analyzed. Eight specimens were tested for each of the five loading rates. For load rates $2 \& 6$ in./min, the extensometer significantly slipped on specimen \#8, which is why the data was removed. 
Table 15. Cure 2 composite double shear specimen data

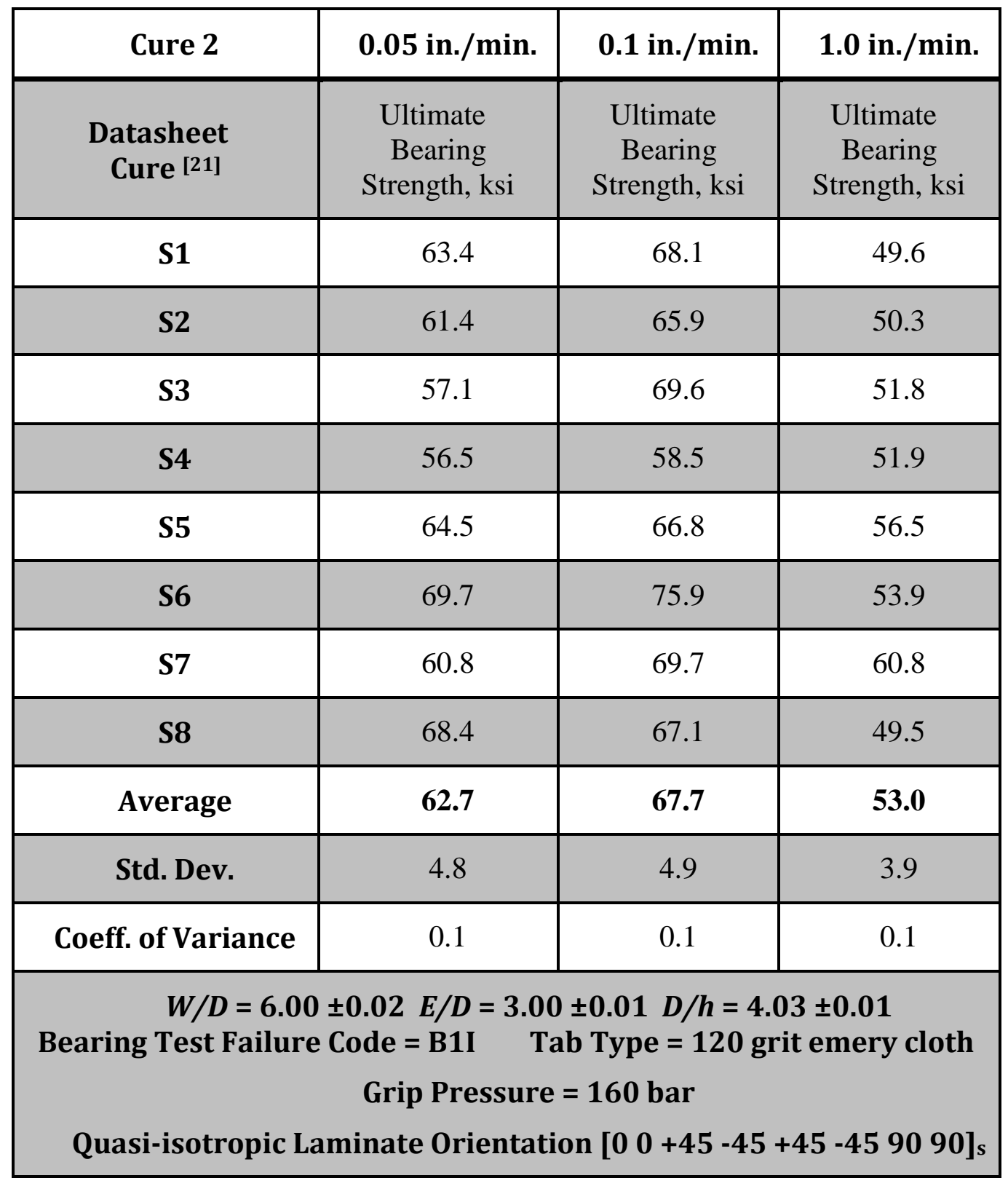


Table 16. Cure 2 composite double shear specimen data continued

\begin{tabular}{|c|c|c|}
\hline Cure 2 & $\mathbf{2 . 0}$ in./min. & 6.0 in./min. \\
\hline $\begin{array}{c}\text { Datasheet } \\
\text { Cure [21] }\end{array}$ & $\begin{array}{c}\text { Ultimate } \\
\text { Bearing } \\
\text { Strength, } \\
\text { ksi }\end{array}$ & $\begin{array}{c}\text { Ultimate } \\
\text { Bearing } \\
\text { Strength, } \\
\text { ksi }\end{array}$ \\
\hline S1 & 52.2 & 52.6 \\
\hline S2 & 51.8 & 49.0 \\
\hline S3 & 49.6 & 51.9 \\
\hline S4 & 54.0 & 49.5 \\
\hline S5 & 49.5 & 51.7 \\
\hline S6 & 47.3 & 51.9 \\
\hline S7 & 51.8 & 52.0 \\
\hline Average & $\mathbf{5 0 . 9}$ & $\mathbf{5 1 . 3}$ \\
\hline Std. Dev. & 2.2 & 1.4 \\
\hline Coeff. of Variance & 0.001 & 0.001 \\
\hline
\end{tabular}

When looking at Figure 47, one can see that as the loading rate increased the non-linear region decreased in size. In Figure 47, the red-circled section also showed the non-linear region decreased, in size, with increased loading rate. 

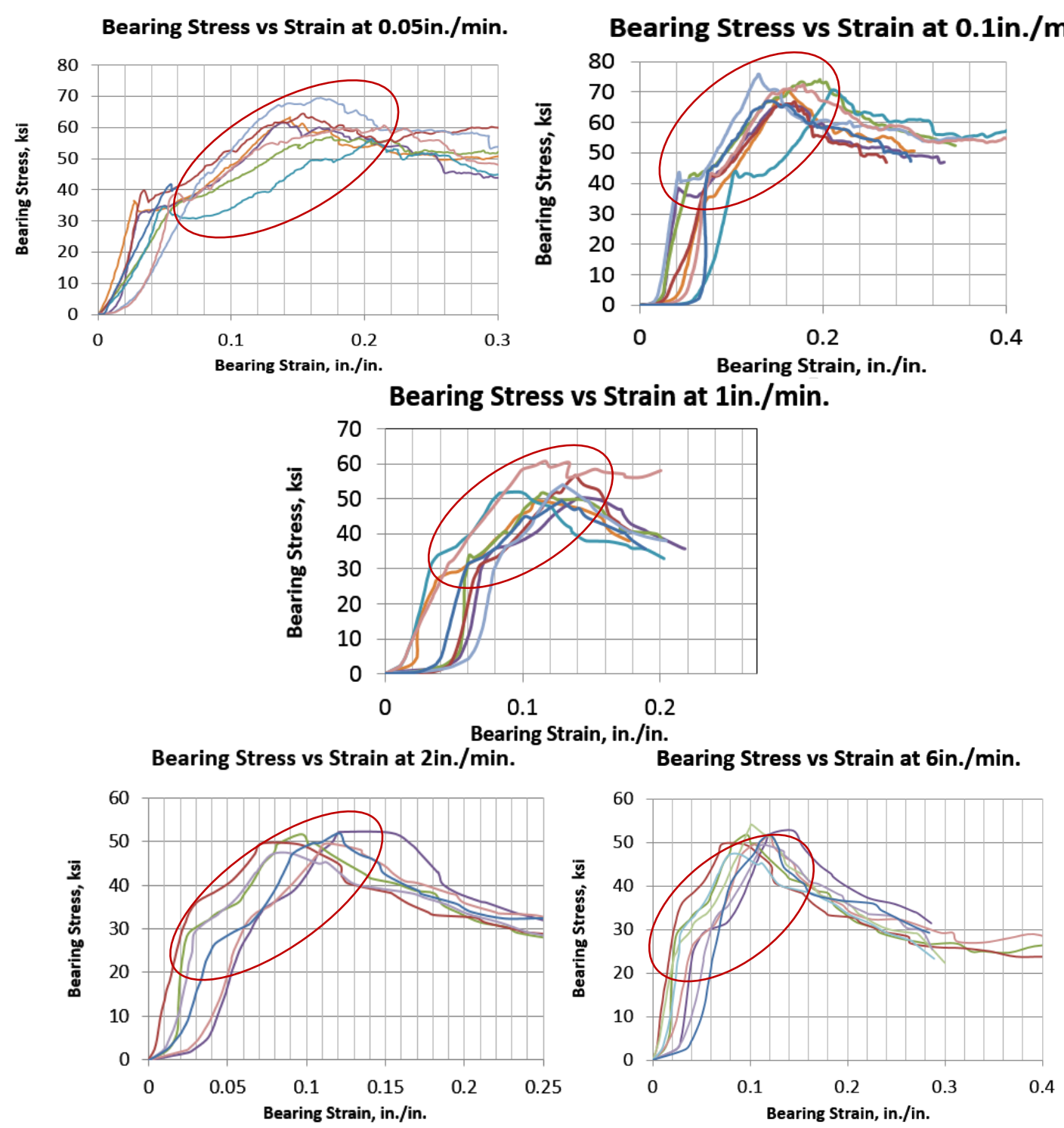

Figure 47. Cure 2 (datasheet cure) bearing stress vs. bearing strain response five speed rates: $0.05 \mathrm{in.} / \mathrm{min} ., 0.1 \mathrm{in.} / \mathrm{min} ., 1 \mathrm{in} . / \mathrm{min} ., 2 \mathrm{in.} / \mathrm{min} . \& 6 \mathrm{in.} / \mathrm{min}$.

5.7.3 Comparison between Cure $1 \&$ Cure 2

In Figure 48, it is very clear that as loading rate increased, the ultimate bearing strength of the 
material decreased regardless of the cure cycle. Further research can be done on how different cure cycles can affect the bearing response of a composite double shear specimen. Making the matrix less brittle and more ductile might improve the ultimate bearing strength of the material. Cure cycle 2 (Umeco's cure cycle) was $2 \%$ stronger in bearing when compared to the cure cycle 1 (Cytec's cure cycle). The MTM 49 Unidirectional carbon fiber pre-preg material was very sturdy by not being affected by an alternate cure cycle.

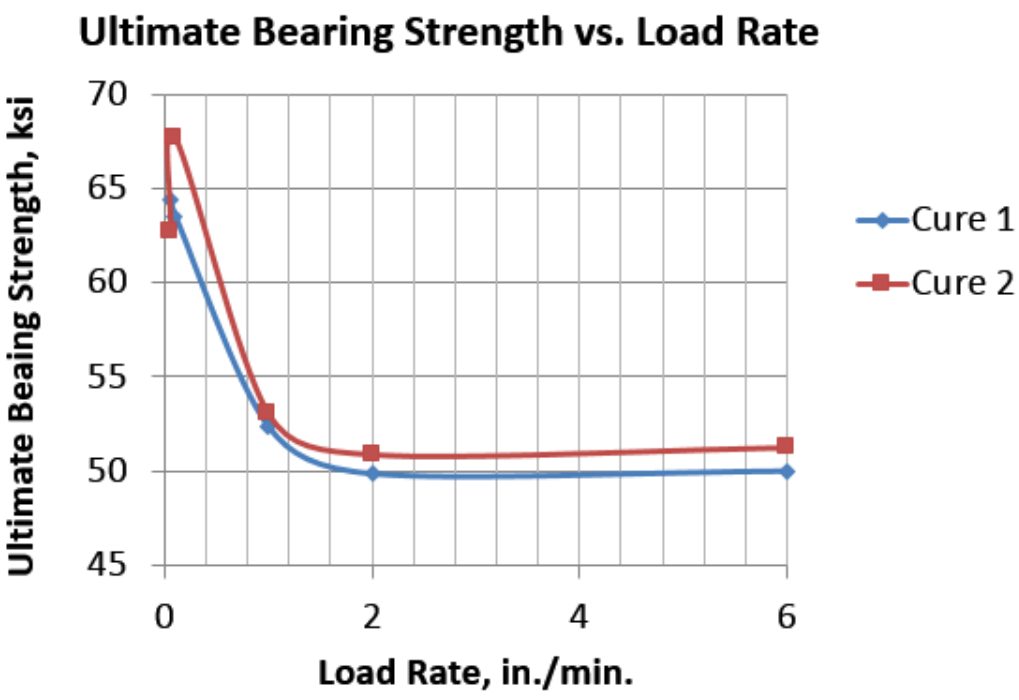

Figure 48. Ultimate bearing strength comparison between both cure cycles

5.7.4 Comparison Between The Aluminum Double Shear Specimens \& Quasi-Statically Loaded (0.05 in./min.) Composite Double Shear Specimens

Aluminum is standardly tested at quasi-static load rate of $0.05 \mathrm{in} . / \mathrm{min}$, since it's strain rate independent ${ }^{[30]}$ (not affected by different loading rates). The Aluminum double shear specimens 95 
performed a lot better in bearing than the composite double shear specimens. Since the carbon fiber is more brittle by nature, its ultimate bearing strength is significantly lower than Aluminum. of the Aluminum double shear specimens was around $118 \mathrm{ksi}$ and the ultimate bearing strength of the composite double shear specimens was around $63 \mathrm{ksi}$. That means that carbon fiber is $53 \%$ weaker than Aluminum 2024-T4 in a double shear joint configuration. The Aluminum double shear specimens yielded at around $40 \mathrm{ksi}$ compared to the composite double shear specimens, which yielded at $30 \mathrm{ksi}$. As one can see from the bearing stress vs. bearing strain graphs, there is a huge difference in ultimate bearing strength between of both materials. It is interesting to note that both materials showed a strain correction region. The Aluminum double shear specimens and the composite double shear specimens did not catastrophically fail (they deformed without significantly dropping the applied load). 


\section{CHAPTER 6: NUMERICAL ANALYSIS}

Chapter 6 explains the overall finite element approach. Section 1 introduces the finite element model and different considerations, which were applied to the model. Section 2 explains the idea behind a convergence plot and its importance. Section 2 explains what factors influenced the numerical results.

\subsection{Finite Element Analysis Introduction}

Once a Finite Element Analysis model is validated with experimental results, it can then be used in the design process. Abaqus 6.14-1 was used to model the double shear bearing test experiment conducted. All the different Finite Element software work very similarly and the only difference between them is their program interface. However, they all essentially break up the model into small elements and calculate the stress state on each element. The material properties are assigned to the elements and then, the boundary conditions and loads are applied to the model. In some cases when there are two or more parts, one might have to define different types of interactions or constraints for the model (for example, how those parts move relative to each other). The numerical software also predicts non-linear behavior, which requires a lot more material properties. Plasticity required the user to model the damage done on the material as load increased, which meant, implementing a degradation model.

First, a numerical model was created and validated for the Aluminum 2024-T4 double shear 
specimen. The Aluminum numerical model was only validated through the linear elastic region of the experimental data, which was shown in Figure 39. The Aluminum numerical model was adjusted for the composite specimen and the experimental results were compared to the numerical results.

Abaqus keeps the units consistent, so when working with US Customary units make sure to stay consistent with the units, if using inches, stick to using inches. The displacement plots should be in the same units as one started with, and the stresses should be in pounds per square inch (psi).

\subsubsection{Geometric Definitions}

The numerical model contained four parts. The two side plates, double shear specimen, and pin were modeled as deformable 3D solids. Both steel plates along with the double shear specimen were partitioned. The steel collars and center middle plate were neglected for simplicity. All the bolts, nuts and washers were also neglected in the model for simplicity reasons.

\subsubsection{Material Creation, Section Assignments, \& Meshing}

All the dimensions were defined in English units and the dimensions for each of the parts came from the fixture design. The fixture used in the numerical model was simplified. All the composite material properties were inputted in the elastic engineering constants. Table 17 showed the material properties, which were, applied to the Aluminum numerical model. A Steel solid homogeneous section and an Aluminum solid homogeneous section were created. 
Table 17. Abaqus model inputs

\begin{tabular}{|c|c|c|c|c|}
\hline Abaqus Parts & $\begin{array}{c}\mathbf{E} \\
\text { Modulus, } \\
\text { msi }\end{array}$ & $\begin{array}{c}\text { v } \\
\text { Poisson's } \\
\text { Ratio }\end{array}$ & Section Type & Element Type \\
\hline $\begin{array}{c}\text { Aluminum 2024- } \\
\text { T4 Specimen }\end{array}$ & 10.0 & 0.25 & Solid, Homogeneous & C3D8: 8-node linear brick. \\
\hline Steel pin & 34.0 & 0.30 & Solid, Homogeneous & $\begin{array}{r}\text { C3D10: 10-node quadratic } \\
\text { tetrahedron. }\end{array}$ \\
\hline Steel side plates & 34.0 & 0.30 & Solid, Homogeneous & $\begin{array}{r}\text { C3D8R: 8-node linear brick, reduced } \\
\text { int., hourglass control. }\end{array}$ \\
\hline
\end{tabular}

A composite layup section was applied to the composite double shear specimen and the element type was set to solid. Table 18 shows the material properties that were applied to the composite double shear specimen. In the composite layup section, the user is able to set the element stacking direction, the coordinate system, and the rotation axis. The user can also specify the laminate orientation and select the region for each ply within the model. In the Appendix, there is a tutorial of how the Abaqus composite double shear specimen was modeled.

A single layer of unidirectional carbon fiber material is considered a transversely orthotropic material, where $E_{2}$ is equal to $E_{3}$ and $G_{12}$ is equal to $G_{13}$. $E_{2}$ and $E_{3}$ are both considered the matrix and $E_{1}$ is considered the fiber. One thing to note was that the compressive modulus in the 1 direction (axial) was slightly lower than the tensile modulus, which was found in the Experimental section of the report. The Poisson's ratio in the 23-direction and the shear modulus in the 23direction are usually very difficult to find experimentally. Autodesk's Simulation Composite Analysis 2015 Material Manager was used to find some of the material properties that could not 
be found experimentally. In the Appendix, one can find the tutorial on how to use Autodesk's Simulation Composite Analysis 2015 Material Manager. One can also find a step-by-step Abaqus tutorial on the composite double shear specimen. Parts of the step-by-step tutorial were found from D.S. Mane ${ }^{[29]}$.

Table 18. Engineering material constants from simulation composite analysis 2015 material manager

\begin{tabular}{|c|c|c|c|c|c|c|c|}
$\begin{array}{c}\text { Abaqus } \\
\text { Engineering } \\
\text { Constant } \\
\text { Inputs }\end{array}$ & $\begin{array}{c}\mathbf{E}_{\mathbf{1}} \\
\text { Axial } \\
\text { Modulus, } \\
\text { msi }\end{array}$ & $\begin{array}{c}\mathbf{E}_{\mathbf{2}} \\
\text { Transverse } \\
\text { Modulus, } \\
\text { msi }\end{array}$ & $\begin{array}{c}\mathbf{E}_{\mathbf{3}} \\
\text { Modulus, } \\
\mathbf{m s i}\end{array}$ & $\begin{array}{c}\mathbf{G}_{\mathbf{1 2}}=\mathbf{G}_{\mathbf{1 3}} \\
\mathbf{S h e a r} \\
\text { Modulus, } \\
\text { msi }\end{array}$ & $\begin{array}{c}\mathbf{G}_{\mathbf{2 3}} \\
\text { Shear } \\
\text { Modulus, } \\
\text { msi }\end{array}$ & $\begin{array}{c}\mathbf{v}_{\mathbf{1 2}}=\mathbf{v}_{\mathbf{1 3}} \\
\text { Poisson's } \\
\text { Ratio }\end{array}$ & $\begin{array}{c}\mathbf{v}_{\mathbf{2 3}} \\
\text { Poisson's } \\
\text { Ratio }\end{array}$ \\
\hline $\begin{array}{c}\text { MTM49 } \\
\text { Unidirectional }\end{array}$ & 19.9 & 0.99 & 0.99 & 0.302 & 0.398 & 0.244 & 0.257 \\
\hline
\end{tabular}

The parts were individually partitioned which made meshing them very simple. Once the partition was created, the user needed to use the Seed Edge command, then select whole part, and for method select "by number". As indicated below in sizing control, the user is able to assign the number of elements from one to however many. The convergence plot was constructed using four different nodes per element. The element's relative thickness was set to 0.5 since there were only two elements that made up the thickness of the part. 


\subsubsection{Assembly, Interactions \& Steps}

The whole assembly was modeled very similarly to the experiment. Each part was given a dependent instance and no tie constraints were used in the model. A contact step and a load step were added to the analysis. The contact step initiated the contact between the pin and the steel plates and also the pin and the specimen. The load step served to apply load to the analysis once full contact was established.

The pin was not constrained to the specimen with a tie constraint because that implied a condition similar to being welded. So in contrast, a surface-to-surface interaction was established between the pin, the steel plates and the specimen. The sliding formulation selected was finite sliding. The pin was set as the master surface and the slave surface consisted of two surfaces. One was the surface in contact with the pin and the inner side of the specimen and the other was the surface in contact with the pin and the inner side of both steel plates. The slave adjustment was set to a value of 0.007 in. A contact property with a tangential behavior (the friction formulation was set to penalty and the friction coefficient was set to 0.46 ). In addition, a normal behavior contact property with the pressure-overclosure was set to "Hard" Contact; constraint enforcement method was set to default, and allowed separation after contact.

\subsubsection{Boundary Conditions \& Loads}

The boundary conditions applied to the model needed to be assigned carefully. The top face of the specimen (opposite face with the hole) was fully fixed in the $\mathrm{x}, \mathrm{y}$ and $\mathrm{z}$ directions. This was 
similar to the clamped condition, which is applied by Instron's crossheads. The second boundary condition that was applied was on the outer pin surface and the inner hole surfaces of the steel plates and the bearing specimen. In the contact step, the pin, steel plates and specimen were not allowed to move in the $\mathrm{x}, \mathrm{y}$ and $\mathrm{z}$ directions. The load step was modified to allow the side plates, pin and specimen to move in only the y-direction.

The combined load of $600 \mathrm{lbs}$. was applied to both of the bottom faces of the steel plates. This was done by applying the load, in the load step, as a total force distribution pressure load. The loading condition used in the model was similar to the experimental loading condition, where a fraction of the force is applied at each time interval. Some elements in the model experienced plastic deformation only when the applied load was over $800 \mathrm{lbs}$. This meant that certain elements were in stress state beyond their linear elastic limit. The ultimate force was not predicted, by the numerical analysis, since that occurred in the non-linear region.

\subsection{Numerical Results}

This section provides the explanation of the convergence plot and talks about the factors, which influenced the numerical results. In Chapter 7, the numerical results are explained in detail.

\subsubsection{Convergence Plot}

For the numerical model, a partition was created on the face of the specimen. Taking time to draw a symmetrical and neat partition prevented the mesh from becoming unsymmetrical and 
prevented unusual results. The partitioned double shear specimen is shown in Figure 49. In Figure 50, one can see a close up of the partitioned region around the hole. After a partition was created, the user was able to assign a specific amount of elements using the Seed Edge command. Here the user is able to set the total amount of nodes per element to any value. For the convergence plot, 2, 6,8 , and 10 nodes per element were chosen, and the final vertical deflection at the pin was compared. A convergence plot was created to see if adding more elements to the model actually improved accuracy. Knowing the optimum amount of elements for the least amount of time for the model to complete is very important in the design process. As one can see from Figure 51, as the total amount of nodes per element increased, the deflection did not change significantly. Using more than six elements per node did not significantly improve accuracy, but it did take longer to run.

\subsubsection{Factors That Influenced the Numerical Results}

Increasing the total amount of elements through the thickness of the part, did not significantly affect the pin deflection results. Changing the axial modulus (from tensile to compressive) significantly affected the pin deflection results. The compressive axial modulus was imported into Abaqus rather than the tensile modulus, because the double shear test is mainly a compression type of loading. The fibers are in compression around the hole.

When initially assuming a frictionless contact (when the frictional coefficient equaled zero) the specimen ended up colliding with one of the side plates. Changing the frictionless coefficient 
from zero to 0.46 helped prevent the specimen from colliding with one of the side plates.

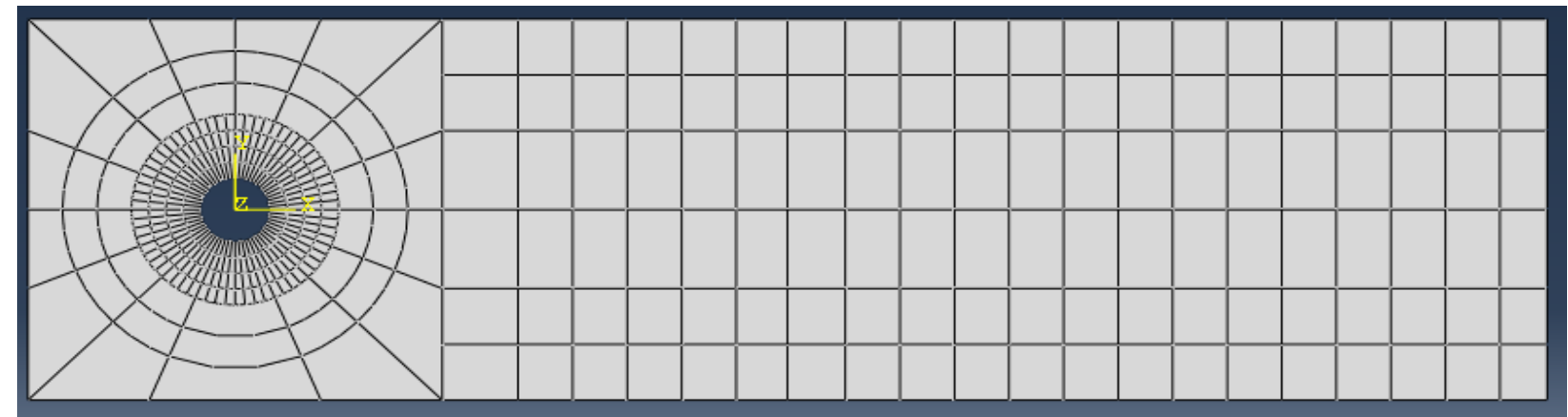

Figure 49. Partitioned double shear specimen drawn carefully to preserve symmetry

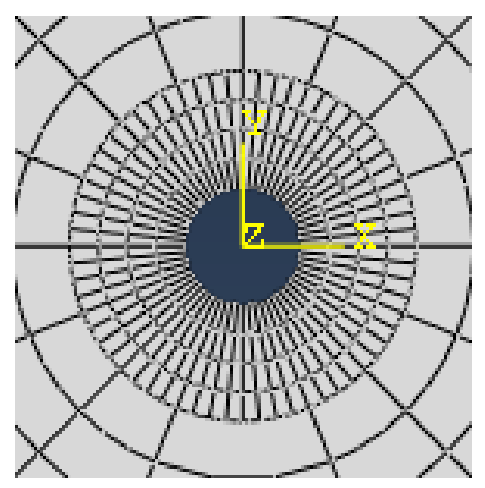

Figure 50. A close-up of the partitioned region around the hole of the double shear specimen 


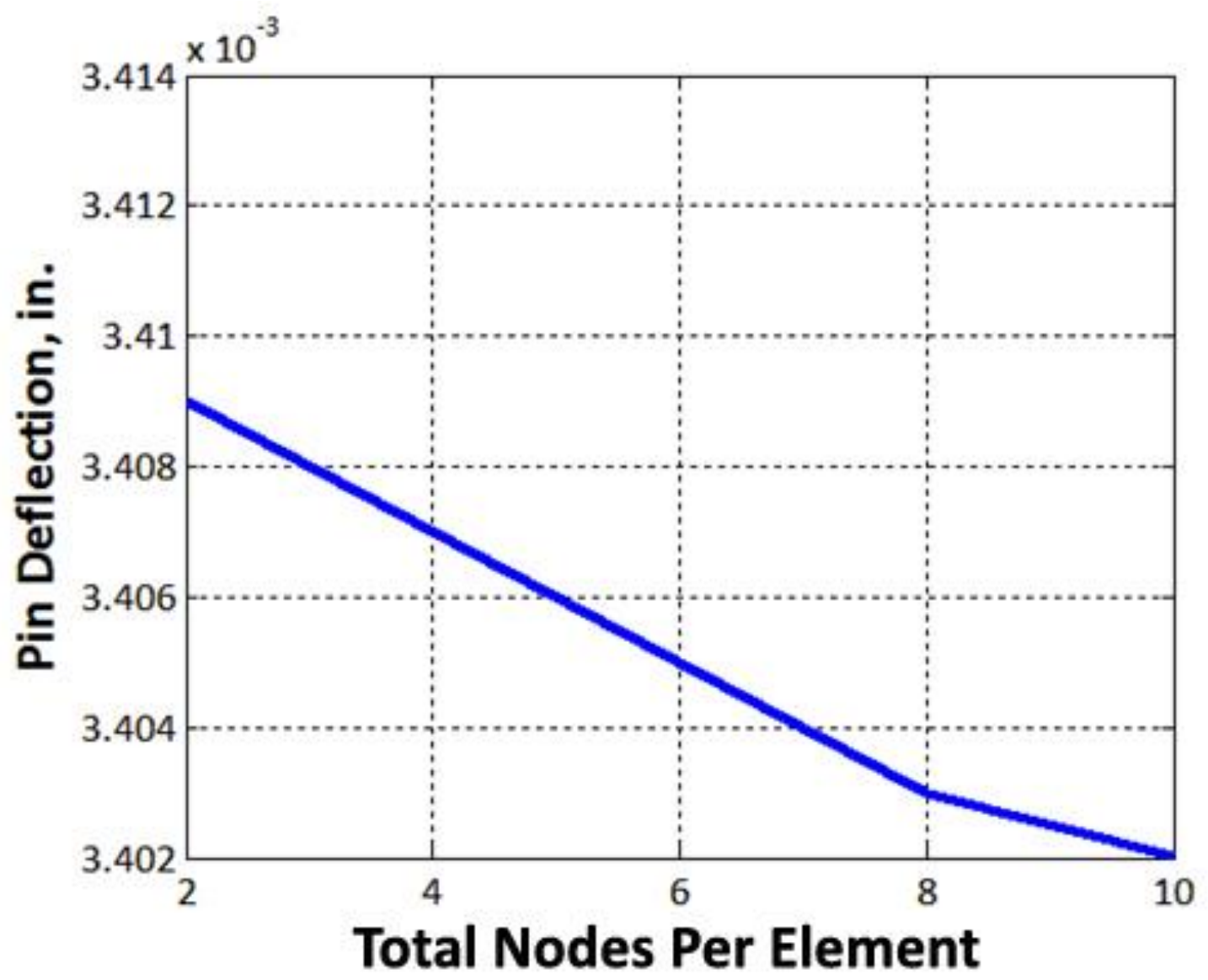

Figure 51. Convergence plot of pin deflection vs. total nodes per element 


\section{CHAPTER 7: COMPARISON BETWEEN EXPERIMENTAL \& NUMERICAL DOUBLE SHEAR RESULTS}

The slope of the reaction force vs. pin displacement was compared between both the experiment data and the numerical model. First, the numerical Aluminum model was validated. Then the numerical composite model was validated.

\subsection{Numerical Aluminum Model Comparison to Experimental Results}

Looking at Figure 59, the region highlighted in red was due to the compliance in the testing assembly. The bearing stress vs. bearing strain plot was then converted to a load (reaction force in the y-direction) vs. pin displacement plot. All of the specimens were plotted up until the linear region. Looking at Figure 60, of the five tested Aluminum double shear specimens, the numerical results only matched up with one. The four other Aluminum double shear specimens might have slipped with respect to the extensometer's knife-edge. One way to tell is by the lower load (reaction force in the y-direction) vs. pin displacement slopes. In Table 19, the total error when comparing the experimental slope to the numerical slope was $16 \%$. Misalignment of the specimen might have caused this significant error to occur. 


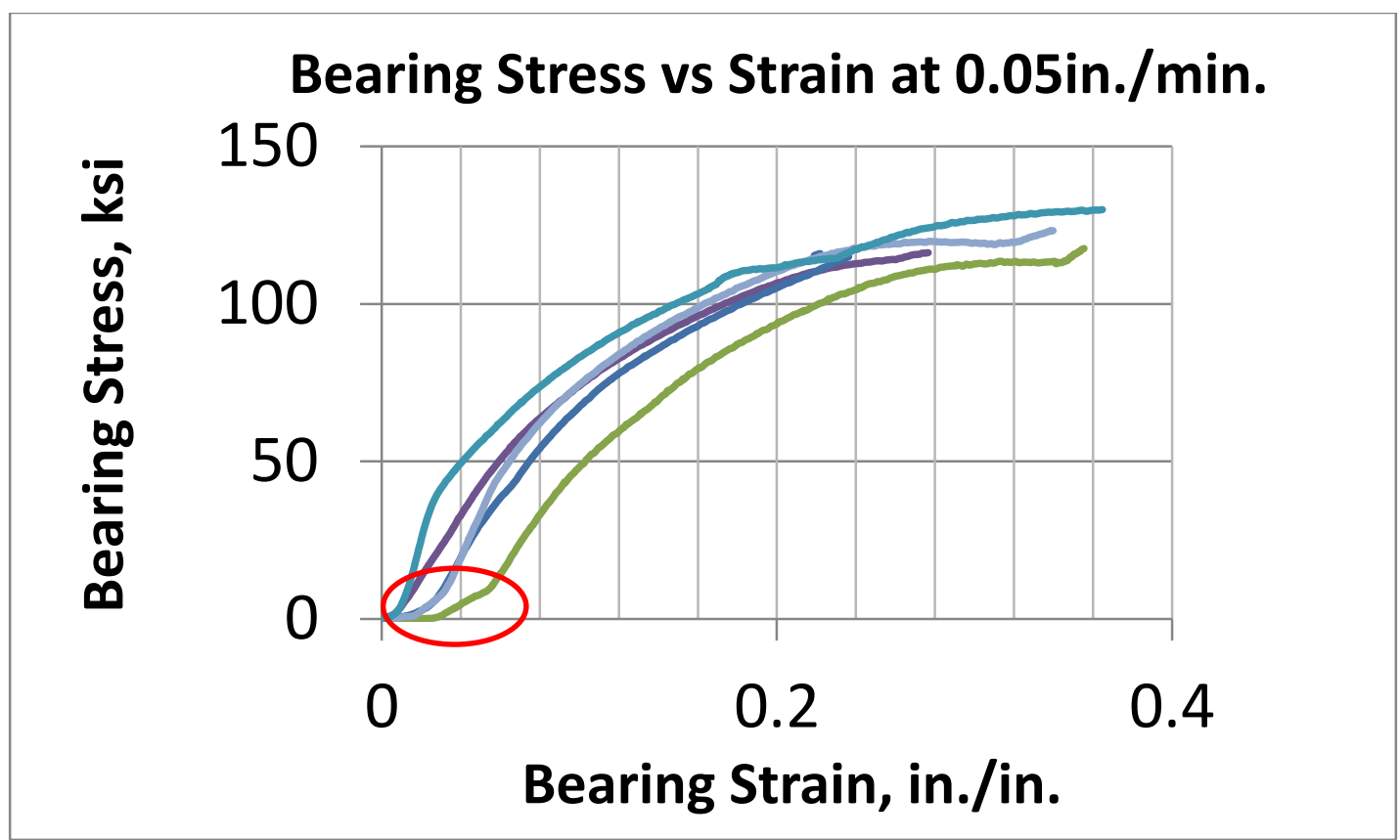

Figure 52. Bearing stress vs. bearing strain response of aluminum 2024-T4 double shear specimen

\section{Comparison Between Numerical and Experimental}

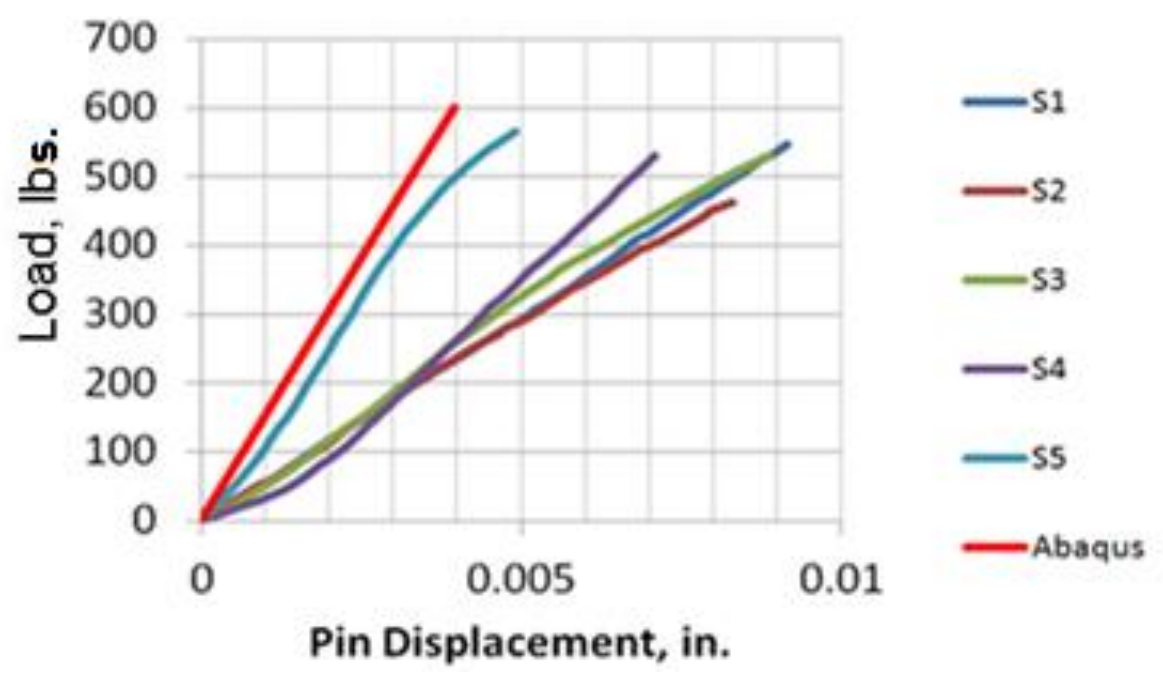

Figure 53. Load (reaction force) vs. pin displacement comparing experimental to numerical of the double shear aluminum specimens 
Table 19. Comparison between experimental slope and numerical slope of the aluminum double shear specimen \#5

\begin{tabular}{|c|c|c|}
\hline $\begin{array}{c}\text { Aluminum } \\
\mathbf{2 0 2 4 - T 4}\end{array}$ & $\begin{array}{c}\text { Slope, } \\
\text { lbs./in., } \\
* \mathbf{1 0}\end{array}$ & $\begin{array}{c}\mathbf{\%} \\
\text { Error }\end{array}$ \\
\hline Specimen \#5 & 1.60 & 16.0 \\
\hline Abaqus & 1.52 & - \\
\hline
\end{tabular}

\subsection{Composite Numerical Model Comparison to Experimental Results}

Figure 54 showed the load (reaction force in y-direction) vs. pin displacement response of the $0.05 \mathrm{in.} / \mathrm{min}$. composite double shear specimens that were cured to the recommended datasheet cure cycle. Three of the eight tested composite double shear specimens at $0.05 \mathrm{in} . / \mathrm{min}$. did not slip. The strain was corrected using the same method that was applied to the Aluminum double shear specimens. Of the eight carbon fiber specimens that were tested, only three of them closely matched up to the numerical results. The numerical model was loaded to $600 \mathrm{lbs}$., which was still within linear elastic limit of the material. The load (reaction force in y-direction) vs. pin displacement slopes between all the experimental specimens shown were compared to the numerical model. In Table 20, the average error between the numerical slope and the experimental slopes was about 7.1\%. Alignment is a huge factor, which can affect experimental results quite significantly.

There will always be error between the experimental and numerical results. The numerical 108 
results are the idealized results and the experimental results have so many factors, which can influence their results. Errors from $7 \%$ to $16 \%$, for both the aluminum double specimens and the composite double shear specimens, are actually quite reasonable because there is always error in the manufacturing process, displacement measuring equipment, load cell, specimen alignment exc.

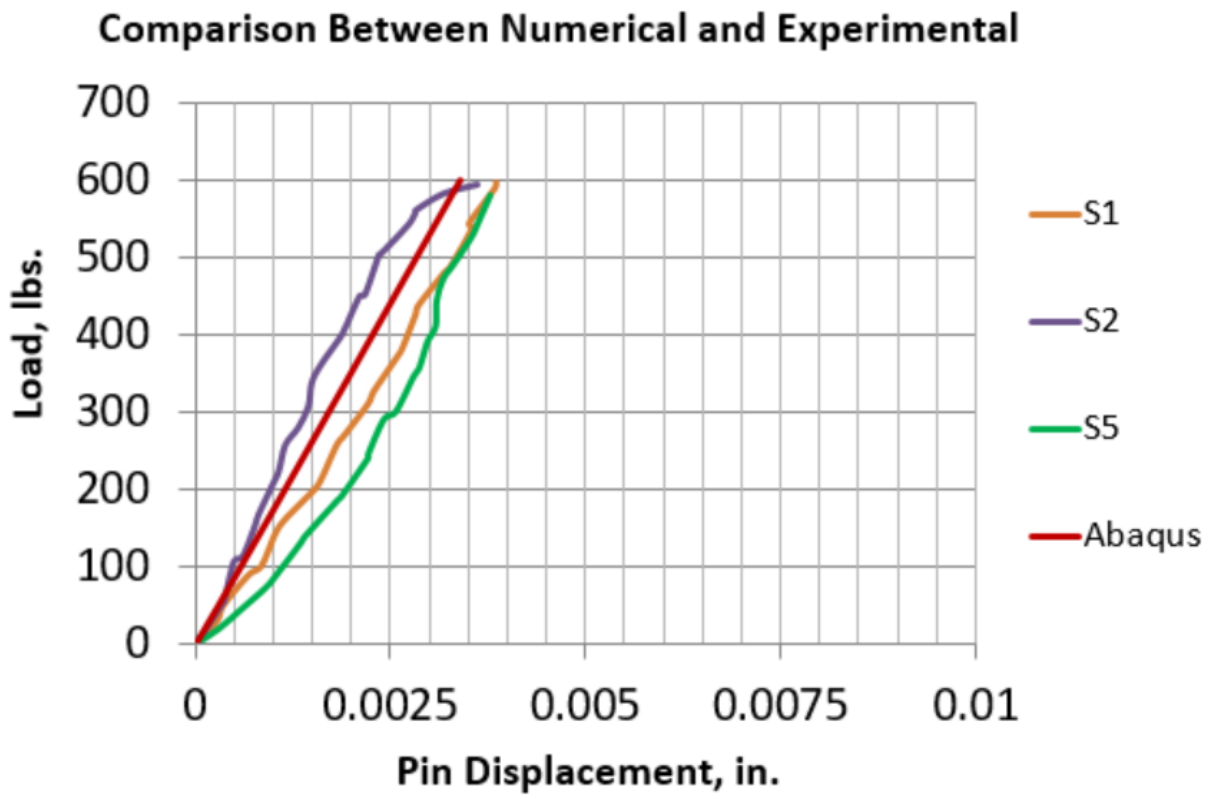

Figure 54. Load (reaction force) vs. pin displacement comparing numerical to experimental of the double shear composite specimens 
Table 20. Comparison between experimental slopes and numerical slope of the composite double shear specimens

\begin{tabular}{|c|c|c|}
\hline Composite & $\begin{array}{c}\text { Slope, } \\
\text { lbs./in., } \\
* \mathbf{1 0}\end{array}$ & \% Error \\
\hline S1 & 1.60 & 9.6 \\
\hline S2 & 1.89 & 6.7 \\
\hline S5 & 1.68 & 4.9 \\
\hline Average & 1.72 & 7.1 \\
\hline Abaqus & 1.77 & - \\
\hline
\end{tabular}




\section{CHAPTER 8: CONCLUSION}

The first important contribution of this study was to see how different loading rates affected the ultimate bearing strength of a composite material. One can see that at $0.05 \mathrm{in} . / \mathrm{min}$. and 0.1 in./min. (for both cure cycles) the composite double shear specimens carried more load compared to higher load rates of $1 \mathrm{in.} / \mathrm{min} ., 2 \mathrm{in.} / \mathrm{min}$. and 6 in./min.. All of the specimens failed in bearing and not in net-tension or shear-out.

The second important contribution of this study was to see how the recommended datasheet cure cycle and the alternate cure cycle affected the ultimate bearing strength. The two different cure cycles behaved very similarly under the five different loading rates. The average ultimate bearing strength of the Aluminum double shear specimens was $118 \mathrm{ksi}$ and for the composite double shear specimens it was $65 \mathrm{ksi}$.

The experiment showed that carbon fiber material is significantly weaker, in a double shear tensile loading configuration, compared to Aluminum. Ductile materials, like Aluminum for example, handle the double shear tensile loading configuration a lot better than the carbon fiber material, which is brittle. Each carbon fiber sheet is relatively thin which is also very poor for carrying bearing stress. Usually what designers do is use inserts inside and around the hole if they need to improve the bearing strength of a composite joint. The inserts help redistribute the stress concentrations (which are caused by mechanical fasteners) and prevent the brittle material from cracking. The inserts are usually made from ductile materials, like fiberglass or Aluminum. 


\subsection{Recommendations}

The experiments were carried out using carbon fiber unidirectional pre-preg tape. Similar research can be done using various other materials like: kevlar, fiberglass, or even hemp. Similar testing can be done using a single shear joint configuration. Various carbon fiber types can be tested as well. MTM-28 material is a thicker type of unidirectional fiber, which would be very interesting to test. A high-speed video camera would be a more efficient way to monitor deflection since the extensometer's range was the limiting factor in the data capture. A more in depth case study can be conducted on different cure cycles of composite resins. The pre-load function in the Bluehill2 software can be utilized in order to try to eliminate some of the strain correction region. In addition, a more in-depth experimental analysis can be conducted on the knee point region of the composite (carbon fiber) double shear specimen. 


\section{REFERENCES}

1. Airbus Versus Boeing-Composite Materials: The sky's the limit. http://www.lemauricien.com/article/airbus-versus-boeing-composite-materials-sky-slimit.

2. Lessard, L.B. (1995). Computer aided design for polymer-matrix composite structures. In S.V. Hoa (Eds.), Design of joints in composite structures. New York: Marcel Dekker.

3. Baker, A. (1997). Composites engineering handbook. In P.K. Mallick (Eds.), Joining and repair of aircraft composite structures. New York: Marcel Dekker.

4. Okutan, B. (2001). Stress and Failure Analysis of Laminated Composite Pinned Joints. Journal of Composite Materials, 19.

5. Chen, J.C., Lu, C.K., Chiu, C.H., \& Chin, H. (1994). On the influence of weave structure on pin-loaded strength of orthogonal 3D composites. Composites, 25, No: 4, 251-262.

6. Quinn, W.J., \& Matthews F.L. (1977, April). The effect of stacking sequence on the pinbearing strength in glass fiber reinforced plastic. Journal of Composite Materials, 11, 139145.

7. Liu, D., Raju, B.B., \& You, J. (1999). Thickness effects on pinned joints for composites. Journal of Composite Materials, 33, 2-21.

8. Stockdale, J.H., \& Matthews, F.L. (1976, January). The effect of clamping pressure on bolt bearing loads in glass fiber-reinforced plastics. Composites, 34-39. 
9. Kim, S.J., \& Kim, J.H. (1995). Effects of geometries, clearances, and friction on the composite multi-pin joints. AIAA Journal, 34, No: 4, 862-864.

10. Hyer, M.W., \& Klang, E.C. (1985). Contact stresses in pin-loaded orthotropic plates. Journal of Solids and Structures, 21, No: 9, 957-975.

11. Pierron, F., Cerisier, F., \& Lermes, M.G. (2000). A numerical and experimental study of woven composite pin-joints. Journal of Composite Materials, 34, No: $12,1028-1053$.

12. Chang, Fu-Kuo, Scott, R.A., \& Springer, G.S. (1982, November). Strength of mechanically fastened composite joints. Journal of Composite Materials, 16, 470-494.

13. Ger, G.S., Kawata, K., Itabashi, M.: Dynamic tensile strength of composite laminate joints fastened mechanically. Theor. Appl. Fract. Mech. 24(2), 147-155 (1996).

14. Li, Q.M., Mines R.A.W., Birch R.S. (2000, September). Static and dynamic behavior of composite riveted joints in tension.

15. United States Naval Academy (USNA). (2003). Composite Orientation Code. http://www.usna.edu/Users/mecheng/pjoyce/composites/Short_Course_2003/7_PAX_Sh ort_Course_Laminate-Orientation-Code.pdf

16. Kretsis, G., \& Matthews, F.L. (1985, April). The strength of bolted joints in glass fiber/epoxy laminates. Journal of Composite Materials, 16, 92-102.

17. Yeole, Amit. (2006, December). Experimental Investigation and Analysis for Bearing Strength Behavior of Composite Laminates. 
18. Anonymous, "Standard Test Method for Bearing Response of Polymer Matrix composite Laminates," ASTM Standards, Designation: 5961/5961M-05.

19. Anonymous, "Standard test method for tensile properties of fiber-resin composites," ASTM Standards, Designation: 3039-76.

20. Anonymous, "Standards. In-plane shear stress-strain response of unidirectional reinforced plastics," ASTM Standards, Designation: 3518-76.

21. Umeco, "MTM 49 Series Pre-preg System - Unidirectional Material Properties."

22. Cytec, "MTM 49-3 -Unidirectional Material Properties."

23. Instron, "Instron 8801 Servo-hydraulic Machine Photo." http://www.instron.us/en-us/

24. Nettles, A.T., (1994, October) "Basic Mechanics of Laminated Composite Plates."

25. ASM Aerospace Specification Metals Inc., "Datasheet Mechanical Properties of Aluminum 2024-T4.”

26. Anonymous, "Project 1 Report" ME-412.

27. Anonymous, "Standard test method for ignition loss of cured reinforced resins," ASTM Standards, Designation: 2584-02.

28. Xiao, Yi. "Bearing strength and failure behavior of bolted composite joints (part II: modeling and simulation).

29. De, S. MANE 4240/CIVL 4240: Introduction to Finite Element. Abaqus Handout. 30. Semb, Evind. "Behavior of Aluminum at Elevated Strain Rates and Temperatures." 


\section{APPENDICES}

\section{A.1. Drawings for the Fixture Assembly}

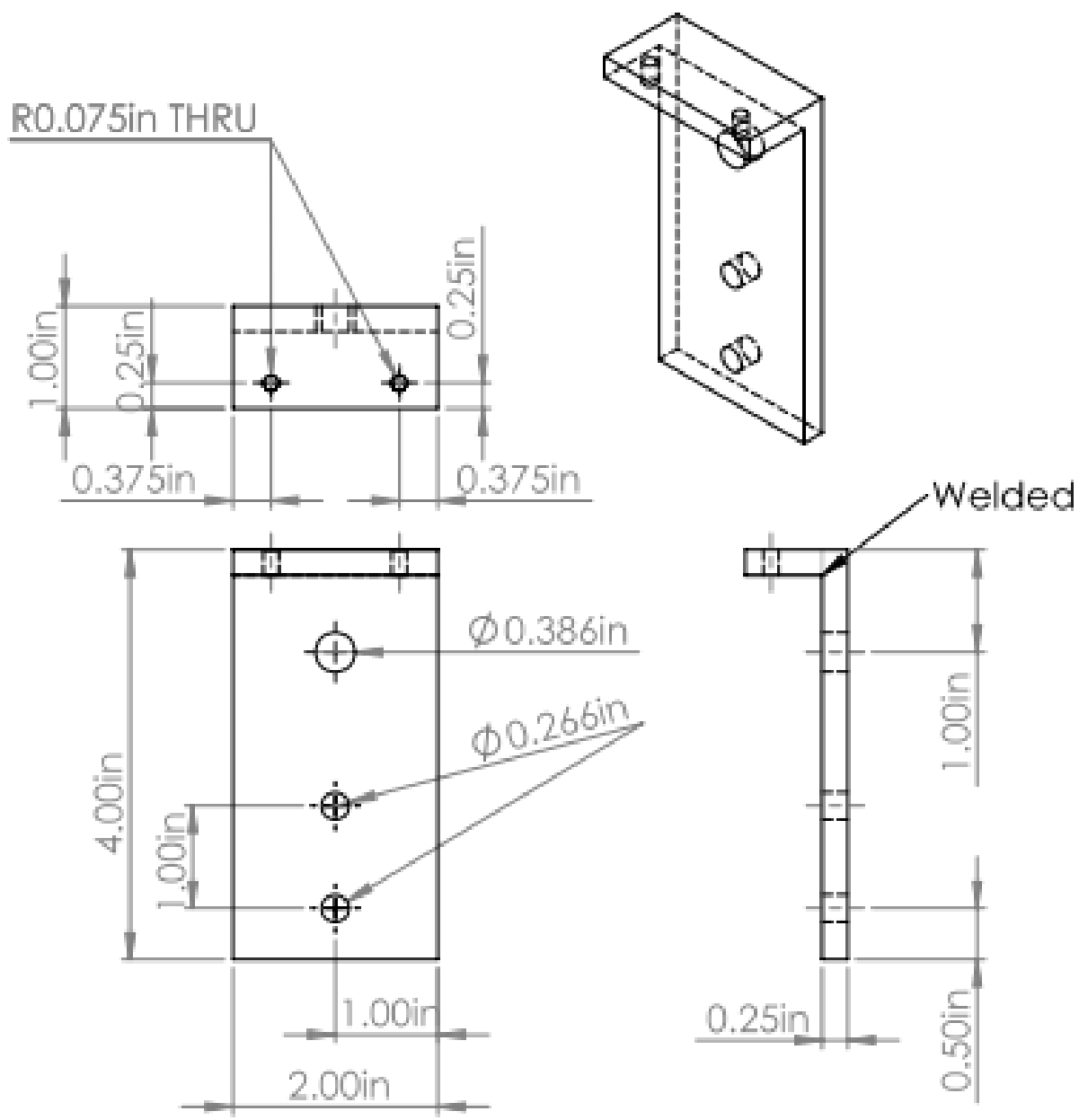

Figure 55. Drawing of the two steel side plates 


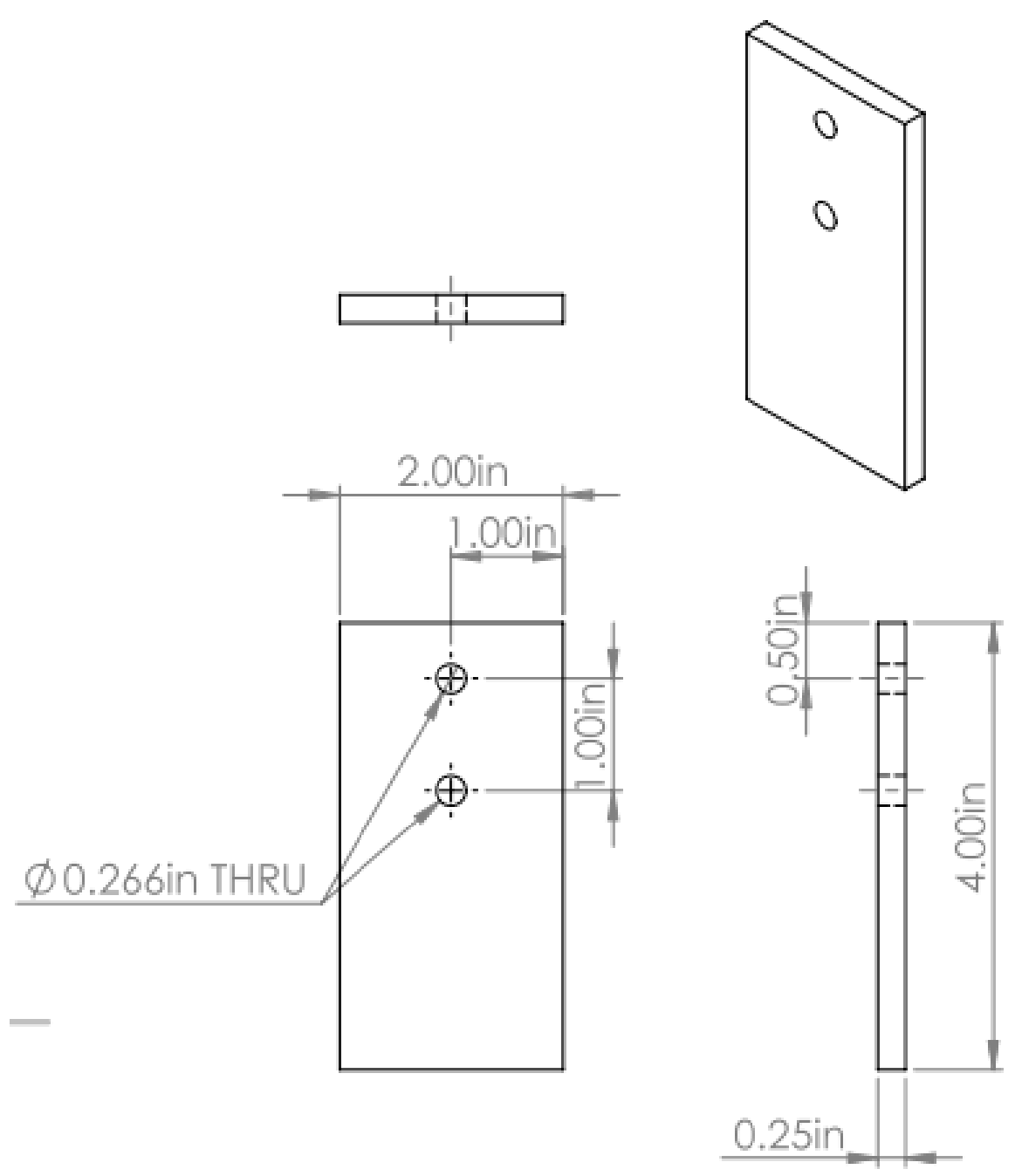

Figure 56. Drawing of the center plate of the fixture 


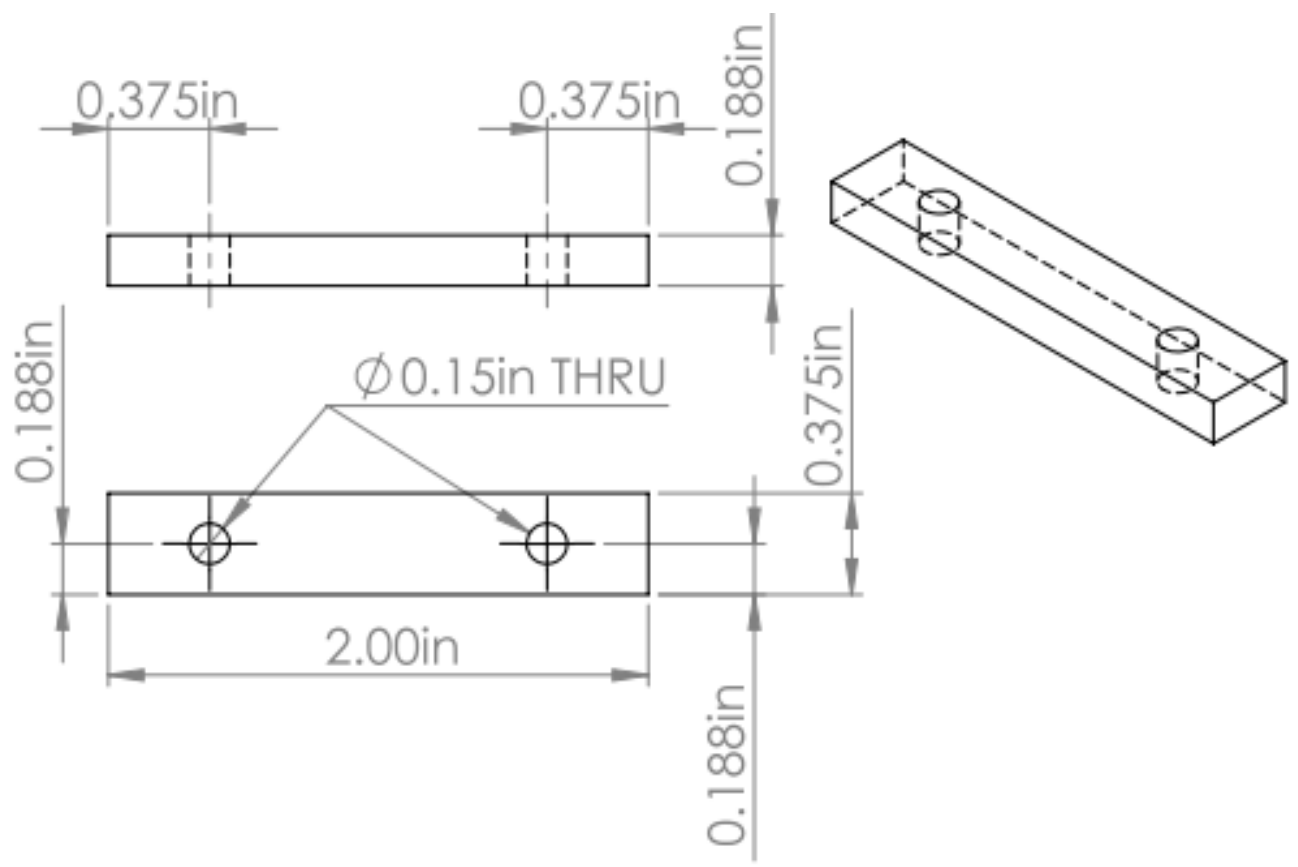

Figure 57. Drawing of the smaller top plate

\section{A.2. Tutorial on Bluehill2 Test File Setup}

Various settings were changed inside the BlueHill2 software. Below, I will show a couple of the parameters that were changed. Navigating through the menus is self-explanatory.

In the Control submenu, the load rate was changed for each test. The quasi-static case was tested first at a load rate of $0.05 \mathrm{in.} / \mathrm{min}$. The second load rate, which was tested, was $0.1 \mathrm{in.} / \mathrm{min}$. , the third was 1 in./min., the fourth was 2 in./min. and the fifth speed, which was tested, was 6 in./min. 


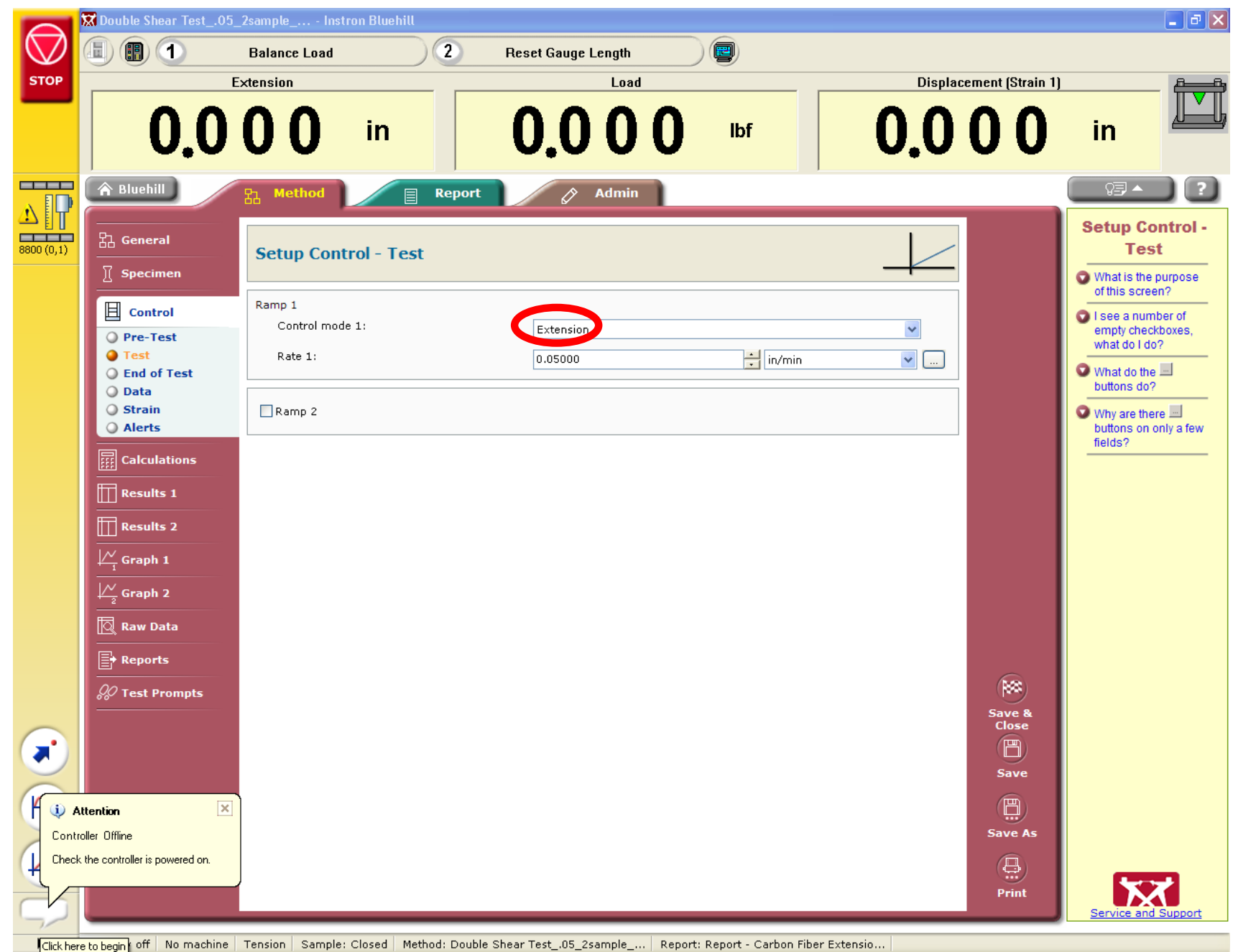

Figure 58. Bluehill2 load rate adjustment screen

The end of test criteria was changed to the ASTM specification. End of test 1 specifies the drop in the load of $30 \%$ the peak value and end of test 2 is specified as an extensometer displacement of 0.1 in. The extensometer shows up at Displacement (Strain 1) as a separate channel. 


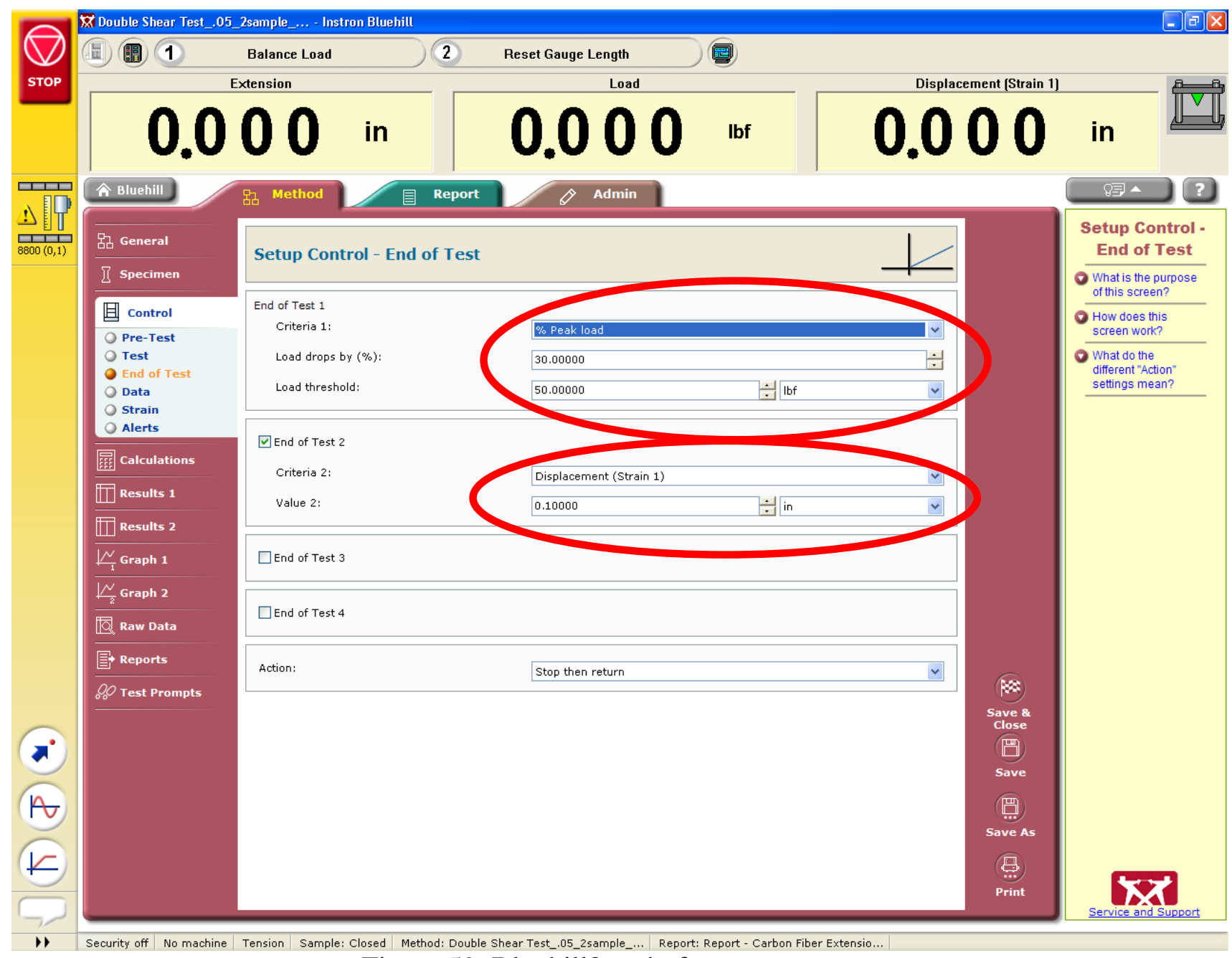

Figure 59. Bluehill2 end of test screen

In the Control submenu, the sampling rate was changed from the default rate of 10 samples/sec to 3 samples/sec as required by ASTM D5961. This change showed a significant reduction of noise within the extensometer displacement readings. A value of $500 \mathrm{~ms}$ was adjusted for the time channel and the load sampling rate was left to default interval of $56 \mathrm{lbf}$. 


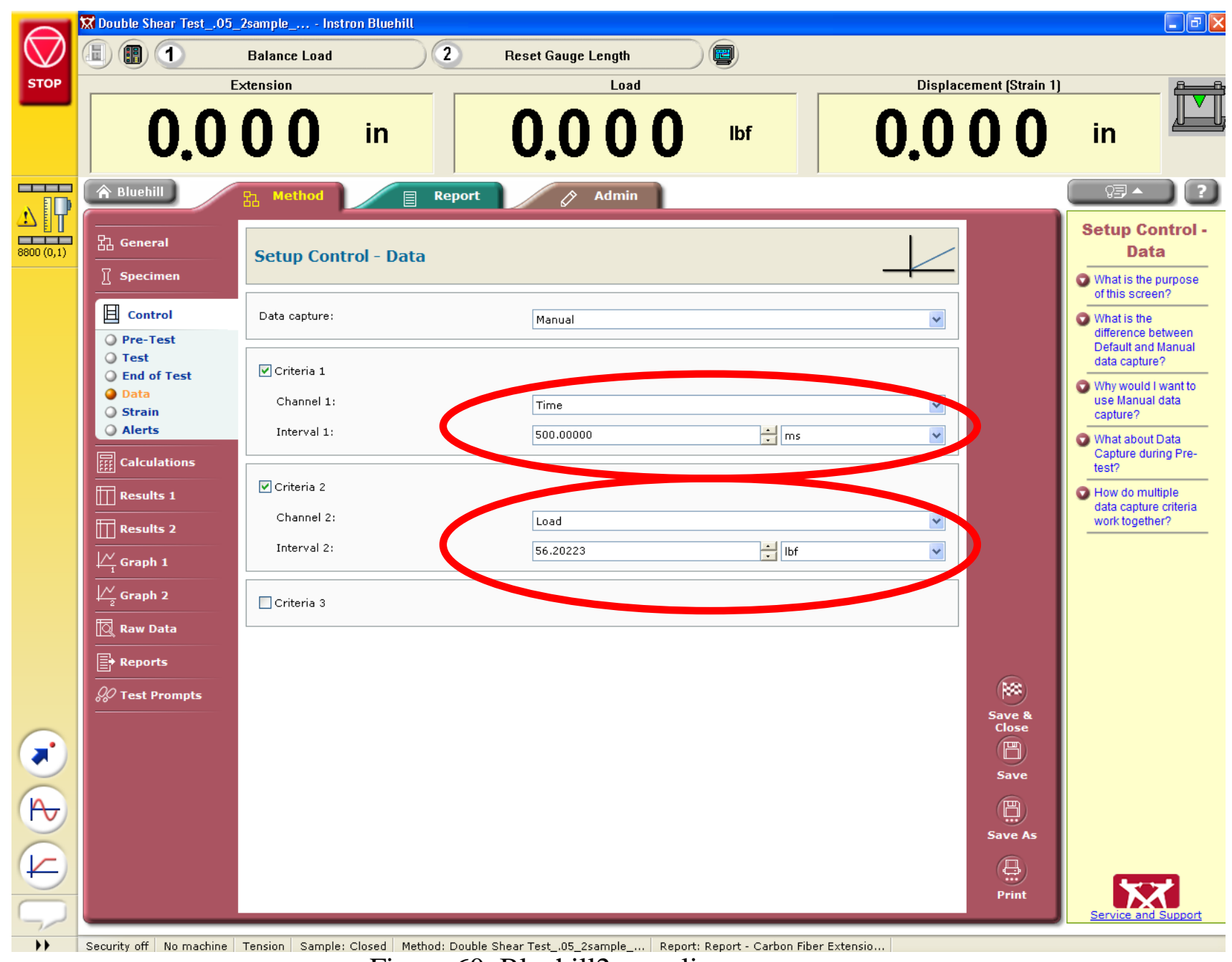

Figure 60. Bluehill2 sampling screen

Below in the Control submenu, the source of tensile strain was changed from the BlueHill2 default channel of "Tensile Strain" to the "Strain 1". The extensometer shows up as "Strain 1". 


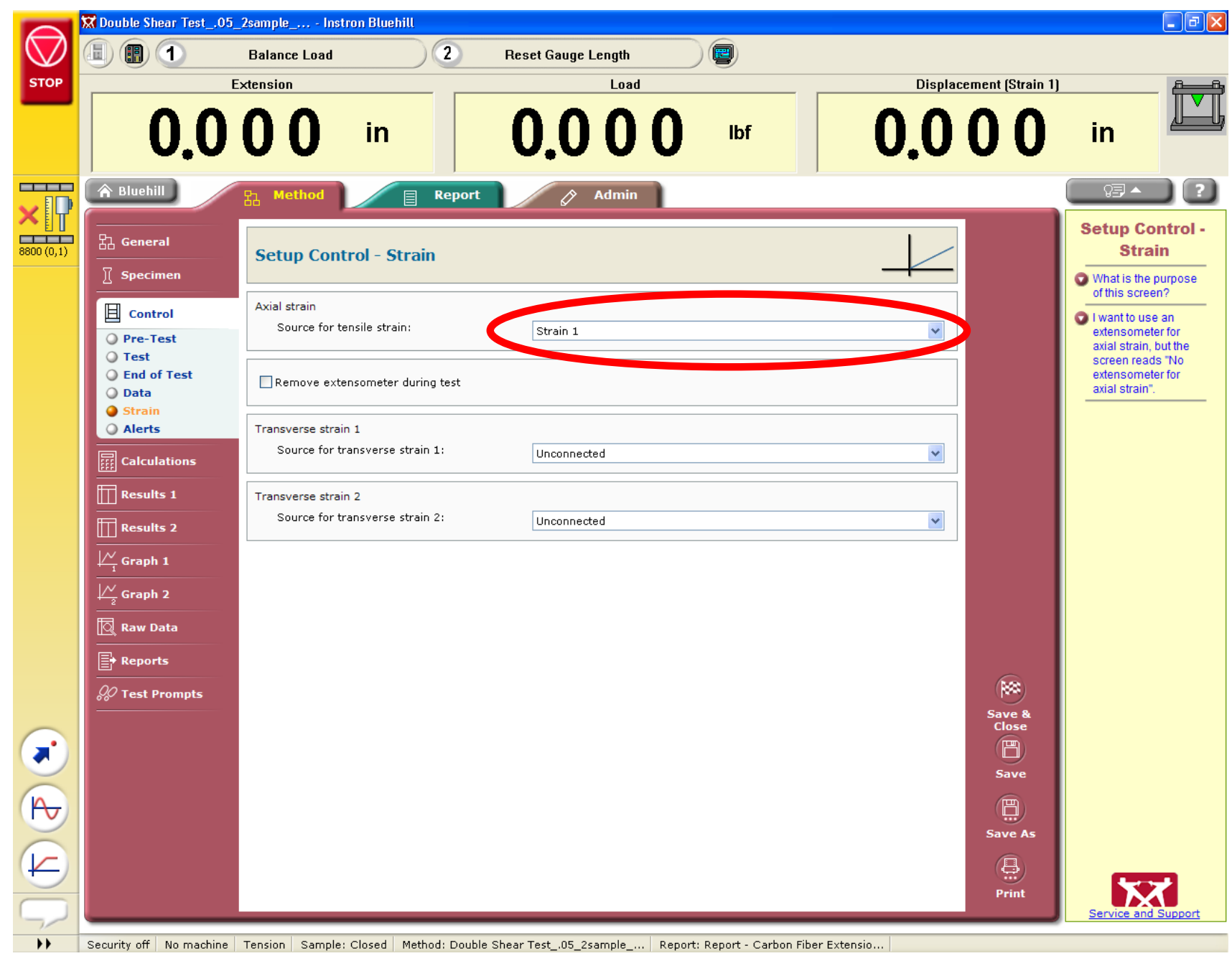

Figure 61. Bluehill2 strain control screen

Bluehill2 also has the option of calculating numerous parameters. In my experimental testing, I needed to calculate the ultimate bearing strength so I picked User Calculation. Then Bluehill2 gives you an option to define various variables like: D (diameter of hole), $\mathrm{k}$ (calculation factor for double shear $\mathrm{k}=1$ ), $\mathrm{P}_{\max }$ (maximum force carried by the specimen prior to failure), and $\mathrm{t}$ (defined as the thickness of the laminate). After all of your variables are defined, the equation designer tool 
is used to create your equation of interest.

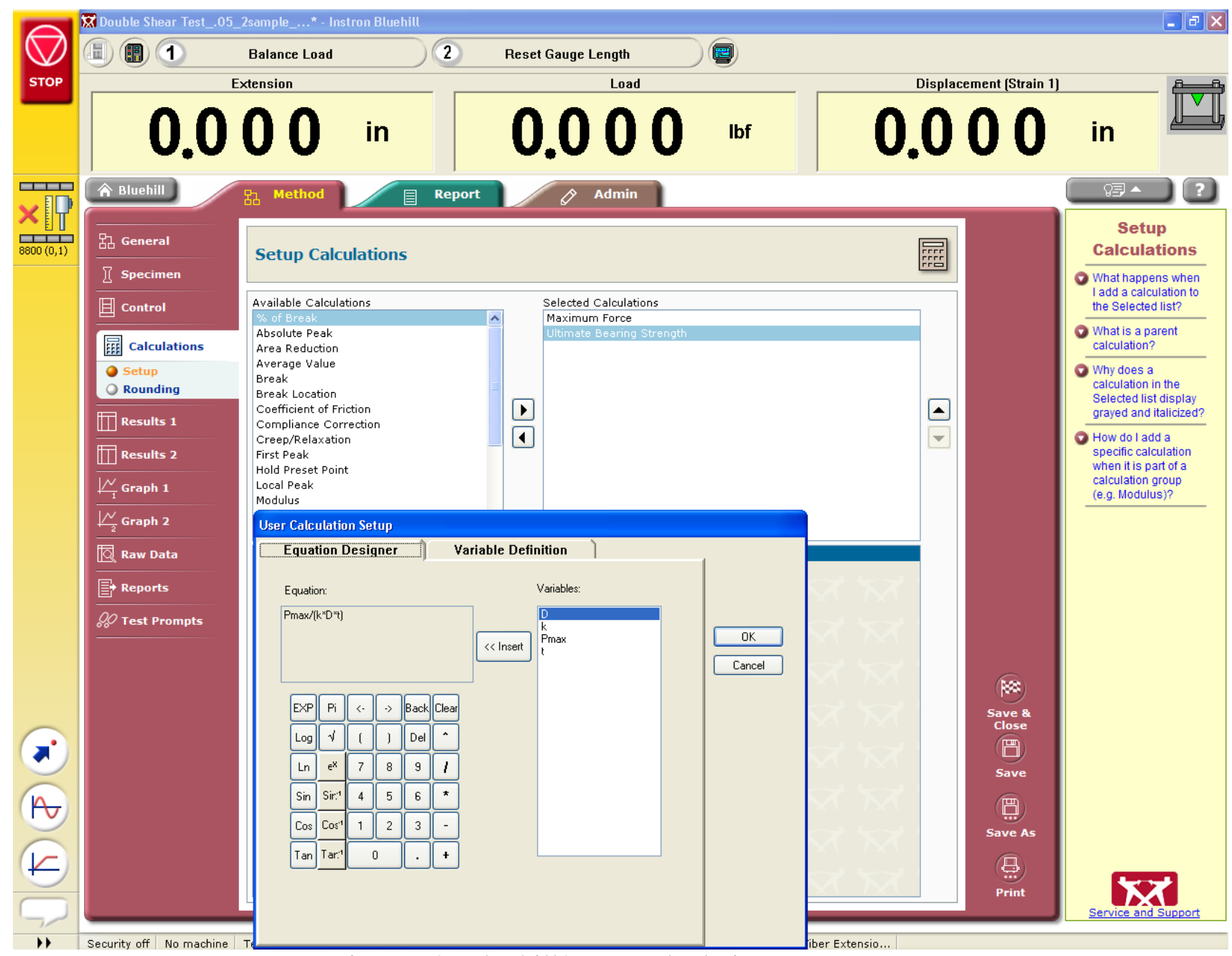

Figure 62. Bluehill2 user calculation screen

In the Results submenu, the user is able to pick exactly which values he/she wants to output while in the test screen. The results are outputted as a column of values for each of the different test specimens. I wanted to output all of these parameters below while I was conducting my tests. 


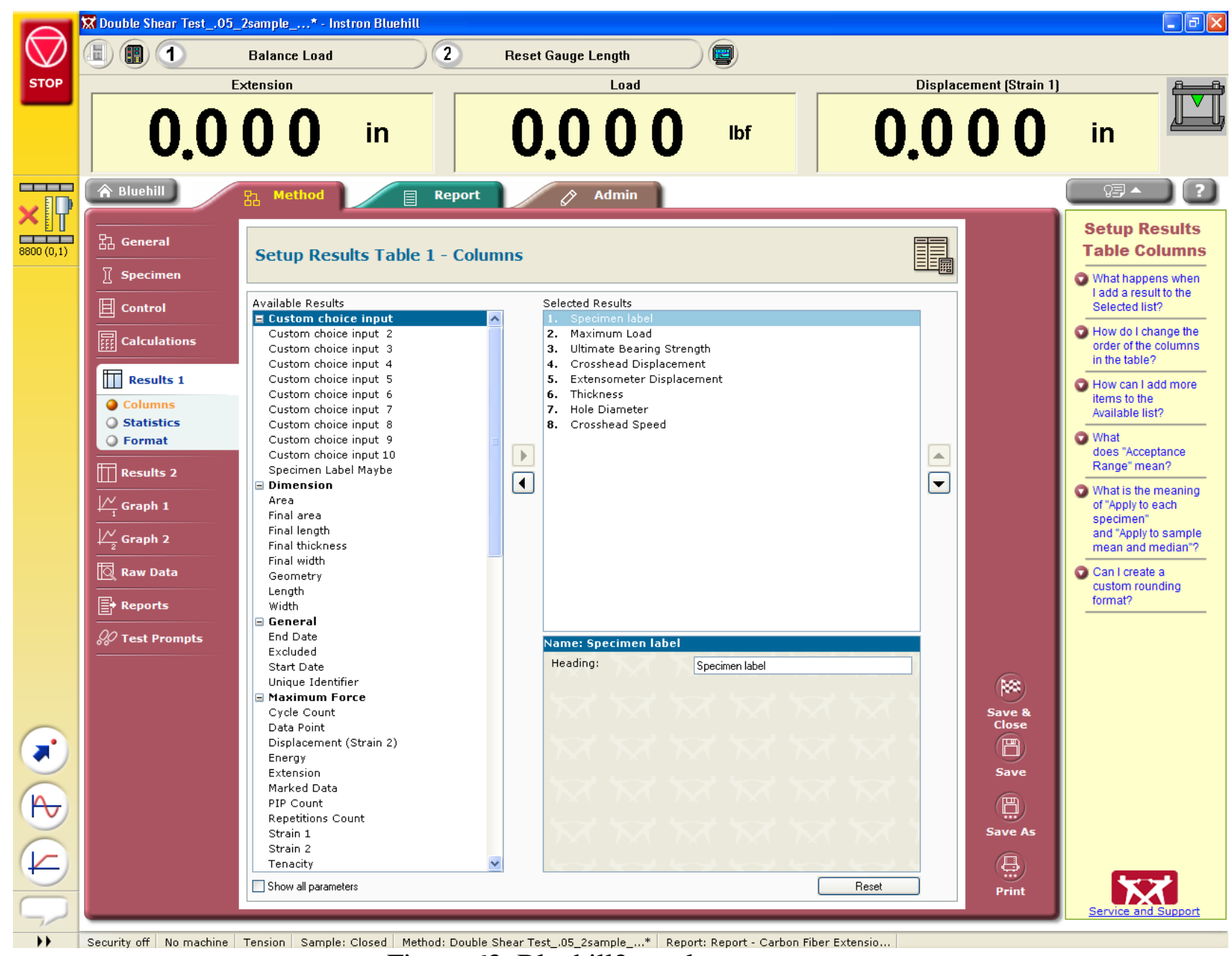

Figure 63. Bluehill2 results screen

In the Graph submenu, the user is able to output two real-time changing graphs. For graph 1, I chose to output Instron crosshead displacement vs. load and for graph 2 I chose to output extensometer displacement vs. load. The X-Data was set to either Extension (for Instron crosshead displacement) or Displacement (Strain 1) (for extensometer displacement. The Y-Data was set to Load for both graph 1 and graph 2. 


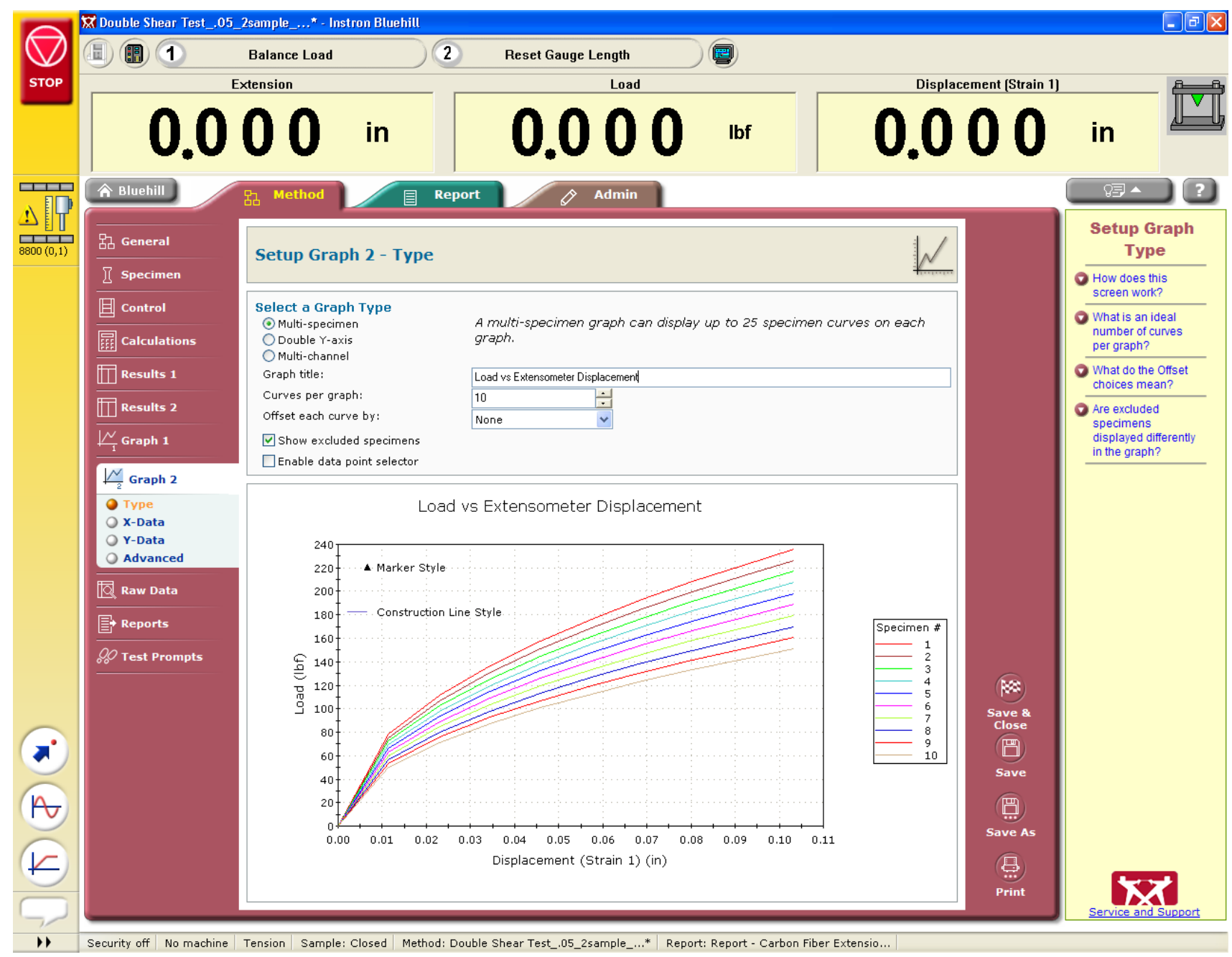

Figure 64. Bluehill2 graph screen

In the Raw Data submenu, Bluehill2 has a great function, which allows the user to export any given output of experimental data into a .csv file. This file can later be opened up with Excel and used to calculate various experimental stresses, strains and other parameters of interest. For my experimental testing, I was interested in outputting: time, crosshead displacement, extensometer 
displacement, load and corrected position.

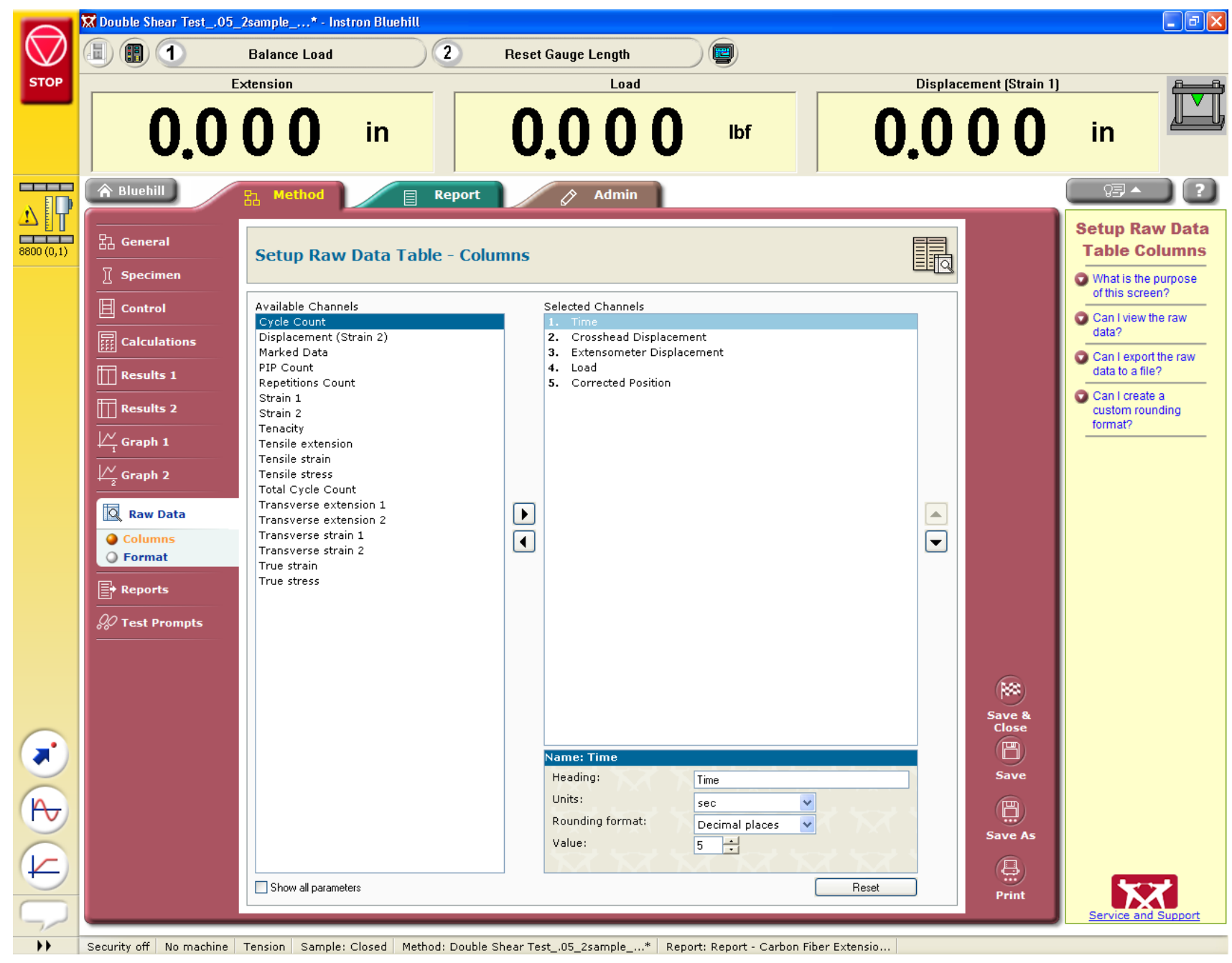

Figure 65. Bluehill2 raw data results screen

The last bit of raw data, which needed to be outputted, is shown below. This set of data is saved onto the same .CSV file as the one specified in the previous screen. This set of data is located in its own set of two columns in the .CSV file. 


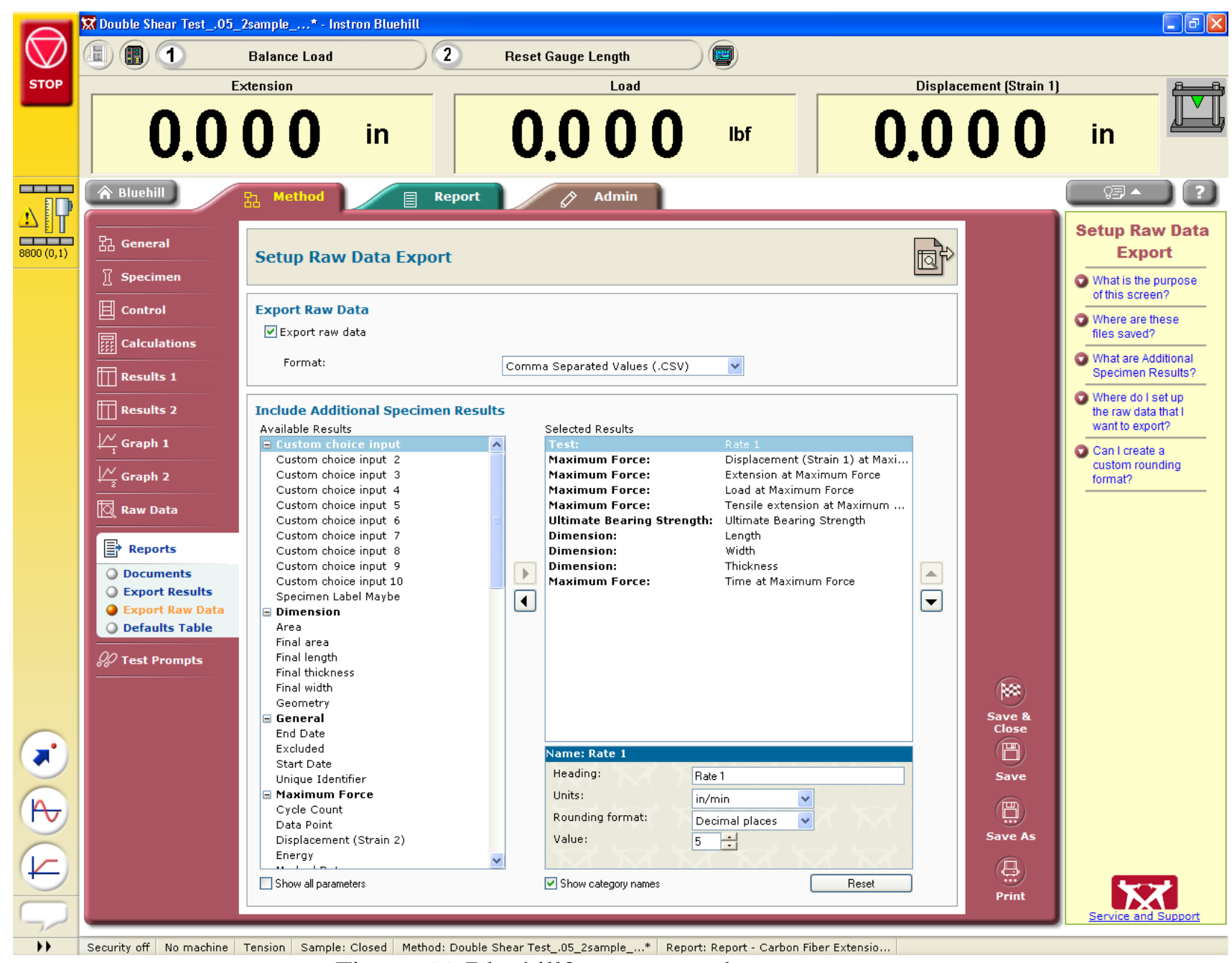

Figure 66. Bluehill2 report raw data screen

\section{A.3. Tutorial on Finding the Unknown Engineering Constants}

Autodesk created a very powerful tool, which can help the user figure out unknown engineering constants of a ply. For example from the experimental results, the user is able to experimentally determine $\mathrm{E}_{1}, \mathrm{E}_{2}, \mathrm{G}_{12}$ and $v_{12}$. Shown below are all the values, which the user inputs into the Autodesk Simulation Composite Analysis 2015 Material Manager. Make sure to label the 
material a unique name and choose the correct units. The fiber type should be carbon intermediate for the MTM 49 since it is not the ultra-high fiber modulus. The volume fraction should be the one, which was found experimentally in the Results chapter, of 0.55. In Figure 67, in the first row of the Ultimate Lamina Strengths the user inputs the tensile strength in the $0^{\circ}$ and the $90^{\circ}$ directions. In the second row, the user inputs the compressive strength in the $0^{\circ}$ and $90^{\circ}$ directions and finally, in the last row, the user the user inputs the in-plane shear strengths.

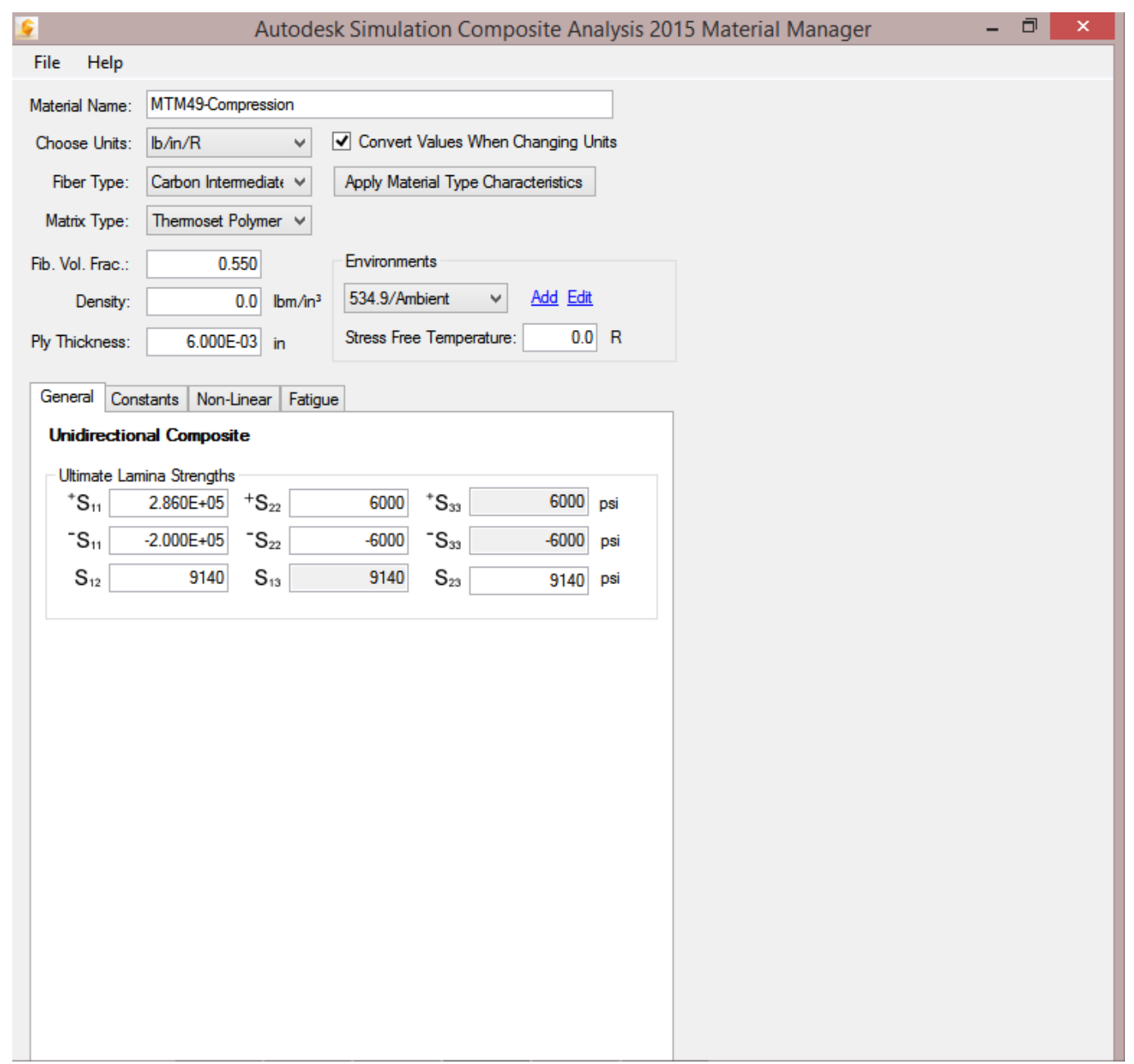

Figure 67. Autodesk simulation composite analysis 2015 material manager strength input menu 
In Figure 68, the user will input the known modulus of elasticity into the Lamina Elastic Constants section. The in-plane Poisson's ratio, which was assumed to be around 0.244 , was used from a previous paper, which found the material property experimentally on the same MTM 49 Unidirectional material. The in-plane shear modulus was inputted from the experimental testing.

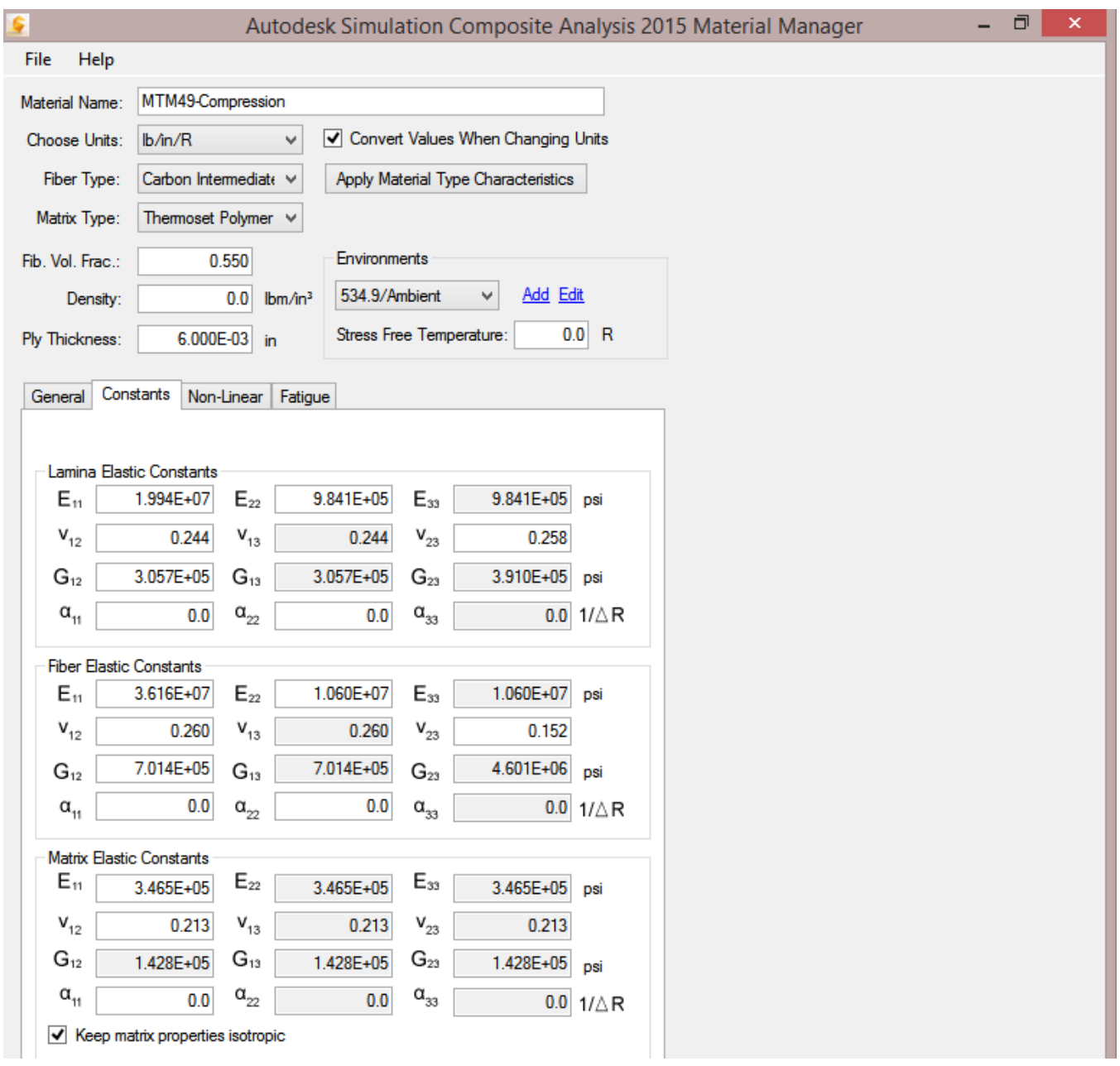

Figure 68. Autodesk simulation composite analysis 2015 material manager lamina engineering constants menu 
The key is to assume a value if you do not know what it is. After all the values have been inserted into the program go into the File, menu and then click optimize. It will ask you if you want to save the material properties somewhere and all you do is specify where you want to save the data. It will take a couple seconds to optimize the values accordingly.

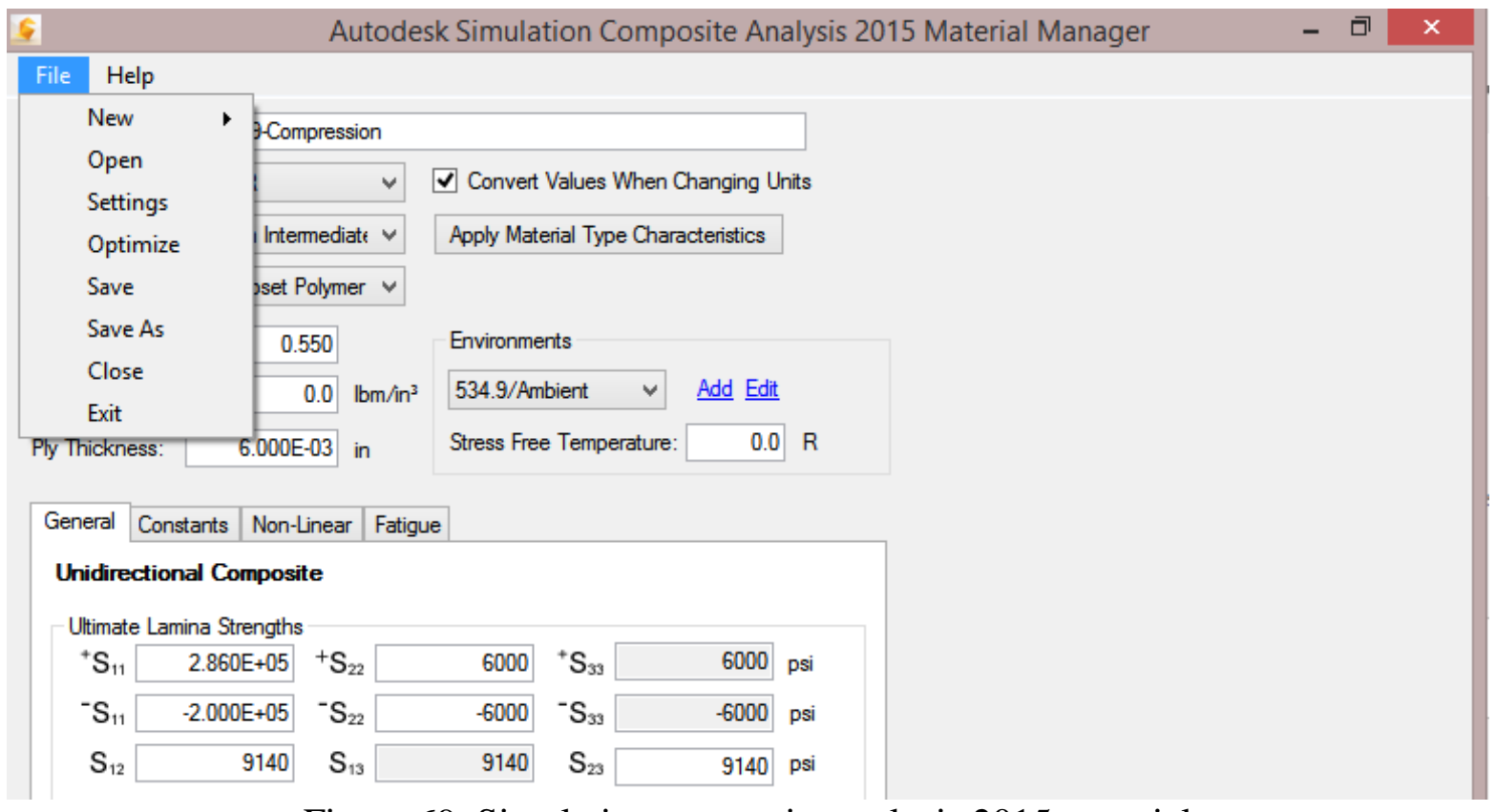

Figure 69. Simulation composite analysis 2015 material manager optimization and save menu

\section{A.4. Tutorial on Outputting Force vs. Pin Deflection from Abaqus}

The pin deflection needed to be monitored for one node on the specimen. The area of interest is shaded in dark blue and the red dot signifies which node was monitored for its vertical deflection. In Figure 70, one can see the deflection in the y-direction, which occurs around the hole. This hole 
is a localized compression zone.

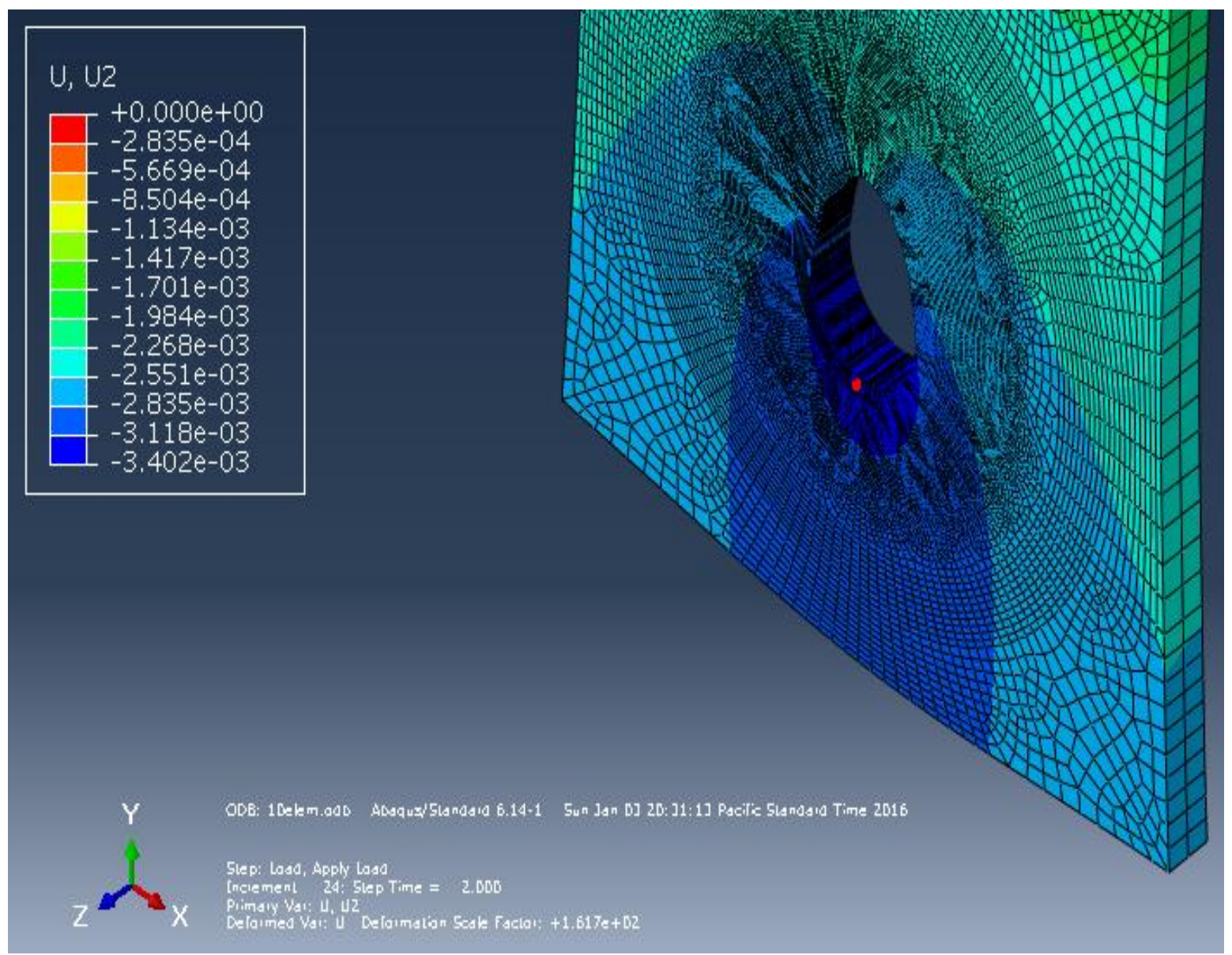

Figure 70. Pin deflection is monitored at the red node 


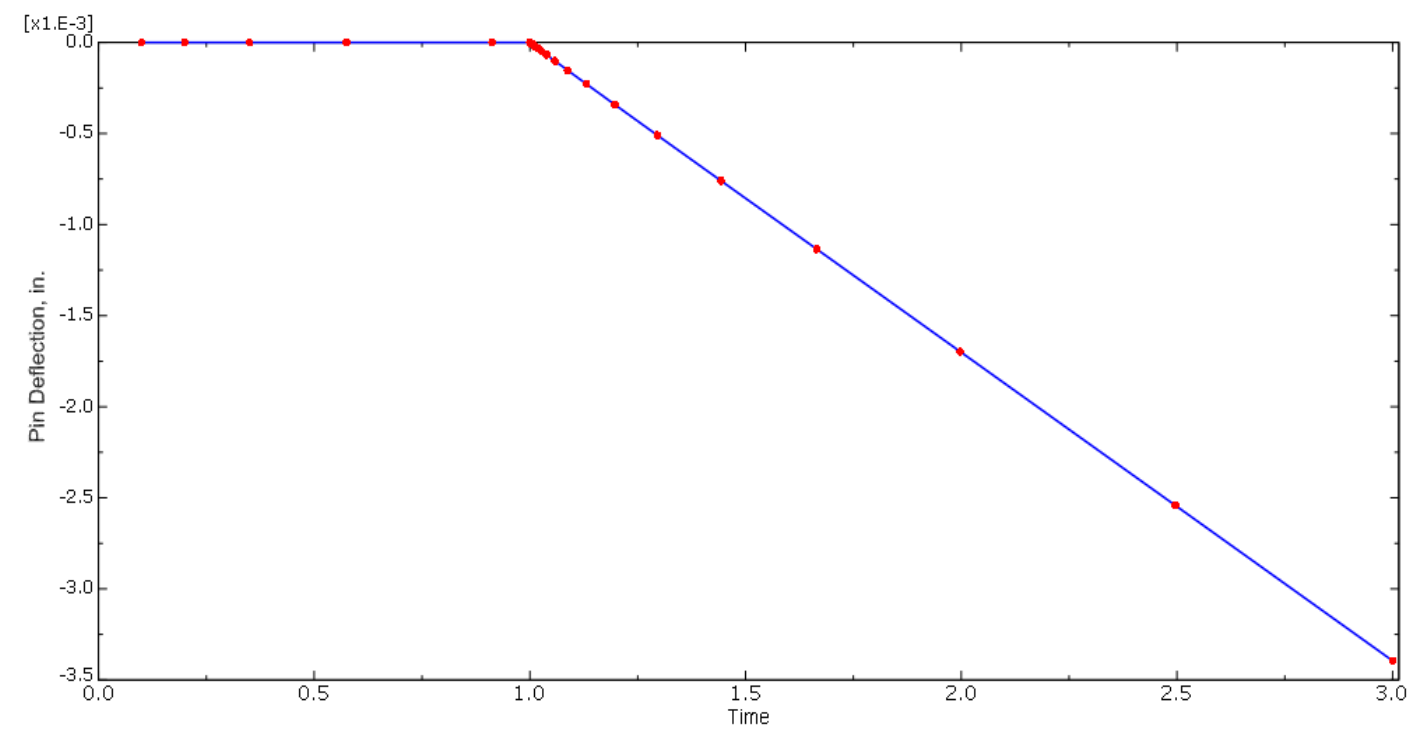

Figure 71. Pin deflection vs. time

Next what was needed was to have a force vs. time graph. The top most nodes on the specimen were fixed using the encastre boundary condition. The reaction force in the y-direction was captured for all the nodes that make up the top of the specimen. Once all the reactions at each nodes were captured, the whole region was summed up. Under create XY plot click ODB field output and then click continue. Under the Variables tab, find the Output variable box, and in the position menu, click Unique Nodal and then go into RF: Reaction Force and check the RF2 button. Since we are interested in the reaction force in the y-direction ( 2 direction). Next, click the Elements/Nodes tab and then pick the from viewport button and then click Edit Selection. Once all the fixed nodes are selected, as shown in Figure 72 below, click the Done button in the viewport. Lastly, go into Active Steps/Frames; make sure All steps are selected and set it to Frame. In the bottom of the window, make sure a green checkmark is applied to both the Contact and the Load steps. 

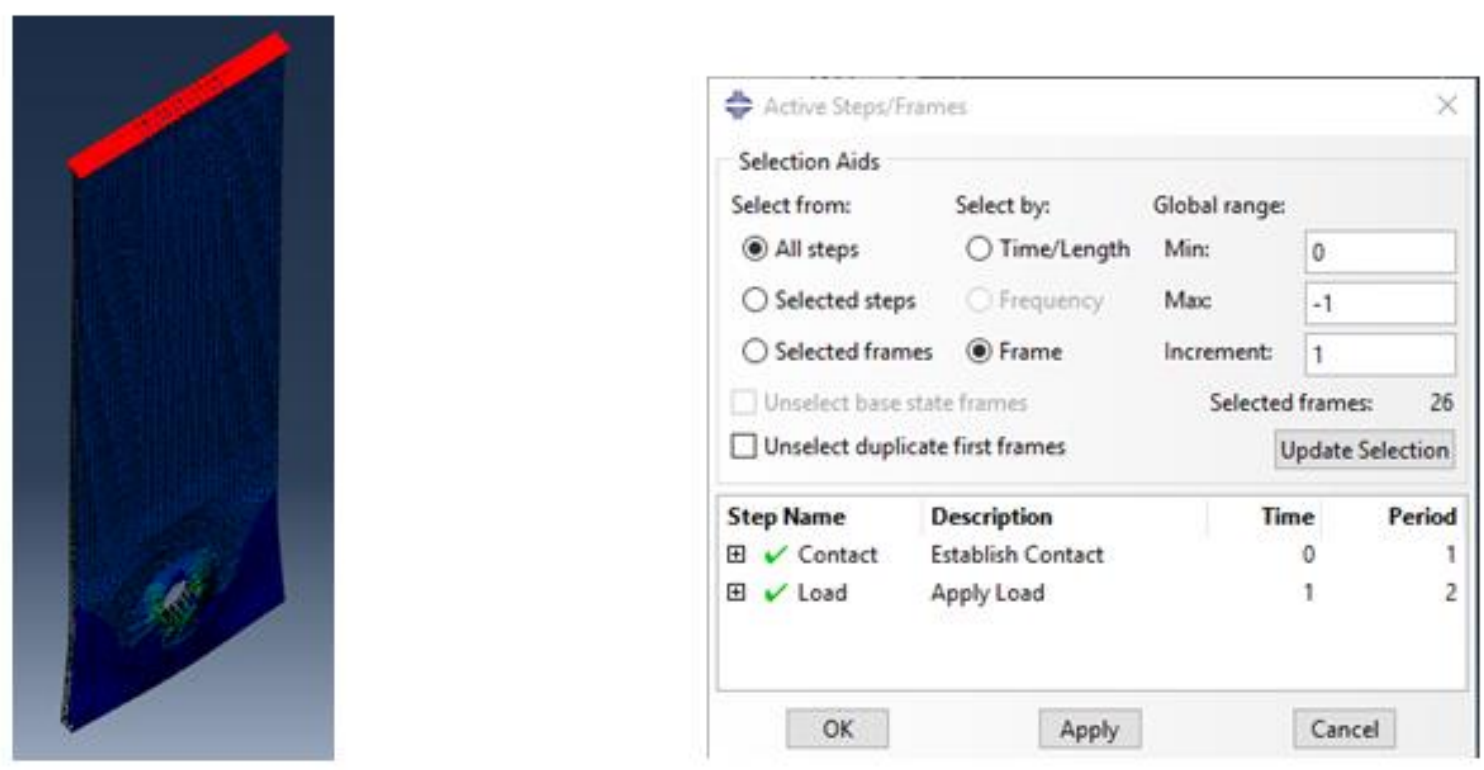

Figure 72. Fixed nodes selected in red (left) selected steps which are monitored in the analysis (right)

Using the Create XY Data option in Abaqus, the user is able to go into Operate on XY data. In the Operators window, pick sum $((\mathrm{A}, \mathrm{A}, \ldots))$, then under $\mathrm{XY}$ data, select all the Reaction Force nodes, which show up as _RF:RF2 and then click Add to Expression. Once all the nodes are inside the Sum operator, hit the Plot Expression button. This will output a force vs. time graph. 

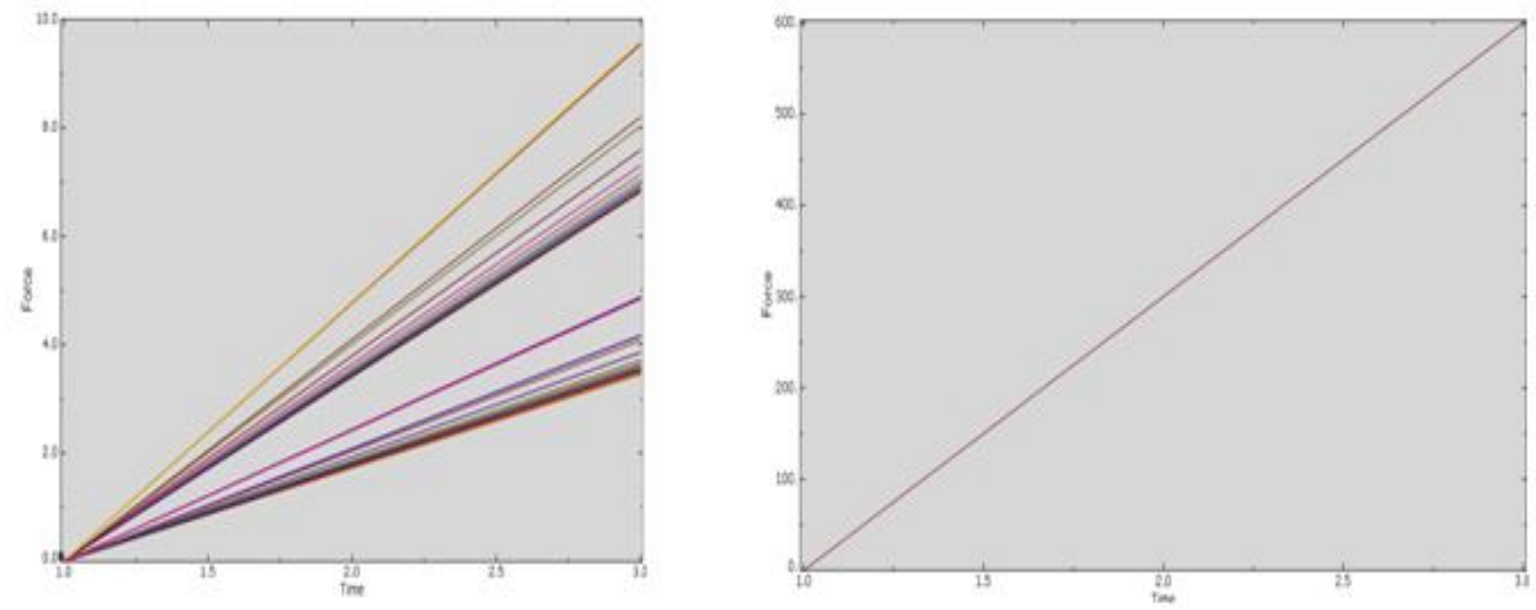

Figure 73. Force vs. time plot at the reaction nodes (left) summed up force vs. time plot (right)

Once both the force vs. time graph and deflection vs. time graph are created, one needs to combine both graphs. In the Create XY Data, click Operate on XY Data and then press Continue. Under the operator tab, find combine $(\mathrm{X}, \mathrm{X})$ and then click it once. The combine operator requires two variables for the plot. For the first variable, click the deflection XY data, and for the second variable, click the Reaction Force $2 \mathrm{XY}$ data. Make sure a comma separates both variables. Once done click the plot expression button and this should bring up a Force vs. Pin Deflection plot as shown in Figure 74. 


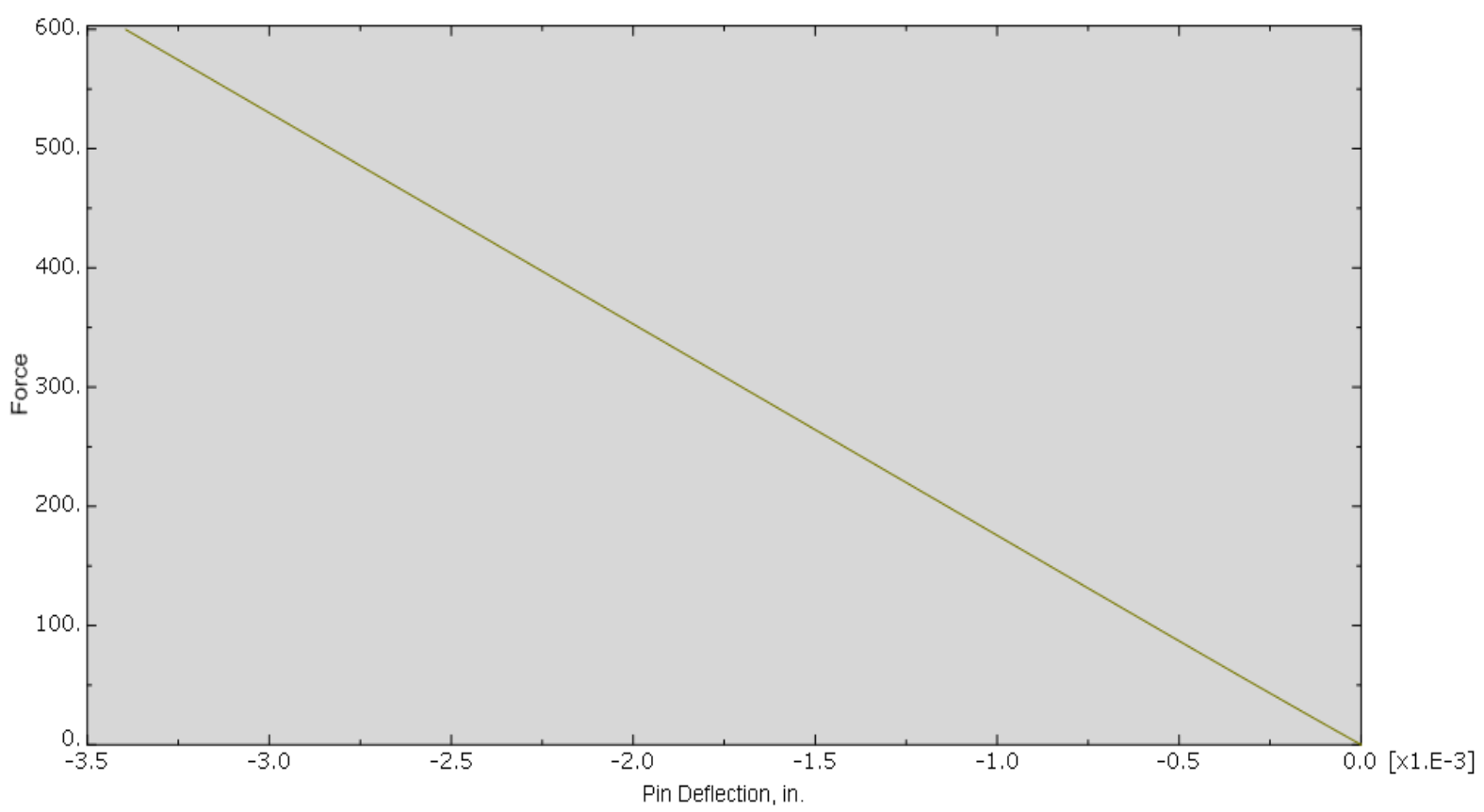

Figure 74. Once combined the force vs. pin deflection plot

\section{A.5. Tutorial on Modeling the Double Shear Bearing Specimen Assembly}

Open up Abaqus 6.14. The numerical model should look like something like this. The complete assembly, the pin and one of the side plates modeled with Abaqus 6.14. 

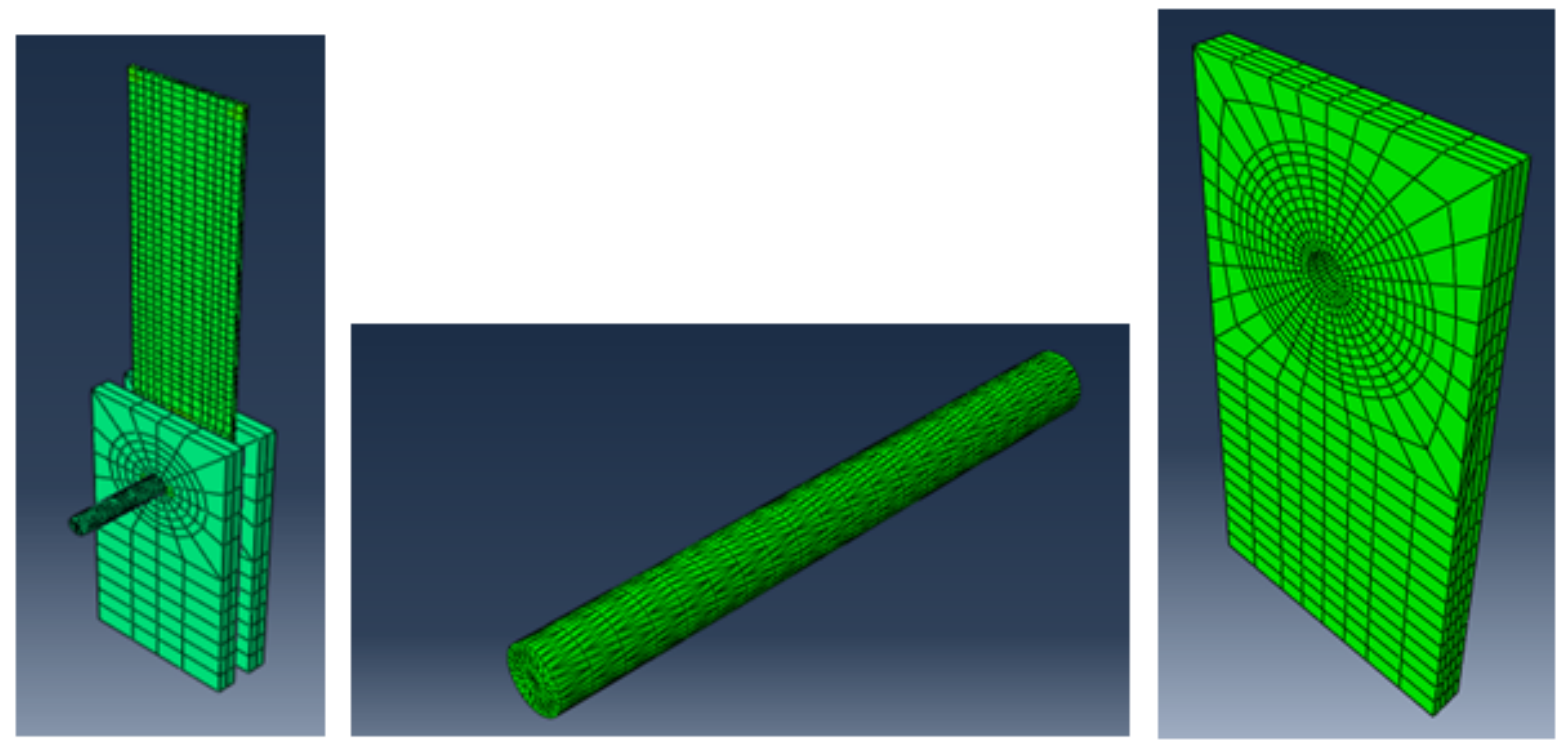

Figure 75. Finished parts for numerical model

\section{A.5.1. Model Creation}

Create a new model by right clicking the Models category. Name it DoubleShear. Then press Ok. 


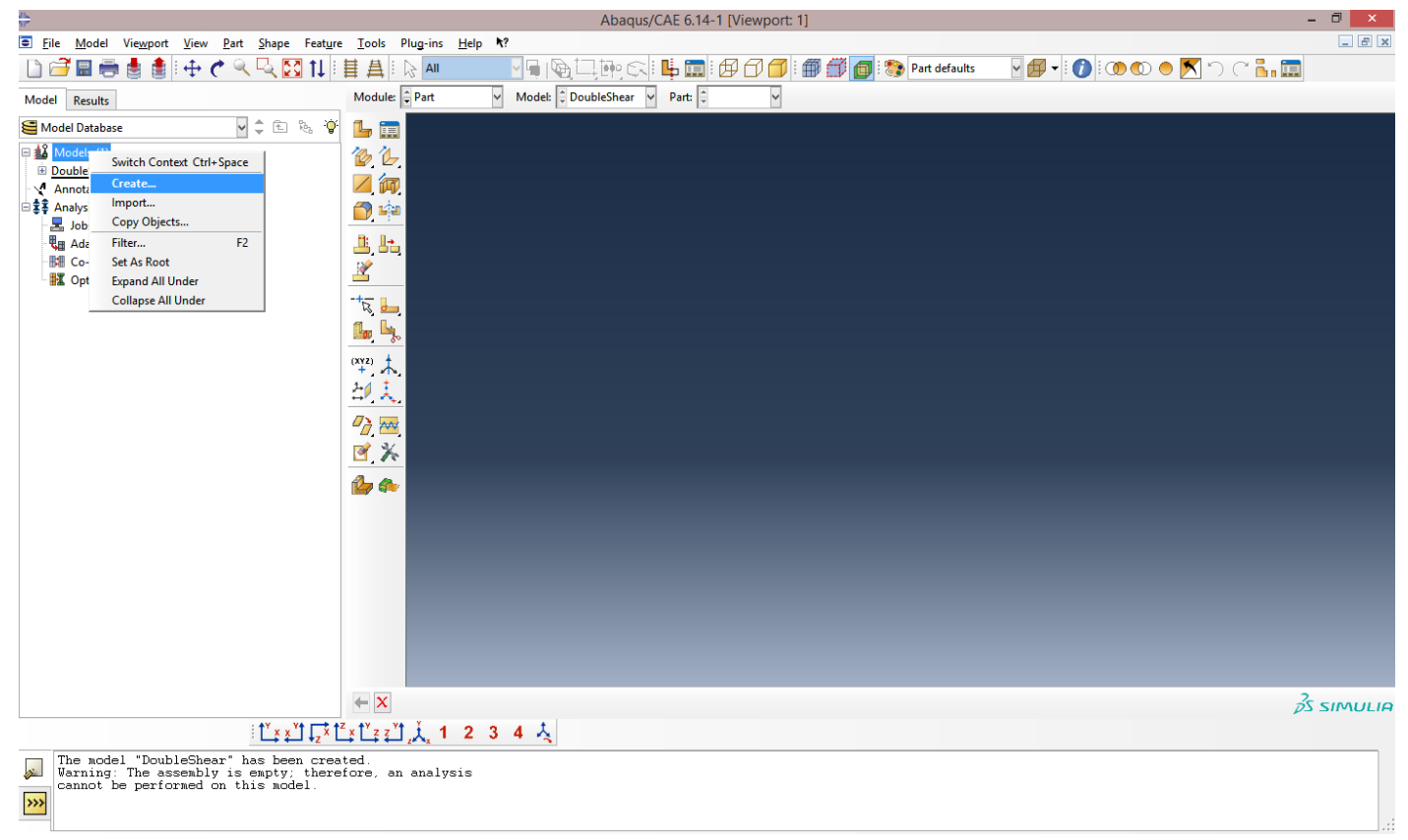

Figure 76. Model creation menu

\section{A.5.2. Part Creation}

Next, we have to create the parts for the model, after that, we partition each of the parts. Click on the + button to expand the options inside the DoubleShear model. Right click on Parts and press Create. A menu will appear like the one shown below. Name the part SteelPin. Keep the modeling space: 3D, the type: deformable, the base feature shape: Solid and for the base feature type: Extrusion. Click continue. 


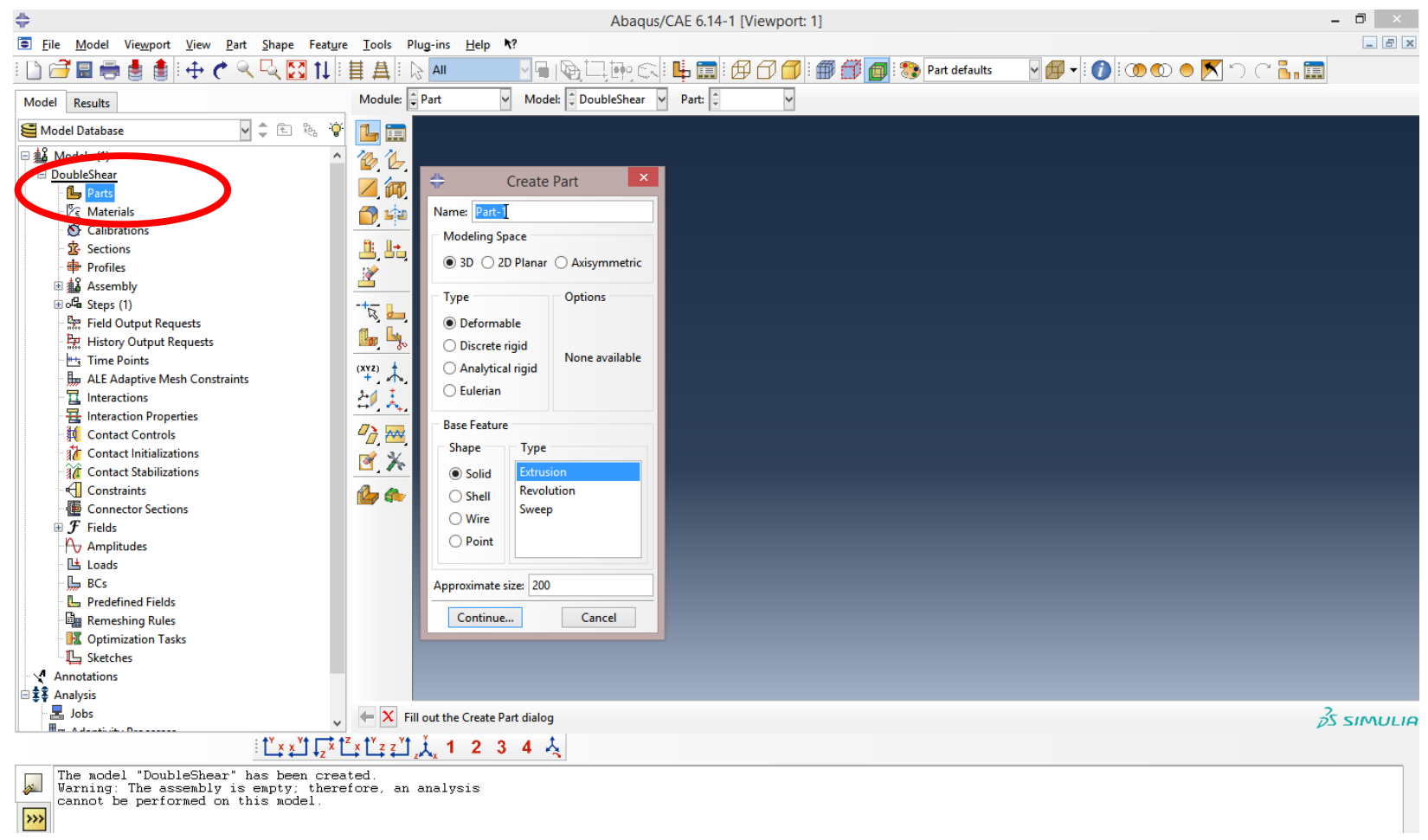

Figure 77. Part creation menu

Click the Create Circle button.

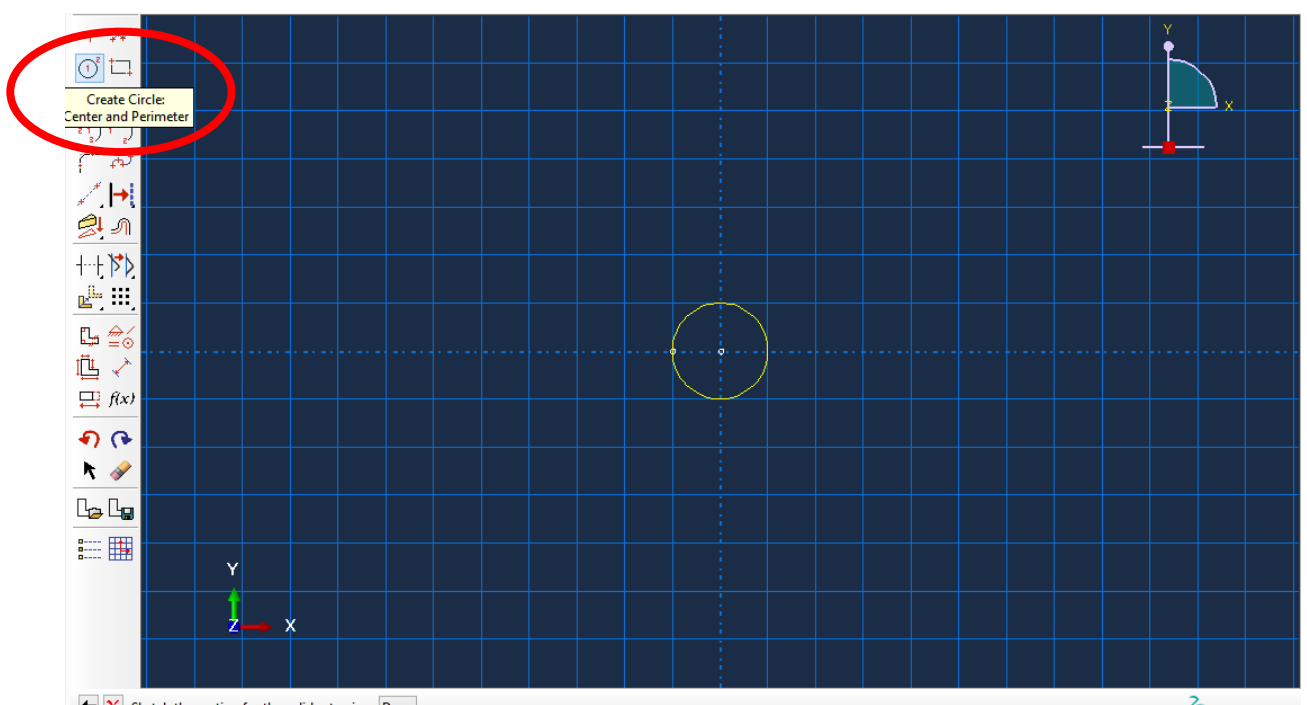

Figure 78. Part sketch window (for pin) 
Using the dimension tool below set the radius to 0.125 in. Always be consistent with your units (I am using inches).

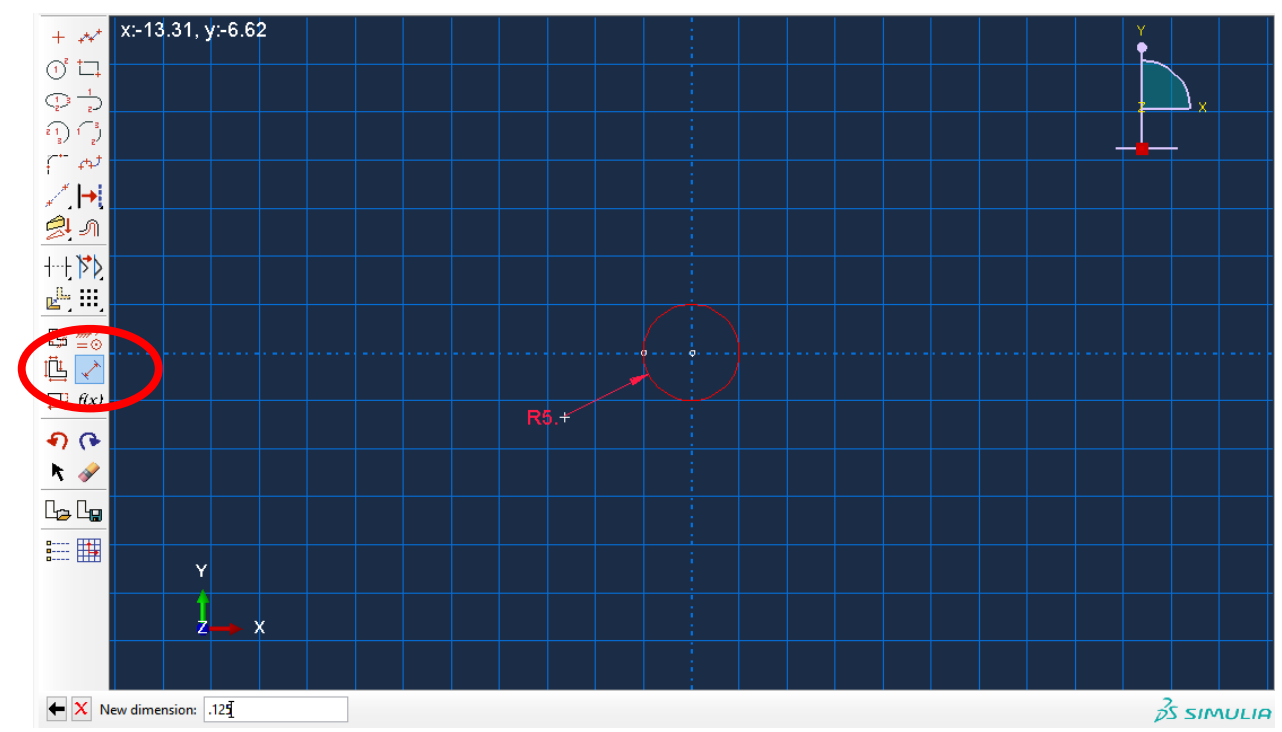

Figure 79. Part dimension tool (for pin)

Next, set the Depth to 2.5 since that was the length of the pin. This will extrude the pin out. 


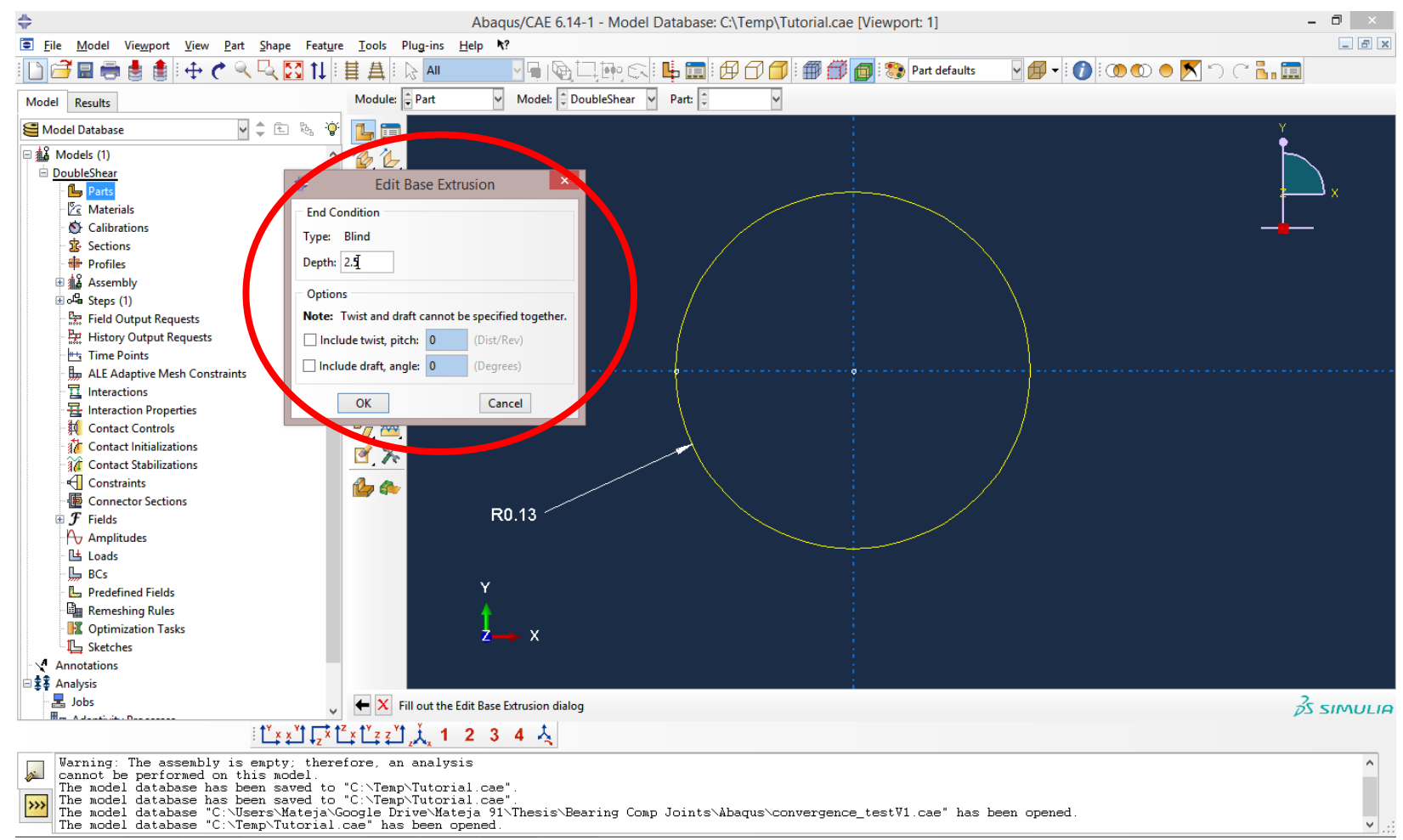

Figure 80. Base extrusion menu (for pin)

Next, we need to create the double shear specimen. Copy the step above and only change the name of the part to Specimen. Use the rectangle tool (to the right of the circle tool) and make a basic rectangle. 


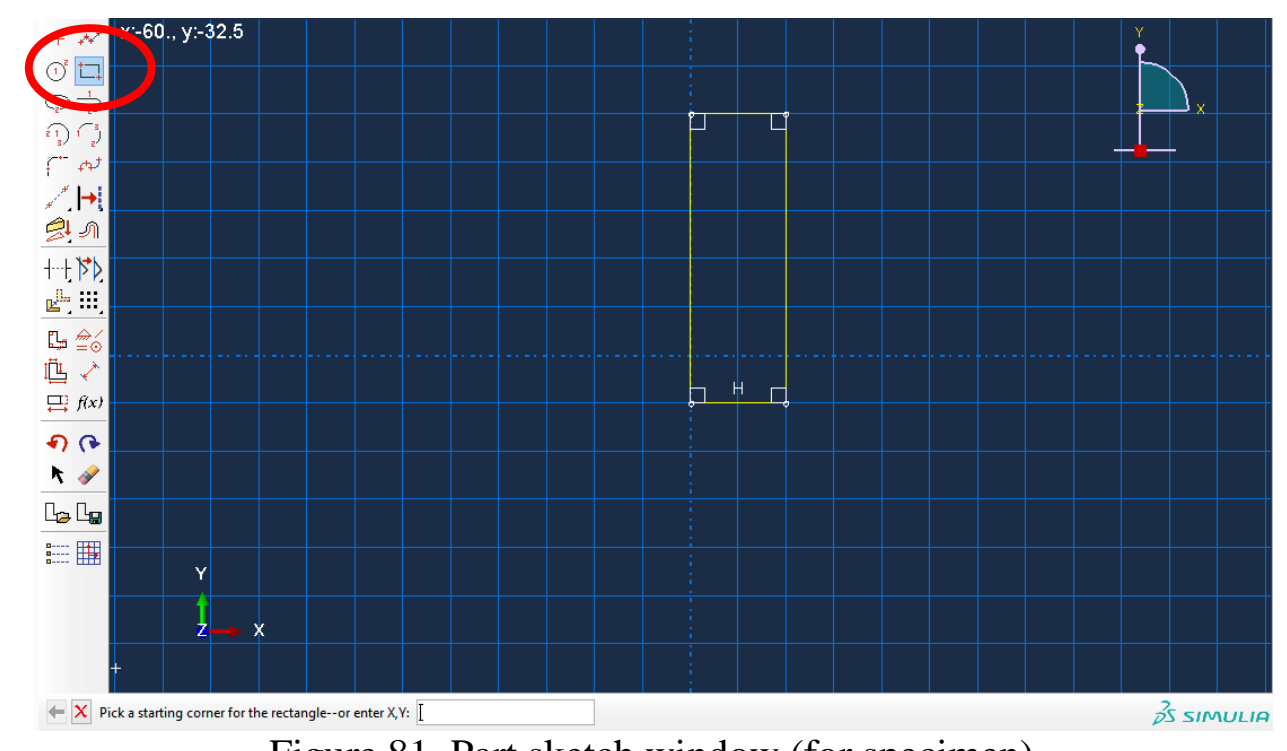

Figure 81. Part sketch window (for specimen)

Using the dimension tool set the width of the part to $1.5 \mathrm{in}$. and the length of the part to 5.5 in. Create a Line down the middle of the part. Locate the center of hole 0.75 in. from the bottom edge of the specimen and make sure the hole is centered along the specimen's width.

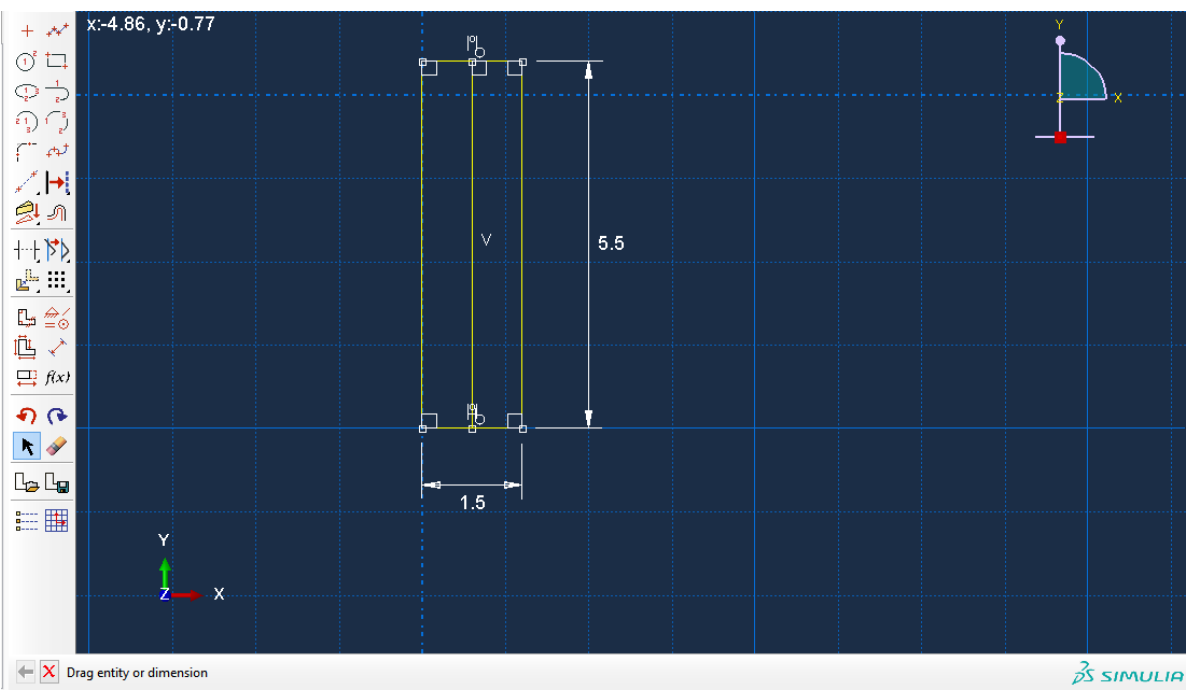

Figure 82. Dimensions \#1 (for specimen) 


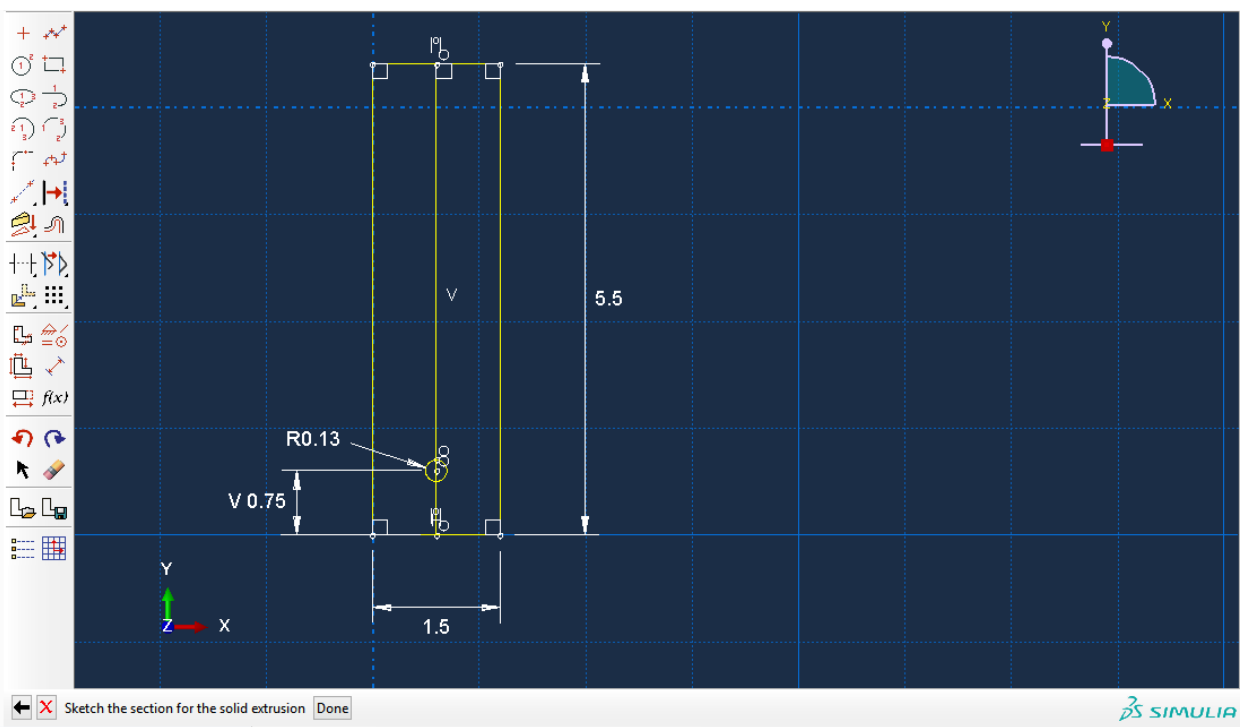

Figure 83. Dimensions \#2 (for specimen)

Now, delete the centerline with the eraser tool, which is highlighted and then click on the centerline (which should highlight in red) and click done. Click the eraser tool to disable it.

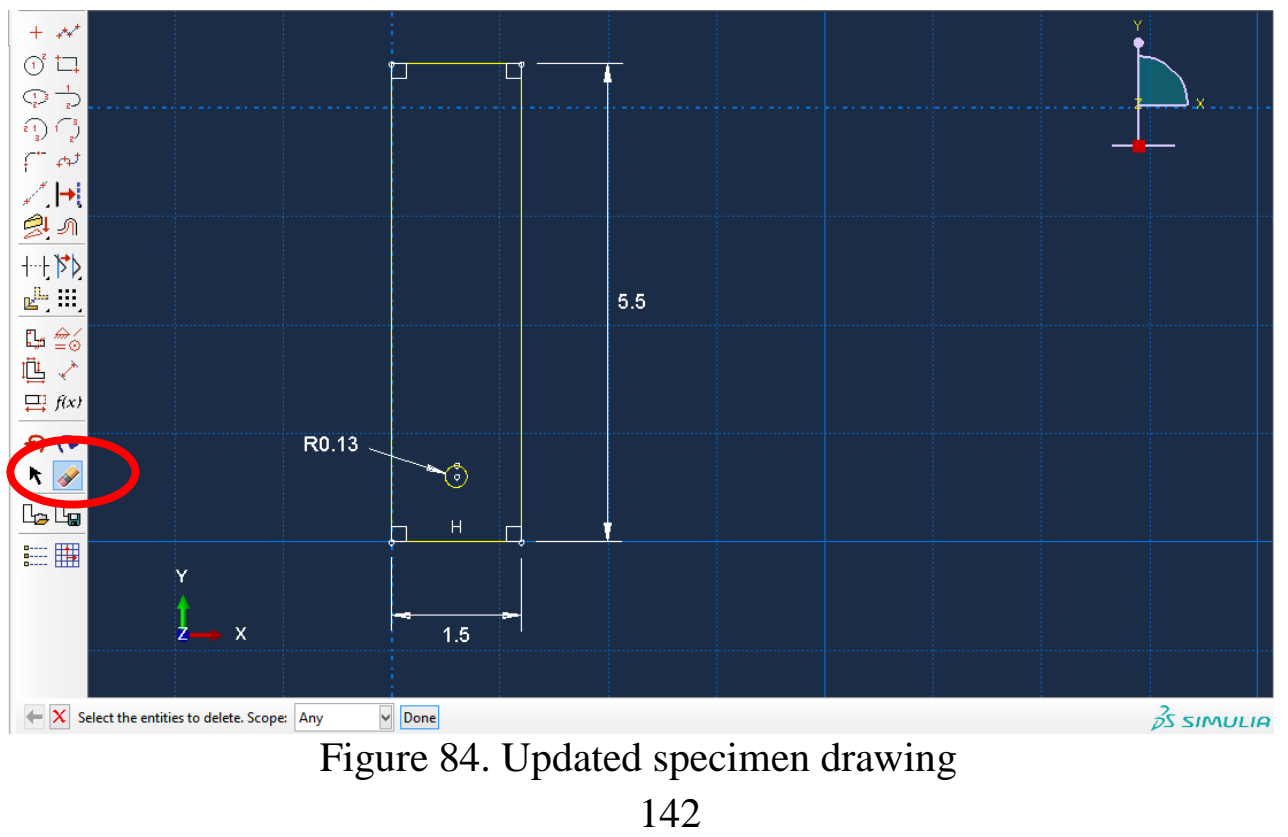


In the bottom of the drawing window, it should read, "Sketch the section for the solid extrusion". Click the Done button. Set the depth to $0.1 \mathrm{in}$. Since the carbon fiber specimen's thickness was $0.1 \mathrm{in}$.

Next, we need to create the side steel plate. Copy the step above and only change the name of the part to SidePlate.

Use the rectangle tool (to the right of the circle tool), make a basic rectangle, and use the circle tool to create a hole in the plate. The side steel plate should be 2 in. by 4 in. and it should have a $0.141 \mathrm{in}$. radius hole. Which is located $1.0 \mathrm{in}$. from the top of the side plate.

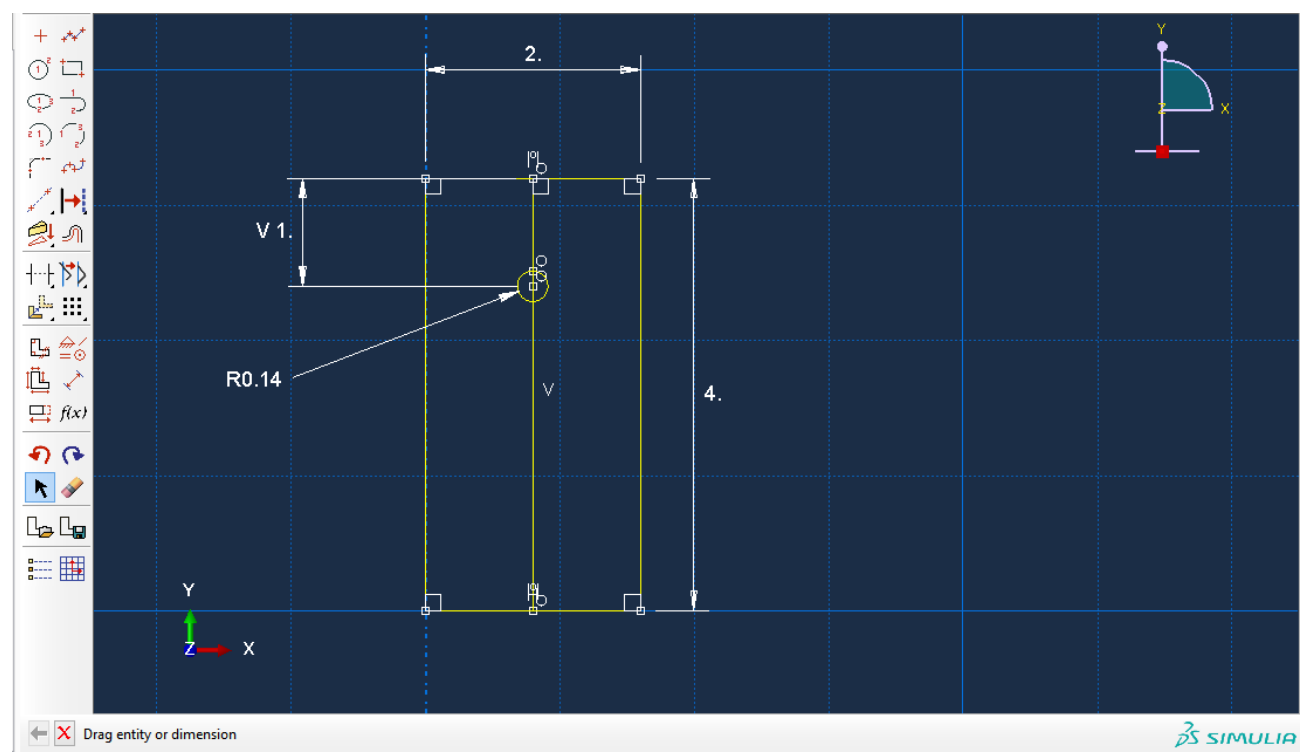

Figure 85. Dimensions (for side plate)

Lastly, remove the centerline and then set the depth to 0.25 in. Since the side steel plates had a thickness of $0.25 \mathrm{in}$. The three parts should look like this once they are completed. 

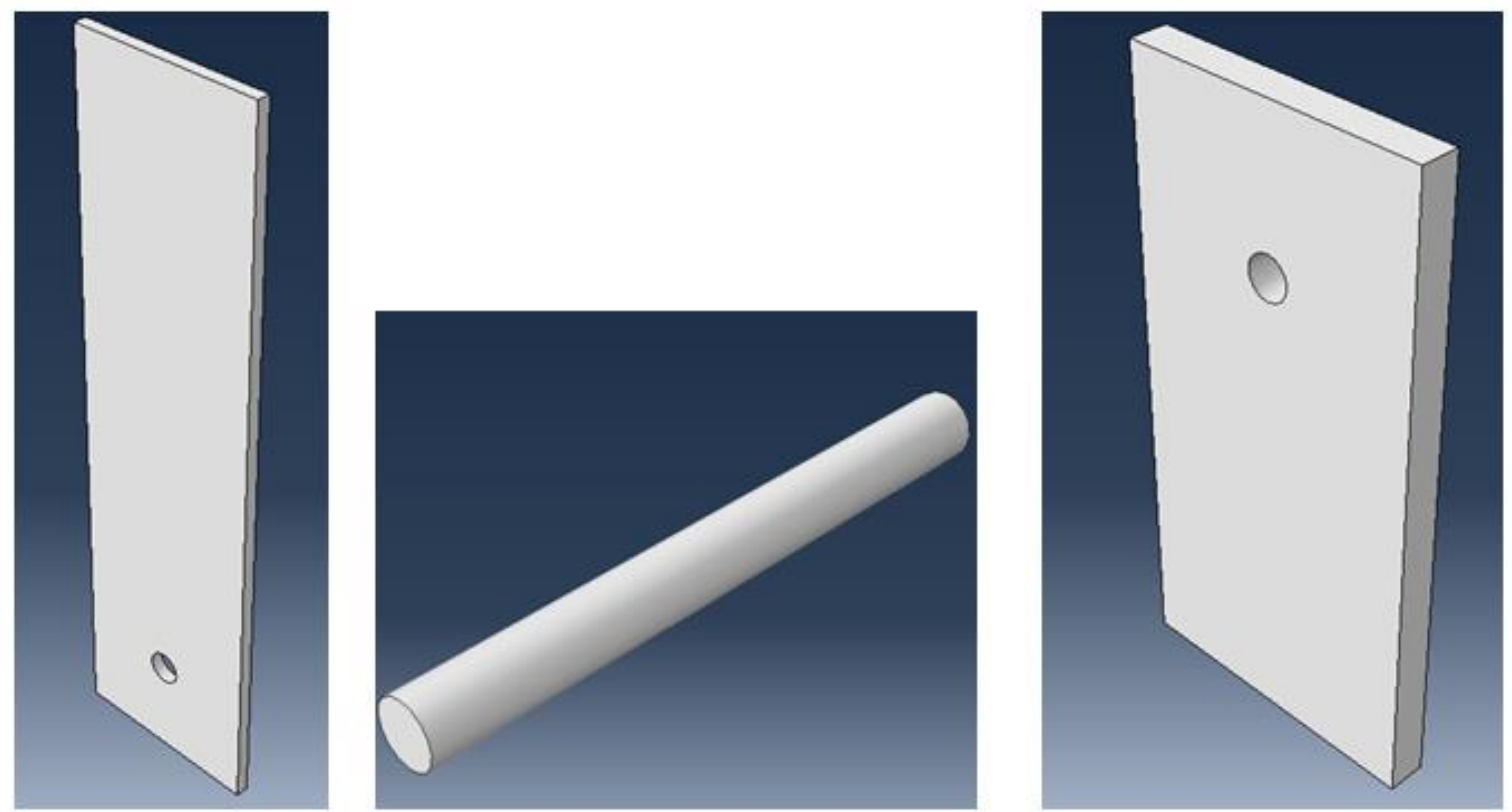

Figure 86. Finished specimen, pin and side plate

\section{A.5.3. Partition Creation}

A partition was created on the side plates and on the specimen. This made sure that when the mesh was generated all the elements stayed symmetrical. One major source of error in finite element analysis is due to elements not being symmetrical and the same size. One way to avoid this problem is to create your own mesh, which requires the user to partition the part based on what is of interest to $\mathrm{him} / \mathrm{her}$.

Pick Tools, in the top drop down menu, and choose Partition. Click Face for the partition type and then click on the side plate face highlighted in orange. 


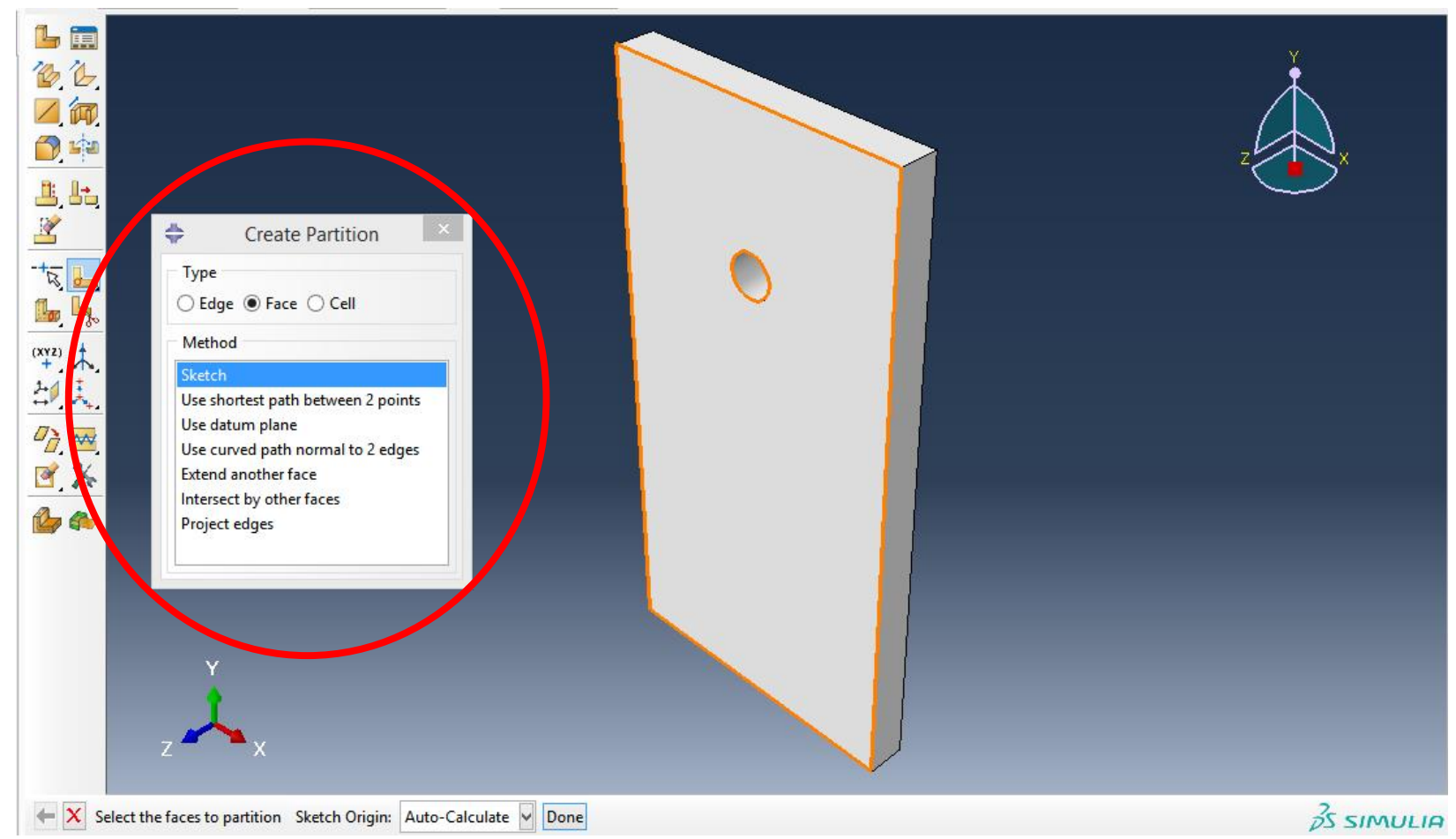

Figure 87. Partition creation screen (for side plate)

Click Done and then it will ask to click a line vertical and to the right. Shown below, the highlighted edge is shown in pink, and the non-highlighted edges are shown in red. The part will switch from $3 \mathrm{D}$ to $2 \mathrm{D}$ and then here the user is able to create the partition desired. Create the partition below with these dimensions using the circle and line tools. It is important to keep the mesh coarse on parts which are not of main interest. 


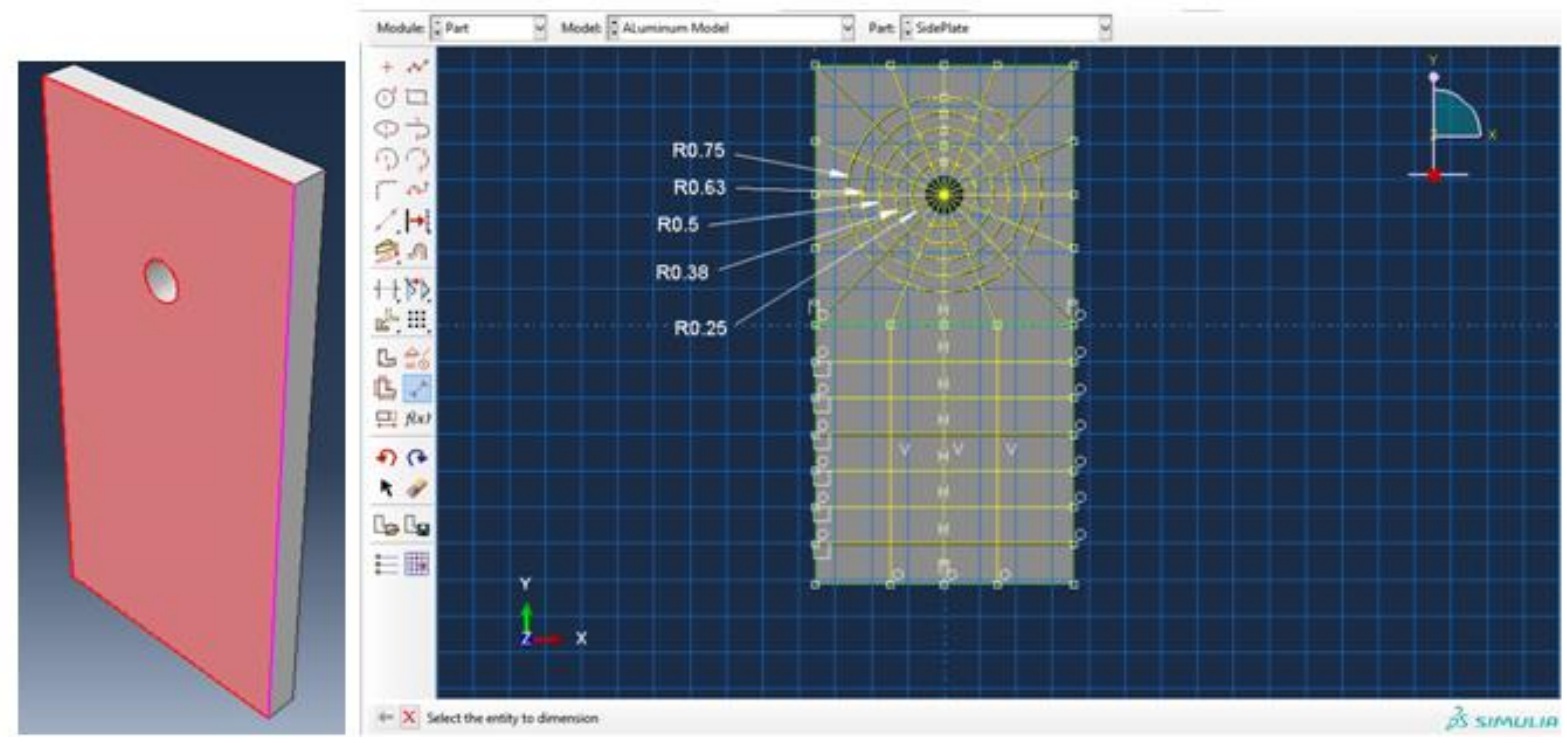

Figure 88. Final partition dimensions (for side plate)

Apply the same method to the double shear specimen. The partition on this specimen was a lot more detailed than on the steel side plate. There are six circles, which are all equally spaced apart. The three outer radii were 0.5 in., 0.375 in., and 0.625 in. The three inner radii were 0.1875 in., 0.25 in., and 0.3125 in. A finer partition was created on the three inner radii where the circle was segmented into 64 equally spaced smaller sections. 


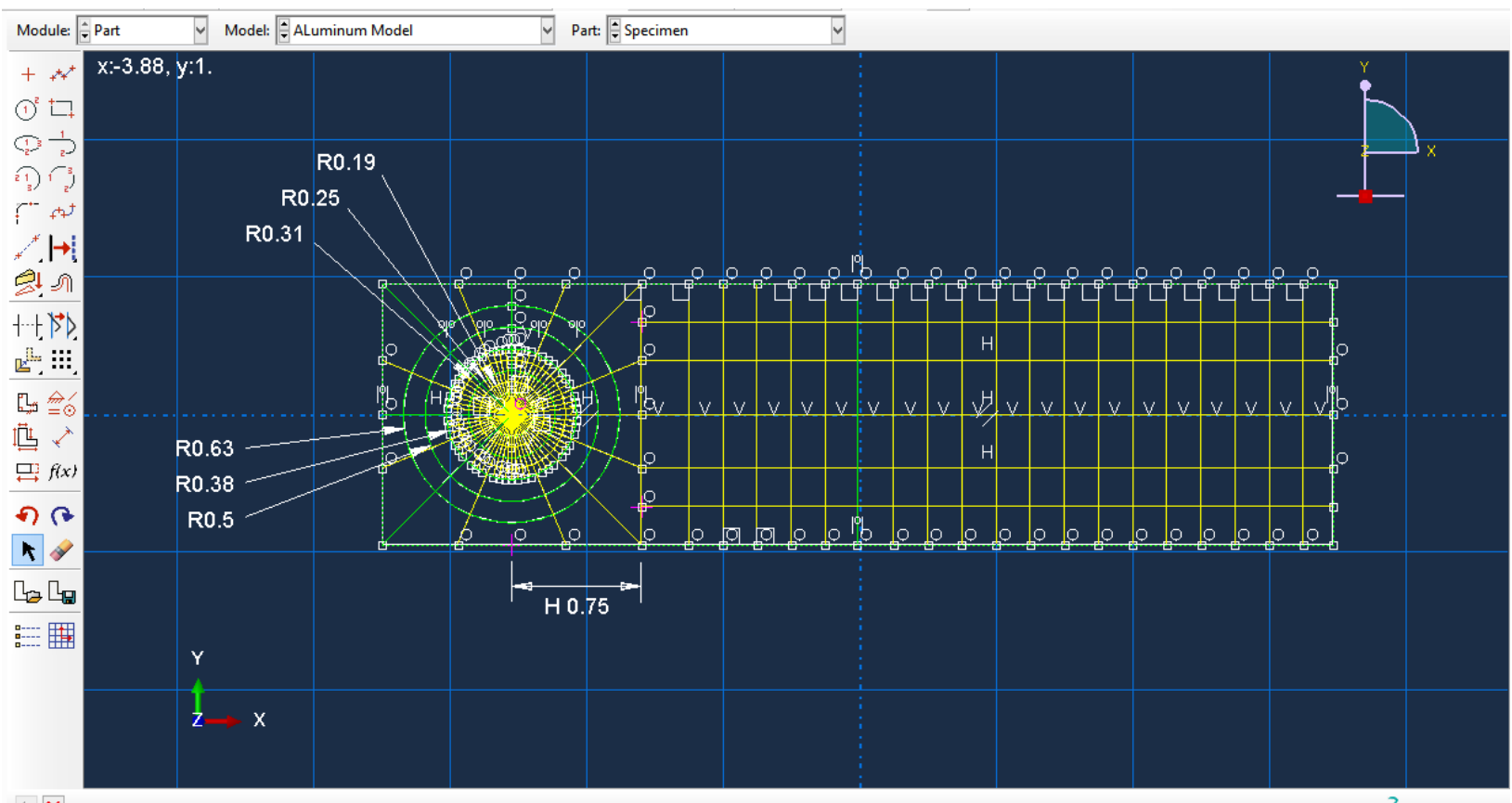

$\leftarrow X$ Drag entity or dimension

Figure 89. Final partition dimensions (for specimen)

The final partitioned parts should look like this.
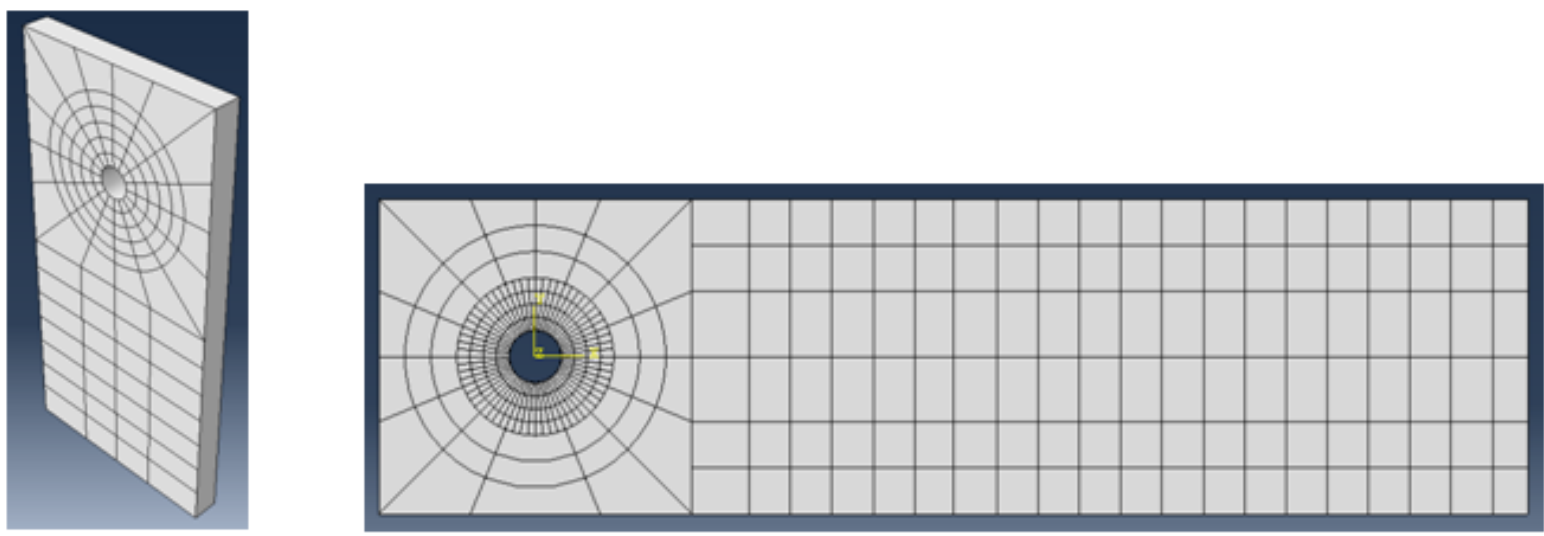

Figure 90. Final partitioned parts 


\section{A.5.4. Material Creation}

The material properties need to be created. Two materials were used in the analysis: steel and a unidirectional carbon fiber material. Under the Parts category, right click and click create. Name the material Steel.

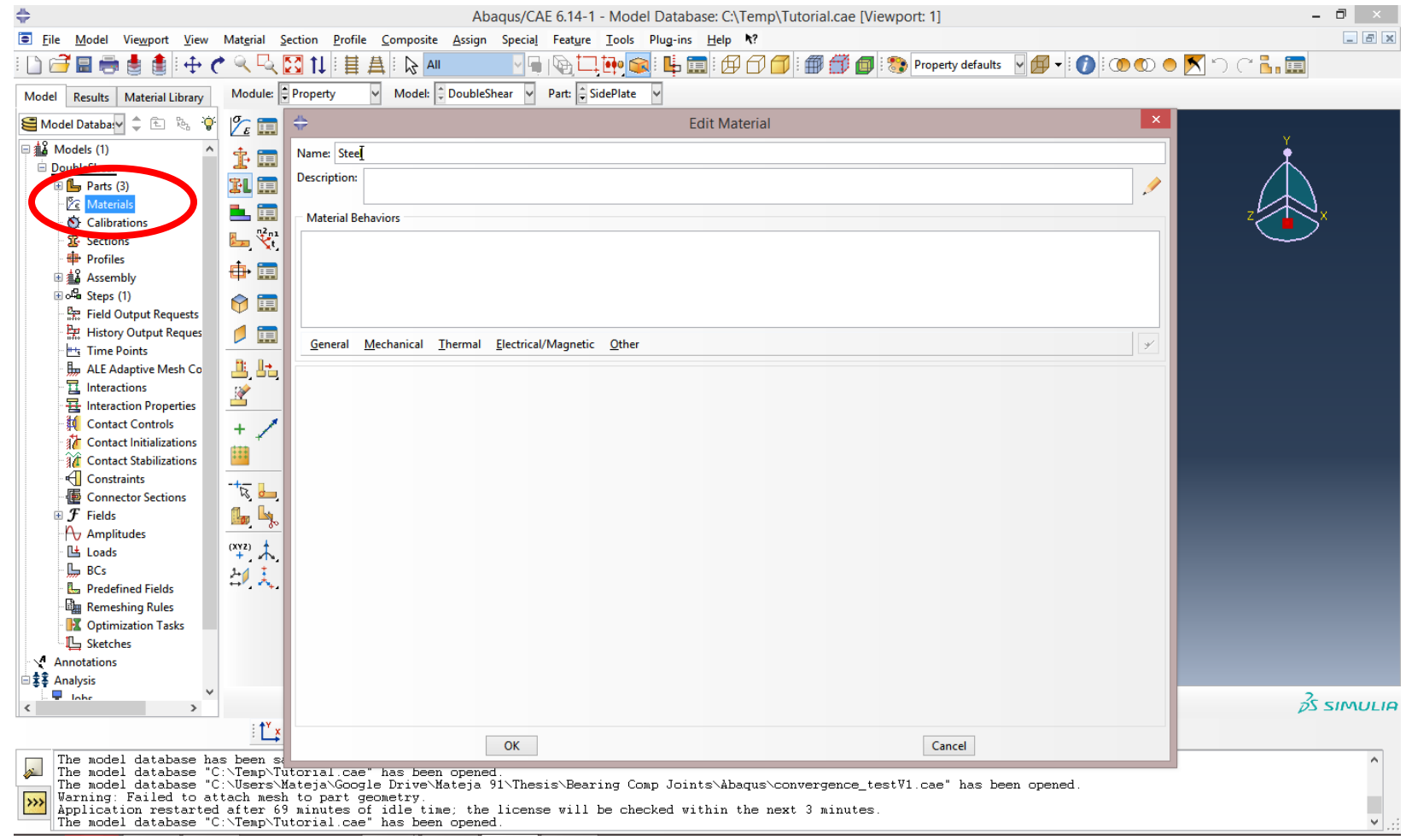

Figure 91. Material creation screen (for steel)

Go into the Mechanical option, then press elasticity, then elastic. Keep the type set to a default isotropic setting. Set the Young's Modulus to $34 \mathrm{e} 6$ and set the Poisson's ratio to 0.3.

Follow the step right above, and create a new material and name it Uni. For the type, select 148 
Engineering Constants. Include the material properties in the Table below (remember that msi is $\left.10^{6} \mathrm{psi}\right)$

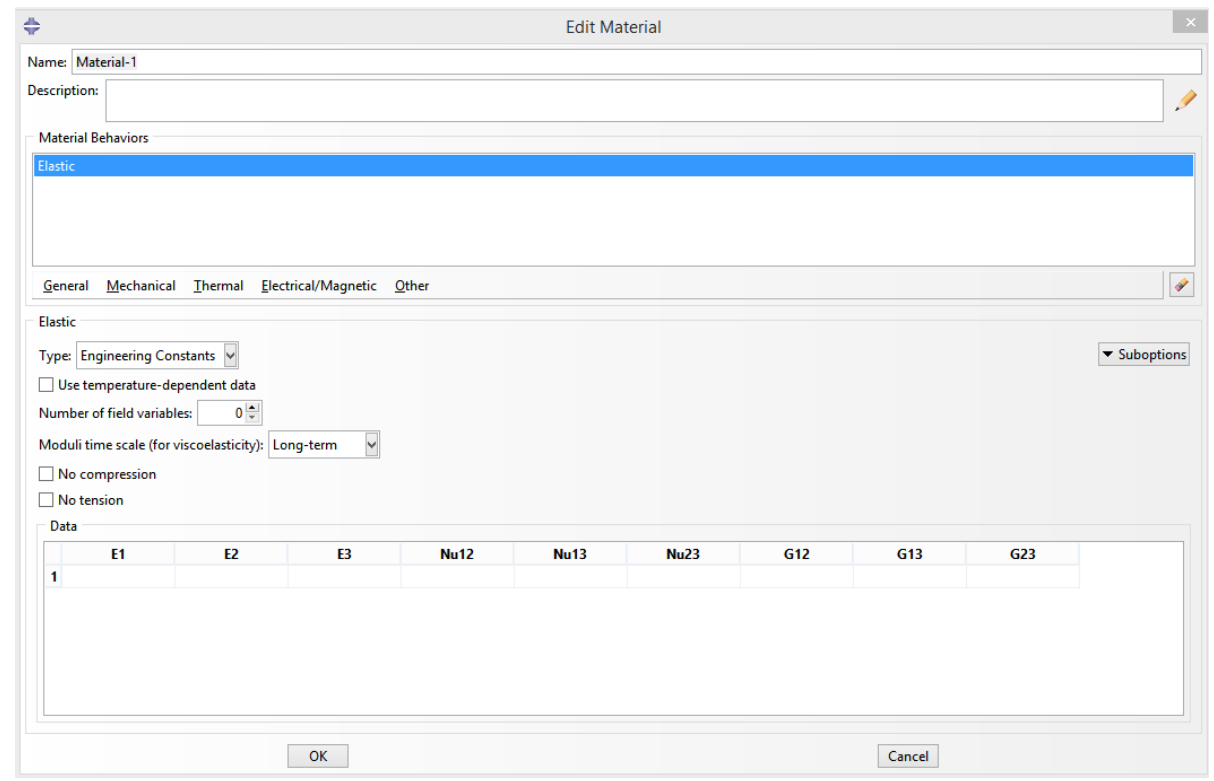

Figure 92. Material creation screen (for uni)

\begin{tabular}{c|c|c|c|c|c|c|c}
$\begin{array}{c}\text { Abaqus } \\
\text { Engineering } \\
\text { Constant } \\
\text { Inputs }\end{array}$ & $\begin{array}{c}\mathbf{E}_{\mathbf{1}} \\
\text { Axial } \\
\text { Modulus, } \\
\text { msi }\end{array}$ & $\begin{array}{c}\mathbf{E}_{\mathbf{2}} \\
\text { Transverse } \\
\text { Modulus, } \\
\text { msi }\end{array}$ & $\begin{array}{c}\mathbf{E}_{\mathbf{3}} \\
\text { Modulus, } \\
\text { msi }\end{array}$ & $\begin{array}{c}\mathbf{G}_{\mathbf{1 2}}=\mathbf{G}_{\mathbf{1 3}} \\
\mathbf{S h e a r} \\
\text { Modulus, } \\
\text { msi }\end{array}$ & $\begin{array}{c}\mathbf{G}_{\mathbf{2 3}} \\
\text { Shear } \\
\text { Modulus, } \\
\text { msi }\end{array}$ & $\begin{array}{c}\mathbf{v}_{\mathbf{1 2}}=\mathbf{v}_{\mathbf{1 3}} \\
\text { Poisson's } \\
\text { Ratio }\end{array}$ & $\begin{array}{c}\mathbf{v}_{\mathbf{2 3}} \\
\text { Poisson's } \\
\text { Ratio }\end{array}$ \\
\hline $\begin{array}{c}\text { MTM 49-LT } \\
\text { Unidirectional }\end{array}$ & 19.9 & 0.99 & 0.99 & 0.302 & 0.398 & 0.244 & 0.257 \\
\hline
\end{tabular}

\section{A.5.5. Isotropic Section Creation}

One section was created for the steel. To make a new section right click Section category and click create. Name it Isotropic, for the category chooses Solid, and for the type choose 
Homogeneous. Click continue, and then choose Steel as the material.
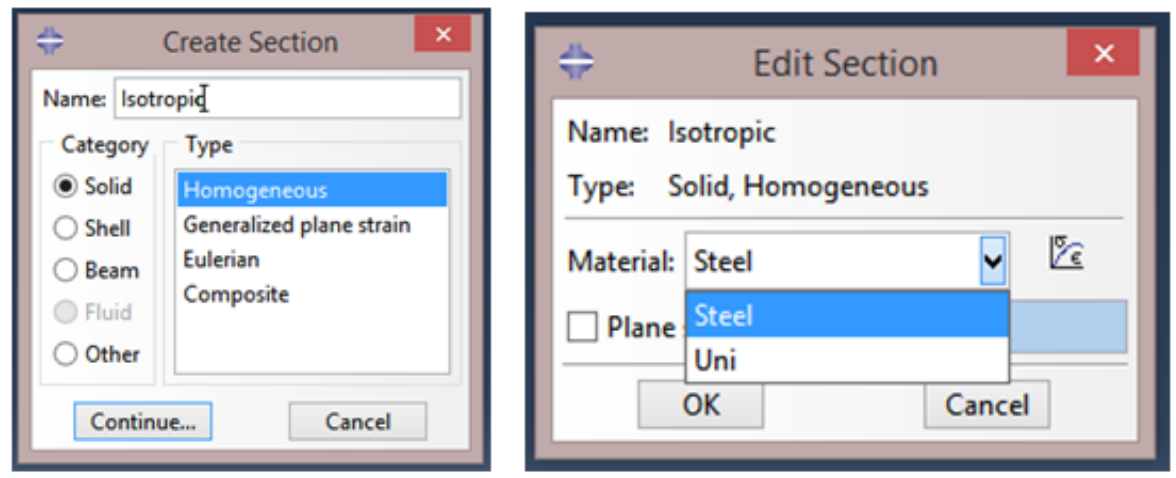

Figure 93. Section creation menu (for a solid/homogeneous material)

Apply the steel section to the steel pin part and the steel side plate. In this step, we also want to duplicate the SidePlate part. Right click on the SidePlate and click copy, name it SidePlate2. Expand the SidePlate options by pressing the $(+)$ icon next to the part name, click Section Assignments, click the part and then it should highlight in red. Click done once selected. For the section choose the Isotropic section which was created then hit Ok. 


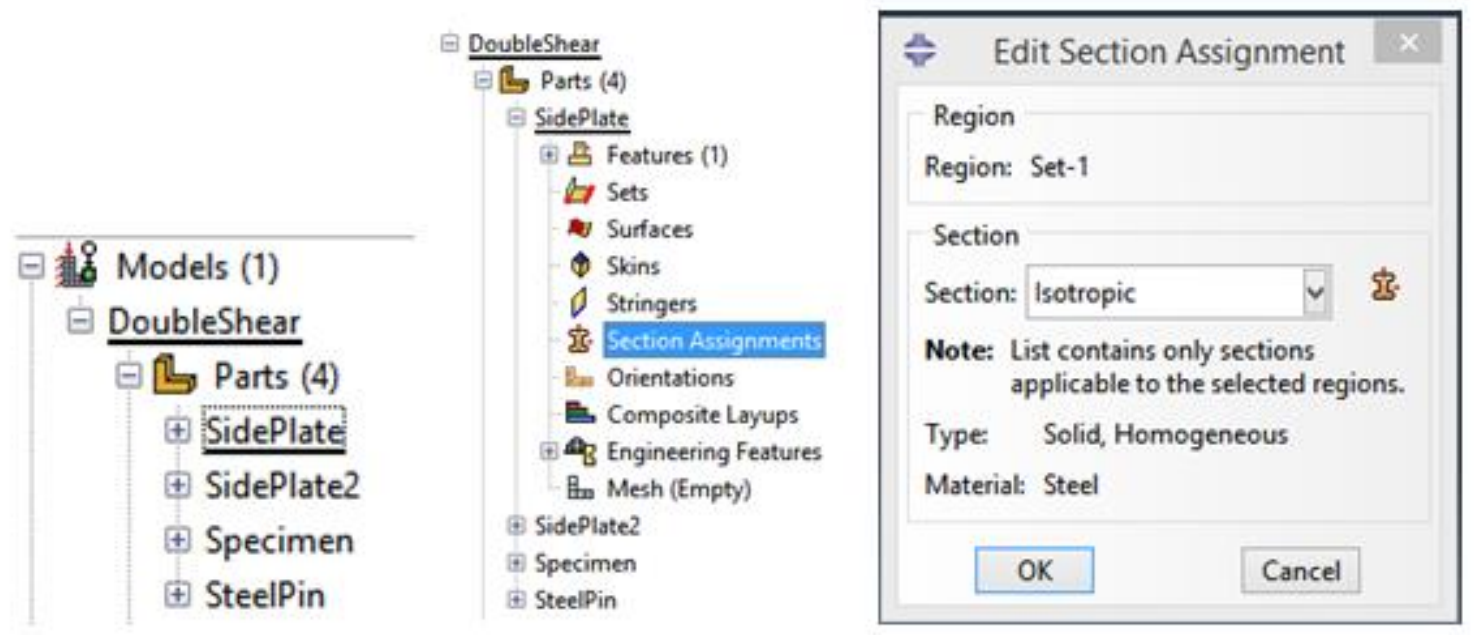

Figure 94. Section assignment screen (for sideplate \& sideplate2)

Apply this same method to the SteelPin part and the Sideplate2 part.

\section{A.5.6. Composite Laminate Section Creation}

The specimen which was created was a carbon fiber laminate composed of 16 layers with an orientation of $[00+45-45+45-459090]_{s}$. Abaqus has a Composite layup tool which is found in each individual part. Keep the name default, set the initial ply count to eight and set the element type to solid. 


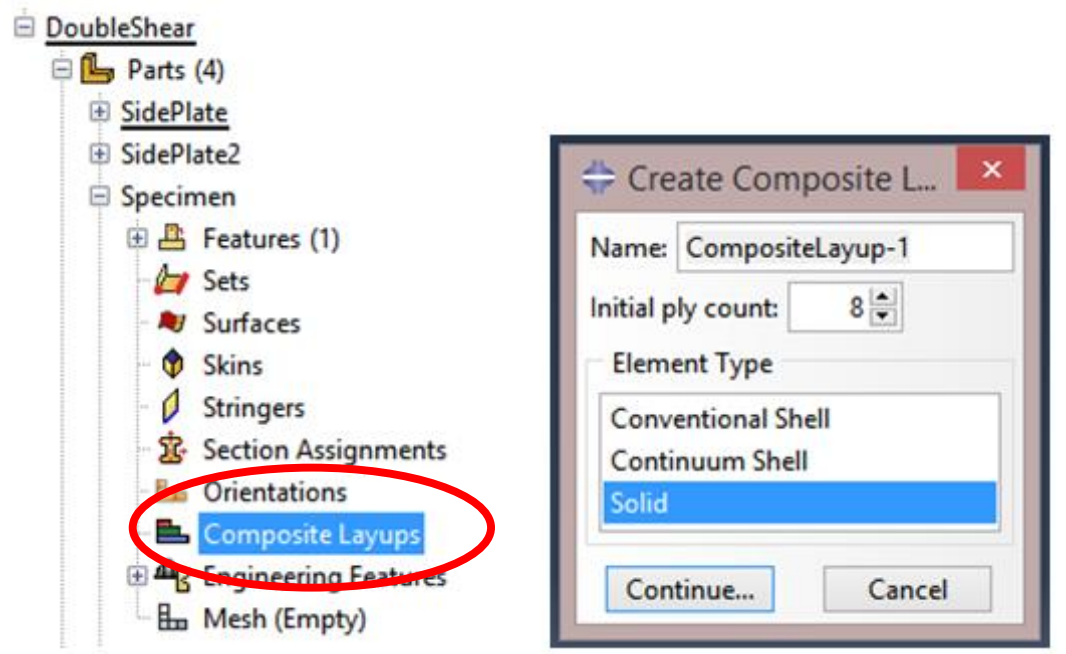

Figure 95. Initial composite layup menu (for specimen)

A new window appears. In this window, all of the laminate stacking directions along with the rotation axis are specified. 


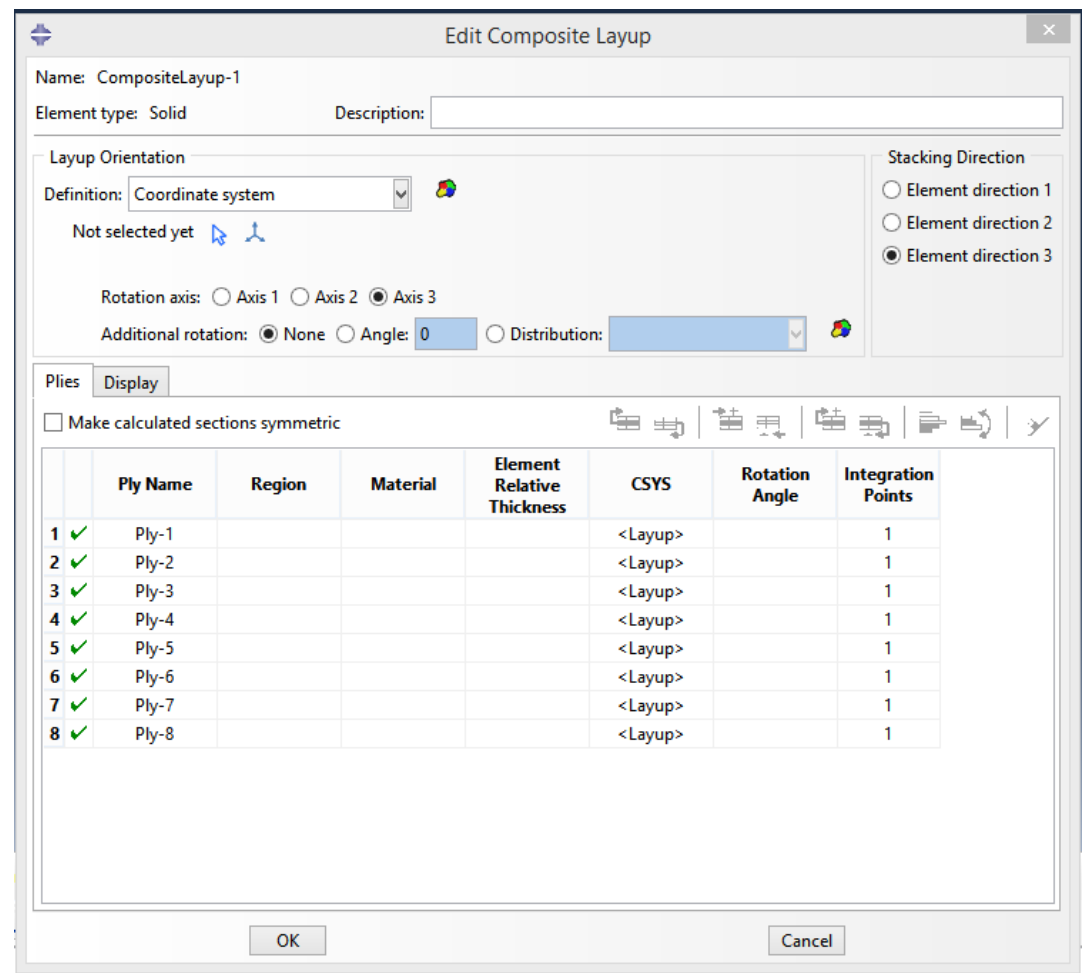

Figure 96. Composite layup menu (for specimen)

Before a layup orientation can be created; a datum coordinate system needs to be defined. Click Create Datum CSYS. Create a rectangular coordinate system and keep the default name. Next, it will ask you to specify a point, click the point in the center of the hole shown below in the figure. Keep the Rotation axis to Axis 3 and keep the Stacking Direction to Element direction 3. Check the box that says, "Make calculated sections symmetric". Since we are only going to specify eight of the plies, which are part of the orientation.

Next, we need to specify where on the part we have this orientation. In the region section, double click it, click on the specimen, and then click the done button. Do that for each layer and then for the material section, choose Uni as the material. The element relative thickness should 
equal the reciprocal of the amount of elements through the thickness of the part. For example, my mesh consists of two element, which span the thickness of the specimen. My element relative thickness was set to $0.5\left(2^{-1}\right)$.
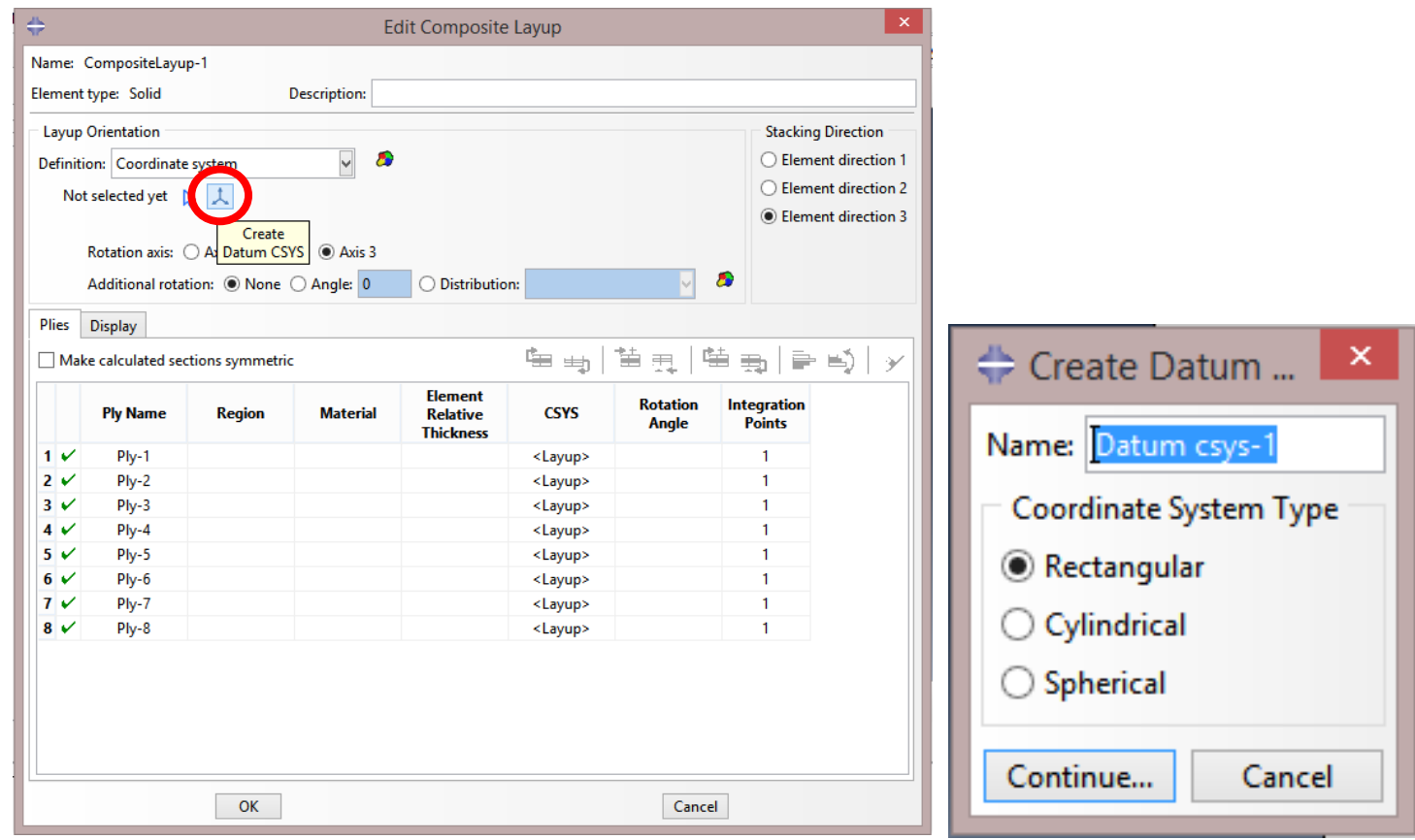

Figure 97. Datum creation tool (for specimen) 


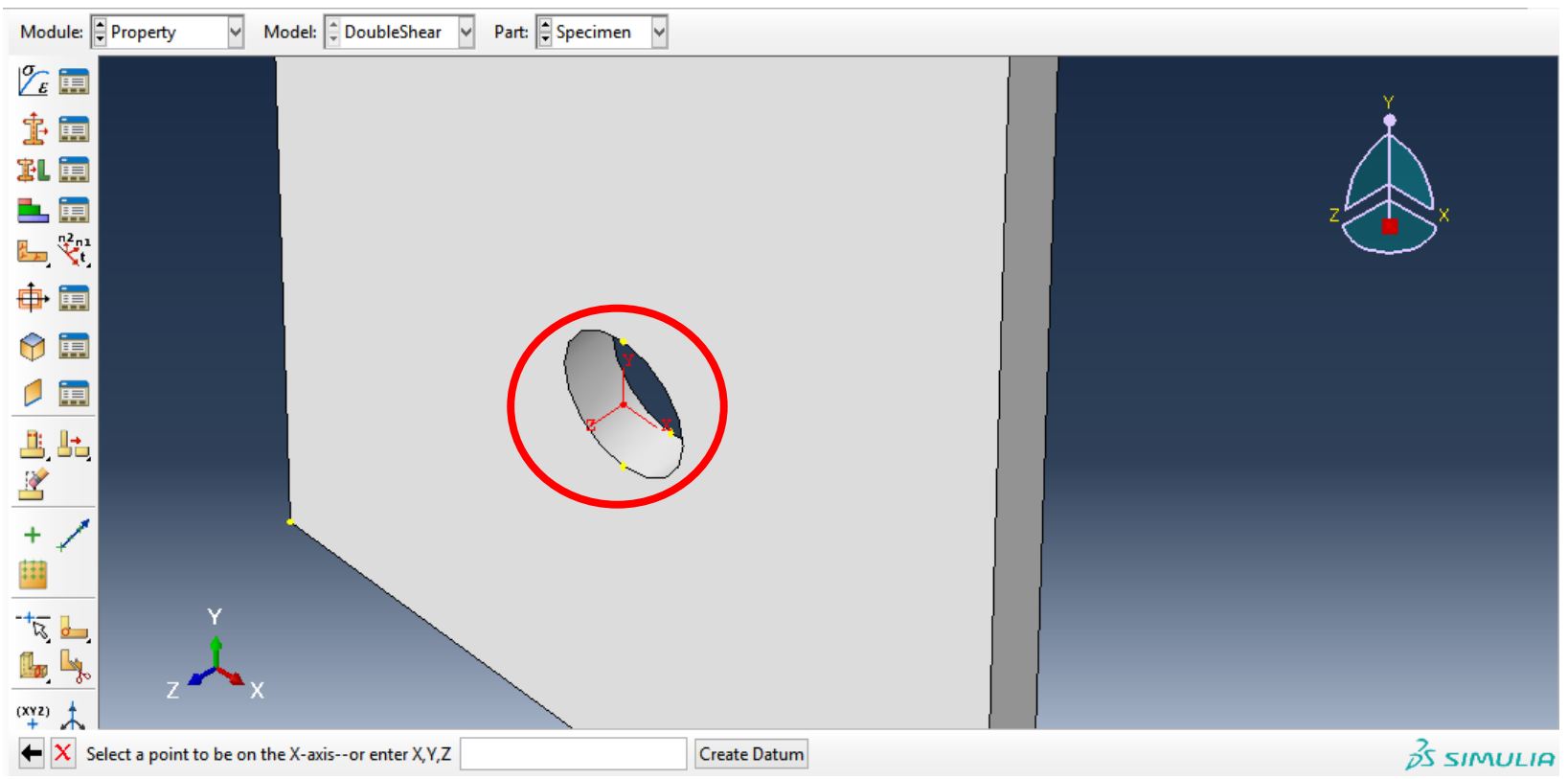

Figure 98. Datum point selection screen (for specimen)

Last of all, set each ply orientation angle starting with the outermost layer. Keep the integration point to one. The result should look like this. 


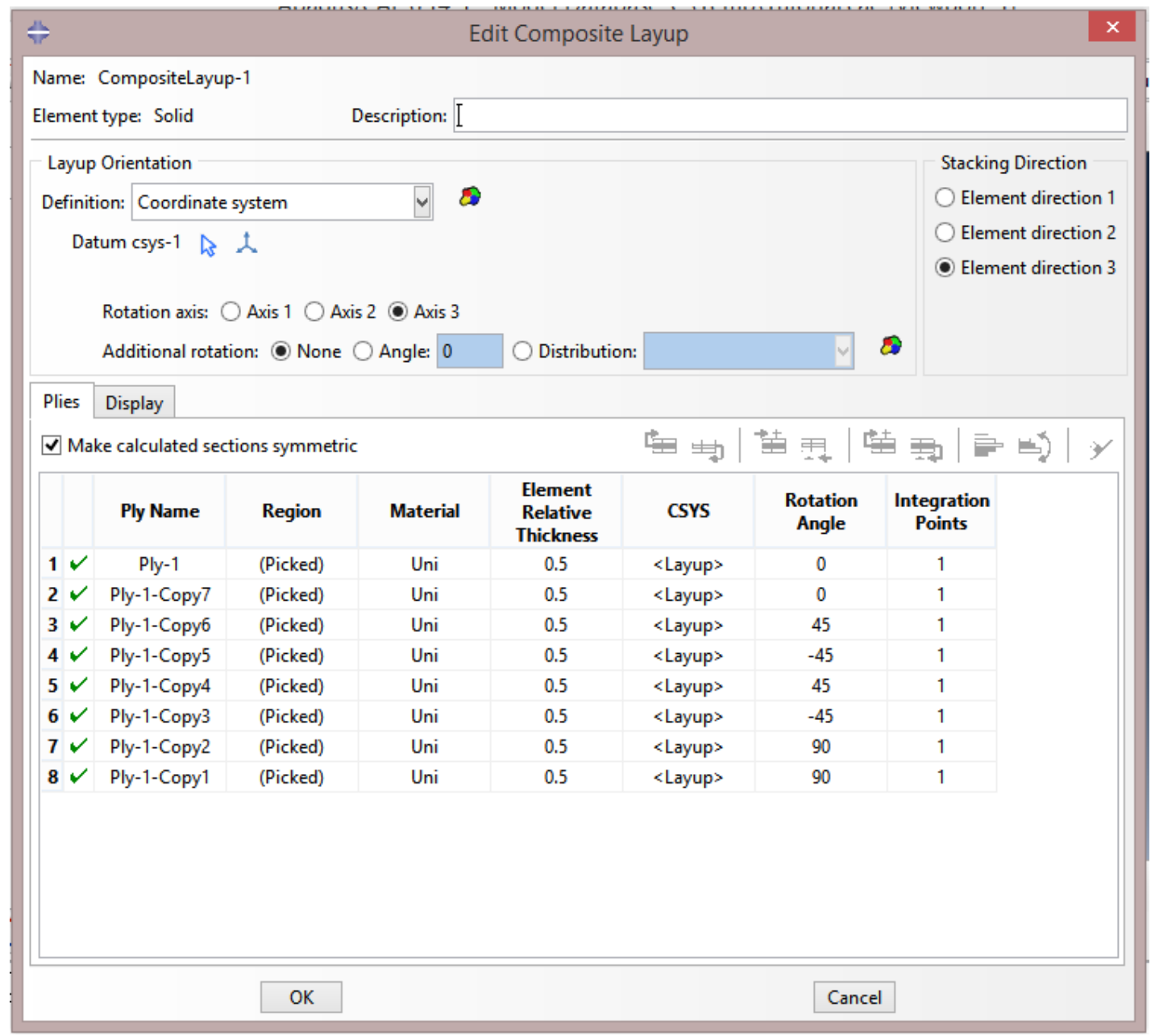

Figure 99. Final composite layup screen (for specimen)

\section{A.5.7. Assembly Creation}

Under the Assembly submenu, create an Instance. Make each of the parts are set as Dependent also make sure to check the Auto-offset from other instances. 


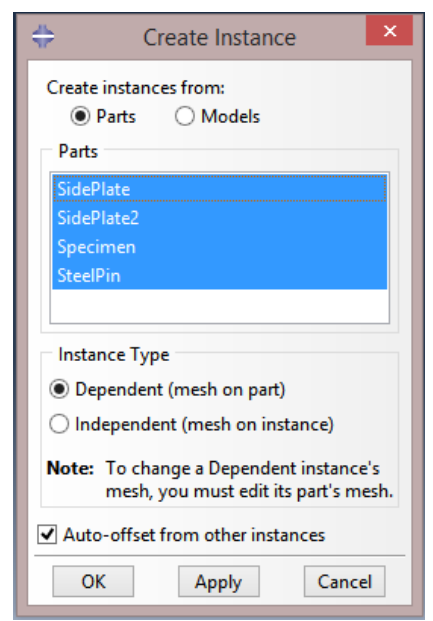

Figure 100. Instance creation menu

The next part requires getting used to Abaqus' assembly options. This can be tricky, but it takes practice. After moving each part around, the final assembly should look something like this below. Make sure the specimen is centered between both of the side steel plates. The specimen should sit 1 in. into the pin, which is how it was loaded in the experiment. The distance between the two side plates is $0.25 \mathrm{in}$. Make sure the top of the pin is touching the top of both of the side steel plates. 

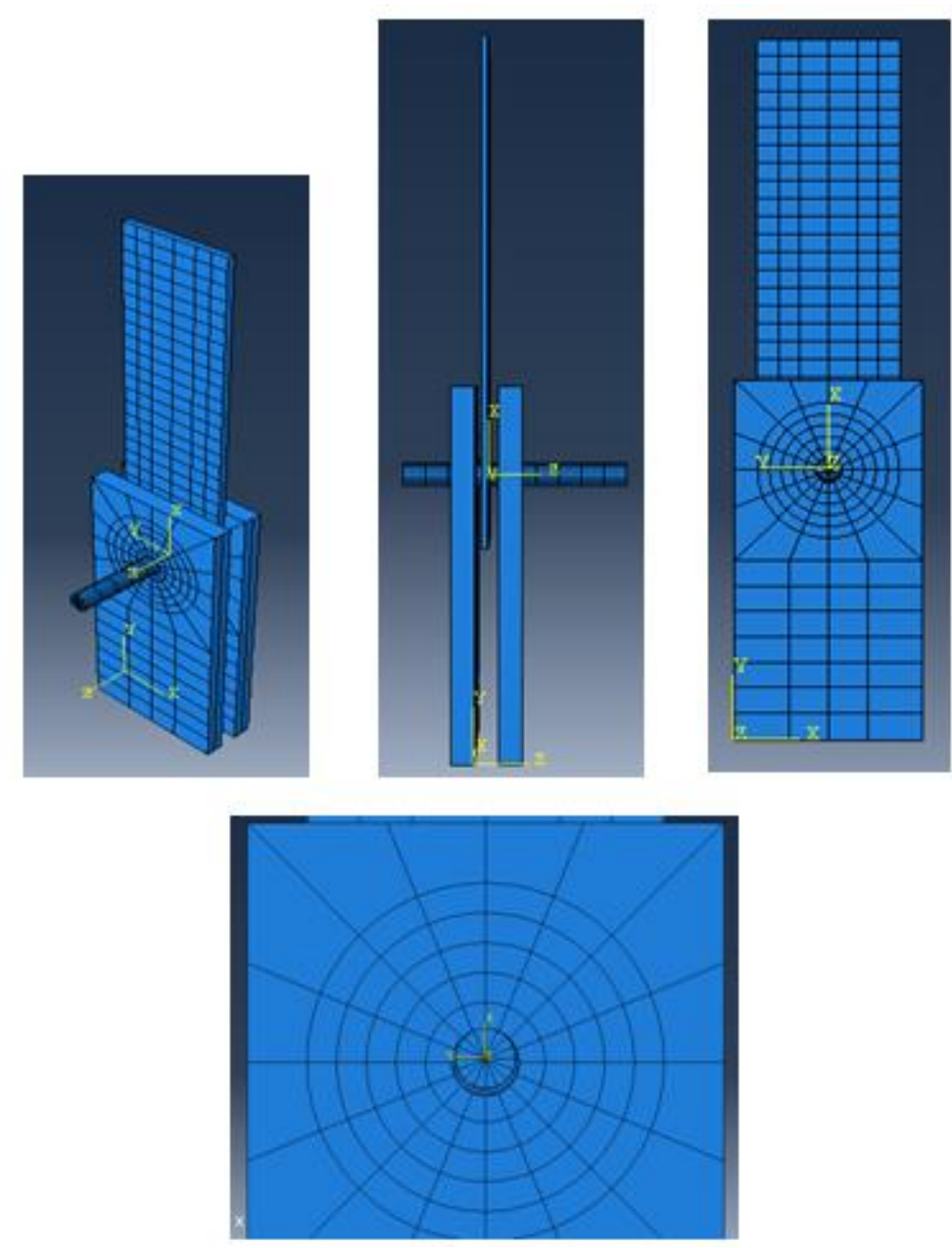

Figure 101. Three views of the assembly (top)

close up of pin and side plate (bottom)

A set needed to be created for a specific node. Abaqus gives you an option to select a specific node of interest and name it whatever you please. Therefore, in my model I wanted to select a node, which is in the middle of the specimen and located at the bottom of the hole. This location is of critical importance to the model because that is the location I want to monitor the vertical 
deflection. This is the location where we will want to compare the experimental extensometer displacement and the nodal displacement in the numerical model.

While in the Assembly module, I created a new set, picked the corresponding node, and named it Monitor. Switch to the Step module and then you will see the main horizontal bar at the top of the screen change accordingly. Now the main horizontal bar should have an Output menu. Click into this menu and click DOF Monitor. There should be an option to toggle on, Monitor a degree of freedom throughout the analysis. Click Edit, and then click Points in the prompt area and choose the node set Monitor from the region selection dialog box. Now we set the Degree of Freedom we want to monitor. In our model, we are interested in the displacement in the Y direction because that is actually, what the extensometer measured in the experiment. As we can see in, we want to monitor the Y-axis displacement so we set the Degree of Freedom to 2. Now we click Ok. 
Table 21. Abaqus' Degrees of Freedom

\begin{tabular}{|c|c|}
\hline $\begin{array}{c}\text { Degrees of } \\
\text { Freedom }\end{array}$ & $\begin{array}{c}\text { Abaqus' } \\
\text { Number } \\
\text { Correlation }\end{array}$ \\
\hline X Axis Displacement & 1 \\
\hline Y Axis Displacement & 2 \\
\hline Z Axis Displacement & 3 \\
\hline X Axis Rotation & 4 \\
\hline Y Axis Rotation & 5 \\
\hline Z Axis Rotation & 6 \\
\hline
\end{tabular}

Surfaces needed to be created for each specific part. A very important feature is located in the surface option, here the user is able to select and define a surface on any particular part in your model. So what I did was define a surface called InnerSpecimen, this was defined as the inner surface of the specimen's hole. The second surface I defined was the outer surface of the pin and named it Pin.

\section{A.5.8. Step Creation}

Two steps need to be created one for the contact step and another for the load step. Abaqus runs the steps in order so first we are going to tell Abaqus that there is contact between some of the parts and after that, contact is established the load step can be applied. Create the contact step 
and make sure all of these match.
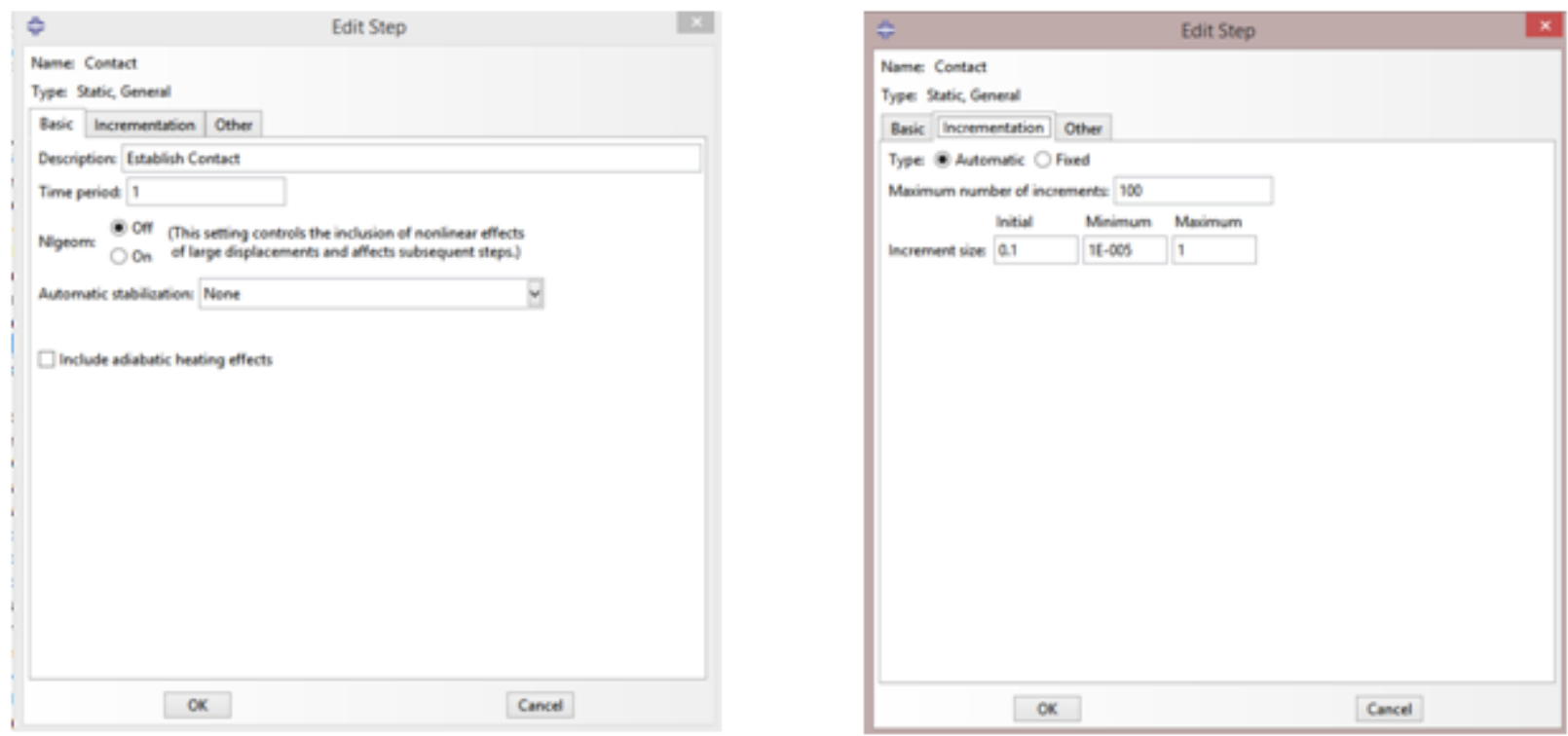

Figure 102. Step creation menu (for contact step)

Create the load step and make sure all of these match. 


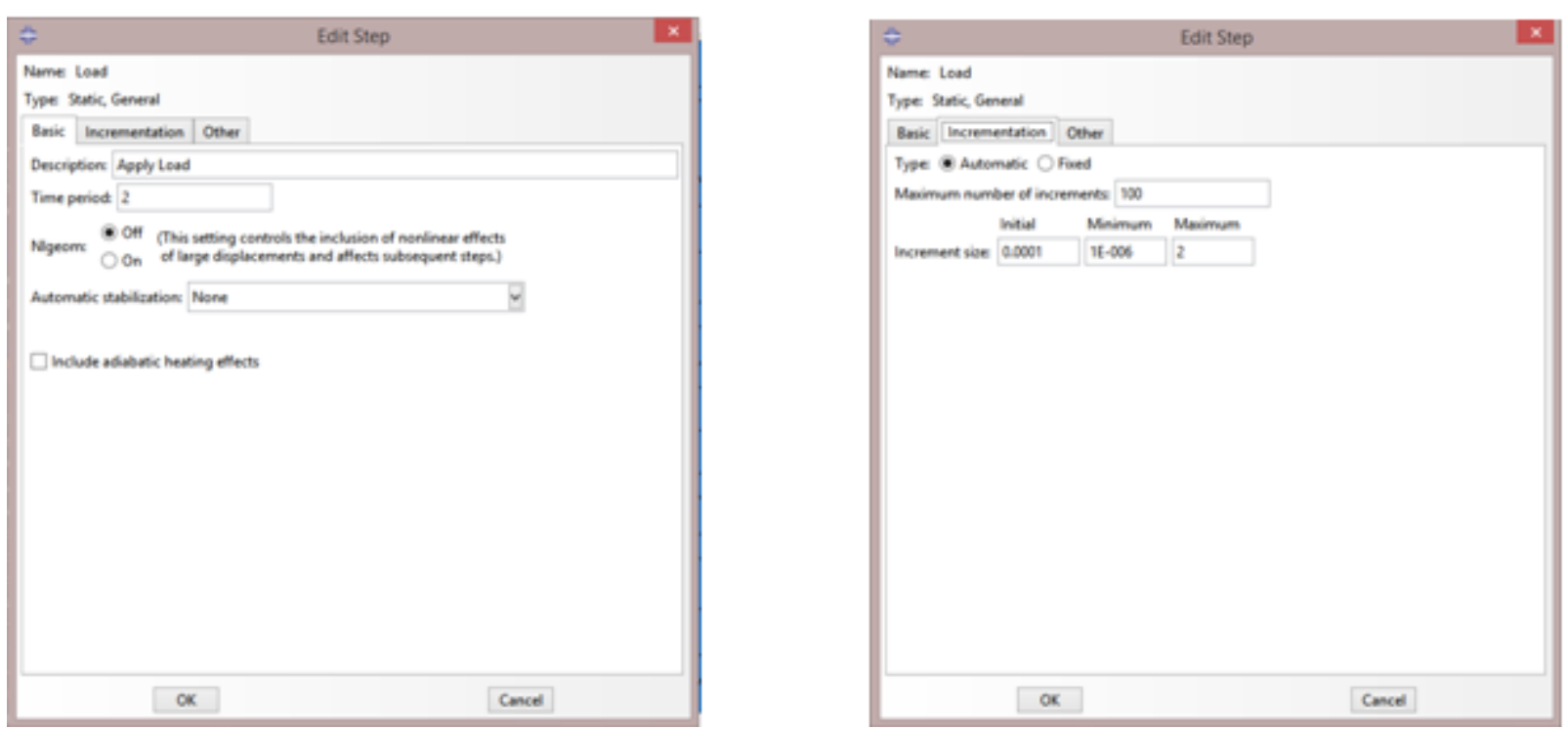

Figure 103. Step creation menu (for load step)

\section{A.5.9. Interaction Creation}

Next, we need to create an interaction between the pin and the specimen along with the two side plates. Right click the Interactions submenu and click Create. Choose Surface-to-surface contact. Keep the name to default and make sure to make it for the Initial Step. Click the outer surface of the pin as the Master Surface. After this step, go into the assembly and hide the SteelPin part by right clicking on it, and selecting Hide. 


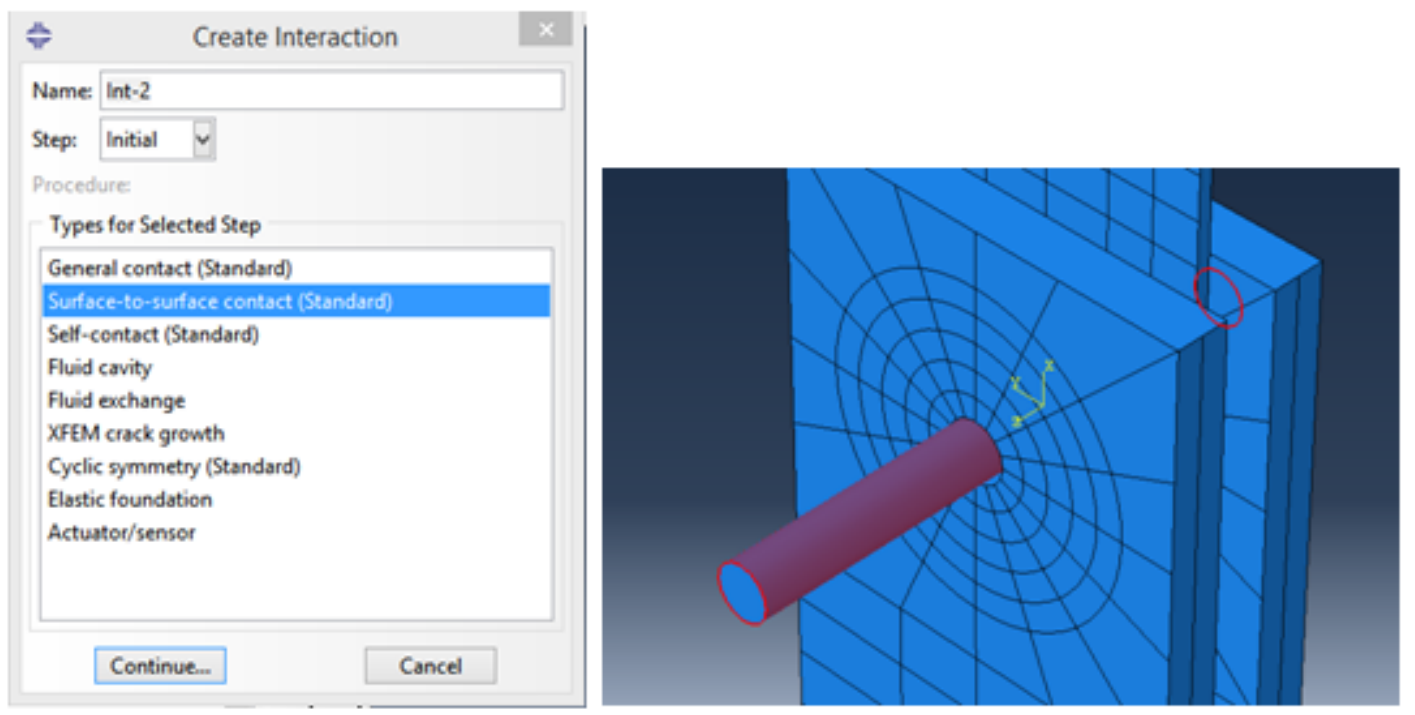

Figure 104. Surface-to-Surface contact menu \& master surface selection screen

Once the pin is hidden, selecting the slave surfaces is a lot easier. Select Slave at the bottom menu and then select the inner hole surface of the two steel plates along with the specimen (hold Shift to select more than one at a time). Then click done and that should be all. Keep it at Finite Sliding and keep the Discretization method to Surface-to-Surface.

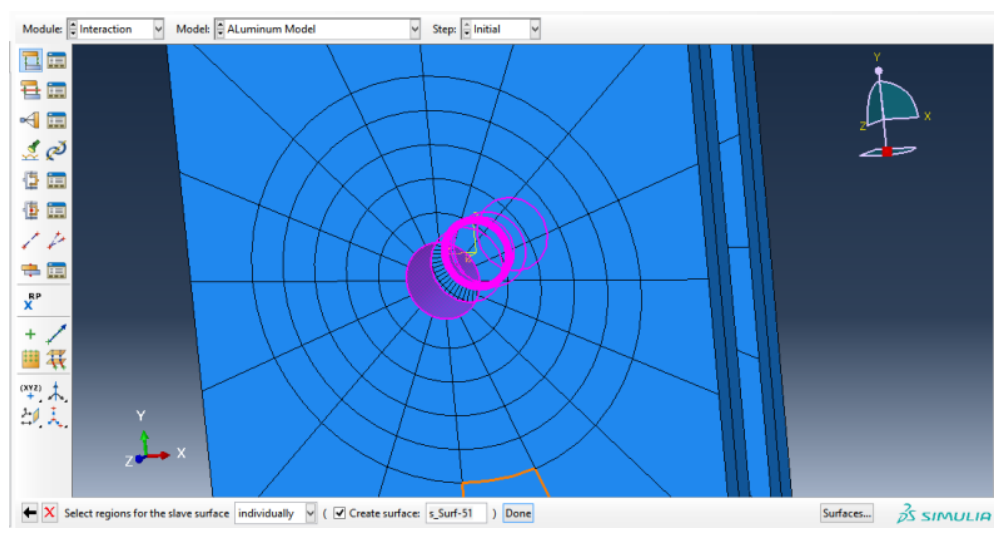

Figure 105. Slave surface selection screen 


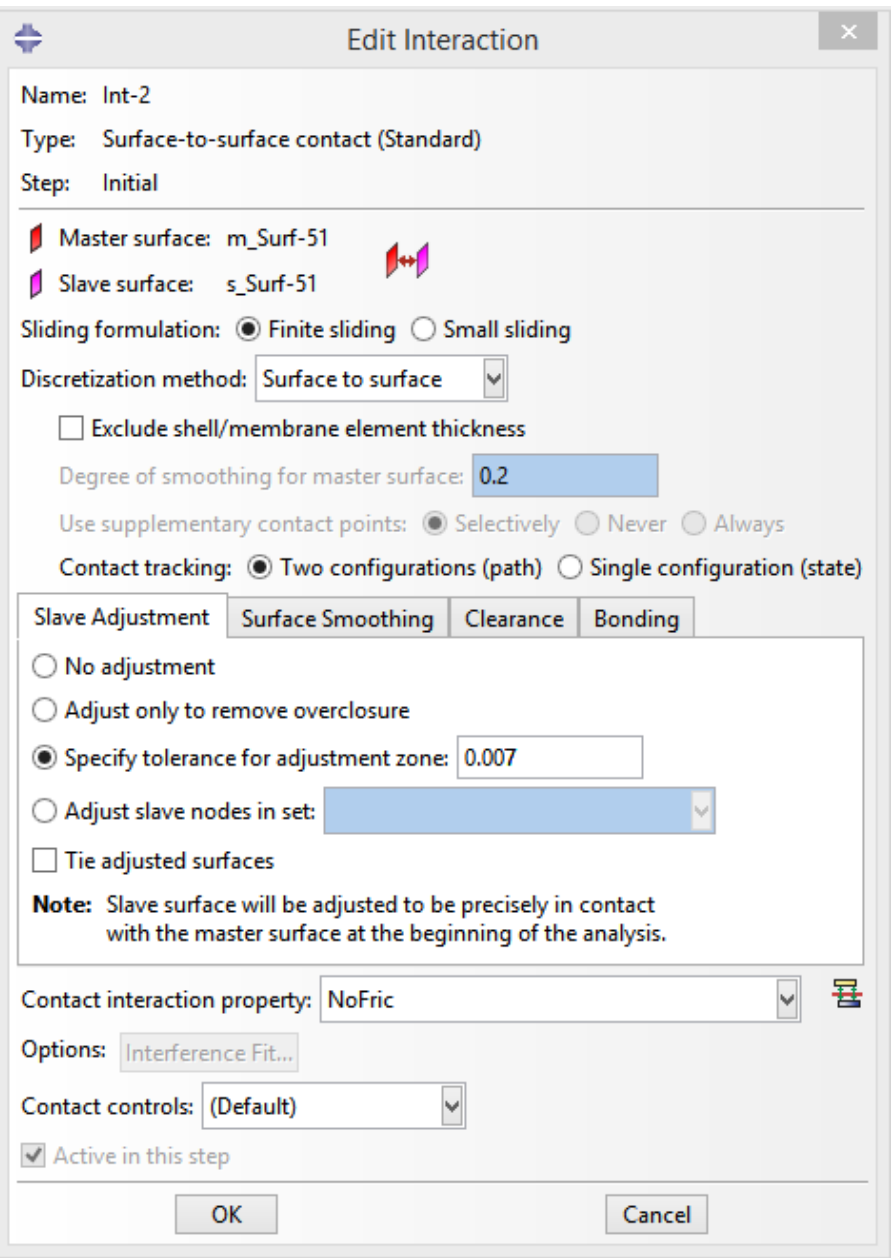

Figure 106. Surface-to-Surface interaction menu

Then click the create Contact interaction property button. Choose Contact and name it NoFric. Then under Mechanical Submenu add Normal and a Tangential Behavior. Pick penalty for Tangential Behavior and choose a friction coefficient of 0.46 . For the normal Behavior, Pressure Over-closure "Hard" Contact, Constraint enforcement method Default and make sure to allow separation after contact is checked. 

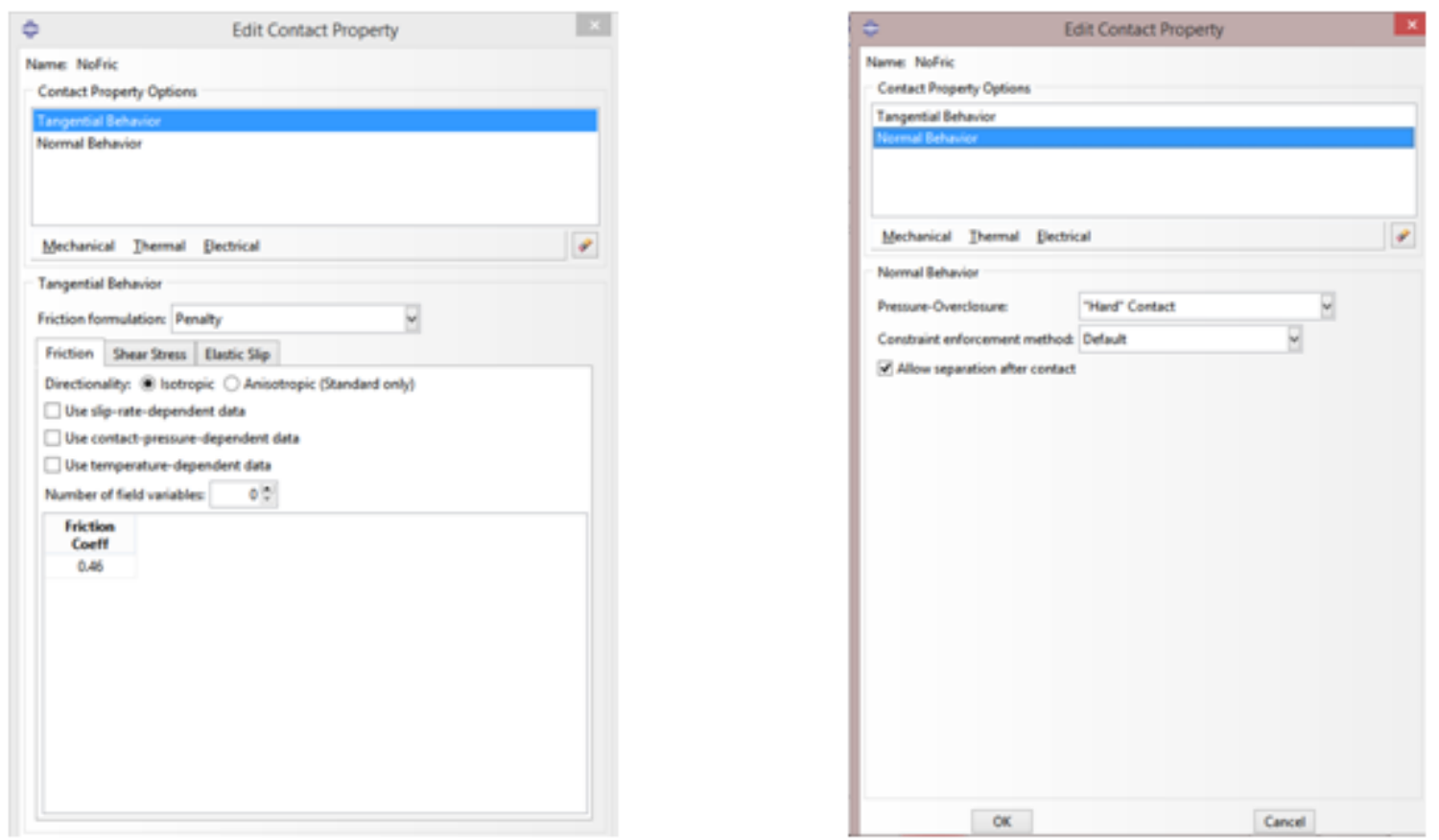

Figure 107. Tangential \& normal behavior contact property menus

\section{A.5.10. Defining the Load}

Next, we need to define a load in the model. Right click the load submenu and click create. Name the load, then apply the load in the load step. Choose a Pressure load for type. Select bottom faces of the two steel plates (shown red in the figure). Select Total Force for the Distribution type, and enter a magnitude of -600 and keep amplitude as ramp. 


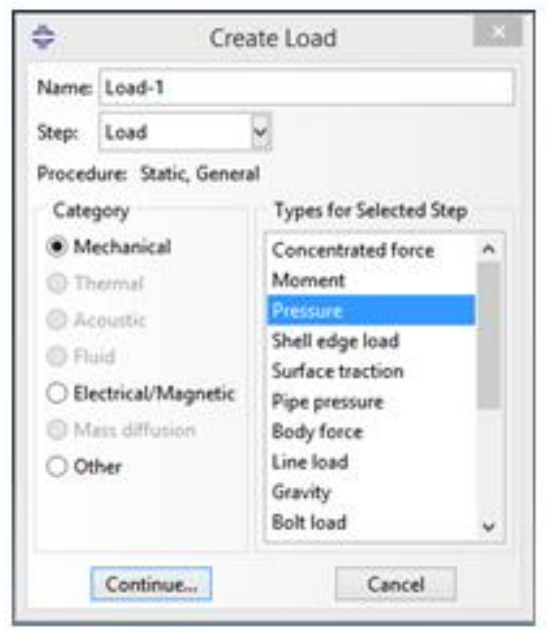

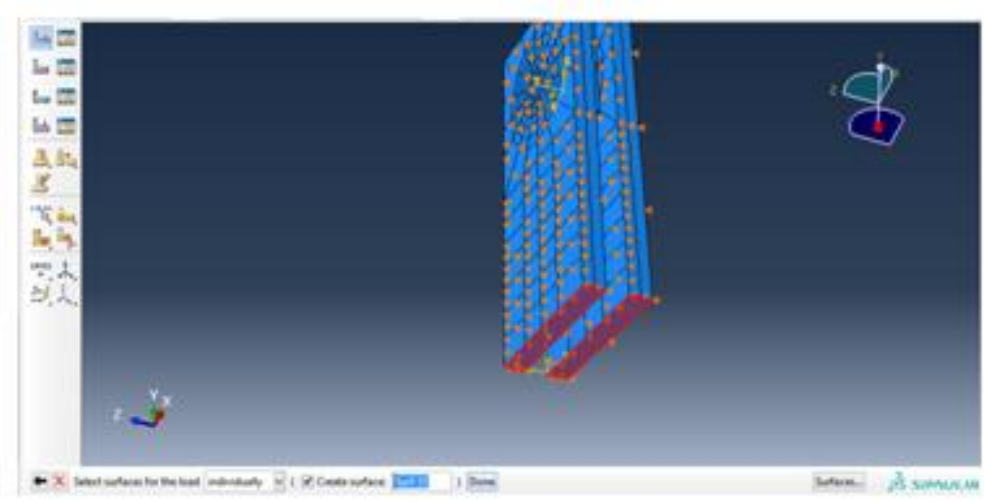

Figure 108. Load creation menu

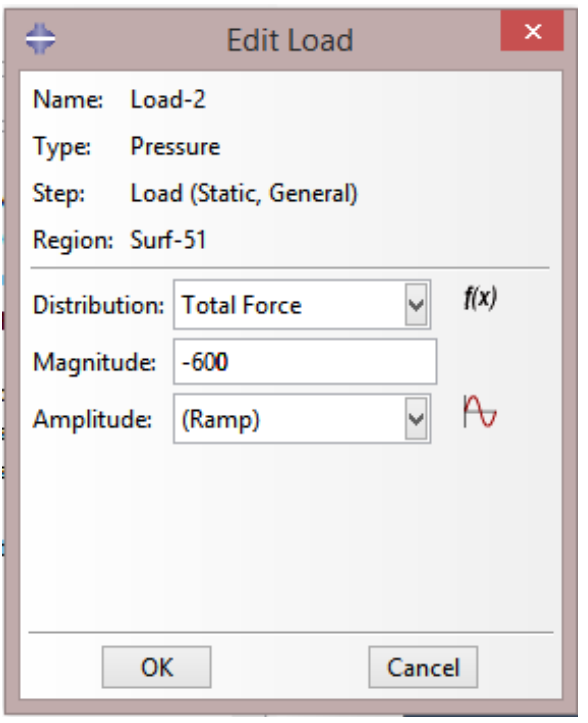

Figure 109. Load magnitude menu 


\section{A.5.11. Defining the Boundary Conditions}

Three boundary conditions were applied to the model. One boundary condition was applied to the top face of the specimen and this will simulate the clamps in the Instron machine. The second boundary condition was applied to the side steel plates. For this condition, we want to prevent the plates from moving out from the z-plane. The last boundary condition was initially applied to the contact step and then it became modified from the load step. The last boundary condition dictated how the pin was to move in the model.

Right click on the boundary conditions (BCs) submenu and click create. Name it Fixed and apply it to the Contact step. For the category choose Mechanical and for type, choose Symmetry/Antisymmetry/Encastre. Then click Continue. Select all of the outer sections of the steel side plates. Choose Encastre as the type. 


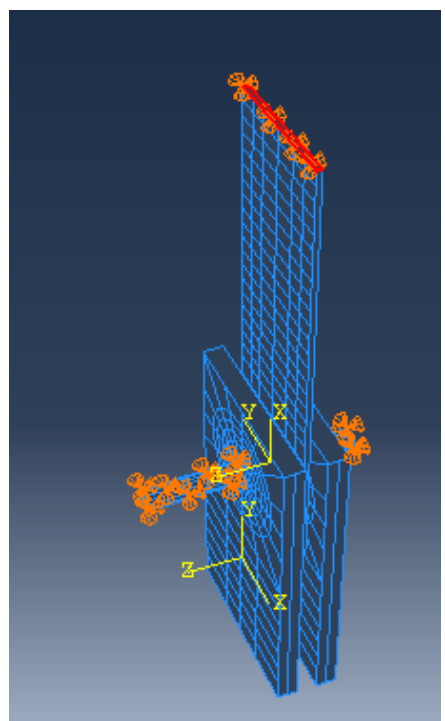

Figure 110. Fixed boundary condition (for top of specimen)

Right click on the boundary conditions (BCs) submenu and click create. Name it SideFaces and apply it to the Load step. For category choose mechanical and for type choose Displacement/Rotation. Then click continue. Select all of the outer sections of the steel side plates. Set the U3 equal to zero since no deflection is expected to occur in this direction. 


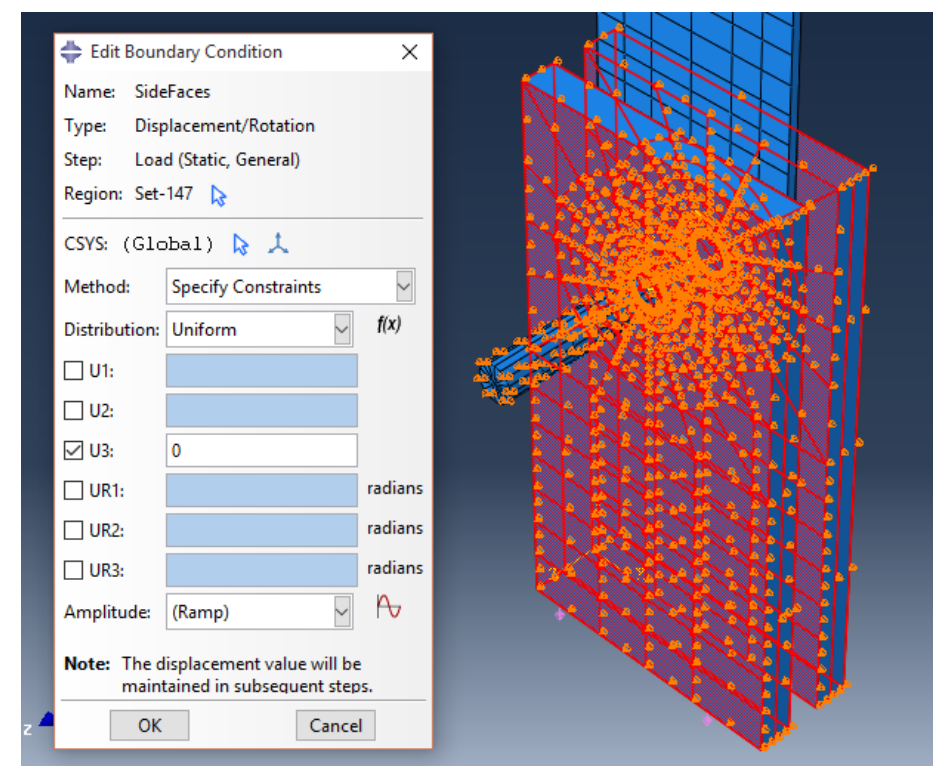

Figure 111. Boundary condition (for side plates)

Right click on the boundary conditions (BCs) submenu and click create. Name it PinBC and apply it to the Contact step. For category, choose mechanical and for type choose Displacement/Rotation. Then click continue. Select all the surfaces of the pin. 


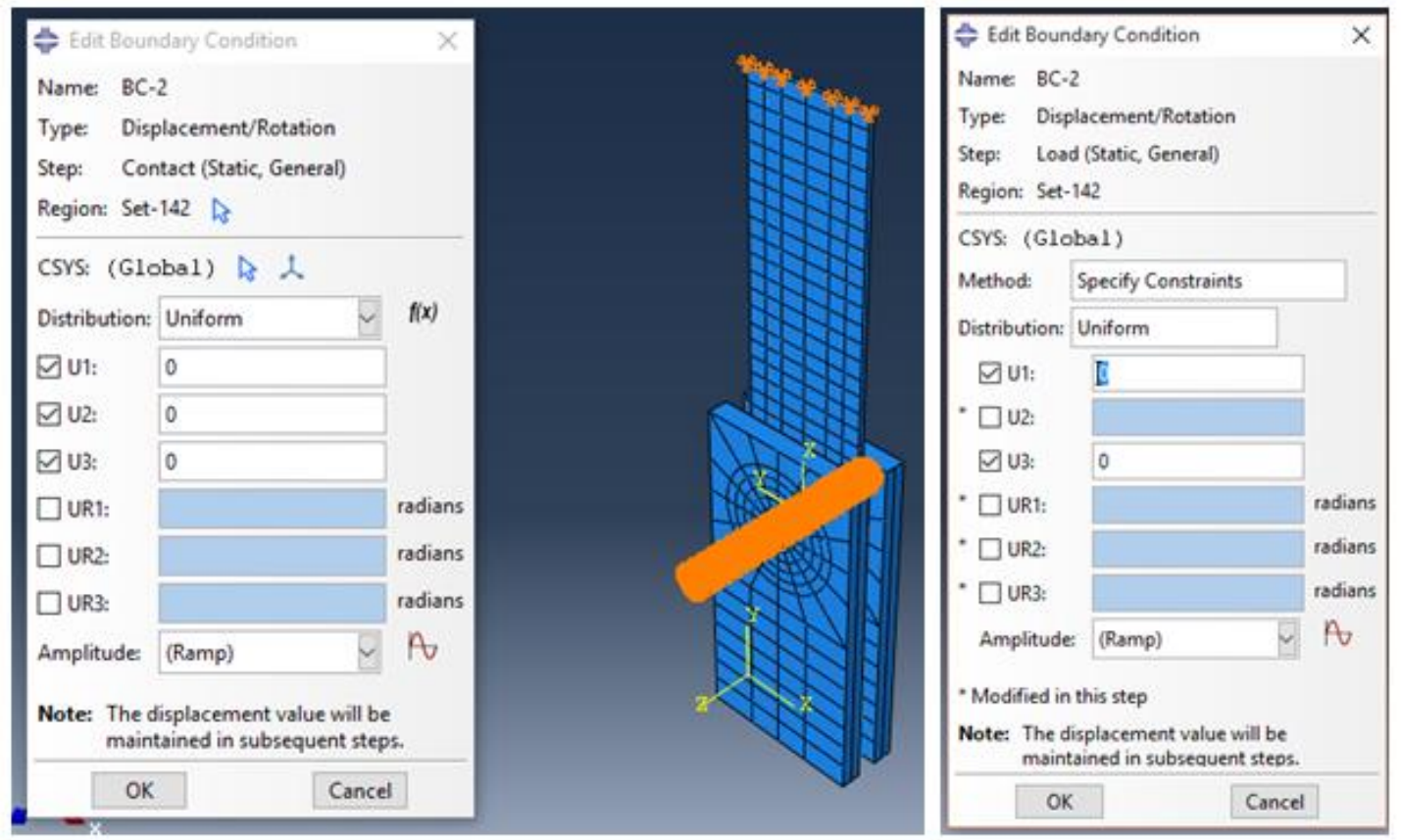

Figure 112. Boundary condition (for pin)

Right click on the load and press edit. Disable the U2 boundary condition by unchecking the box.

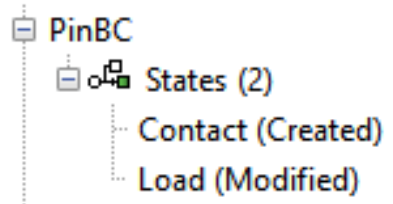

Figure 113. Modifying the boundary condition (for pin)

\section{A.5.12. Defining the Mesh}

The partitions that were created for the side plates and the specimen simplified the mesh defining process. The Seed Edges command was used for each part and each part was highlighted. 
In the options, the number method was chosen and the bias was set to none. The sizing controls options defined how many elements would be assigned to each element of the partition. For my model, I kept the number of elements equal to two. After this, I clicked Ok.

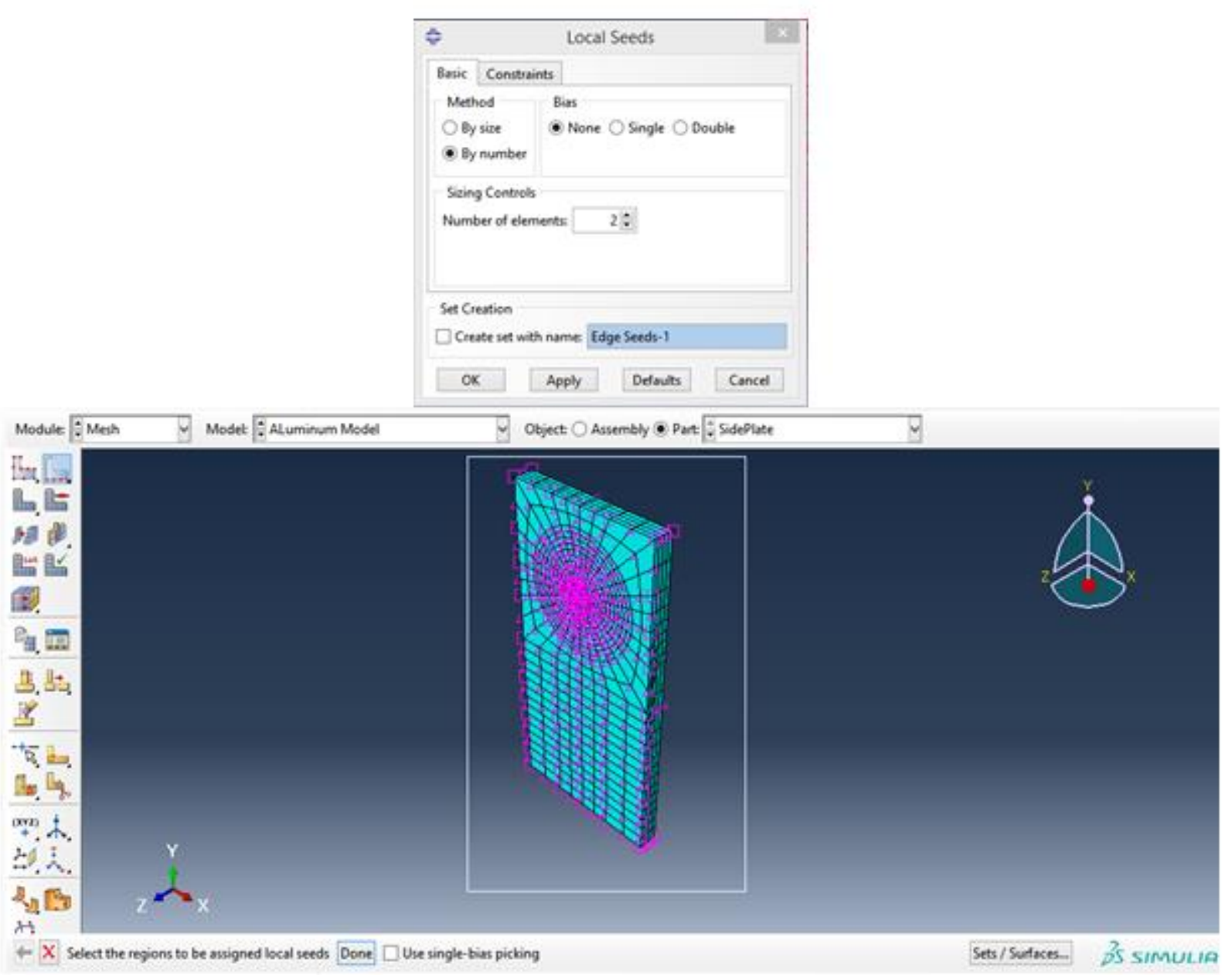

Figure 114. Element selection screen

Apply the same method to all the parts. Apply these settings under the Mesh Controls options. 


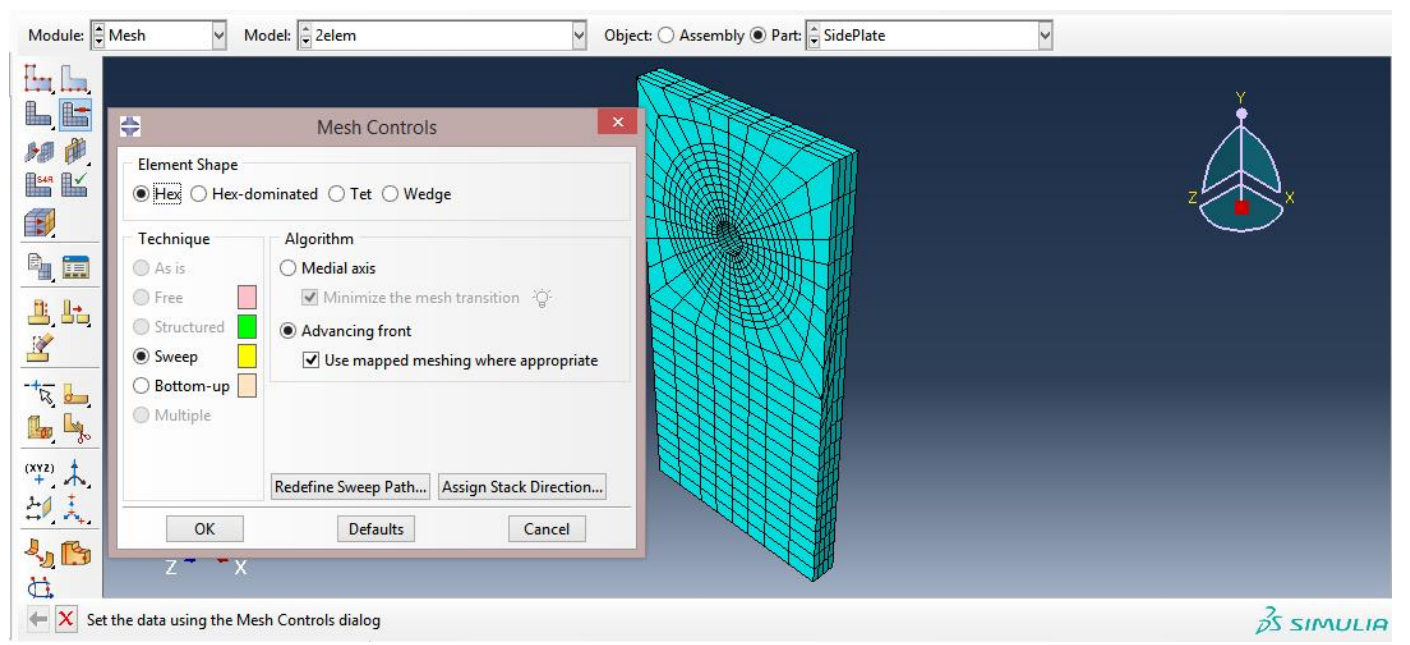

Figure 115. Mesh control menu

In the element type settings, make sure all of these are applied to both the pin and side plate parts. All of these settings should be default. For the specimen, only difference was to uncheck the Reduced integration box.

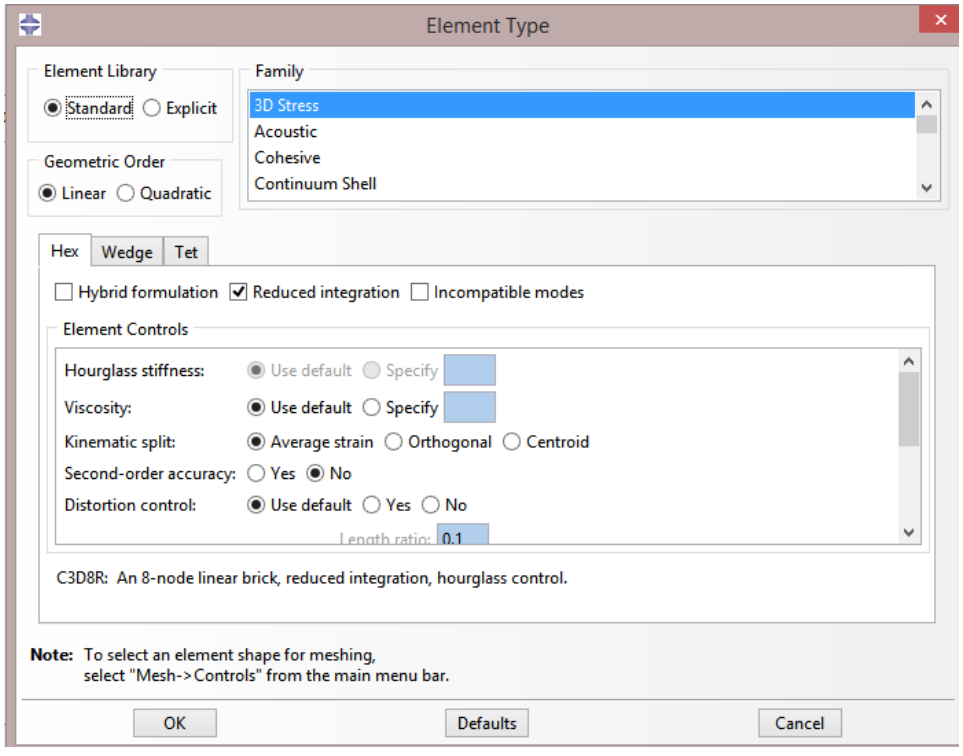

Figure 116. Element type menu 


\section{A.5.13. Creating the Job}

Lastly, we need to create a specific job for your model. Once a job is created, you need to right click on the job and submit it. Once submitted, the job will run and once it converges, it will say Completed assuming everything runs smoothly. To see the results, right click on the job and click the results. This should open up another tab where the user is able to see the different displacements and stresses in the different directions. 